\title{
ipen
}

AUTARQUIA ASSOCIADA À UNIVERSIDADE DE SÃO PAULO

EFEITOS DA ATMOSFERA DE SINTERIZAÇÃO E DO TAMANHO DE PARTÍCULA NA SINTERIZAÇÃO DA CÉRIA-GADOLÍNIA

Rafael Morgado Batista

Tese apresentada como parte dos requisitos para obtenção do Grau de Doutor em Ciências na Área de Tecnologia Nuclear - Materiais

Orientadora:

Profa. Dra. Eliana Navarro dos Santos Muccillo 


\title{
INSTITUTO DE PESQUISAS ENERGÉTICAS E NUCLEARES
}

Autarquia associada à Universidade de São Paulo

\section{EFEITOS DA ATMOSFERA DE SINTERIZAÇÃO E DO TAMANHO DE PARTÍCULA NA SINTERIZAÇÃO DA CÉRIA-GADOLÍNIA}

\author{
Rafael Morgado Batista
}

\begin{abstract}
Tese apresentada como parte dos requisitos para obtenção do Grau de Doutor em Ciências na Área de Tecnologia Nuclear - Materiais

Orientadora:

Profa. Dra. Eliana Navarro dos Santos Muccillo
\end{abstract}

Versão Corrigida

Versão Original disponível no IPEN

São Paulo

2014 
Aos meus pais, Helio e Maria. 
"Nenhuma grande descoberta foi feita jamais sem um palpite ousado."

(Isaac Newton) 


\section{AGRADECIMENTOS}

Primeiramente gostaria de agradecer a Deus e a meus pais. Meus pais com certeza são os maiores responsáveis pela minha formação acadêmica e pessoal. Sem eles, nunca teria condições de ter desenvolvido este trabalho.

Meus sinceros agradecimentos a minha orientadora, a Dra. Eliana Muccillo, que tem acompanhado boa parte de minha carreira acadêmica. Agradeço pelas oportunidades, ensinamentos, paciência e por tudo mais. Não teria aqui como citar toda minha gratidão.

Agradeço aos doutores Reginaldo Muccillo e Fabio Coral Fonseca que, ao longo dos anos, têm me fornecido todo tipo de suporte necessário. Além do suporte laboratorial, tive o prazer de discutir diversos temas de fundo acadêmico com os mesmos.

Aos amigos Felipe Naranjo e Léon Rueda, que me auxiliaram no desenvolvimento do programa de análise de dados utilizado neste trabalho.

Agradecimentos à doutora Ana Maria Costa, do Instituto de Química da USP, não só pelas medidas de ressonância eletrônica paramagnética, como pelas frutíferas discussões acerca dos resultados.

Ao professor Luiz Galego, que gentilmente forneceu o material utilizado como padrão para as análises de difratometria de raios $\mathrm{X}$.

Ao professor Vito Vanin, do Instituto de Física da USP, que sempre se mostrou acessível e forneceu suporte teórico em relação ao tratamento estatístico de dados.

Ao laboratório de insumos cerâmicos do Ipen, pelas análises de área de superfície específica.

Aos companheiros de laboratório, Shirley, Sabrina, Emanuelle, Tatiane, Mayra, Talita, Yone, Robson, Olavo, pelas engrandecedoras discussões e pelo apoio técnico. 
Aos técnicos dos laboratórios do Ipen, especialmente aqueles do laboratório de microscopia, pelo suporte laboratorial.

Ao Ipen, pela utilização dos laboratórios e equipamentos.

A Capes, pela bolsa de doutorado concedida.

Um especial agradecimento aos meus professores, tanto da Graduação como da Pós Graduação, que sempre me incentivaram e me impeliram ao desenvolvimento do espírito crítico e da criatividade.

Aos membros da comissão julgadora, pelas discussões e apontamentos sobre 0 desenvolvimento e da análise de dados deste trabalho.

Por fim, gostaria de agradecer a todas as pessoas que direta ou indiretamente possam ter influenciado este trabalho.

A todos vocês, Meus sinceros agradecimentos e muito obrigado! 


\title{
EFEITOS DA ATMOSFERA DE SINTERIZAÇÃO E DO TAMANHO DE PARTÍCULA NA SINTERIZAÇÃO DA CÉRIA-GADOLÍNIA
}

\author{
Rafael Morgado Batista
}

\begin{abstract}
RESUMO
Os efeitos da atmosfera de sinterização e do tamanho inicial das partículas na sinterização da céria contendo $10 \%$ em mol de gadolínia $\left(G d O_{1,5}\right)$ foram sistematicamente estudados neste trabalho. Materiais de partida com três valores para a área de superfície específica foram utilizados, $210 \mathrm{~m}^{2} / \mathrm{g}, 36,2 \mathrm{~m}^{2} / \mathrm{g}$ e 7,4 $\mathrm{m}^{2} / \mathrm{g}$. Diferentes cinéticas de sinterização foram verificadas. Quanto menor 0 tamanho inicial das partículas, menor é a temperatura para o início da sinterização e mais acelerada a densificação do material. Curvas mestres de sinterização foram construídas para cada um dos materiais analisados. Um programa computacional foi especialmente desenvolvido para este propósito. Diferenças significativas entre as energias de ativação para densificação foram verificadas. Para este trabalho foi determinado que, quanto menor o tamanho inicial de partícula, menores as energias de ativação. A evolução das distribuições de tamanhos de cristalitos foi investigada para os materiais de maior área superficial específica. Foi determinado que a eliminação e migração de poros ("pore drag") é o mecanismo predominante para o crescimento de grãos durante $o$ início da sinterização da céria gadolínia. Os efeitos da atmosfera de sinterização no desvio de estequiometria, na densificação, na evolução microestrutural e na condutividade elétrica da céria-gadolínia foram analisados. Atmosferas redutoras, oxidantes e inertes foram usadas para este propósito. Desvios na estequiometria da céria foram verificados no volume do material, sendo este dependente da área de superfície específica e da atmosfera utilizada. Quanto maior o potencial de redução da atmosfera utilizada, maior a concentração de $\mathrm{Ce}^{3+}$ no material. Com o aumento da concentração de $\mathrm{Ce}^{3+}$ um aumento no tamanho médio de grãos foi verificado. Uma diminuição na condutividade elétrica total, intra e intergranular foram determinadas para as amostras sinterizadas em atmosferas redutoras.
\end{abstract}




\title{
EFFECTS OF SINTERING ATMOSPHERE AND INITIAL PARTICLE SIZE ON SINTERING OF GADOLINIA-DOPED CERIA
}

\author{
Rafael Morgado Batista
}

\begin{abstract}
The effects of the sintering atmosphere and initial particle size on the sintering of ceria containing $10 \mathrm{~mol} \%$ gadolinia $\left(\mathrm{GdO}_{1.5}\right)$ were systematically investigated. The main physical parameter was the specific surface area of the initial powders. Nanometric powders with three different specific surface areas were utilized, $210 \mathrm{~m}^{2} / \mathrm{g}, 36,2 \mathrm{~m}^{2} / \mathrm{g}$ e $7,4 \mathrm{~m}^{2} / \mathrm{g}$. The influence on the densification, and micro structural evolution were evaluated. The starting sintering temperature was verified to decrease with increasing on the specific surface area of raw powders. The densification was accelerated for the materials with smaller particle size. Sintering paths for crystallite growth were obtained. Master sintering curves for gadolinium-doped ceria were constructed for all initial powders. A computational program was developed for this purpose. The results for apparent activation energy showed noticeable dependence with specific surface area. In this work, the apparent activation energy for densification increased with the initial particle size of powders. The evolution of the particle size distributions on non isothermal sintering was investigated by WPPM method. It was verified that the grain growth controlling mechanism on gadolinia-doped ceria is the pore drag for initial stage and beginning of intermediate stage. The effects of the sintering atmosphere on the stoichiometry deviation of ceria, densification, microstructure evolution, and electrical conductivity were analyzed. Inert, oxidizing, and reducing atmospheres were utilized on this work. Deviations on ceria stoichiometry were verified on the bulk materials. The deviation verified was dependent of the specific surface area and sintering atmosphere. Higher reduction potential atmospheres increase $\mathrm{Ce}^{3+}$ bulk concentration after sintering. Accelerated grain growth and lower electrical conductivities were verified when reduction reactions are significantly present on sintering.
\end{abstract}




\section{ÍNDICE}

Lista de Figuras $\quad$ iv

Lista de Tabelas $\quad$ xiii

Lista de Símbolos $\quad$ XV

1. INTRODUÇÃO

2. FUNDAMENTOS TEÓRICOS 3

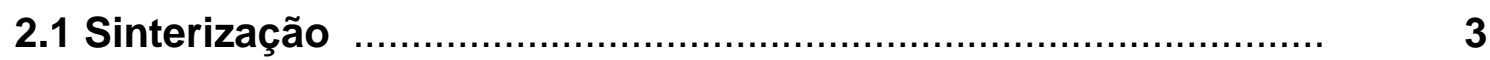

2.1.1 Classes de sinterização ................................................... 4

2.1.2 Termodinâmica do processo ............................................. 5

2.1.3 Força motriz para sinterização ................................................ 6

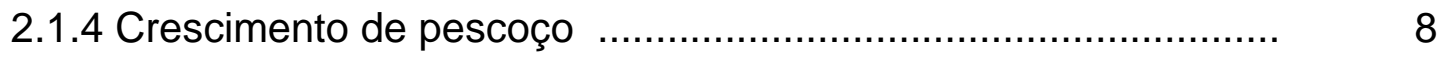

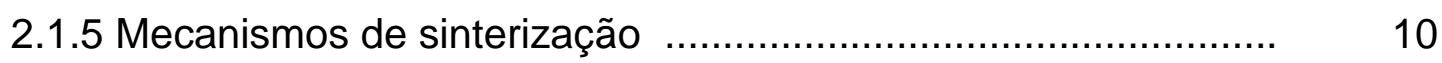

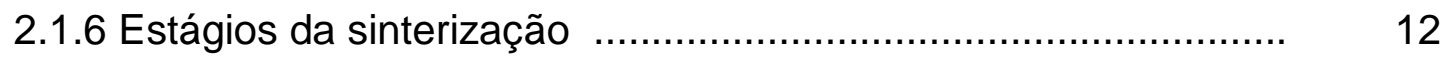

2.1.7 Eliminação de poros ...................................................... 14

2.1.8 Crescimento de grãos ................................................. 16

2.1.9 Pesquisas recentes ........................................................... 20

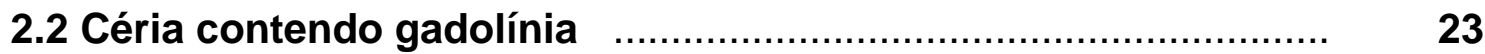

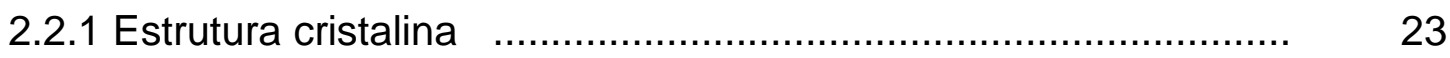

2.2.2 Condutividade elétrica ...................................................... 24

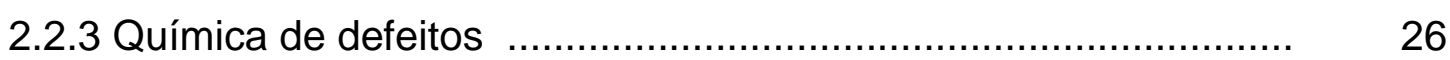

2.2.4 Energia de ativação para difusão do cério ............................... 28

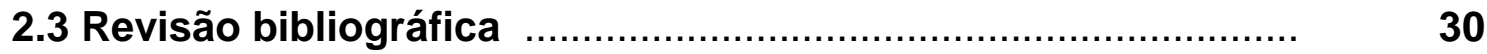

2.3.1 Curva mestre de sinterização ............................................. $\quad 30$

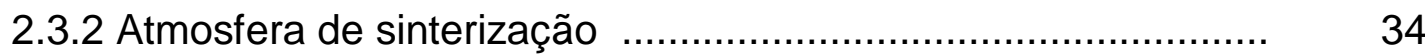

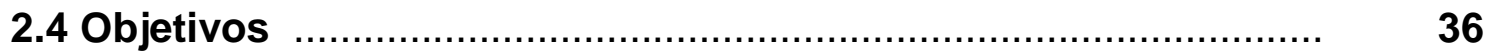


3. EXPERIMENTAL 37

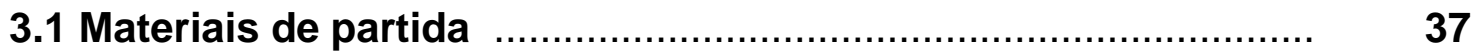

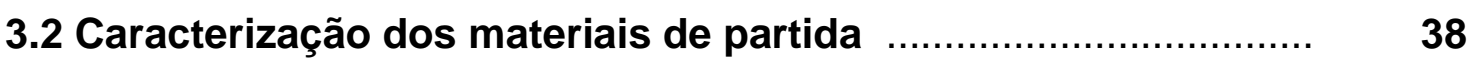

3.3 Elaboração de amostras.................................................. $\quad 39$

3.4 Caracterização das amostras à verde e sinterizados ............... $\quad 39$

3.4.1 Dilatometria .................................................................. 40

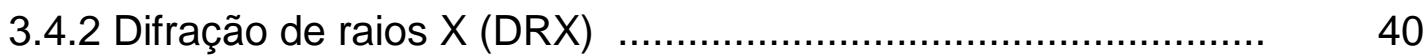

3.4.3 Microscopia eletrônica de varredura (MEV) ........................... 41

3.4.4 Espectroscopia de impedância ........................................ 41

3.4.5 Ressonância paramagnética eletrônica (RPE) ....................... 42

3.4.6 Espectroscopia Raman ............................................... 42

3.4.7 Fluxograma .................................................................. 42

4. RESULTADOS E DISCUSSÃO

4.1 Caracterização física e química dos materiais de partida ..... 44

4.1.1 Tamanho médio de partícula e de cristalito para os materiais de partida ................................................................. 44

4.1.2 Morfologia dos materiais de partida ................................. 47

4.1.3 Estrutura cristalina dos materiais .................................... 47

4.1.4 Impurezas nos materiais de partida ..................................... $\quad 49$

4.1.5 Densidades à verde ........................................................ 52

4.2 Efeito da atmosfera de sinterização ........................................ 54

4.2.1 Densificação .......................................................... 54

4.2.2 Redução da céria ..................................................... 55

4.2.3 Microestrutura ......................................................... 60

4.2.4 Condutividade elétrica .................................................. 64

4.3 Metodologia para construção da MSC …................................. 71

4.3.1 Retração linear devido à sinterização ..................................... 72

4.3.2 Outras correções ........................................................ 77

4.3.3 Programa de análise de dados ....................................... $\quad 79$

4.3.4 Discussão ............................................................... 82 


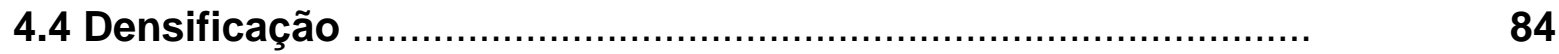

4.4.1 Densidades relativas e retração linear ..................................... 84

4.4.2 Construção da MSC para o material 10N ……….................... 88

4.4.3 Construção da MSC para o material 10TC .............................. 93

4.4.4 Construção da MSC para o material 10M ................................ 97

4.4.5 Discussão ....................................................................... 101

4.5 Evolução microestrutural ....................................................... 103

4.5.1 Crescimento do tamanho médio de cristalito ........................... 103

4.5.2 Evolução das distribuições de tamanho de cristalito ................. 104

4.5.3 Curvas de trajetória para crescimento de cristalito ................... 106

5. CONCLUSÕES 108

APÊNDICE A - Notação de Kroeger e Vink $\quad 110$

APÊNDICE B - Refinamentos Rietveld

APÊNDICE C - ZARC $\quad 116$

APÊNDICE D - Cálculo da densidade aparente por dilatometria $\quad 117$

APÊNDICE E - Correção interna em medidas de dilatometria 119

APÊNDICE F - Expansão térmica $\quad 121$

APÊNDICE G - Correção da temperatura inicial de medida 122

APÊNDICE H - Correção do comportamento inicial das curvas de

retração 123

APÊNDICE I - Método de Arrhenius para densificação 126

REFERÊNCIAS BIBLIOGRÁFICAS 127 


\section{LISTA DE FIGURAS}

Figura

Descrição

Página

Figura 1: Efeitos principais produzidos na microestrutura de um material durante a sinterização. Figura retirada e modificada da referência [19].

Figura 2: $\quad$ Regiões de interface sólido-sólido e sólido-vapor na microestrutura de um material cristalino durante a sinterização. Figura retirada $e$ modificada da referência [17].

Figura 3: A sinterização age de modo a remover as concavidades e convexidades tornando as superfícies planas. Um fluxo de massa ocorre das regiões de maior convexidade para as de maior concavidade. Figura retirada e modificada da referência [17].

Figura 4: $\quad$ Micrografia obtida com microscópio eletrônico de varredura. Partículas de bronze de $26 \mu \mathrm{m}$ após a sinterização a $800^{\circ} \mathrm{C}$. Figura retirada da referência [17].

Figura 5: Evolução do crescimento de pescoço em um sistema composto por duas partículas. Figura retirada e modificada da referência [17].

Figura 6: Esquema mostrando os principais mecanismos de sinterização em estado sólido. Figura retirada e modificada da referência [11].

Figura 7: Evolução microestrutural de um sólido cristalino durante cada um dos estágios de sinterização. Figura retirada e modificada da referência [17]. 
Figura 8: (a) Estrutura esquemática de aglomerados, domínios e partículas em uma microestrutura. (b) Distribuição dos números de coordenação de poros $(R)$ indicando as três classes de poros. Figuras retiradas e modificadas da referência [42].

Figura 9: $\quad$ Arranjo de duas partículas de raio $R_{1}$ (maior) e $R_{2}$ (menor). (a) Antes da formação do pescoço. (b) Quando $R_{1} / R_{2}$ é menor que o valor crítico. (c) $R_{1} / R_{2}=$ valor crítico. (d) $R_{1} / R_{2}$ é maior que o valor crítico. Figura retirada da referência [42].

Figura 10: $\quad$ Configuração de duas partículas após a formação do ângulo diedral

$\phi_{e}$. (a) Configuração quando $R_{1} / R_{2}$ é menor do que o valor crítico (Contornos de grãos imóveis). (b) Configuração resultante do transporte de massa entre partículas. (c) Configuração transiente devido a movimentação dos contornos de grãos. (d) Configuração final após transporte de massa entre partículas e após migração dos contornos de grãos. Figura retirada da referência [42].

Figura 11: Figura esquemática mostrando um tetradecaedro, a forma geométrica assumida para os grãos no estágio final de sinterização. Figura retirada da referência [17].

Figura 12: $\quad$ Micrografia obtida por microscopia eletrônica de varredura. A imagem mostra grãos poliedrais similares a estrutura idealizada para 0 estágio final de sinterização, o tetradecaedro. Figura retirada da referência [17].

Figura 13: Estrutura cristalina da céria, cúbica de faces centradas do tipo fluorita e grupo espacial Fm-3m.

Figura 14: Diagrama de fases para a $\mathrm{Ce}_{0,818} \mathrm{Gd}_{0,182} \mathrm{O}_{1,909-x}$ após o trabalho de Steltzer. Figura retirada da referência [75].

Figura 15: $\quad$ Condutividade elétrica para diversos óxidos de estrutura tipo fluorita. Figura retirada da referência [15]. 
Figura 16: $\quad$ Condutividade elétrica para a $\mathrm{Ce}_{0,8} \mathrm{Gd}_{0,2} \mathrm{O}_{1,9}$ obtida por vários autores utilizando diferentes rotas de preparação. Figura retirada da referência [15].

Figura 17: $\quad$ Figura ilustrativa da construção da MSC para a alumina. O gráfico a esquerda mostra o ajuste da densidade relativa em função do parâmetro $\Theta(t, T)$. O gráfico da direita mostra a curva do resíduo quadrático médio em função da energia de ativação utilizada no ajuste. Figuras retiradas da referência [60].

Figura 18: $\quad$ Curva mestre de sinterização acoplada à trajetória da microestrutura obtida para a fita dielétrica de baixa temperatura Dupont 951. Figura retirada da referência [59].

Figura 19: Fluxograma indicando a ordem de execução das análises empregadas neste trabalho.

Figura 20: $\quad$ Micrografias obtidas por microscopia eletrônica de transmissão pela análise da céria-gadolínia (a)10M, (b) 10TC e (c) 10N.

Figura 21: Difratograma de raios $X$ do material GDC10TC, perfil refinado e resíduo entre os dois obtidos pelo refinamento Rietveld. O valor do chi quadrado reduzido para o refinamento foi de 1,109. Os números entre parênteses são os respectivos índices de Miller associado a cada reflexão.

Figura 22: $\quad$ Micrografias dos materiais de partida conforme recebidos obtidos por microscópio eletrônico de varredura. (a) e (a') 10M, (b) e (b') 10TC, (c) e (c') $10 \mathrm{~N}$.

Figura 23: (a) Curvas termogravimétrica e (b) termo diferencial dos materiais de partida.

Figura 24: Espectros obtidos a $100^{\circ} \mathrm{C}, 290^{\circ} \mathrm{C}$ e $400^{\circ} \mathrm{C}$ por espectrometria de massa durante análise térmica diferencial da amostra 10N. 
Figura 25: (a) Densidades relativas à verde dos compactos em função da pressão aplicada na compactação isostática. A micrografia em (b) mostra uma típica microtrinca interna verificada na amostra $10 \mathrm{~N}$ após a sinterização.

Figura 26: Espectros Raman obtidos para amostras $10 \mathrm{~N}$ sinterizadas em diferentes atmosferas.(a) região de fônons, (b) região eletrônica.

Figura 27: Espectros RPE dos materiais de partida calcinados a $600^{\circ} \mathrm{C}$. Também é mostrado o espectro RPE do porta amostra utilizado.

Figura 28: $\quad$ Espectros RPE de amostras sinterizadas a partir do material 10N. Espectros RPE em atmosferas inerte e oxidante (superior) e inerte e redutora (inferior).

Figura 29: $\quad$ Micrografias selecionadas de amostras elaboradas a partir da $10 \mathrm{M} \mathrm{e}$ sinterizadas ao (a) ar ou em atmosferas de (b) $\mathrm{Ar}$, (c) $\mathrm{N}_{2}$ e (d) mistura de $4 \%$ de $\mathrm{H}_{2} / \mathrm{Ar}$.

Figura 30: $\quad$ Micrografias selecionadas de amostras elaboradas a partir da 10TC e sinterizadas ao (a) ar ou em atmosferas de (b) $A r$, (c) $N_{2}$ e (d) mistura de $4 \%$ de $\mathrm{H}_{2} / \mathrm{Ar}$.

Figura 31: $\quad$ Micrografias selecionadas de amostras elaboradas a partir da $10 \mathrm{~N} \mathrm{e}$ sinterizadas ao (a) ar ou em atmosferas de (b) $\mathrm{Ar}$, (c) $\mathrm{N}_{2}$ e (d) mistura de $4 \%$ de $\mathrm{H}_{2} / \mathrm{Ar}$.

Figura 32: (a) Diagrama de impedância para a amostra da 10TC sinterizada ao ar. Medida realizada a $245^{\circ} \mathrm{C}$. O ajuste não linear foi obtido com o programa LEVM. (b) Circuito equivalente utilizado para efetuar o ajuste aos dados experimentais.

Figura 33: Gráfico de Arrhenius da condutividade elétrica intragranular para amostras sinterizadas em diferentes atmosferas de sinterização. 
Figura 34: Gráfico de Arrhenius da condutividade elétrica intergranular para amostras sinterizadas utilizadas diferentes atmosferas.

Figura 35: Gráfico de Arrhenius da condutividade elétrica total para amostras sinterizadas utilizadas diferentes atmosferas.

Figura 36: Esquema mostrando os fundamentos envolvidos numa medida de dilatometria. O sensor de deslocamento é preso ao tubo do dilatômetro. Como o terminal que toca a amostra e o tubo são fabricados com o mesmo material, ambos apresentam os mesmos coeficientes de expansão térmica. Assim, a contribuição à medida pela dilatação térmica do terminal é anulada pela contribuição devido a dilatação térmica da porção do tubo paralela ao terminal. O valor aferido pelo sensor de deslocamento é dado então apenas pela diferença entre o deslocamento produzido pelas alterações dimensionais na amostra e pela dilatação térmica da porção do tubo paralela a amostra.

Figura 37: $\quad$ Curvas de retração linear obtidas para amostras elaboradas a partir dos materiais $10 \mathrm{~N}$ e 10M. As curvas sólidas foram obtidas pela utilização da equação 5.10 enquanto as curvas pontilhadas foram obtidas pelo modo usual, sendo feita apenas a correção devido à expansão térmica da porção do tubo paralela à amostra.

Figura 38: Curvas de densidade em função da temperatura obtidas por dilatometria para amostras elaborada a partir da amostra $10 \mathrm{~N}$ e sinterizadas com taxa de aquecimento constante de $10^{\circ} \mathrm{C} / \mathrm{min}$. A curva sólida foi obtida segundo as correções mostradas neste tópico. A curva em pontilhado foi obtida sem a correção devido à perda de massa pela amostra. Os símbolos representam resultados de densidade aparente obtidos para amostras sinterizadas em forno convencional. 
Figura 39: Esquema mostrando o algoritmo desenvolvido e utilizado para construção da curva mestre de sinterização.

Figura 40: $\quad$ Tela do programa de análise de dados de dilatometria desenvolvido para construção da MSC.

Figura 41: Retração linear em função da temperatura de análise para amostras produzidas a partir de cada um dos materiais analisados. Taxa de aquecimento constante de $10^{\circ} \mathrm{C} / \mathrm{min}$.

Figura 42: Retração linear na direção radial $-r$ e transversal -t de amostras cilíndricas produzidas a partir de compactos das amostras 10N, 10M e 10 TC em função da temperatura de sinterização.

Figura 43: Densidades relativas em função da temperatura de sinterização para amostras elaboradas a partir de cada um dos materiais utilizados neste trabalho. As linhas contínuas mostram os dados interpolados obtidos por dilatometria. Os dados discretos mostram os resultados de densidade aparente determinados pelo método geométrico.

Figura 44: Taxa de variação da densidade com a temperatura em função da temperatura de sinterização para amostras 10N, 10M e 10TC. As curvas foram suavizadas utilizando o algoritmo de interpolação de Savitzky-Golay para preservar os picos das curvas.

Figura 45: Densidade relativa em função da temperatura de análise. Curvas obtidas com diferentes taxas de aquecimento para amostras elaboradas a partir do material $10 \mathrm{~N}$.

Figura 46: $\quad$ Gráfico de Arrhenius da densidade e ajustes lineares obtidos para o material $10 \mathrm{~N}$.

Figura 47: Energias de ativação aparentes em função da densidade relativa utilizada em sua determinação. Energias obtidas para o material 10N. 
Figura 48: Curva mestre de sinterização para o material 10N. O resíduo quadrático total do ajuste em função da energia de ativação aparente é mostrado na região interna do gráfico.

Figura 49: $\quad$ Curva mestre de sinterização para amostras elaboradas a partir do material 10N. Dados discretos representam densidades aparentes de amostras sinterizadadas em forno convencional e determinadas pelo método geométrico.

Figura 50: Densidade relativa e em função da temperatura de análise. Os dados foram obtidos pela análise de amostras elaboradas a partir do material $10 T C$.

Figura 51: Energias de ativação aparente em função da densidade relativa. As energias de ativação foram obtidas pelo método de Arrhenius para o material 10TC.

Figura 52: Energias de ativação estimadas em função da densidade relativa final utilizada para composição do intervalo de dados. A densidade inicial foi mantida fixa em $50 \%$ da densidade teórica. Resultados obtidos para o material 10TC.

Figura 53: Curva mestre de sinterização para o material 10TC. O resíduo quadrático total do ajuste em função da energia de ativação aparente é mostrado na região interna do gráfico.

Figura 54: $\quad$ Curva mestre de sinterização para amostras elaboradas a partir do material 10TC. Dados discretos representam densidades aparentes de amostras sinterizadadas em forno convencional e determinadas pelo método geométrico.

Figura 55: Densidade relativa em função do tempo de análise para amostras sinterizadas com diferentes taxas de aquecimento. A temperatura inicial de todas as análises é de aproximadamente $25^{\circ} \mathrm{C}$. 
Figura 56: Energias de ativação aparente estimadas pelo método de Arrhenius. Resultados obtidos para amostras elaboradas a partir do material $10 \mathrm{M}$.

Figura 57: Curva mestre de sinterização para o material 10M. O resíduo 100 quadrático total do ajuste em função da energia de ativação aparente é mostrado na região interna do gráfico.

Figura 58: $\quad$ Curva mestre de sinterização para amostras elaboradas a partir do 101 material 10M. Dados discretos representam densidades aparentes de amostras sinterizadadas em forno convencional e determinadas pelo método geométrico.

Figura 59: Tamanho de cristalito em função da temperatura de sinterização para as amostras sinterizadas por tempo nulo na temperatura de patamar.

Figura 60: Evolução das distribuições de tamanhos de cristalito com o aumento 105 da temperatura de sinterização para os materiais $10 \mathrm{~N}$ e $10 T C$. Resultados obtidos supondo uma distribuição lognormal de cristalitos esféricos.

Figura 61: Curvas de trajetória para o crescimento de cristalito da céria gadolínia 106 com diversos tamanhos iniciais de cristalito. Os tamanhos médios de cristalito são normalizados pelo tamanho inicial.

Figura 62: Difratograma de raios $X$ do material $G D C 10 N$, perfil refinado e resíduo entre os dois obtidos pelo refinamento Rietveld. O valor do chi quadrado reduzido para o refinamento foi de 1,05. Os números entre parênteses são os respectivos índices de Müller associados a cada pico. 
Figura 63: $\quad$ Valores do $\chi^{2}$ dos ajustes das análises realizadas em amostras elaboradas a partir de cada um dos materiais de partida. Os resultados são mostrados em função da temperatura de sinterização. A temperatura de $25^{\circ} \mathrm{C}$ é associada aos materiais como recebidos.

Figura 64: Gráfico do refinamento Rietveld da amostra $10 \mathrm{M}$ sinterizada à $700^{\circ} \mathrm{C}$. $O \chi^{2}$ do ajuste é de 3,63. Na região ampliada do gráfico é mostrado a aderência da curva ajustada aos dados experimentais na região do pico de maior intensidade.

Figura 65: Circuito equivalente ao ZARC.

Figura 66: Curvas de retração linear obtidas para amostras elaboradas a partir da 10TC. Nenhuma correção foi aplicada ao comportamento inicial das amostras.

Figura 67: Curvas de retração linear obtidas para amostras elaboradas a partir da 10TC e corrigidas pelo método de translação descrito no texto.

Figura 68: $\quad$ Curvas de retração linear obtidas para amostras elaboradas a partir 125 da $10 T C$ e corrigidas pelo método de extrapolação já descrito no texto. 


\section{LISTA DE TABELAS}

Tabela

Descrição

Página

Tabela 1: $\quad$ Valores da energia de ativação para difusão catiônica no cristal de $8 Y S Z$.

28

Tabela 2: $\quad$ Coeficiente de expansão térmico médio $\alpha_{M}$ e temperatura de fusão TF para a céria, e para zircônia estabilizada com ítria 8YSZ.

Tabela 3: $\quad$ Valores da área de superfície específica $S$, pureza e tamanho de partícula $M$ fornecidos pelo fabricante. Entre parênteses são relacionados os métodos utilizados na determinação destes valores.

Tabela 4: $\quad$ Tamanhos médios de partículas estimados por microscopia eletrônica de transmissão MET, tamanhos médios de cristalito obtidos por DRX, e tamanhos médios de partícula estimados por adsorção gasosa supondo partículas esféricas. Unidades em nanômetros.

Tabela 5: $\quad$ Microdeformação $<e>$ e sua incerteza sigma. Para $a=5 \%, z_{\text {limite }}=$ 1,96 .

Tabela 6: $\quad$ Densidade teórica $d_{t}$ e parâmetro de rede a obtidos.

Tabela 7: Densidade à verde relativa das amostras elaboradas para cada material.

Tabela 8: $\quad$ Densidades relativas de amostras sinterizadas a $1250^{\circ} \mathrm{C}$ por 2 horas em atmosfera de $\mathrm{N}_{2}$, Argônio, mistura de $4 \% \mathrm{H}_{2} / \mathrm{Ar}$ e ao ar.

Tabela 9: Intensidades integradas dos sinais RPE medidos. As intensidades foram normalizadas pela massa das amostras.

Tabela 10: Tamanho médio de grãos de amostras sinterizadas em diferentes atmosferas.

Tabela 11: Descrição das correções utilizadas em cada uma das metodologias de tratamento de dados de dilatometria.

Tabela 12: Energias de ativação obtidas pelo ajuste não linear ao conjunto de dados obtidos pelos métodos M1, M2, M3 e M4 para o material 10N. 
Tabela 13: $\quad$ Notação de Kroeger e Vink para os termos utilizados nas reações de defeitos. 


\section{LISTA DE SÍMBOLOS}

$\mathbf{G}_{\mathbf{B}}-$ Energia livre de Gibbs

$\mathbf{U}$ - Energia interna

p - Pressão

V - Volume

$\mathbf{T}$ - Temperatura

S - Entropia

$\boldsymbol{\delta}$ - Variação

$\gamma_{\text {ss }}$ - Energia de interface sólido- sólido

$\gamma_{\mathbf{s v}}$ - Energia de interface sólido- vapor

A - Área

$\boldsymbol{\mu}$ - Potencial químico

$\mathbf{N}$ - Número de mols

$\boldsymbol{\Omega}$ - Volume de um sítio atômico

C - Concentração de espécie química

k - Constante de Boltzmann

K - Curvatura superficial

$\sigma_{\mathrm{N}}-$ Tensão normal à superfície

G - Tamanho médio de grão

$\mathbf{t}-$ Tempo

$\mathbf{K}_{\mathbf{G}}-$ Fator de Arrhenius para

crescimento de grãos

$\mathbf{P}(\mathbf{G})$ - Probabilidade de se encontrar um grão com tamanho $\mathrm{G}$ no material
$\mathbf{P}_{\mathbf{M}}$ - Pico da frequência de distribuiçãa de tamanhos de grãos

$\mathbf{G}_{\mathbf{M}}$ - Moda da distribuição de tamanhos de grãos

b - Constante tipicamente entre 2 e 6

$\mathbf{L}$ - Comprimento da amostra

$\rho$ - Densidade

$\Gamma_{G}-$ Fator geométrico

$\mathbf{Q}$ - Energia de ativação

$\boldsymbol{\gamma}$-Energia livre superficial específica

$\delta_{\mathrm{gb}}-$ Espessura dos contornos de grãos

D - Coeficiente de difusão

n - Constante entre 1 e 4

$\Theta$ - Trabalho da sinterização

$\Phi$ - Função dependente apenas da densidade

M - Tamanho médio de partícula

S - Área de superfície específica

$\mathbf{a}_{\mathbf{R}}$ - Parâmetro de rede

e - Microdeformação

$\sigma-$ Condutividade elétrica

$\mathbf{L}$ - Comprimento de uma amostra na direção transversal 
$\mathbf{R}$ - Resistência elétrica

C - Capacitância

$\mathbf{d}_{\mathrm{G}}-$ Área de interface média entre dos grãos

$\tau$ - Tempo de relaxação para o processo de polarização

$\Delta \mathbf{L}$ - Deslocamento

$\mathrm{L}_{0}$ - Comprimento inicial

$\mathrm{L}_{0}{ }^{\circ}$ - Comprimento inicial instantâneo
$\mathbf{A}_{\mathbf{C}}$ - Função de correção interna para

dilatômetro

E - Função correção devido a dilatação térmica de uma amostra em ensaios de dilatometria

$\mathbf{f}(\mathbf{t}, \mathbf{T})$ - Função de correção em ensaios de dilatometria devido a perda de massa da amostra

$\mathbf{N}_{\mathbf{P}}$ - Grau do polinômio 


\section{INTRODUÇÃO}

Sinterização é um processo termodinâmico presente em diversas áreas das Ciências dos Materiais [1-3]. Quando materiais predominantemente sólidos são aquecidos, um aumento significativo no fluxo de transporte de massa ocorre [4-6]. Como consequência, os materiais podem apresentar densificação, aumento da resistência mecânica e diversas alterações microestruturais [7-9]. O termo sinterização é utilizado para designar o conjunto destas alterações promovidas devido ao aumento na temperatura.

Civilizações antigas há milhares de anos já utilizavam a sinterização para a produção de cerâmicas, tijolos ou fabricação de peças artísticas [3]. Apesar disso, os primeiros estudos científicos sobre o tema datam de meados dos anos 40 do século passado [10,11]. Atualmente a sinterização é utilizada para fabricação de peças cerâmicas de forma complexa, produção de conectores em circuitos semicondutores, fabricação de tijolos e, para alterar as propriedades de ligas metálicas, entre outras $[2,8,12]$.

O controle do processo de sinterização é de fundamental importância para diversas áreas da tecnologia. Embora um grande progresso tenha sido feito em direção a este objetivo, diversas questões ainda permanecem em aberto, tais como a descrição da interação entre os diversos mecanismos de sinterização ou, como obter o controle da microestrutura durante a sinterização [13,14]. Os modelos atuais têm uma série de limitações que impedem ou dificultam sua aplicação prática dentro da indústria [14]. Portanto, uma ampla pesquisa é feita neste campo.

Este trabalho tem como objetivo contribuir com a pesquisa de alguns aspectos não esclarecidos referentes à sinterização. Dois tópicos serão enfatizados neste trabalho. $O$ primeiro consiste na análise da evolução microestrutural de materiais cerâmicos nanométricos durante a sinterização não isotérmica. O segundo consiste no estudo dos efeitos da atmosfera de sinterização na condutividade de óxidos não estequiométricos. O material utilizado neste trabalho é a céria contendo gadolínia, que é um condutor de íons oxigênio com potencial aplicação em cé- 
lulas a combustível de óxido sólido que operam em temperaturas intermediárias $\left(\leq 800^{\circ} \mathrm{C}\right)[15,16]$.

No capítulo seguinte serão brevemente revisados os conceitos fundamentais ligados à sinterização, detalhadas as principais propriedades da cériagadolínia para este trabalho e os objetivos específicos apresentados. No terceiro capítulo a metodologia proposta será descrita em detalhes. No quarto capítulo serão mostrados e analisados os resultados da pesquisa. Uma breve discussão sobre os resultados será feita e novas possibilidades de pesquisa na área serão identificadas. Por fim, no quinto capítulo, as conclusões do trabalho serão sumarizadas. 


\section{FUNDAMENTOS TEÓRICOS}

\subsection{SINTERIZAÇÃO}

Como foi dito anteriormente a sinterização é um processo onde o aumento da temperatura acaba por produzir uma série de mudanças na microestrutura de um material. Dois efeitos principais ocorrem na sinterização, a diminuição da área superficial das partículas e a diminuição do volume do material $[17,18]$. Tais efeitos e outros que serão descritos a seguir ocorrem devido ao aumento do fluxo de transporte de massa pela elevação da temperatura $[5,6]$. A Figura 1 exemplifica as mudanças ocorridas na microestrutura de um material ao longo da sinterização.

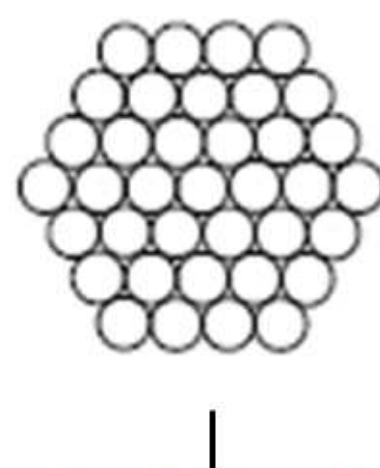

Diminuição da área superficial "Engrossamento"

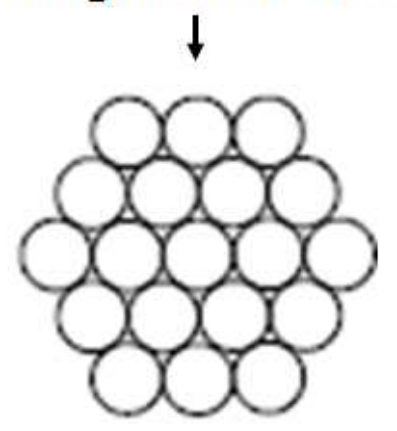

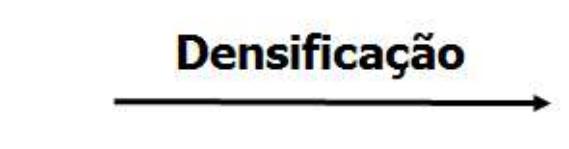
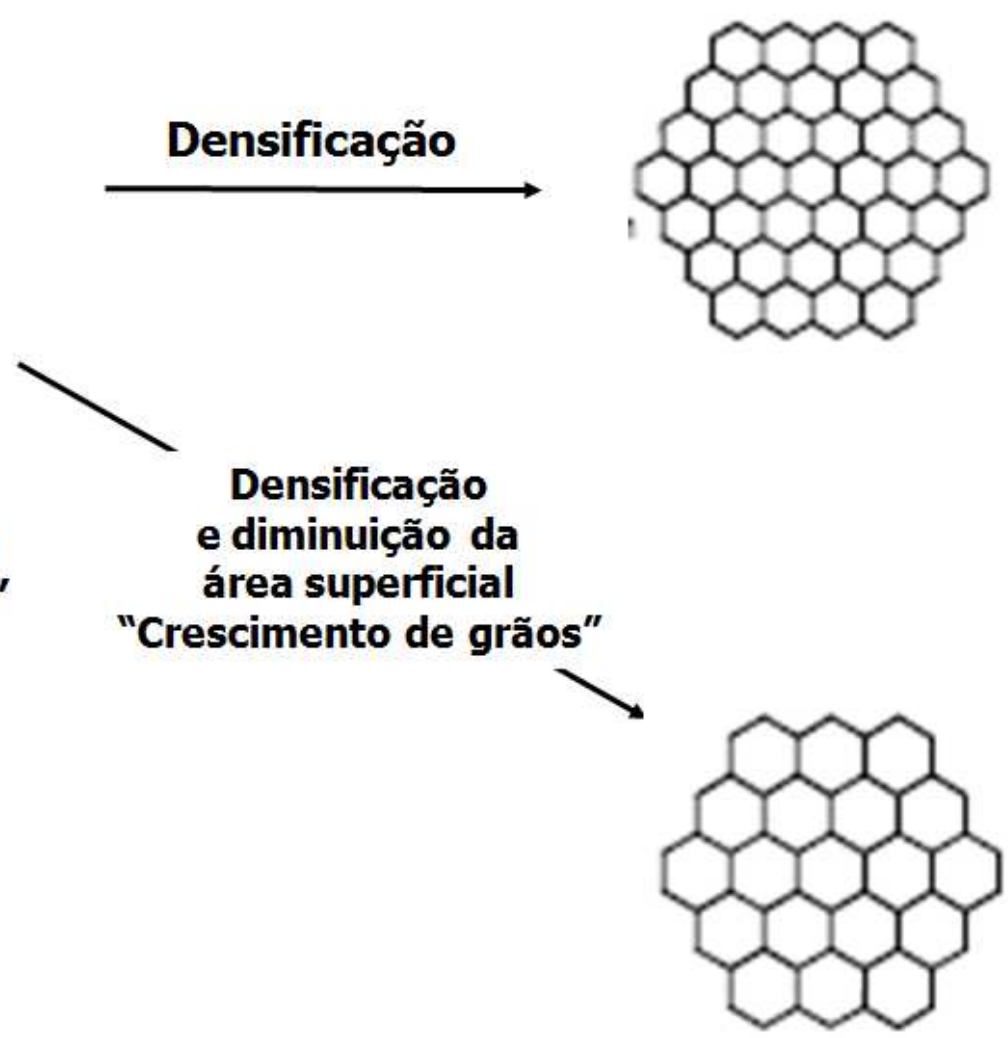

Figura 1: Efeitos principais produzidos na microestrutura de um material durante a sinterização. Figura retirada e modificada da referência [19]. 
Visto que as propriedades de um material, sejam mecânicas, térmicas, elétricas, ópticas ou magnéticas se relacionam com sua microestrutura, a sinterização pode ser utilizada para otimizar propriedades de acordo com a aplicação de interesse [2, 7-9].

\subsubsection{Classes de sinterização}

Usualmente a sinterização é dividida em duas classes distintas, a sinterização em estado sólido e na presença de fase líquida [19]. A sinterização em estado sólido ocorre quando todos os componentes sujeitos ao tratamento térmico possuem temperatura de fusão acima da temperatura à qual são submetidos. A descrição dos fenômenos envolvidos neste tipo de sinterização é complexa devido aos diversos mecanismos de transporte de massa que atuam em nível atômico $[11,19]$.

A sinterização na presença de fase líquida, abreviada como LPS ("liquid phase sintering"), ocorre quando pelo menos um dos componentes apresenta-se na fase líquida. Geralmente esta é dividida em duas subclasses, a sinterização viscosa e a sinterização na presença de uma fase líquida convencional. A sinterização viscosa ocorre principalmente em vidros e polímeros, onde a fração volumétrica da fase líquida é suficientemente grande para que a densificação se dê pelo escoamento viscoso no material [19]. Sua descrição matemática é baseada no trabalho pioneiro de Frenkel, e geralmente é tida como mais simples que a descrição da sinterização por reação em estado sólido [10,11]. Na sinterização na presença de uma fase líquida convencional uma fração do material apresenta-se em equilíbrio químico com um sólido cristalino. O líquido mantém-se nas regiões de interface, como os contornos de grãos/interfaces entre as partículas, aumentando o fluxo de transporte de massa entre partículas ou grãos adjacentes [20]. Outra subclasse da sinterização na presença de fase líquida é denominada "supersólida". Esta ocorre apenas em algumas ligas metálicas, especificamente nos aços ferramenta e não será tratada aqui [21]. Neste trabalho somente a sinterização em estado sólido será abordada. 


\subsubsection{Termodinâmica do processo}

Todo e qualquer sistema físico tem a tendência de buscar sua configuração de mínima energia e máxima entropia [22]. Materiais cristalinos, por exemplo, apresentam átomos dispostos em uma estrutura organizada porque esta é a configuração que minimiza sua energia potencial eletromagnética [9]. A estrutura cristalina de um material depende das densidades eletrônicas de cada um dos átomos que o compõem e do tipo de ligações químicas entre os mesmos.

Materiais cristalinos em temperaturas acima do zero absoluto apresentam defeitos em sua estrutura, como vacâncias e discordâncias, decorrentes da tendência de maximização da entropia [23]. O potencial termodinâmico que permite a inferência da configuração de mínima energia e máxima entropia de um sistema é a energia livre, dada pela equação 2.1 [24].

$$
G_{B}=U+p . V-T . S
$$

onde $G$ é a energia livre do sistema, $U$ a energia interna, $p$ a pressão, $V$ o volume, $T$ a temperatura e $S$ a entropia.

Quando um sistema é constituído por mais de uma partícula, este não está em sua configuração de equilíbrio. As regiões de interface entre as partículas e/ou poros apresentam rompimento da estrutura cristalina, e, constituem regiões de elevada densidade de energia [18]. Como consequência durante a sinterização o sistema busca a diminuição destas áreas de interface [17,18]. A variação na energia livre do sistema durante a sinterização é equacionada conforme a equação $2.2[25]$.

$$
\delta G=\delta \int \gamma_{S V} \cdot d A+\delta \int \gamma_{S S} \cdot d A
$$

onde $\delta$ é a variação de uma grandeza física, $\gamma_{S S}$ e $\gamma_{S V}$ as energias de interfaces entre sólido-sólido e sólido-vapor, respectivamente e $d A$, o elemento de área. 
Em sólidos cristalinos a energia da interface $\gamma_{S V}$ é da ordem de 1 a $2 \mathrm{~J} / \mathrm{m}^{2}$ em média [17]. Já a energia da interface sólido-sólido assume valores ainda menores e que dependem também das orientações cristalográficas das partículas [17]. A Figura 2 exemplifica as regiões de interface formadas em um sistema composto por várias partículas.

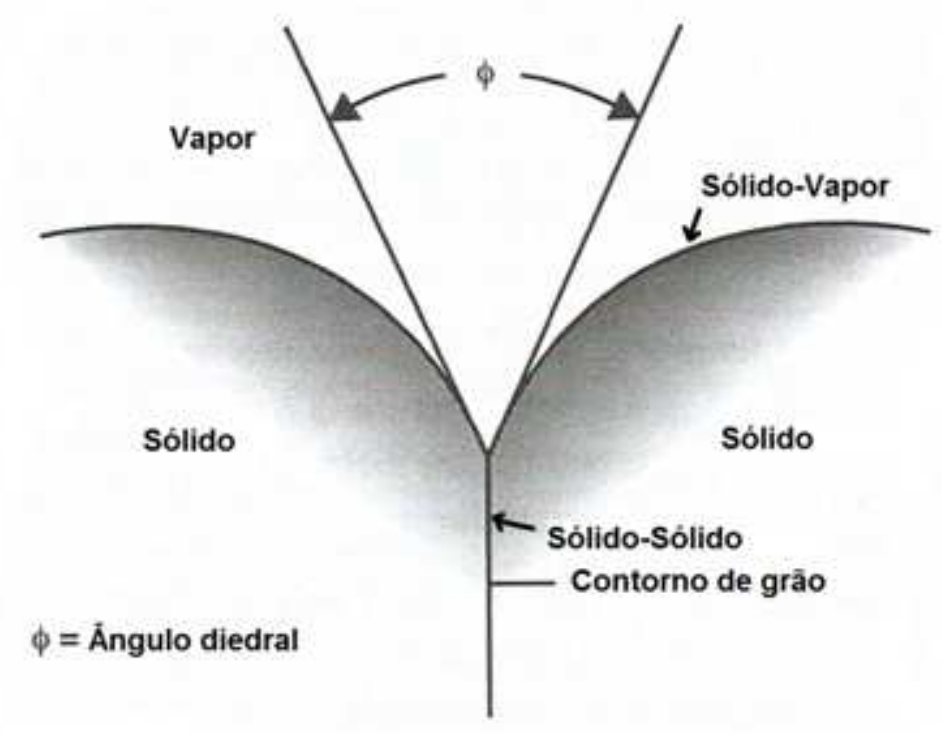

Figura 2: Regiões de interface sólido-sólido e sólido-vapor na microestrutura de um material cristalino durante a sinterização. Figura retirada e modificada da referência [17].

A discussão feita até aqui apenas mostra quais são as configurações termodinâmicas mais estáveis do sistema. No entanto, não necessariamente um sistema alcança sua configuração de menor energia, pois muitas vezes uma barreira de potencial precisa ser superada para que isto ocorra.

\subsubsection{Força Motriz para a sinterização}

Materiais sólidos usualmente apresentam heterogeneidades em sua composição e defeitos em sua estrutura. Tais características, como contornos de grãos ou precipitados, produzem gradientes da energia livre dentro do material. A força motriz para a sinterização é a eliminação destes gradientes, que promovem tensões no material $[6,11,17,26]$. Um sistema somente alcançará sua configuração de menor energia se a força motriz for suficientemente intensa para vencer as barreiras de potencial criadas pelas heterogeneidades no material. 
A quantificação da energia livre em micro regiões do material é feita pelo potencial termodinâmico denominado potencial químico. O potencial químico é definido pela equação 2.3 [27].

$$
\mu=\left(\frac{\partial G}{\partial N}\right)_{T, p}
$$

onde $\mu$ é o potencial químico e $\mathrm{N}$ o número de mols.

Fluxos de transporte de massa serão verificados das regiões de maior potencial químico para as de menor potencial químico. No volume do material o potencial químico de átomos e de vacâncias será descrito pela equação 2.4 [6,25].

$$
\mu_{i}=\mu_{0 i}+p \cdot \Omega_{i}+k \cdot T \cdot \ln C_{i}
$$

onde $\mu_{\mathrm{i}}$ é o potencial químico da espécie atômica $i$ no volume do material, $\mu_{0 i}$ é o potencial químico de referência, $p$ a pressão, $\Omega_{\mathrm{i}}$ o volume da espécie química e $\mathrm{C}_{\mathrm{i}}$ a concentração da mesma.

A análise da equação 2.4 permite inferir que um fluxo de massa ocorrerá das regiões de maior concentração para as de menor concentração. Portanto, durante a sinterização a tendência é a de homogeneizar as espécies químicas solubilizadas no volume do material.

O potencial químico também pode ser calculado nas superfícies dos materiais. Desprezando termos de segunda ordem e considerando uma superfície isotrópica o mesmo é dado pela equação $2.5[6,25]$.

$$
\mu_{i}=\mu_{0 i}+\left(p+\gamma_{S V} \cdot K\right) \cdot \Omega_{i}+k T \cdot \ln C_{i}
$$

onde K é a curvatura da superfície. 
A análise da equação 2.5 mostra que durante a sinterização o fluxo de massa ocorre das regiões de maior curvatura para as de menor curvatura. Assim, o transporte de massa ocorre das superfícies convexas para as superfícies côncavas. A Figura 3 esquematiza esta afirmação.

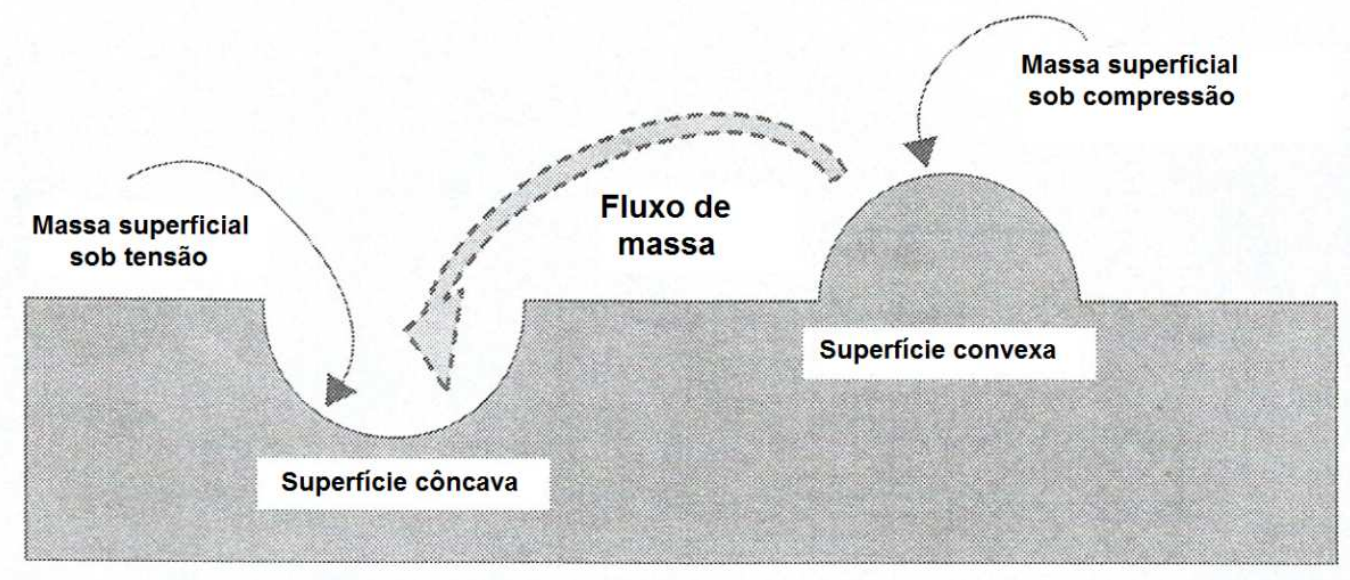

Figura 3: A sinterização age de modo a remover as concavidades e convexidades tornando as superfícies planas. Um fluxo de massa ocorre das regiões de maior convexidade para as de maior concavidade. Figura retirada e modificada da referência [17].

Por fim, o potencial químico também é calculado nas regiões dos contornos de grãos. Herring mostrou que para contornos de grãos de forma plana o potencial químico é dado pela equação 2.6 [28].

$$
\mu_{i}=\mu_{0 i}+\sigma_{N} \Omega
$$

onde $\sigma_{N}$ é a tensão na direção normal à superfície do contorno de grão.

Logo, o fluxo de massa ocorrerá nos contornos de grãos de regiões mais tensionadas para as regiões menos tensionadas.

\subsubsection{Crescimento de Pescoço}

O fluxo de massa das regiões de maior para as de menor curvatura promove o fenômeno denominado crescimento de pescoço ("neck growth") 
[13,17,25,29]. Matéria é transportada para as interfaces das partículas de modo a diminuir a concavidade entre as mesmas. Como consequência, um aumento da região de interface sólido-sólido é verificado [13,17,25,29]. A Figura 4 mostra uma micrografia de um

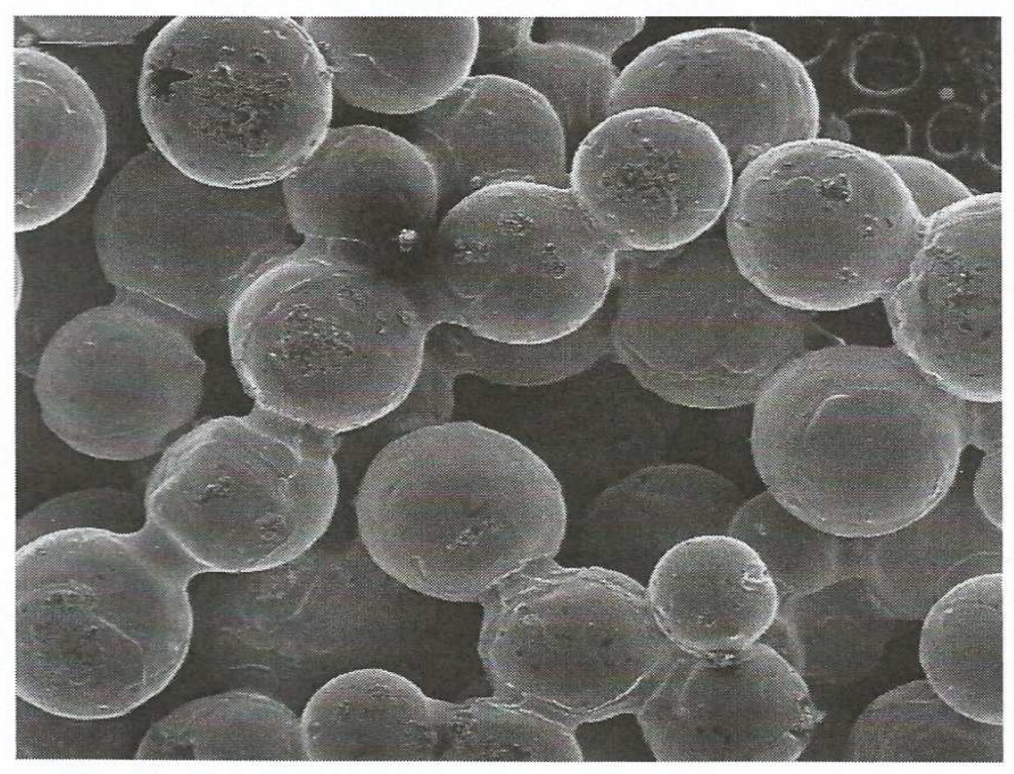

Figura 4: Micrografia obtida com microscópio eletrônico de varredura. Partículas de bronze de $26 \mu \mathrm{m}$ após a sinterização a $800^{\circ} \mathrm{C}$. Figura retirada da referência [17].

material sinterizado evidenciando a formação e o crescimento de pescoço. A Figura 5 mostra a evolução do crescimento de pescoço em materiais particulados.

Apesar do crescimento de pescoço promover um aumento na área de interface sólido-sólido, este diminui as interfaces sólido-vapor. Como foi visto em materiais cristalinos a energia da interface sólido-vapor é maior que da interface sólido-sólido. Portanto, isto torna o fenômeno termodinamicamente favorável.

O crescimento de pescoço tem fundamental importância na dinâmica de sinterização. Os mecanismos que dominam cada estágio da sinterização dependem, dentre outros fatores, da magnitude destas regiões de interface sólido-sólido $[13,30]$. 


\subsubsection{Mecanismos de Sinterização}

Mecanismos de sinterização possuem três parâmetros importantes, a localização inicial das espécies químicas, o destino final e o trajeto percorrido durante o transporte. Vários são os mecanismos responsáveis pelo transporte de massa na sinterização em estado sólido [13,17]. Estes podem ser divididos em duas categorias, os superficiais e os de volume [17].

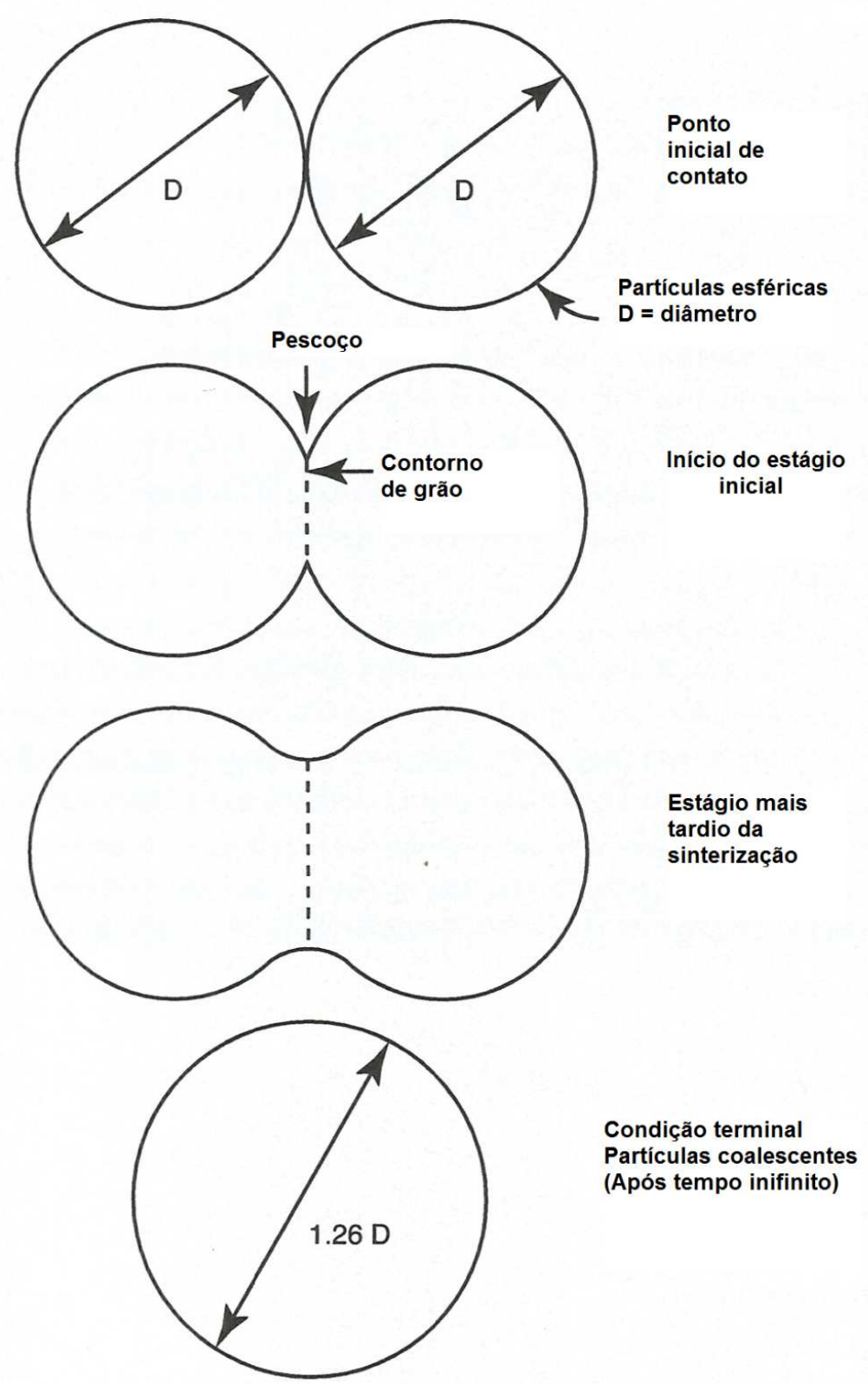

Figura 5: Evolução do crescimento de pescoço em um sistema composto por duas partículas. Figura retirada e modificada da referência [17]. 
Mecanismos superficiais são aqueles no qual a matéria é transportada da superfície do material para as regiões de pescoço ou de menor potencial. Os mecanismos promovem a diminuição da área de interface sólido-vapor sem alterar o volume dos poros. A densidade do material não é modificada por estes mecanismos de sinterização. O fluxo de massa pode ocorrer pela superfície das partículas (difusão superficial) ou por evaporação de uma superfície de menor energia e posterior condensação numa superfície de maior energia (evaporaçãocondensação) [17]. A difusão superficial é importante principalmente no estágio inicial da sinterização onde o crescimento de pescoço é bastante significativo $[13,17]$. Com o desenvolvimento da sinterização este se torna menos importante devido a atuação de outros mecanismos [13,17]. A evaporação-condensação é ativa apenas nos casos onde a pressão de vapor no material é elevada [13,17]. Mecanismos superficiais promovem o fenômeno denominado engrossamento ("coarsening"), pois diminuem a área superficial sem promover a densificação do material $[13,17]$.

Mecanismos de volume por outro lado, transportam a matéria de regiões internas do material para a superfície. Deste modo, tanto a área da interface sólidovapor como o volume dos poros diminui. Os mecanismos via volume são responsáveis pelo fenômeno de densificação no material. Importantes mecanismos via volume em materiais cerâmicos e metálicos são a difusão ao longo dos contornos de grãos e a difusão através do volume do material $[13,17]$. Outros mecanismos de sinterização via volume são o escoamento viscoso, o escoamento plástico e a difusão via discordâncias. $O$ escoamento viscoso é presente somente em materiais amorfos ou de baixa cristalinidade [11,17]. O escoamento plástico é importante durante $\mathrm{o}$ aquecimento em materiais com alta densidade de discordâncias, sendo promovido pela movimentação das mesmas [17]. Este mecanismo é mais ativo em metais, sendo desprezado muitas vezes na análise de materiais cerâmicos. A difusão via discordâncias também depende da densidade de discordâncias e, portanto, é mais importante em metais [17].

Modelos que permitem o cálculo do fluxo de massa em cada um dos mecanismos de sinterização foram desenvolvidos nos últimos 70 anos por uma série 
de pesquisadores [31-39]. Detalhes dos modelos serão omitidos aqui por fugirem do escopo deste trabalho.

A Figura 6 esquematiza os principais mecanismos de sinterização em materiais metálicos e cerâmicos.

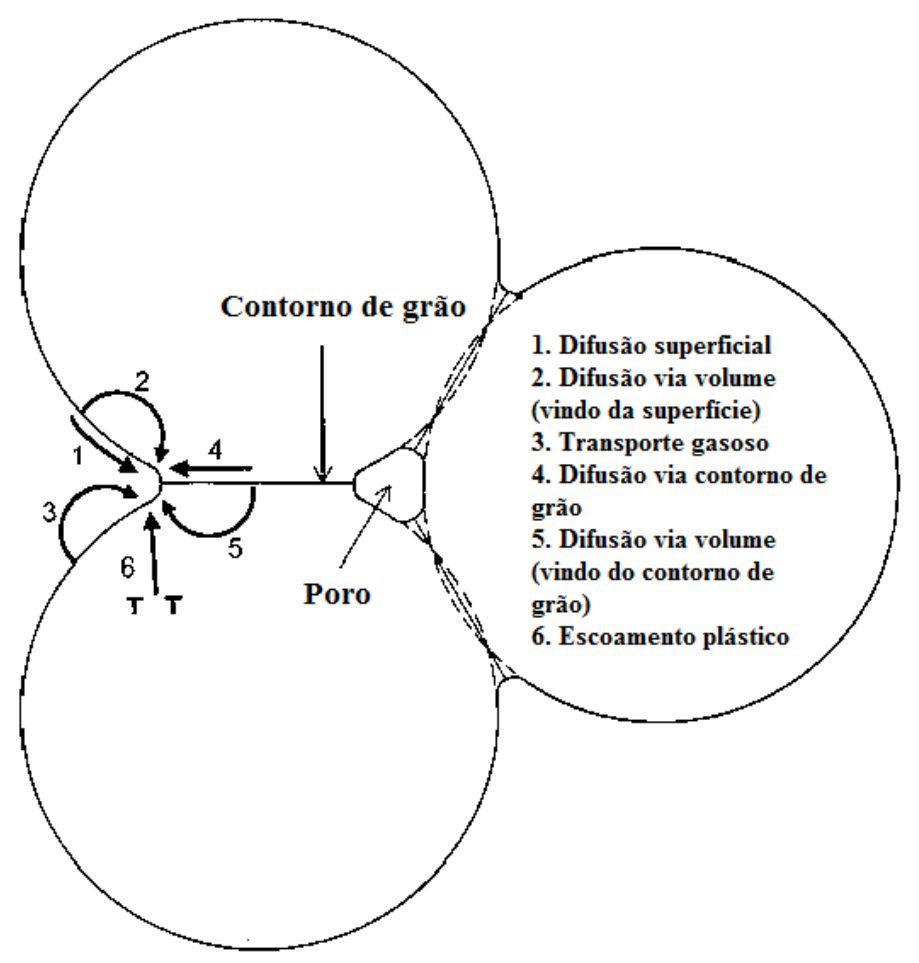

Figura 6: Esquema mostrando os principais mecanismos de sinterização em estado sólido. Figura retirada e modificada da referência [11].

\subsubsection{Estágios da sinterização}

A sinterização é classicamente dividida em três estágios, o estágio inicial, o intermediário e o final $[11,17,25,40]$. Alguns autores ainda incluem uma etapa anterior ao início da sinterização denominada adesão [11,41]. A adesão seria o estágio associado com a formação das áreas de contato entre as partículas durante o processamento do material [11]. Os estágios da sinterização em estado sólido serão descritos aqui idealizando o sistema mais simples possível, material monofásico e sem dificuldades na eliminação dos poros. As partículas são também assumidas possuírem formato esférico e tamanho único. 
O estágio inicial da sinterização é caracterizado por um extenso crescimento de pescoço. As áreas de contato entre as partículas aumentam mais de $20 \%$. Os mecanismos de sinterização via superfície, por possuírem energias de ativação inferiores aos mecanismos via volume, dominam este estágio. A porosidade é interconectada. A retração neste estágio é limitada, sendo da ordem de 3-5\%, em geral $[17,40]$.

O estágio intermediário da sinterização é aquele no qual ocorre a maior parte da retração do material. No final deste estágio, os poros deixam de ser interconectados. Isto ocorre devido ao fechamento dos canais devido sua forma se tornar instável. A área sólido-vapor diminui rapidamente no material e a densificação é significativa. Os mecanismos de sinterização via volume se tornam ativos. A área dos contornos de grão cresce e bordas são verificadas. Próximo ao fim do estágio intermediário os contornos de grãos adquirem mobilidade significativa e o crescimento dos grãos é verificado $[17,40]$.

O estágio final da sinterização tem início quando toda a conectividade entre os poros se torna nula. Os poros são isolados e podem se tornar aprisionados no interior dos grãos adquirindo formas arredondadas. O estágio é marcado pela eliminação da porosidade residual, se possível, e principalmente pelo crescimento de grãos [17,40].

A Figura 7 esquematiza a maior parte das mudanças na microestrutura de um material durante os estágios de sinterização. 

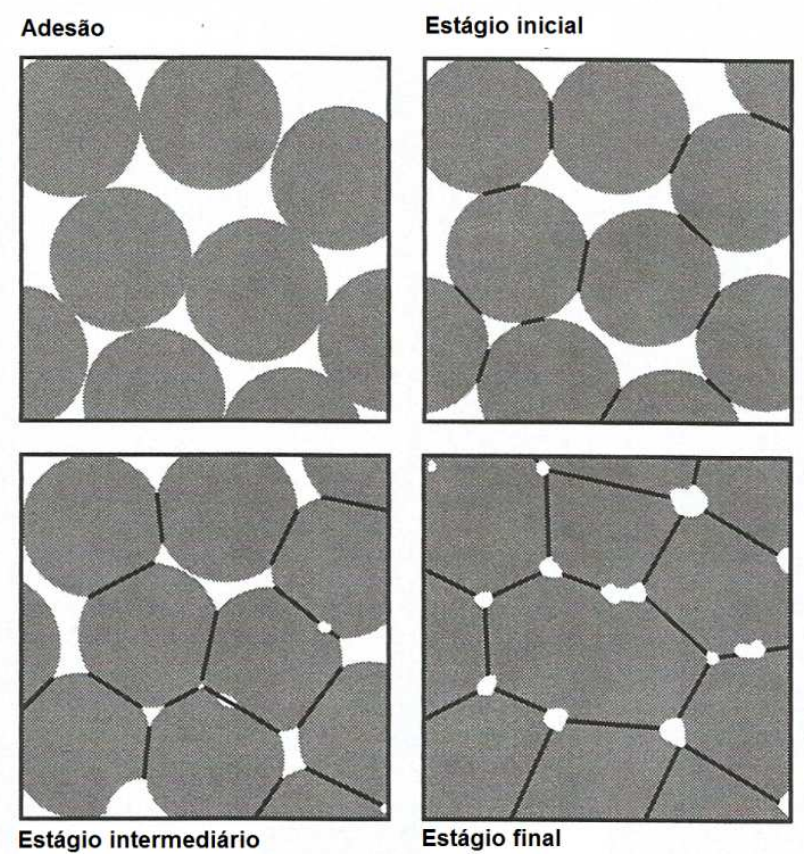

Figura 7: Evolução microestrutural de um sólido cristalino durante cada um dos estágios de sinterização. Figura retirada e modificada da referência [17].

\subsubsection{Eliminação de poros}

A eliminação de poros durante o fim do estágio intermediário e durante o estágio final de sinterização ocorre quando a porosidade se torna não conectada $[17,40]$. Nesta fase da sinterização uma distribuição de tamanhos de poros é formada. Os poros com maior tamanho apresentam menor curvatura média e se comportam como sorvedouros de vacâncias. Já os menores poros, com maior curvatura em média, comportam-se como fonte de vacâncias. Este gradiente na concentração de vacâncias favorece o crescimento dos maiores poros em detrimento dos menores. Tal fenômeno é denominado engrossamento de poros e quando ocorre torna difícil a eliminação da porosidade residual e consequente densificação completa do material $[7,17]$. Para que o engrossamento de poros seja evitado em materiais monofásicos, duas condições devem ser satisfeitas. Os poros devem se manter atados nas regiões dos contornos de grãos e o número de coordenação dos poros (número de partículas ao redor do poro) deve ser menor que um valor crítico [42].

Os poros devem se manter ligados aos contornos de grãos porque estes atuam como aniquiladores de vacâncias e evitam o fluxo de massa entre os po- 
ros. Portanto, é importante que os poros possuam mobilidade compatível com a dos contornos de grãos durante o estágio de crescimento de grãos $[7,17,42]$. Taxas de aquecimento e temperaturas de sinterização adequadas devem ser utilizadas para evitar a separação dos poros dos contornos de grãos. Quando temperaturas ou taxas de aquecimento muito elevadas são utilizadas, a porosidade pode migrar para dentro dos grãos do material, tornando quase impossível sua eliminação [17].

O efeito do número de coordenação dos poros é explicado com base no trabalho de Lange [43]. Lange classificou a estrutura de um material particulado compactado utilizando subestruturas hierárquicas, os aglomerados, os domínios e as partículas. A Figura 8 exemplifica cada uma das subestruturas utilizadas por Lange.

Definindo o número de coordenação dos poros como o número de partículas ao seu redor, pode-se mostrar que o número de coordenação é menor para os poros formados entre as partículas, intermediário para os poros formados entre os domínios e maior para os poros formados entre os aglomerados [43]. Lange mostrou que somente poros com número de coordenação inferior ao valor crítico podem ser eliminados na sinterização $[42,44]$. Assim, o processamento do material é de fundamental importância para completa eliminação dos poros. Alguns trabaIhos na literatura evidenciam que a eliminação da porosidade residual é independente do tamanho inicial de partícula, mas sim dos tamanhos dos aglomerados e de sua estrutura [42, 45-46]. Etapas de processamento como a moagem, prensagem a quente ou utilização de suspensões coloidais são utilizadas para obter distribuições de tamanhos de poros mais estreitas, e assim, de mais fácil eliminação $[42,47]$.

Outro fator decisivo para completa eliminação da porosidade residual é o efeito da atmosfera de sinterização. Com a evolução da sinterização os gases da atmosfera ficam contidos na porosidade fechada. Para que os poros sejam eliminados então, é necessário que os gases apresentem solubilidade adequada no material $[48,49]$. 


\subsubsection{Crescimento de grãos}

O crescimento de grãos durante a sinterização é um fenômeno termodinamicamente favorável devido à diminuição das áreas de interface. A dinâmica de crescimento de grãos ainda não é totalmente compreendida, mas acredita-se que é dominada por quatro tipos de mecanismos, a difusão entre partículas, a migração dos contornos de grãos, a solubilização-reprecipitação e a coalescência de partículas [42]. A solubilização-reprecipitação é um mecanismo existente somente na sinterização na presença de fase líquida e não será abordada neste trabalho $[20,42]$.

A difusão entre partículas é um mecanismo proposto para o estágio inicial e para o estágio intermediário de sinterização. Massa é transportada da superfície de uma partícula para a superfície de outra, sendo este processo dominado pela difusão superficial [17,40,42]. A força motriz do mecanismo de difusão entre partículas é a diferença de curvatura entre as partículas adjacentes [6,25].

A migração dos contornos de grãos é o mecanismo usual de crescimento de grãos durante o fim do estágio intermediário de sinterização e no estágio final. A migração dos contornos de grãos ocorre em elevadas temperaturas ou quando a área de pescoço é suficientemente grande para promover um fluxo significativo de massa através dos contornos de grãos $[7,17,42]$.

Lange mostrou que a dinâmica de crescimento de grãos depende da razão entre o tamanho de partículas adjacentes [50]. Para valores maiores que um certo valor crítico a difusão entre partículas domina o processo aumentando a área de pescoço. Com a evolução da sinterização esta razão diminui até que os contornos de grãos se tornem móveis [50]. As Figuras 9 e 10 esquematizam a dinâmica de crescimento de grãos. 

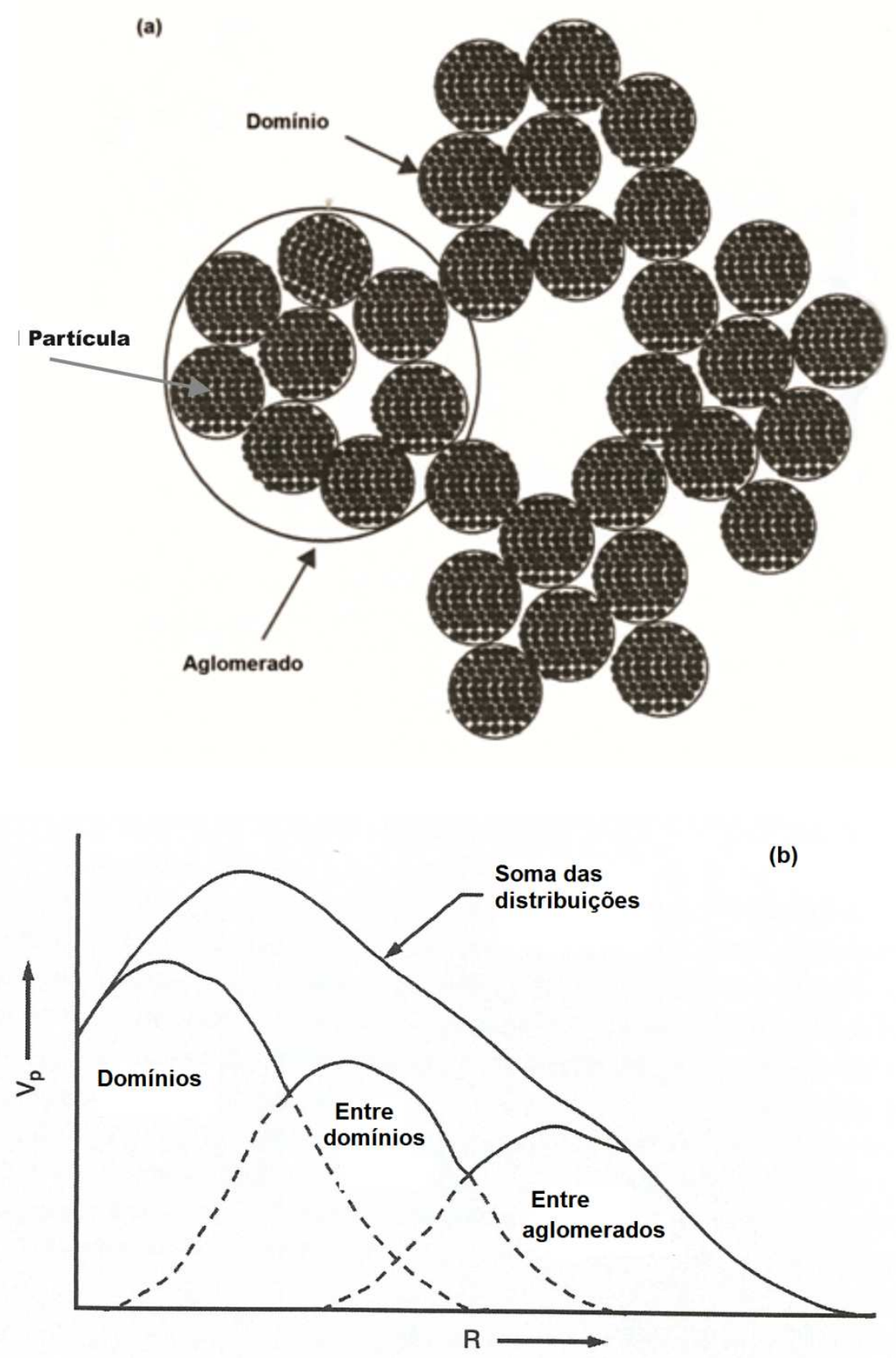

Figura 8: (a) Estrutura esquemática de aglomerados, domínios e partículas em uma microestrutura. (b) Distribuição dos números de coordenação de poros (R) indicando as três classes de poros. Figuras retiradas e modificadas da referência [42]. 


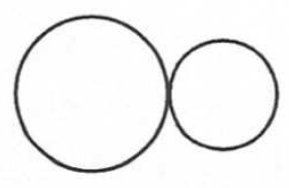

(a)

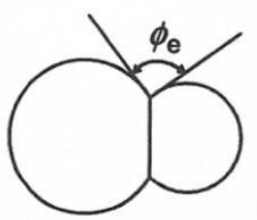

(b)

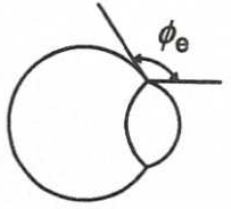

(c)

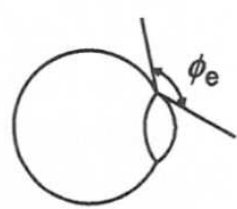

(d)

Figura 9: Arranjo de duas partículas de raio $R_{1}$ (maior) e $R_{2}$ (menor). (a) Antes da formação do pescoço. (b) Quando $R_{1} / R_{2}$ é menor que o valor crítico. (c) $R_{1} / R_{2}=$ valor crítico. (d) $R_{1} / R_{2}$ é maior que o valor crítico. Figura retirada da referência [42].

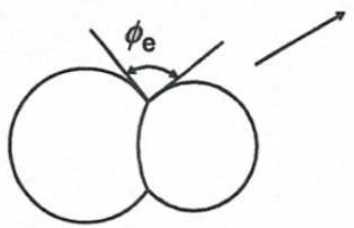

(a)

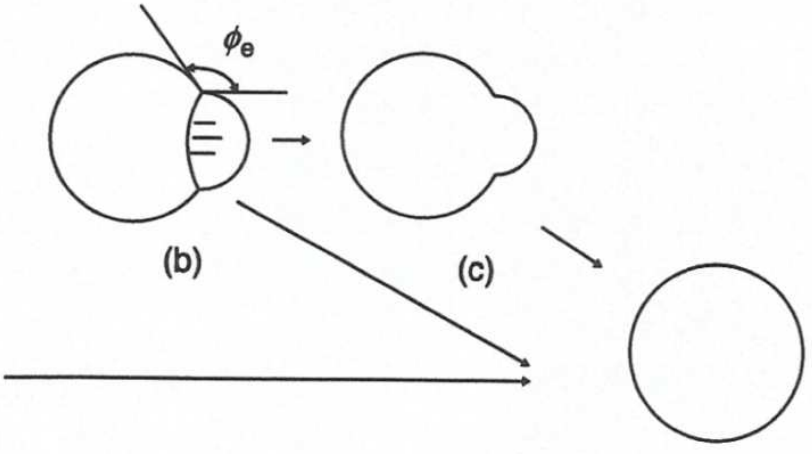

(d)

Figura 10: Configuração de duas partículas após a formação do ângulo diedral $\phi_{e}$. (a) Configuração quando $R_{1} / R_{2}$ é menor do que o valor crítico (Contornos de grãos imóveis).

(b) Configuração resultante do transporte de massa entre partículas. (c) Configuração transiente devido a movimentação dos contornos de grãos. (d) Configuração final após transporte de massa entre partículas e após migração dos contornos de grãos. Figura retirada da referência [42]

Quando o crescimento de grãos é atribuído a migração dos contornos de grãos, o tamanho dos grãos é frequentemente descrito pela equação 2.7 [7].

$$
G^{3}=G_{0}^{3}+K_{G} \cdot t
$$

onde $t$ é o tempo, $G_{0}$ o tamanho médio inicial dos grãos, $G$ o tamanho médio dos grãos e $K_{G}$ um fator de Arrhenius dependente da temperatura. 
Outro mecanismo de crescimento de grãos, importante especialmente para materiais nanométricos, é a coalescência de partículas [42]. A coalescência de partículas é o fenômeno pelo qual as partículas do material escorregam ou rotacionam durante a sinterização promovendo o alinhamento das orientações cristalográficas entre partículas adjacentes. Quando alinhadas, as partículas coalescem formando uma única partícula. Um súbito aumento no tamanho de grãos é verificado neste caso. $O$ fenômeno foi verificado tanto experimentalmente [51] quanto em simulações numéricas [52]. Este mecanismo foi pouco estudado.

Conforme se desenvolve o crescimento de grãos, tanto o tamanho como a forma dos grãos é modificada [40]. No estágio final da sinterização os grãos maiores costumam apresentar entre 4 e 6 lados em imagens bidimensionais e entre 13 e 15 lados em estruturas tridimensionais [40]. A forma média assumida no estágio final é a de um tetradecaedro, conforme o da Figura 11 [17,38]. A Figura 12 mostra uma micrografia evidenciando o formato similar dos grãos no estágio final com a forma do tetradecaedro apresentado.

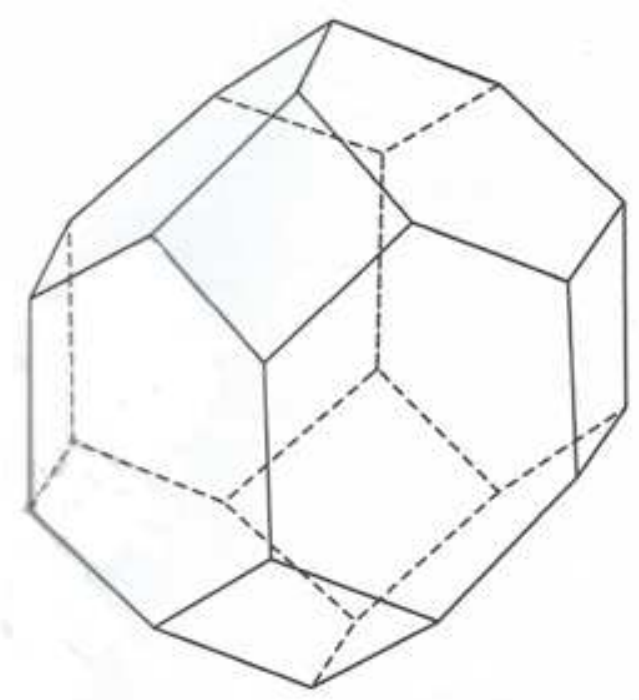

Figura 11: Figura esquemática mostrando um tetradecaedro, a forma geométrica assumida para os grãos no estágio final de sinterização. Figura retirada da referência [17]. 


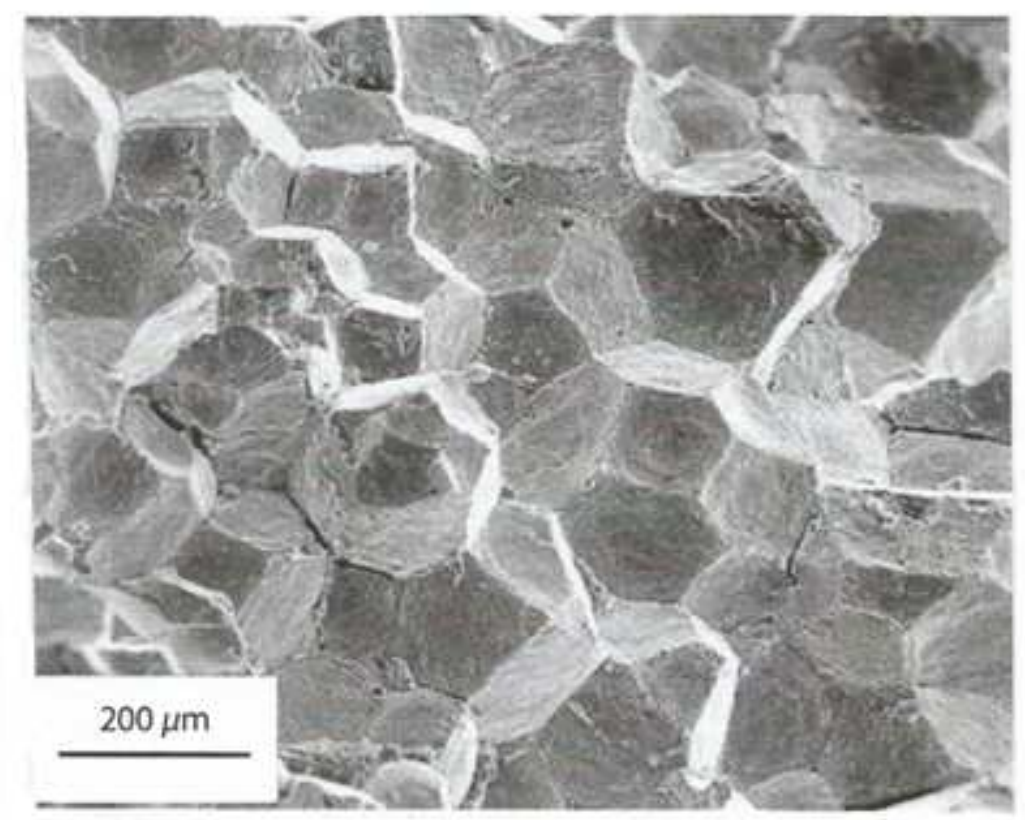

Figura 12: Micrografia obtida por microscopia eletrônica de varredura. A imagem mostra grãos poliedrais similares a estrutura idealizada para o estágio final de sinterização, o tetradecaedro. Figura retirada da referência [17].

A forma da distribuição de tamanhos de grãos também não é aleatória. Para muitos casos se verifica que esta segue uma distribuição exponencial e que a distribuição cumulativa é do tipo Weibull, dada pela equação 2.8 [17].

$$
P(G)=P_{M} \cdot \exp \left[-b \cdot\left(\sqrt{\left.\frac{G}{G_{M}-1}\right)^{2}}\right]\right.
$$

onde $P(G)$ é a probabilidade de encontrar grãos de tamanho $G$. $G_{M}$ é a moda da distribuição de tamanhos de grãos, $b$ uma constante tipicamente entre 2 e 6 e $P_{M}$ o pico de frequência da distribuição.

\subsubsection{Pesquisas Recentes}

A conferência sobre sinterização, que acontece a cada três anos, mostrou algumas tendências para a pesquisa na área [53]. Um crescente interesse nos métodos de simulação, principalmente os de multi escala tem sido verificado. Tais 
métodos tem permitido um avanço na descrição e na compreensão da evolução microestrutural durante a sinterização.

Outro tópico que tem despertado interesse atualmente é o desenvolvimento de métodos mais eficientes de promover a sinterização, como aqueles devido a utilização de campos elétricos ou microondas. Tais métodos têm permitido sinterizar materiais em temperaturas e tempos cada vez menores, embora uma série de questões teóricas ainda não seja bem compreendida [53-57].

A sinterização de materiais nanométricos também é um tema bastante atual. Cada vez mais os materiais nanométricos se tornam importantes em aplicações tecnológicas. Estes materiais apresentam diversas características distintas durante a sinterização em relação aos materiais de maior tamanho de partícula. $A$ descrição da sinterização destes materiais e de métodos que permitam o controle microestrutural é de muito interesse $[42,53,58]$.

Dentre os métodos utilizados para se obter uma microestrutura mais controlada, destaca-se a curva mestre de sinterização. A curva mestre de sinterização é um método utilizado para prever a densidade de um compacto após um tratamento térmico qualquer. Trabalhos têm mostrado ainda a possibilidade de utilizar a curva mestre em conjunto com dados do tamanho de grão para permitir um melhor controle microestrutural. O método tem sido aplicado para diversos materiais, embora possua limitações [59-73].

Dentro deste contexto, a proposta deste trabalho é de estudar a sinterização da céria contendo gadolínia quando utilizados materiais de partida com diferentes áreas superficiais específicas. A ênfase do estudo será dada às mudanças microestruturais durante a sinterização não isotérmica dos materiais. As curvas de trajetória para o crescimento de cristalito (cristalito versus densidade) serão obtidas para todos os materiais. Os efeitos do tamanho inicial de partícula na construção da curva mestre de sinterização serão analisados. Outros aspectos também relacionados ao método da curva mestre de sinterização serão analisados neste trabalho.

Ainda, conforme será mostrado, a céria dopada com gadolínia possui baixa estabilidade química em baixas pressões parciais de oxigênio ou em altas temperaturas. Assim, o efeito de diferentes atmosferas de sinterização será investigado 
e relacionado com a sua condutividade elétrica, principal característica de interesse.

As características da céria contendo gadolínia serão discutidas em detaIhes a seguir, justificando a sua utilização. Breves revisões do método de curva mestre de sinterização e dos efeitos da atmosfera de sinterização serão feitos na sequência. 


\section{2 CÉRIA - GADOLÍNIA}

\subsubsection{Estrutura cristalina}

A céria contendo $10 \%$ em mol de gadolínia $\left(\mathrm{Ce}_{0,9} \mathrm{Gd}_{0,1} \mathrm{O}_{2-x}\right)$ é um material que apresenta uma única estrutura cristalina conhecida, a cúbica de faces centradas do tipo fluorita e grupo espacial Fm-3m [74]. O parâmetro de rede do material é da ordem de $5,418 \AA$, que indica uma densidade cristalográfica de aproximadamente $7,22 \mathrm{~g} / \mathrm{cm}^{3}$ [74]. A Figura 13 esquematiza sua estrutura cristalina.

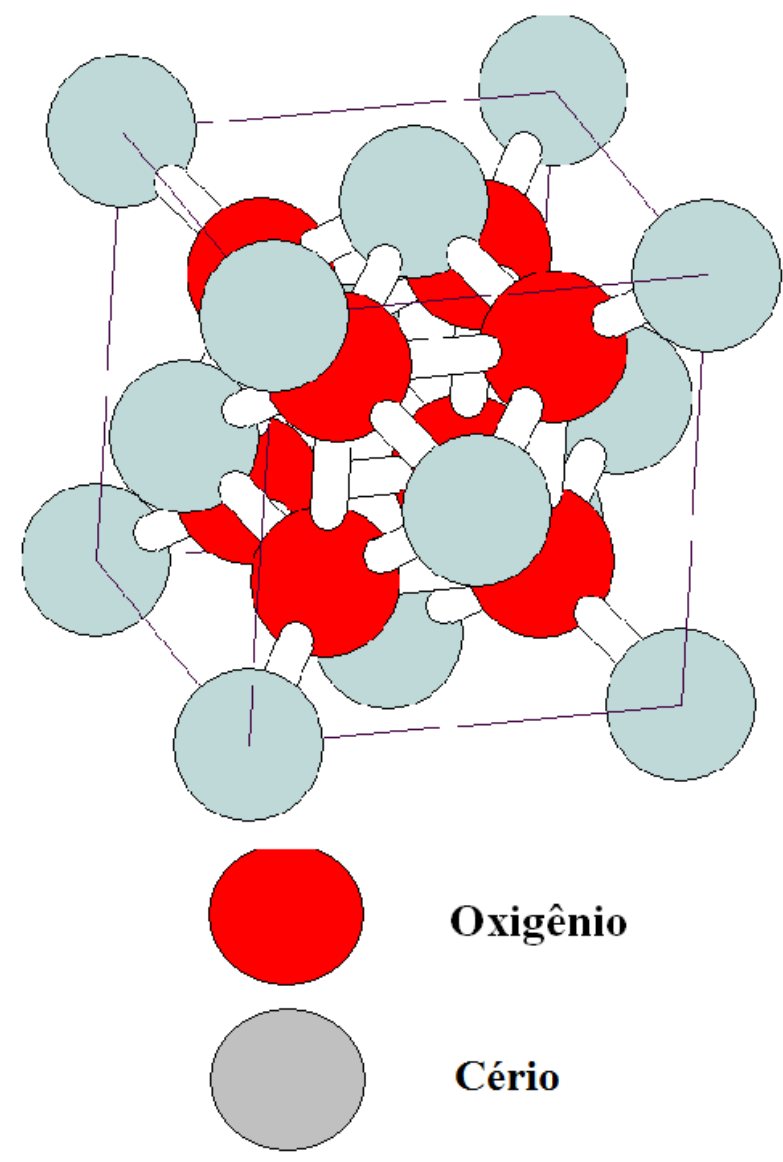

Figura 13: Estrutura cristalina da céria, cúbica de faces centradas do tipo fluorita e grupo espacial Fm-3m.

A estrutura cristalina do tipo fluorita forma ligações aniônicas tetraédricas e ligações catiônicas octaédricas. A estrutura é relativamente aberta, o que confere altos valores de condutividade iônica para o íon oxigênio [15, 74]. O diagrama de fases reportado por Steltzer [75] em 1995, foi construído para a composição con- 
tendo $10 \%$ em mol de $\mathrm{Gd}_{2} \mathrm{O}_{3}$. A Figura 14 mostra o diagrama de fases obtido por Steltzer em medidas de calor específico.

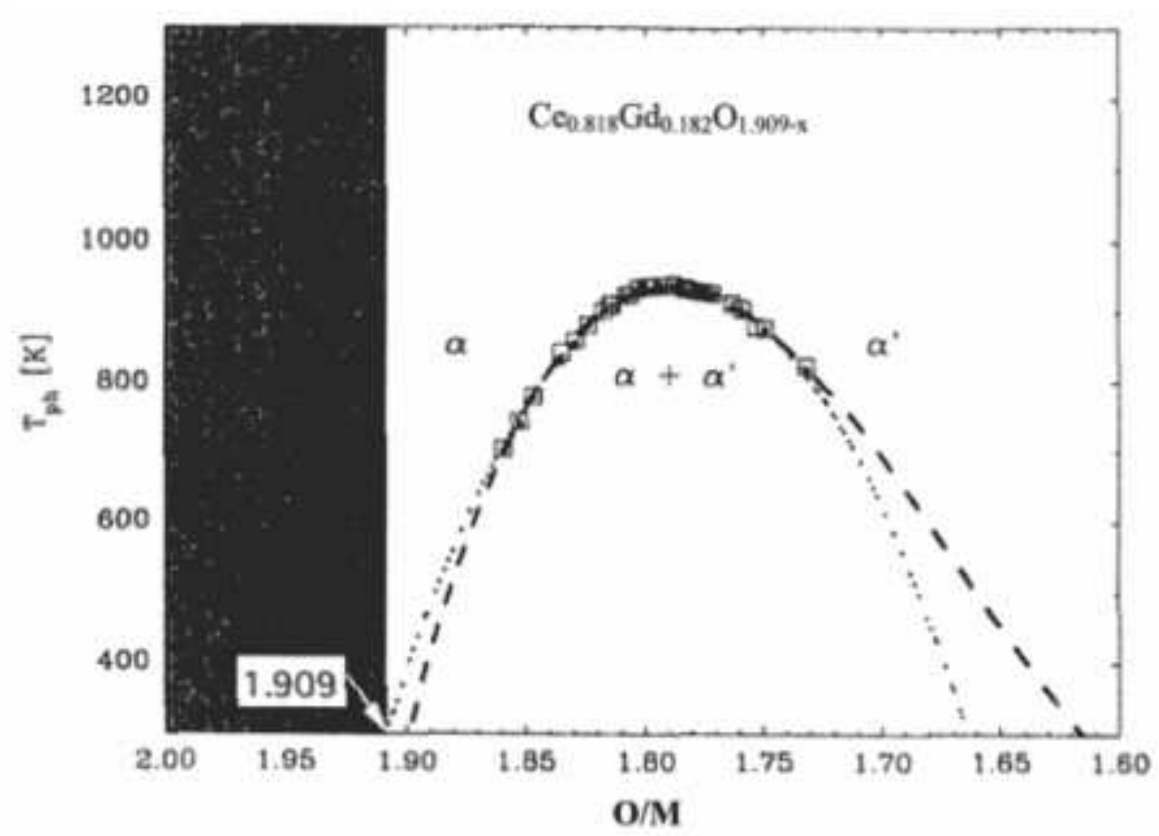

Figura 14: Diagrama de fases para a $\mathrm{Ce}_{0,818} \mathrm{Gd}_{0,182} \mathrm{O}_{1,909-x}$ após o trabalho de Steltzer. Figura retirada da referência [75].

Duas fases são verificadas no diagrama, a cúbica do tipo $\alpha$ e a cúbica do tipo $\alpha$. Ambas as fases admitem a redução do $\mathrm{Ce}^{4+}$ para $\mathrm{Ce}^{3+}$ tornando o material não estequiométrico. Entretanto, enquanto a fase $\alpha$ admite um intervalo contínuo de valores para $\mathrm{x}$, a fase $\alpha$ ' admite apenas uma quantidade discreta de composições não estequiométricas [76]. Estas fases apresentam coeficientes de expansão térmica distintos, entre outras propriedades [76].

\subsubsection{Condutividade elétrica}

A céria contendo gadolínia (GDC) é um material com potencial aplicação como eletrólito sólido em células a combustível de óxido sólido devido sua elevada condutividade iônica $[15,16,74]$. O material apresenta a condutividade de 0,1 $\mathrm{S} / \mathrm{cm}$ em aproximadamente $800^{\circ} \mathrm{C}[15,74]$. Este valor é o mesmo verificado a $1000^{\circ} \mathrm{C}$ para a zircônia estabilizada com ítria (YSZ), material padrão utilizado atualmente [16,74]. A utilização da GDC como eletrólito sólido permitiria a diminuição da temperatura de operação desses dispositivos e do aumento da eficiência das 
células a combustível $[15,16,74,77]$. O gráfico da Figura 15 compara a condutividade da GDC com diversos materiais conhecidos como possíveis substitutos da YSZ como eletrólito sólido.

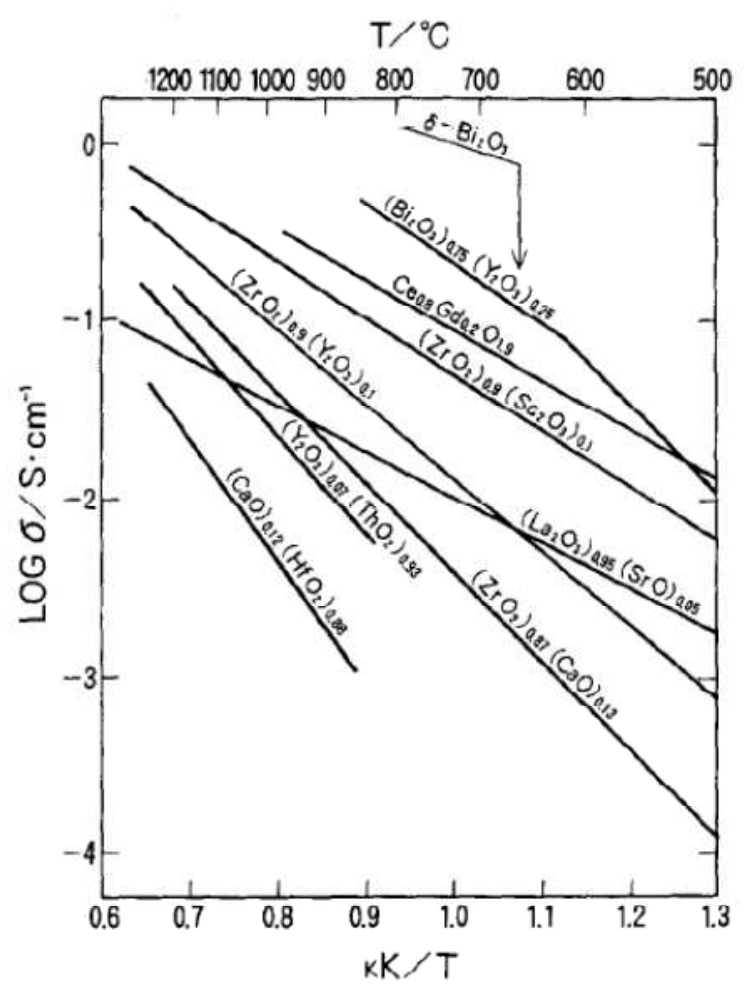

Figura 15: Condutividade elétrica para diversos óxidos de estrutura tipo fluorita. Figura retirada da referência [15].

Considerando a elevada condutividade elétrica da céria contendo gadolínia em relação a outros materiais, um amplo interesse sobre as propriedades e características deste material tem sido verificado na literatura $[15,16,74]$.

A condutividade elétrica nos contornos de grãos da GDC mostra forte dependência com a rota de preparação das amostras [74]. Tal variação se reflete nos valores da condutividade total obtidos por diversos autores, conforme o gráfico da Figura 16. Tanto a energia de ativação para condução dos íons $\mathrm{O}^{2-}$ como os fatores pré exponenciais variam fortemente no gráfico da Figura 16. 


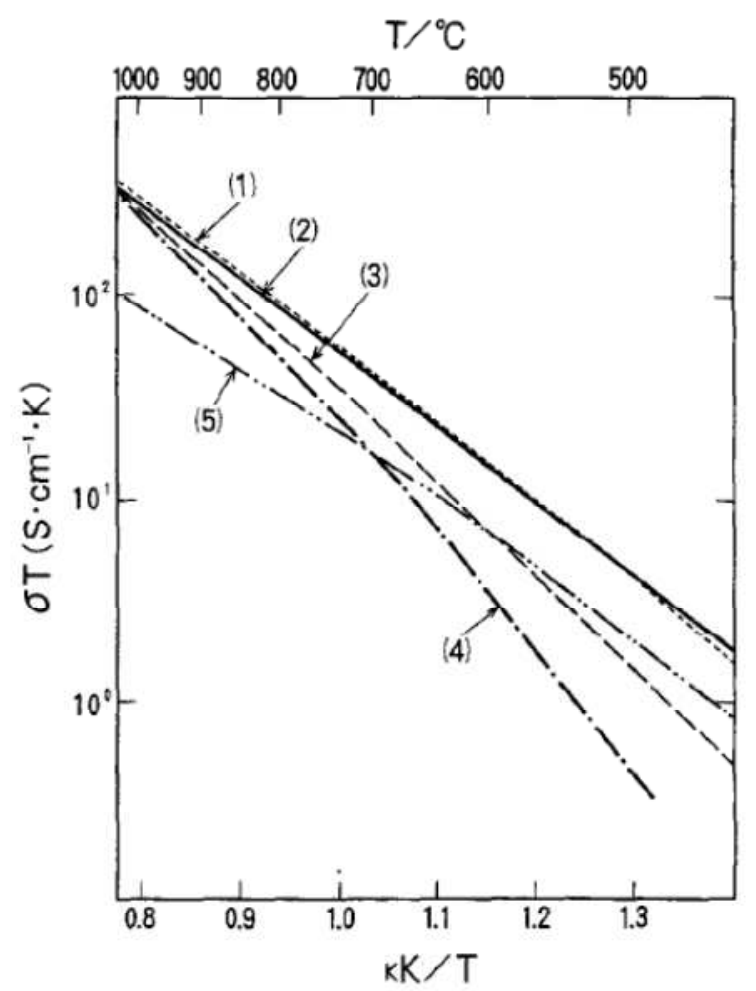

Figura 16: Condutividade elétrica para a $\mathrm{Ce}_{0,8} \mathrm{Gd}_{0,2} \mathrm{O}_{1,9}$ obtida por vários autores utilizando diferentes rotas de preparação. Figura retirada da referência [15].

A condutividade intragranular (no volume do material), entretanto, não mostra dependência significativa com a rota de preparação das amostras, mas sim com a concentração e o tipo de dopante utilizado [15,74]. As energias de ativação para condução do íon $\mathrm{O}^{2-}$ na rede cristalina é de aproximadamente $0,82 \mathrm{eV}$ para a céria contendo $10 \%$ em mol de $\mathrm{GdO}_{1,5}[15]$.

Embora a céria-gadolínia apresente alta condutividade iônica, o material possui baixa estabilidade química quando sujeito a baixas pressões parciais de oxigênio e elevadas temperaturas [15,74]. Nestas condições, o $\mathrm{Ce}^{4+}$ pode reduzir para $\mathrm{Ce}^{3+}$ produzindo o aumento da condutividade eletrônica [15].

\subsubsection{Química de defeitos}

A introdução do gadolínio na rede da céria promove o aumento da concentração de vacâncias de oxigênio. Como consequência, um aumento na condutividade iônica do material também é verificado até concentrações de $10 \%$ em mol 
de $\mathrm{Gd}_{2} \mathrm{O}_{3}$ [15]. A equação de defeitos que rege a reação química é dada, segundo a notação de Kroeger e Vink [78,79], pela equação 2.9. Detalhes sobre a notação de Kroeger e Vink são discutidos no Apêndice A.

$$
G d_{2} O_{3} \Leftrightarrow 2 G d_{C e}^{\prime}+3 O_{O}^{x}+V_{o}^{*}
$$

onde $\mathrm{Gd}_{\mathrm{Ce}}$ representa um átomo de gadolínio na posição do cério na rede cristalina. A carga efetiva do gadolínio é negativa. $0^{\times}$na equação 2.9 representa um átomo de oxigênio em sua posição normal na rede com carga efetiva nula. $V_{o}^{*}$ significa que uma vacância de oxigênio é produzida pela eliminação de um átomo de oxigênio para o meio ambiente. A vacância de oxigênio apresenta carga efetiva duplamente positiva. Como os materiais cerâmicos devem manter a eletroneutralidade local, as vacâncias de oxigênio e os átomos do aditivo interagem durante a difusão na rede $[6,80]$.

Ainda como foi discutido, quando sujeito a baixas pressões parciais de oxigênio ou elevadas temperaturas, o $\mathrm{Ce}^{4+}$ apresenta redução para o $\mathrm{Ce}^{3+}$. A equação de defeitos que rege essa reação química é a 2.10.

$$
O_{o}^{x} \Leftrightarrow 2 \cdot C e_{C e}^{\cdot}+\left[V_{o}^{* \bullet}\right]+\frac{1}{2} \cdot O^{2-}
$$

onde Ce'Ce representa uma reação de redução do $\mathrm{Ce}^{4+}$ para $\mathrm{Ce}^{3+}$ formando um pólaron [81]. O termo $\mathrm{O}^{2-}$ representa a eliminação de um íon de oxigênio para o meio ambiente.

Para que a eletroneutralidade seja mantida no cristal, a eliminação do oxigênio para a atmosfera requer a redução do $\mathrm{Ce}^{4+}$ para $\mathrm{Ce}^{3+}$. A concentração de $\mathrm{Ce}^{3+}$ produzida na superfície depende das condições termodinâmicas, e logo, diferentes atmosferas de sinterização podem produzir efeitos distintos devido aos diferentes potencias de redução.

Outro fator relevante é a área superficial das partículas. Quanto maior a área superficial, provavelmente maior será a concentração de $\mathrm{Ce}^{3+}$ no volume do 
material. O aumento da área superficial específica do material de partida deve atuar como um amplificador dos efeitos discutidos.

\subsubsection{Energia de ativação para difusão do cério}

Na sinterização as espécies químicas mais lentas são as responsáveis pelo controle da cinética de reação [6,80]. No caso da céria-gadolínia, as espécies que controlam o processo são o cério e o gadolínio. Uma ampla dispersão de valores é encontrada na literatura para a energia de ativação para difusão destes elementos no material. Os valores variam entre 66,4 e $770 \mathrm{~kJ} / \mathrm{mol}$ e nenhum destes foi obtido pelo método de traçadores radioativos [63,64,82-93]. Portanto, torna-se difícil uma escolha adequada de valores ideais para esta grandeza.

Uma boa estimativa, entretanto, pode ser obtida através da análise e da comparação de propriedades correlacionadas, como o coeficiente de expansão térmica e o ponto de fusão do material. Tais grandezas físicas dependem da intensidade das ligações iônicas no material, e assim, permitem a comparação feita a seguir.

A energia de ativação para difusão do zircônio na zircônia estabilizada com $8 \%$ em mol de ítria foi determinada, tanto pelo método de traçador radioativo, como por outros métodos. Os resultados para a 8YSZ são mostrados na Tabela 1.

Tabela 1: Valores da energia de ativação para difusão catiônica no cristal de 8YSZ.

\begin{tabular}{cc}
\hline Energia (kJ/mol) & Método / [Ref.] \\
\hline 435 & Traçador radioativo/ [94] \\
450 & Espectroscopia de impedância/[95] \\
475 & Traçador radioativo/ [96] \\
\hline
\end{tabular}

Procede-se então a comparação entre os coeficientes de expansão térmica e ponto de fusão da YSZ e da céria. Os dados são mostrados na Tabela 2. 
Tabela 2: Coeficiente de expansão térmico médio $\alpha_{M}$ e temperatura de fusão TF para a céria, e para zircônia estabilizada com ítria 8YSZ.

\begin{tabular}{ccc}
\hline Material & $\alpha_{M}\left(\mathbf{K}^{-1}\right)$ & TF $\left({ }^{\circ} \mathbf{C}\right)$ \\
\hline $8 Y S Z$ & $1,05.10^{-5}[97]$ & $2700[99]$ \\
Céria & $1,7.10^{-5}[98]$ & $2600[99]$ \\
\hline
\end{tabular}

Nota-se que os valores das grandezas analisadas são muito próximos, porém em geral, os valores indicam ligações químicas ligeiramente mais fracas na céria. A adição da gadolínia na céria promove a diminuição da energia de ligação entre os átomos, e logo, deve aumentar o coeficiente de expansão térmica e diminuir o ponto de fusão do material. Assim, espera-se que o valor para energia de ativação para difusão via volume durante a sinterização da céria-gadolínia seja da mesma ordem de grandeza que o verificado para o zircônio na 8YSZ. Uma boa faixa de valores estaria entre $400 \mathrm{~kJ} / \mathrm{mol}$ e $500 \mathrm{~kJ} / \mathrm{mol}$ aproximadamente. 


\subsection{REVISÃO BIBLIOGRÁFICA}

\subsubsection{Curva mestre de sinterização}

Em 1992 Hansen e colaboradores [100] propuseram um modelo de sinterização que permite a análise da taxa de densificação de um material ao longo de todos os estágios da sinterização. Este foi chamado de modelo de sinterização combinada e a equação proposta é a mostrada em 2.11.

$$
-\frac{d L}{L d t}=\frac{d \rho}{3 \rho d t}=\frac{\gamma \Omega}{k T}\left(\frac{\delta_{g b} D_{g b} \Gamma_{G g b}}{G^{4}}+\frac{D_{v} \Gamma_{G_{v}}}{G^{3}}\right)
$$

onde $L$ é o comprimento da amostra, $\rho$ a densidade do material, $t$ o tempo, $T$ a temperatura, $G$ o tamanho médio de grão, $k$ a constante de Boltzmann, $\gamma$ a energia livre superficial específica, $\Omega$ o volume atômico, $\delta_{\gamma b}$ a espessura dos contornos de grãos e $D$ e $\Gamma_{G}$ os coeficientes de difusão e fatores geométricos, respectivamente. Os subíndices $g b$ e $v$ são associados aos mecanismos de difusão via contornos de grão e via volume, respectivamente. Os fatores geométricos $\Gamma_{G}$ são variáveis dependentes de diversas características da microestrutura, como a curvatura dos grãos ou a área dos contornos de grãos. Os coeficientes de difusão por sua vez são definidos pela equação 2.12 .

$$
D_{i}=D_{0 i} \cdot \exp \left(\frac{-Q_{i}}{k T}\right) \quad i=g b \text { ou } v
$$

sendo $D_{0 i}$ o fator pré-exponencial e $Q_{i}$ a energia de ativação para o mecanismo de difusão indicado pelo subíndice $i$.

Diferente dos demais modelos que admitiam uma geometria específica para os grãos, no de sinterização combinada, a forma dos grãos é arbitrária, sendo poliedros irregulares. Tal suposição foi baseada no modelo de evolução microestrutural criado por DeHoff e idealizada anos antes por Rhines [40,59]. 
Mais tarde, em 1996, Su e Johnson [60] utilizaram a equação do modelo de sinterização combinada e mostraram que caso certas hipóteses fossem satisfeitas, seria possível a construção de uma única curva relacionando a densidade de um material a um perfil de tempo e temperatura qualquer. Esta curva foi denominada: curva mestre de sinterização, MSC.

Para que isto seja possível, considera-se inicialmente que a microestrutura do material analisado é apenas uma função da densidade, sendo independente do perfil tempo/temperatura [60]. Tal hipótese é geralmente aceitável quando as amostras do material são processadas de forma idêntica e quando os mecanismos de sinterização superficiais não são suficientemente intensos para modificar as taxas de densificação $[59,60,101]$. Ainda, uma segunda hipótese necessária é que apenas um mecanismo de densificação via volume domine a densificação [60]. Caso esta hipótese seja satisfeita a equação 2.11 poderá ser rearranjada tal qual a equação 2.13 .

$$
\int_{0}^{t} \frac{1}{T} \cdot \exp \left(\frac{-Q}{R T}\right) \cdot d t=\frac{k}{\gamma \Omega D_{0}} \cdot \int_{\rho_{0}}^{\rho} \frac{(G(\rho))^{n}}{3 \rho \Gamma_{G}(\rho)} \cdot d \rho
$$

onde o lado direito é apenas função da densidade do material e o lado esquerdo apenas do tempo e temperatura. Assim definem-se novas variáveis, segundo 2.14 e 2.15, que, substituídas na equação 2.13 , geram a equação 2.16 .

$$
\begin{aligned}
& \Theta(t, T(t))=\int_{0}^{t} \frac{1}{T} \cdot \exp \left(\frac{-Q_{i}}{R T}\right) d t \\
& \Phi(\rho)=\frac{k}{2 \Omega D_{0 i}} \cdot \int \frac{(G(\rho))^{n}}{3 \rho \Gamma_{G i}(\rho)} d \rho \\
& \Phi(\rho)=\Theta(t, T(t))
\end{aligned}
$$


Na equação 2.15, $n$ assume o valor 3 ou 4 dependendo do mecanismo de sinterização dominante. Se $n$ for igual a 4 , o termo $\delta$ deve ser multiplicado ao lado direito da equação 2.15. A variável $\Theta(t, T(t))$ é denominada na literatura como trabalho da sinterização [67].

A equação 2.15 relaciona duas funções crescentes que não dependem da mesma variável. Assim, pode-se afirmar que para uma dada densidade apenas um valor de $\Theta(t, T(t))$ será possível, e logo, uma única curva relaciona a densidade do material com o trabalho da sinterização. Esta curva pode ser utilizada para previsão da densidade de um material sujeito a um tratamento térmico qualquer dadas as condições impostas pelo método.

O procedimento experimental para determinação da curva mestre é relativamente simples. Diversas curvas de retração linear são obtidas com diferentes perfis de tempo/temperatura e os dados de retração linear convertidos para densidade. Calcula-se a variável $\Theta(t, T(t))$ para cada perfil tempo/temperatura usando um valor qualquer fixo para a energia de ativação. Um único ajuste é feito a todo o conjunto de dados e o resíduo quadrático total ou médio calculado. Repete-se todo procedimento de análise utilizando um novo valor para a energia de ativação e calcula-se novamente o resíduo quadrático do ajuste. Tal procedimento é repetido até que seja determinada a energia de ativação que minimiza o resíduo quadrático, sendo esta a curva mestre do material analisado [59-73]. A Figura 17 mostra um exemplo de construção da curva mestre de sinterização para a alumina.

O conceito da curva mestre ainda pode ser ampliado relacionando-a, por exemplo, com a microestrutura, conforme mostrado na Figura 18. A associação desta com informações acerca da evolução microestrutural é uma das proeminentes abordagens estudadas atualmente com o objetivo de otimizar microestruturas [12].

A curva mestre de sinterização tem sido construída com sucesso para diversos materiais, entretanto, alguns problemas ainda podem ser identificados [59-73]. Primeiro, a energia de ativação determinada pelo método depende do correto ajuste aos dados. Entretanto nenhum estudo na literatura demonstrou qual função 
se adere melhor aos dados de modo não tendencioso. Segundo, o valor determinado para energia de ativação também não possui incerteza, pois segundo a metodologia atual, o ajuste é feito com um valor fixo para a energia de ativação.

Além disso, uma ampla dispersão de resultados é verificada para materiais similares utilizando estes métodos. Os valores reportados para materiais cerâmicos na literatura variam entre $218 \mathrm{~kJ} / \mathrm{mol}$ até $2530 \mathrm{~kJ} / \mathrm{mol}$ [59-73]. Para a alumina, por exemplo, valores são encontrados entre 487,6 e $1148 \mathrm{~kJ} / \mathrm{mol}$ $[60,62,65,68,70]$.

Neste trabalho a curva mestre da sinterização foi construída para a céria contendo $10 \%$ em mol de gadolínia com diferentes valores de área de superfície específica. Aprimoramentos serão propostos para o método de construção da curva mestre tentando identificar possíveis causas para a grande dispersão dos resultados verificados na literatura.
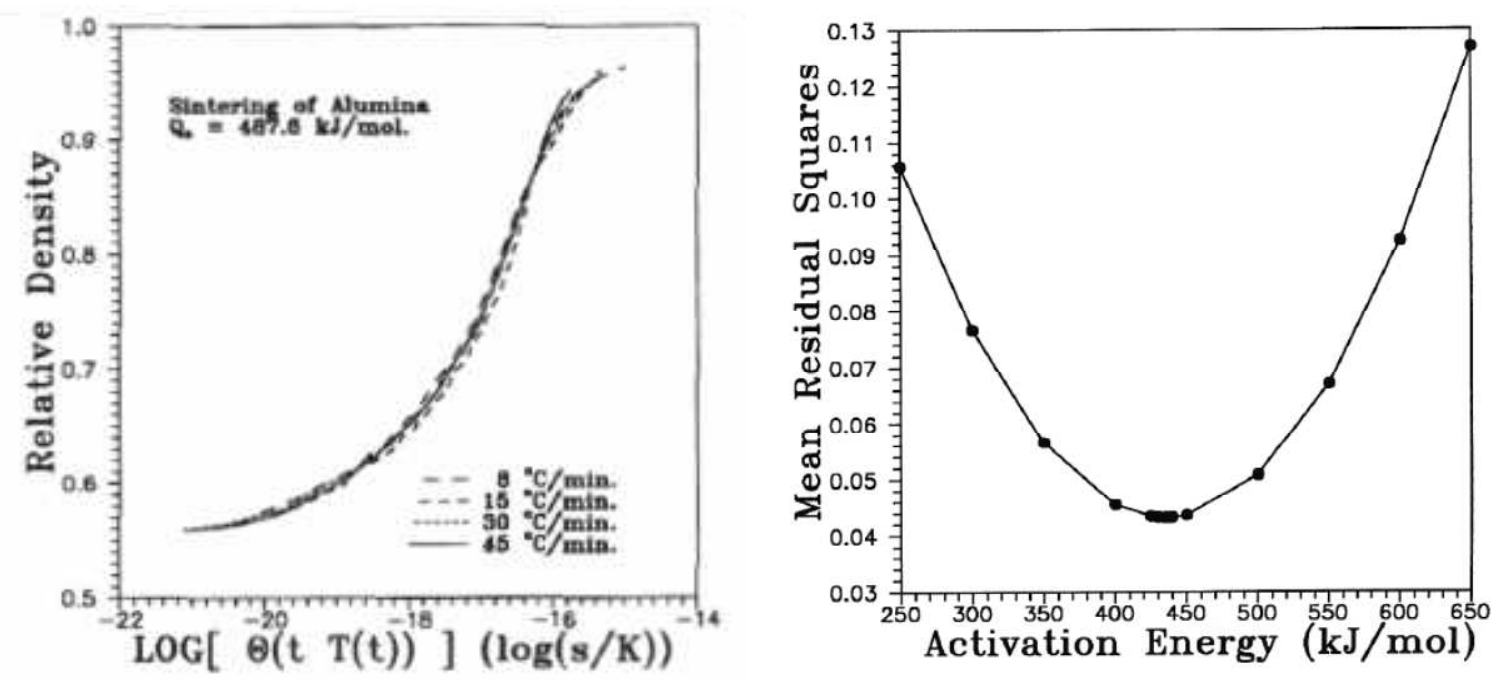

Figura 17: Figura ilustrativa da construção da MSC para a alumina. O gráfico a esquerda mostra o ajuste da densidade relativa em função do parâmetro $\Theta(t, T)$. O gráfico da direita mostra a curva do resíduo quadrático médio em função da energia de ativação utilizada no ajuste. Figuras retiradas da referência [60]. 


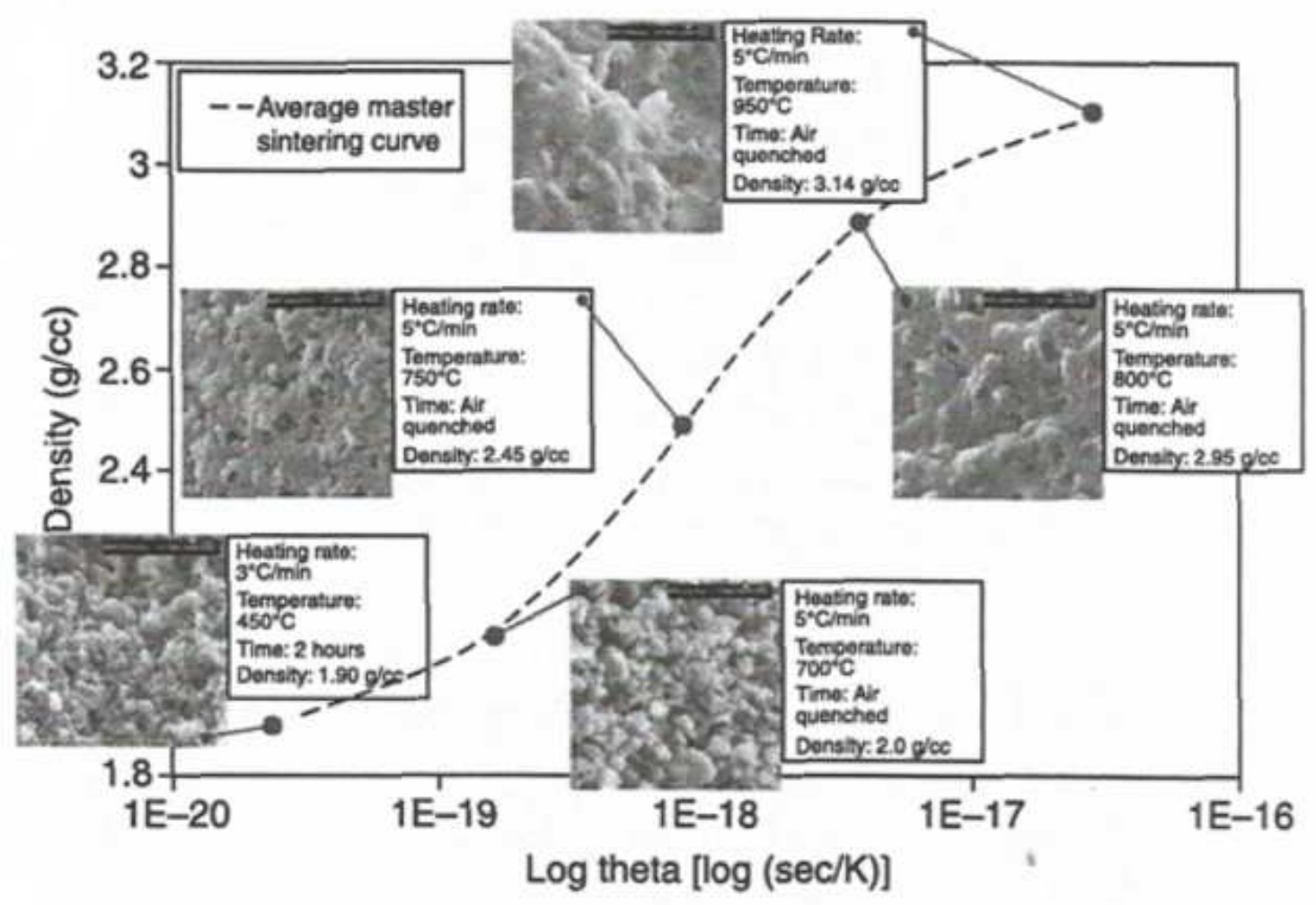

Figura 18: Curva mestre de sinterização acoplada à trajetória da microestrutura obtida para a fita dielétrica de baixa temperatura Dupont 951. Figura retirada da referência [59].

\subsubsection{Atmosfera de sinterização}

A utilização de diferentes atmosferas de sinterização não é um tópico recente. Trabalhos são reportados na literatura desde a década de 50 [102]. Basicamente a aplicação de diferentes atmosferas de sinterização tem como possíveis objetivos [48,103]:

(i) Promover ou impedir reações químicas na superfície dos materiais. Atmosferas redutoras podem ser utilizadas em metais promovendo a limpeza das superfícies e evitando a oxidação em altas temperaturas. Como consequência o crescimento de pescoço é acelerado. Em óxidos não estequiométricos a utilização de diferentes atmosferas produz desvios na estequiometria do material. Estes desvios podem acelerar ou retardar a densificação e o crescimento de grãos. 
(ii) Alterar a dinâmica de eliminação de poros durante o estágio final de sinterização. Como já foi discutida, a eliminação da porosidade fechada depende da difusibilidade dos gases confinados na estrutura cristalina dos materiais.

(iii) Alterar a dinâmica de crescimento de grãos no material. Alguns dos mecanismos superficiais de transporte de massa dependem da pressão de vapor dos gases nos poros. Diferentes pressões de vapor também podem influenciar o equilíbrio das interfaces sólido-sólido e sólido-vapor. Assim, atmosferas de sinterização podem modificar a curva de trajetória para 0 crescimento de grãos.

Poucos são os trabalhos na literatura que descrevem o efeito de diferentes atmosferas de sinterização na céria-gadolínia. He e colaboradores [91] reportaram os efeitos da utilização de atmosferas redutoras na densificação da GDC. Foi verificado que a densificação se inicia em temperaturas inferiores quando utilizadas atmosferas redutoras. Entretanto, menor densificação ao final da sinterização foi verificado. O aumento da sinterabilidade no estágio inicial da sinterização foi associado ao aumento da concentração de vacâncias de oxigênio.

Zhou e Rahaman [104] avaliaram os efeitos da utilização de atmosferas redutoras na céria durante o estágio final da sinterização. Foi mostrado que trincas são formadas no material devido à eliminação de gases durante as reações de redução do $\mathrm{Ce}^{4+}$.

Anatharaman e Bauri [105] investigaram o efeito da utilização da atmosfera de $\mathrm{O}_{2}$ na condutividade da $\mathrm{Ce}_{0,82} \mathrm{Gd}_{0,18} \mathrm{O}_{1,909-x}$. Foi reportado um ligeiro aumento na condutividade das amostras. É importante ressaltar que os gráficos de Arrhenius da condutividade elétrica apresentaram uma oscilação incomum.

Vincenzo e colaboradores [86] analisaram o efeito da atmosfera redutora $9 \% \mathrm{H}_{2} / \mathrm{N}_{2}$ na densificação, crescimento de grãos e condutividade elétrica da $\mathrm{Ce}_{0,9} \mathrm{Gd}_{0,1} \mathrm{O}_{1,95-x}$. Foi verificado um aumento na densificação e no crescimento de grãos devido à utilização da atmosfera redutora. Não foram verificadas variações significativas na condutividade total do material.

O presente trabalho tem como objetivo investigar o efeito da utilização de atmosferas redutora, inertes e oxidante na condutividade elétrica da 
$\mathrm{Ce}_{0,9} \mathrm{Gd}_{0,1} \mathrm{O}_{1,95-x}$. Os resultados da condutividade serão relacionados com a microestrutura do material e desvio de estequiometria após a sinterização.

\subsection{OBJETIVOS}

Os objetivos específicos deste trabalho são:

- Avaliar os efeitos do tamanho inicial de partícula nas curvas de trajetória para o crescimento de cristalitos em materiais nanométricos.

- Verificar como ocorre a evolução da largura da distribuição de tamanhos de partícula ao longo da sinterização.

- Construir a curva mestre de sinterização para a céria-gadolínia, e verificar o efeito do tamanho inicial de partícula nas energias de ativação aparentes.

- Elaborar um algoritmo que possibilite o ajuste não linear da curva mestre de sinterização.

- Desenvolver um programa computacional com interface adequada que permita a análise de dados de dilatometria e a construção da curva mestre de sinterização por terceiros.

- Analisar os efeitos da atmosfera de sinterização, redutora, inerte e oxidante, na condutividade elétrica da céria-gadolínia.

- Analisar os efeitos da área de superfície específica na sinterização com as diferentes atmosferas de sinterização. 


\section{EXPERIMENTAL}

Neste capítulo serão fornecidas informações sobre os materiais de partida, bem como dos métodos de elaboração de amostras. Serão apresentadas também as técnicas de caracterização e detalhadas as condições experimentais durante as análises.

\subsection{MATERIAIS DE PARTIDA}

Céria contendo $10 \%$ mol gadolínia $\left(\mathrm{GdO}_{1,5}\right), \mathrm{Ce}_{0,9} \mathrm{Gd}_{0,1} \mathrm{O}_{1,95}$ (Fuel Cell Materials) com diferentes valores de área de superfície específica foi utilizada neste trabalho. A Tabela 3 mostra as informações fornecidas pelo fabricante.

Tabela 3: Valores da área de superfície específica $S$, pureza e tamanho de partícula $M$ fornecidos pelo fabricante. Entre parênteses são relacionados os métodos utilizados na determinação destes valores.

\begin{tabular}{cccc}
\hline Material & Pureza $(\%)$ & $\mathbf{S}\left(\mathbf{m}^{2} / \mathbf{g}\right)$ & $\mathbf{M}(\boldsymbol{\mu m})$ \\
\hline $10 \mathrm{M}$ & $>99,5$ & $7,4(\mathrm{BET})$ & $0,1-0,4$ (Horiba) \\
$10 \mathrm{TC}$ & $>99,5$ & $36,2(\mathrm{BET})$ & $0,3-0,5$ (Horiba) \\
$10 \mathrm{~N}$ & $>99,5$ & $210(\mathrm{BET})$ & $*$ \\
\hline
\end{tabular}

* Não fornecido pelo fabricante.

Os materiais foram utilizados como recebido, sem qualquer tratamento adicional. 


\subsection{CARACTERIZAÇÃO DOS MATERIAIS DE PARTIDA}

Os materiais de partida foram caracterizados quanto à sua área de superfície específica, composição de fases, morfologia, tamanho médio de partícula, distribuição de tamanhos de cristalito, comportamento térmico e tipos de impurezas.

Os valores da área de superfície específica foram obtidos por adsorção gasosa de nitrogênio (Quantachrome, NOVA-1200) utilizando o método BET (Brunauer, Emmett e Teller) [106]. As medidas foram realizadas no laboratório de insumos cerâmicos do CCTM.

O tamanho médio de partícula foi estimado pela inspeção de cerca de 100 partículas por microscopia eletrônica de transmissão (MET, JEOL JEM 2100). Partículas foram dispersas em água destilada na proporção de $2 \%$ em massa. Adicionou-se um dispersante, o poliacrilato de amônio, na proporção de $1 \%$ em massa. $\mathrm{O}$ pH da suspensão foi controlado entre 9 e 10 pela adição de hidróxido de amônio. Toda a mistura foi realizada durante agitação mecânica em um ultrassom (Unique, 800A). As análises das micrografias foram feitas com auxílio do programa computacional ImageJ. Para determinação dos tamanhos médios considerou-se a maior distância entre as faces de cada partícula. O procedimento foi adotado de acordo com a referência [107] porque mostrou que a metodologia produzia suspensões estáveis de céria-gadolínia.

A morfologia dos pós foi analisada por meio de imagens obtidas com um microscópio eletrônico de varredura (MEV, Philips, $X L$ 30). As imagens foram obtidas pela detecção dos elétrons secundários. Estas análises foram realizadas no laboratório de microscopia eletrônica do CCTM.

A composição de fases e a distribuição dos tamanhos de cristalito foram obtidas pela técnica de difração de raios X (Bruker-AXS, D8 Advance). Detalhes da metodologia utilizada são descritos a seguir separadamente.

O comportamento térmico foi verificado por medidas de termogravimetria e análise térmica diferencial (Netzsch, STA 409E) até a temperatura de $1300^{\circ} \mathrm{C}$. As medidas foram realizadas utilizando cadinho de alumina, em atmosfera de ar sintético com fluxo de $5 \mathrm{~mL} / \mathrm{min}$. Diversas taxas de aquecimento foram utilizadas para resolução dos eventos térmicos. Em determinadas análises espectroscopia de 
massa (Thermostar, GSD 320) foi feita para determinação dos tipos de impurezas orgânicas presentes nos materiais.

O teor e os tipos de impurezas inorgânicas foram determinados por análises de fluorescência de raios X (PANalytical, X Axios Advanced). As análises foram realizadas no laboratório de caracterização tecnológica da Escola Politécni$\mathrm{ca} / \mathrm{USP}$.

\subsection{ELABORAÇÃO DE AMOSTRAS}

Amostras cilíndricas foram conformadas por compactação uniaxial (Skay) a frio com pressão de 50 MPa e seguida de compactação isostática (National Forge Company) utilizando $70 \mathrm{MPa}$. As amostras para dilatometria apresentavam cerca de 1,2-1,6 cm de altura e diâmetro de aproximadamente $5 \mathrm{~mm}$. As amostras utilizadas nas demais análises apresentavam diâmetro próximo a $10 \mathrm{~mm}$ e massa de aproximadamente $0,6 \mathrm{~g}$.

Os compactos foram sinterizados em forno tubular (Lindberg, Tube furnace) ou em forno tipo caixa (Lindberg BlueM, 51524), cujos perfis de aquecimento foram calibrados com um termopar tipo K. Amostras selecionadas foram sinterizadas em atmosferas de $\mathrm{Ar}, \mathrm{N}_{2}$ e em mistura de $\mathrm{Ar} / 4 \% \mathrm{H}_{2}$. A pureza da composição dos gases foi de $99,99 \%$. As temperaturas de sinterização ao ar variaram entre $600^{\circ} \mathrm{C}$ e $1400^{\circ} \mathrm{C}$ com tempos de patamar entre 0 e 15 horas. A temperatura de sinterização quando utilizada as diferentes atmosferas foi de $1250^{\circ} \mathrm{C}$ pelo tempo de 2 horas. Em todas as sinterizações utilizou-se a taxa de aquecimento de 10 ${ }^{\circ} \mathrm{C} / \mathrm{min}$.

\subsection{CARACTERIZAÇÃO DAS AMOSTRAS À VERDE E SINTERIZADAS}

Amostras foram caracterizadas quanto a sua densidade aparente geométrica pela determinação de suas dimensões e de sua massa (micrômetro,Tesa, $\mathrm{CH}-1020$; balança analítica, Mettler, H315). A retração linear foi analisada durante a sinterização em ensaios de dilatometria (Anter, Unitherm 1161). 
A evolução microestrutural das amostras sinterizadas foi avaliada por análises de difração de raios X (Bruker-AXS, D8 Advance) e por microscopia eletrônica de varredura por emissão de campo (FEl, inspect F50 e JEOL). A condutividade elétrica das amostras sinterizadas foi analisada pela técnica de espectroscopia de impedância (HP, 4192A). A composição de fases foi verificada por análises de difração de raios $\mathrm{X}$. A fim de analisar a possível redução do $\mathrm{Ce}^{4+}$ para $\mathrm{Ce}^{3+}$ durante a sinterização, as técnicas de ressonância paramagnética eletrônica e espectroscopia Raman foram utilizadas. Detalhes experimentais das principais técnicas utilizadas são fornecidos a seguir.

\subsubsection{Dilatometria}

Ensaios de dilatometria com taxas de aquecimento constante foram feitos em um dilatômetro vertical (Anter Unitherm 1161). A temperatura máxima para todos os ensaios foi de $1400^{\circ} \mathrm{C}$ com taxas de aquecimento de $3,6,10$ ou $12{ }^{\circ} \mathrm{C}$ por minuto. $\mathrm{O}$ forno utiliza diversos elementos aquecedores do tipo Khantal Super 33. A temperatura durante o ensaio era verificada constantemente dentro da câmara da amostra por um termopar tipo S (Platina/ Ródio-Platina). Medidas de deslocamento foram feitas utilizando um transdutor eletrônico digital de deslocamento com precisão absoluta de $0,001 \mathrm{~mm}$, resultando assim numa precisão para a retração do material de aproximadamente $0,01 \%$. A correção interna (expansão térmica do terminal) do equipamento foi feita pela análise de uma alumina translúcida padrão, Crystalox ${ }^{\circledR}$, com expansão térmica bem conhecida. Um programa computacional de análise de dados foi desenvolvido especialmente para esta finalidade.

\subsubsection{Difração de raios $X(D R X)$}

Um difratômetro (Bruker-AXS D8 Advance) com configuração de BraggBrentano simétrica foi utilizado em todas as medidas. A eliminação do componente $K_{\square}$ foi feita pela utilização de um filtro de níquel. Duas fendas de Soller foram utilizadas para delimitar a divergência do feixe. $O$ intervalo angular varrido foi entre $23^{\circ}$ e $73^{\circ}$ com passos de $0,04^{\circ}$ e tempo de integração de $5 \mathrm{~s}$. Para correção do alargamento instrumental uma amostra de céria padrão (tamanho de cristalito 
$10 \mu \mathrm{m})$ foi utilizada [108,109]. Os dados obtidos foram analisados pelo método de refinamento Rietveld utilizando o programa computacional GSAS [110] e pelo método WPPM (Whole Powder Pattern Modelling) utilizando o programa computacional PM2K $[111,112]$.

\subsubsection{Microscopia eletrônica de varredura (MEV)}

Superfícies polidas de amostras sinterizadas foram analisadas por microscopia eletrônica de varredura para determinação dos tamanhos médios de grãos do material, e para verificação de outros aspectos da microestrutura. O método estereológico na determinação dos tamanhos médios de grãos foi o de contagem de interceptos [113,114]. O programa computacional ImageJ foi utilizado nestas análises. As superfícies das amostras foram polidas em pastas de diamante de 6 e $1 \mu \mathrm{m}$. Para delinear os contornos de grãos, as amostras já polidas foram atacadas termicamente em temperaturas $50^{\circ} \mathrm{C}$ a $80^{\circ} \mathrm{C}$ inferiores as utilizadas nas sinterizações.

\subsubsection{Espectroscopia de Impedância}

Medidas de condutividade elétrica por espectroscopia de impedância foram feitas utilizando um analisador de impedância Hewlett Packard 4192A. Para tais análises, finas camadas de prata foram aplicadas (pintura) às superfícies planas das amostras. As amostras pintadas foram tratadas termicamente a $400^{\circ} \mathrm{C}$ por 15 minutos em forno tipo caixa (Quimis) para cura da prata. As medidas da condutividade elétrica foram feitas utilizando uma câmara porta-amostras de inconel que permite a determinação da resistência em três amostras para cada temperatura específica. Durante as análises a câmara porta-amostras foi inserida dentro de um forno tubular, e um termopar tipo $\mathrm{K}$ foi mantido próximo às amostras para verificação da temperatura. As medidas foram tomadas entre 150 e $330^{\circ} \mathrm{C}$, sendo utilizado um tempo mínimo de 45 minutos entre medições para que as temperaturas do forno e da amostra se estabilizassem. A coleta dos dados foi feita na faixa de frequência de $5 \mathrm{~Hz}$ a $13 \mathrm{MHz}$ com 20 medições por década. Tensão aplicada de $100 \mathrm{mV}$ entre as faces paralelas das amostras foi utilizada. A análise dos diagramas de impedância foi feita utilizando o programa computacional LEVM [115]. 


\subsubsection{Ressonância paramagnética eletrônica (RPE)}

Análises de ressonância paramagnética eletrônica foram realizadas nos materiais de partida, em amostras sinterizadas em diferentes atmosferas e em óxido de cério sem aditivos. $O$ equipamento utilizado foi um espectrômetro Bruker EMX que opera na banda X. A frequência utilizada na cavidade foi de $9,5 \mathrm{GHz}$. A potência da cavidade microondas foi mantida em 20,07 mW com campo magnético modulado em $100 \mathrm{kHz}$. Todas as medidas foram realizadas em temperatura ambiente. Estas análises foram realizadas no laboratório do grupo de Bioinorgânica e Catálise do Instituto de Química da Universidade de São Paulo.

\subsubsection{Espectroscopia Raman}

As amostras sinterizadas nas diferentes atmosferas foram analisadas por espectroscopia Raman. A técnica foi utilizada para verificar possíveis desvios de estequiometria na superfície das amostras. Para diminuir a influência de uma possível reoxidação das superfícies devido ao contato com o ar, suas superfícies foram polidas horas antes de cada medida. Um laser de He-Ne com comprimento de onda de $633 \mathrm{~nm}$ foi utilizado em um espectrômetro Raman (Micro Raman Renishaw, InVia). Os espectros foram obtidos nos intervalos espectrais de 200 até $800 \mathrm{~cm}^{-1}$ e 1800 a $2300 \mathrm{~cm}^{-1}$.

\subsubsection{Fluxograma}

A Figura 19 sumariza todas as análises feitas neste trabalho. 


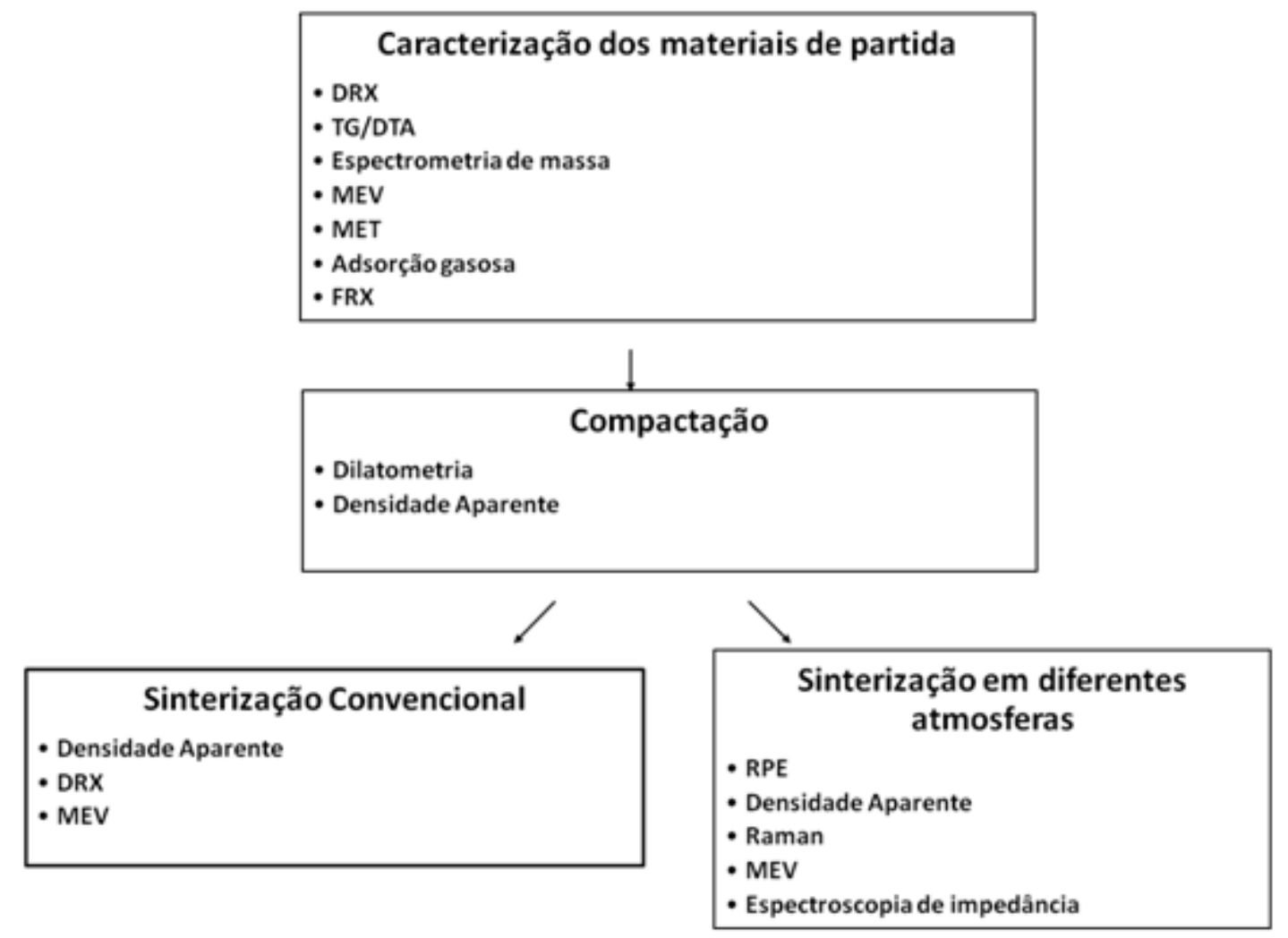

Figura 19: Fluxograma indicando a ordem de execução das análises empregadas neste trabalho. 


\section{RESULTADOS E DISCUSSÃO}

\subsection{CARACTERIZAÇÃO FÍSICA E QUÍMICA DOS MATERIAIS DE PARTIDA}

Como discutido anteriormente, as características iniciais dos materiais de partida têm forte influência na dinâmica e na cinética de sinterização de um material. Neste item serão apresentados os resultados da caracterização dos materiais de partida que foram utilizados neste trabalho. Os resultados referentes à evolução microestrutural, construção da curva mestre de sinterização e utilização de diferentes atmosferas de sinterização, serão apresentados posteriormente.

\subsubsection{Tamanho médio de partícula e de cristalito para os materiais de partida}

O tamanho médio de partícula é um importante parâmetro para avaliação da cinética de sinterização. Este foi determinado para os materiais de partida pela análise de imagens obtidas por microscopia eletrônica de transmissão. A Figura 20 mostra micrografias selecionadas para cada um dos materiais. Os tamanhos das partículas são significativamente diferentes, embora distribuições relativamente estreitas tenham sido verificadas para cada pó. Embora procedimentos de dispersão dos materiais tenham sido executados ainda é possível verificar certo grau de aglomeração.

Os tamanhos de diversas partículas foram medidos pela maior distância possível entre duas faces opostas. A partir da estatística obtida, os tamanhos médios e suas incertezas foram determinados. A Tabela 4 sumariza os resultados. Também é listado na Tabela 4 o tamanho médio de cristalito determinado por difração de raios $\mathrm{X}$ e o tamanho médio de partícula estimado por adsorção gasosa. $\mathrm{Na}$ estimativa obtida por adsorção gasosa a aproximação de partículas esféricas foi considerada.

Os tamanhos médios de cristalito foram obtidos por meio do procedimento de análise descrito no Apêndice $B$. Amostras do material particulado foram submetidas à análise por difração de raios $\mathrm{X}$ e seus difratogramas ajustados pelo método de refinamento Rietveld. A contribuição ao alargamento dos picos pelo tamanho dos 
(a)
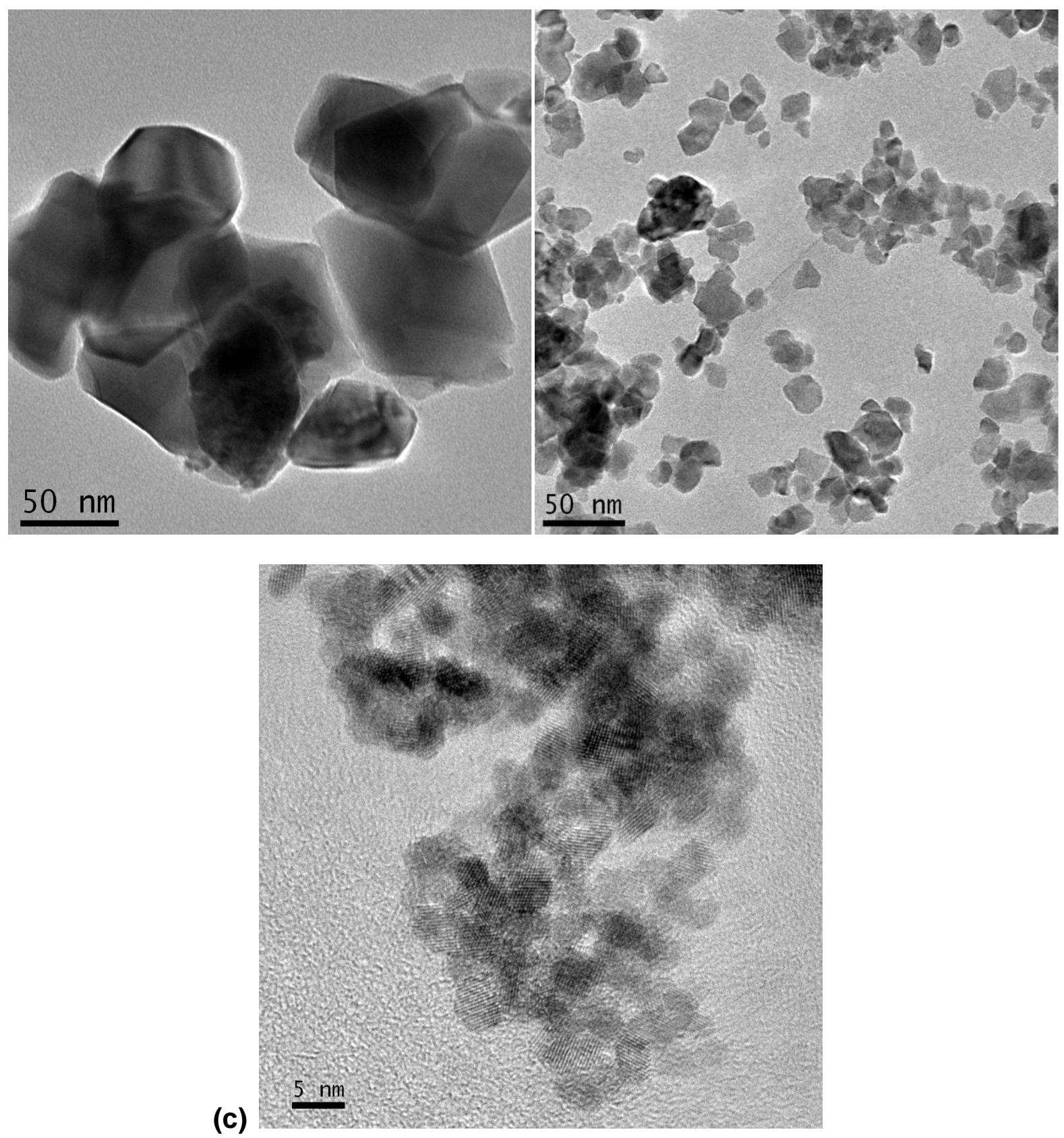

Figura 20: Micrografias obtidas por microscopia eletrônica de transmissão pela análise da céria-gadolínia (a)10M, (b) 10TC e (c) 10N.

cristalitos foi obtida como resultado dos ajustes, permitindo o cálculo do tamanho médio de cristalito. A Figura 21 mostra, a título de exemplo, um dos difratogramas obtidos e refinados neste trabalho. 


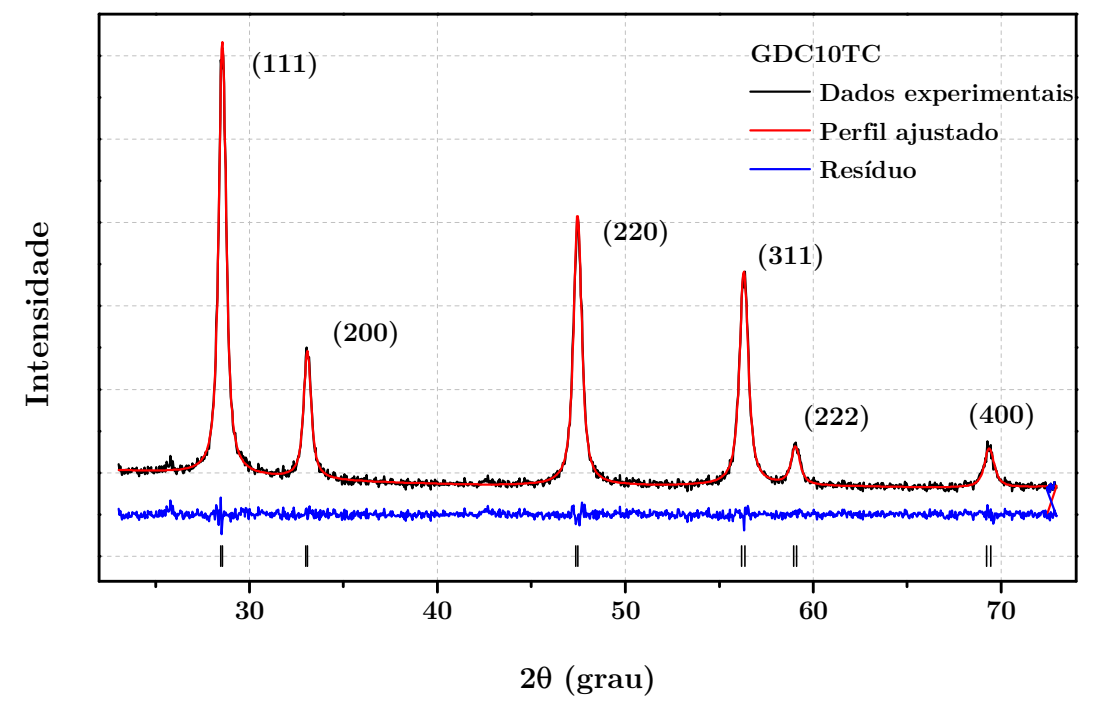

Figura 21: Difratograma de raios $X$ do material GDC10TC, perfil refinado e resíduo entre os dois obtidos pelo refinamento Rietveld. $O$ valor do chi quadrado reduzido para o refinamento foi de 1,109. Os números entre parênteses são os respectivos índices de Miller associado a cada reflexão.

Excelente concordância entre os resultados experimentais e o perfil ajustado é verificado. Tais resultados indicam que o material 10TC é composto apenas por uma fase, a estrutura tipo fluorita de grupo espacial Fm-3m. Resultados similares foram verificados para todos os outros materiais. Os critérios utilizados para análise de convergência, bem como os métodos utilizados para evitar a convergência a mínimos locais nos ajustes também são descritos no Apêndice B.

Tabela 4: Tamanhos médios de partículas estimados por microscopia eletrônica de transmissão MET, tamanhos médios de cristalito obtidos por DRX, e tamanhos médios de partícula estimados por adsorção gasosa supondo partículas esféricas. Unidades em nanômetros.

\begin{tabular}{cccc}
\hline Material & Partícula - MET & Cristalito - DRX & Partícula - BET \\
\hline $10 \mathrm{TC}$ & $12,4(4)$ & $14,9(3)$ & 22,5 \\
$10 \mathrm{M}$ & $82,1(29)$ & $72(5)$ & 71,4 \\
$10 \mathrm{~N}$ & $3,3(1)$ & $4,25(25)$ & 5,3 \\
\hline
\end{tabular}


A análise da Tabela 4 mostra boa concordância entre os valores obtidos em cada uma das técnicas. Os resultados indicam que as partículas de todos os materiais de partida são preferencialmente monocristalinas

\subsubsection{Morfologia dos materiais de partida}

Os tipos, tamanhos e formas dos aglomerados, têm destacada importância durante a eliminação de poros na sinterização. A Figura 22 mostra micrografias selecionadas para cada um dos materiais. Nota-se que os aglomerados da amostra $10 \mathrm{M}$ possuem um aspecto mais coeso do que dos demais materiais, enquanto os aglomerados da amostra 10N apresentam-se mais porosos. Não foi possível obter outras informações por esta análise.

\subsubsection{Estrutura cristalina dos materiais}

O tipo de estrutura cristalina de um material pode determinar qual o mecanismo de transporte de massa predomina durante a sinterização. A evolução de características como o parâmetro de rede ou a microdeformação também fornece importantes indícios da presença de reações químicas na amostra ou pode explicar um possível crescimento preferencial dos grãos. Assim, aspectos da estrutura cristalina dos materiais foram caracterizados por difração de raios $\mathrm{X}$.

O tipo de estrutura cristalina foi verificado pelo método de refinamento $\mathrm{Ri}$ etveld seguindo o procedimento descrito no Apêndice B. Apenas a estrutura cúbica do tipo fluorita e grupo espacial Fm-3m foi verificada. Um exemplo típico dos verificados foi mostrado na Figura 21.

O parâmetro de rede e a microdeformação foram avaliados em função da temperatura de sinterização pelo método de refinamento Rietveld e pelo método WPPM ("Whole powder pattern modelling") [111,112]. Os resultados obtidos por ambos os métodos foram comparados a fim de verificar alguma possível inconsistência. 

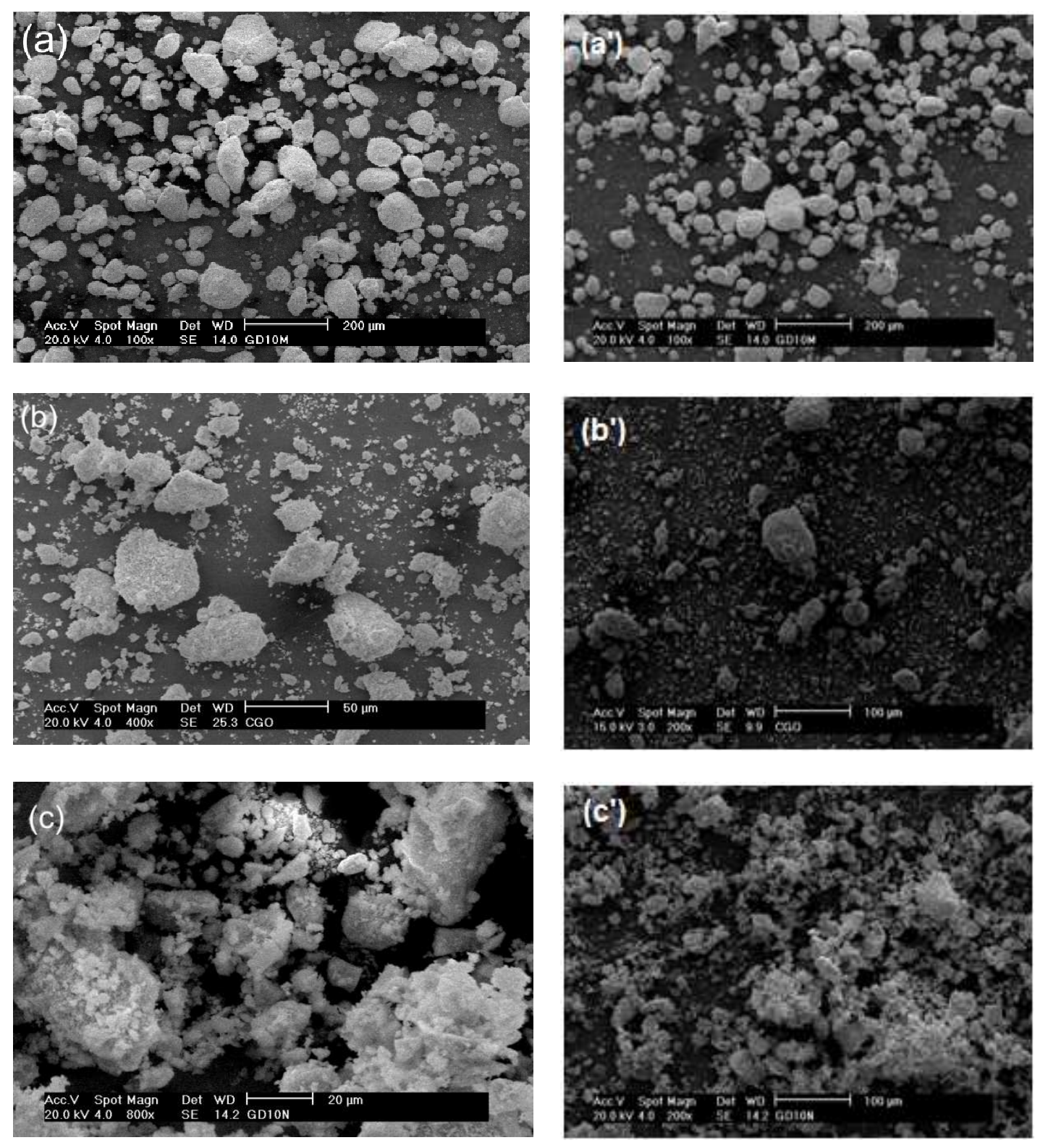

Figura 22: Micrografias dos materiais de partida conforme recebidos obtidos por microscópio eletrônico de varredura. (a) e (a') 10M, (b) e (b') 10TC, (c) e (c') 10N.

A microdeformação foi determinada e se mostrou desprezível para os materiais de partida. Tal conclusão foi tomada após a aplicação de um teste z durante os ajustes dos parâmetros relacionados à microdeformação. Na Tabela 5 são mostrados os valores resultantes durante as análises. 
Tabela 5: Microdeformação $<e>$ e sua incerteza sigma. Para $a=5 \%, z_{\text {limite }}=1,96$.

\begin{tabular}{cccc}
\hline Material & $<\mathrm{e}>\mathbf{. 1 0 ^ { 4 }}(\%)$ & Sigma & $\mathbf{Z}$ \\
\hline $10 \mathrm{M}$ & 0 & 0,1 & 0 \\
$10 T C$ & 0,3 & 0,2 & 1,5 \\
$10 \mathrm{~N}$ & 5,0 & 3,2 & 1,56 \\
\hline
\end{tabular}

Pode-se afirmar que os materiais de partida não apresentam microdeformação expressiva, embora uma tendência possa ser verificada. Quanto menor o tamanho de cristalito, maior a microdeformação no material.

Os parâmetros de rede dos materiais de partida e das amostras sinterizadas foram determinados. Após análise de variância (ANOVA) pôde-se inferir que o parâmetro de rede não varia com o material de partida e nem com a temperatura de sinterização para as condições empregadas neste trabalho.

Todos os resultados dos parâmetros de rede foram utilizados para determinação de uma única estimativa. A densidade teórica dos materiais foi calculada a partir deste parâmetro de rede. Os resultados são mostrados na Tabela 6 . A densidade teórica obtida para estes materiais está em pleno acordo com os valores verificados na literatura $[74,116]$.

Tabela 6: Densidade teórica $\rho_{t}$ e parâmetro de rede $a_{R}$ obtidos.

\begin{tabular}{ccc}
\hline Material & $a_{\mathbf{R}}(\mathbf{n m})$ & $\rho_{\mathrm{t}}\left(\mathbf{g} / \mathbf{c m}^{\mathbf{3}}\right)$ \\
\hline GDC10 & $0,54209(13)$ & $7,2146(9)$ \\
\hline
\end{tabular}

\subsubsection{Impurezas nos materiais de partida}

Vários são os possíveis efeitos produzidos por impurezas durante a sinterização. Impurezas podem entrar em solução sólida modificando a difusibilidade de espécies em seu volume [80]. Podem permanecer nos contornos de grãos evitando/acelerando o crescimento de grãos [7]. Podem ser eliminados para o meio ambiente produzindo porosidade no material, dentre outros efeitos. 
Neste trabalho os tipos de impurezas orgânicas foram determinados por espectrometria de massa dos gases liberados nas análises simultâneas termogravimétricas e termodiferencial. A Figura 23 mostra as curvas de perda de massa e de análise térmica diferencial obtidas com taxa de aquecimento constante de $10^{\circ} \mathrm{C} /$ min. Outras análises foram executadas com diferentes taxas de aquecimento para confirmação dos eventos térmicos no material $10 \mathrm{~N}$.

Diversos eventos térmicos podem ser verificados para as amostras $10 \mathrm{~N} \mathrm{e}$ 10TC, embora estes sejam mais significativos para a amostra 10N. Somente um evento térmico é verificado em todos os materiais. Este é um evento endotérmico e ocorre a aproximadamente $100^{\circ} \mathrm{C}$, sendo associado a desidratação dos pós.
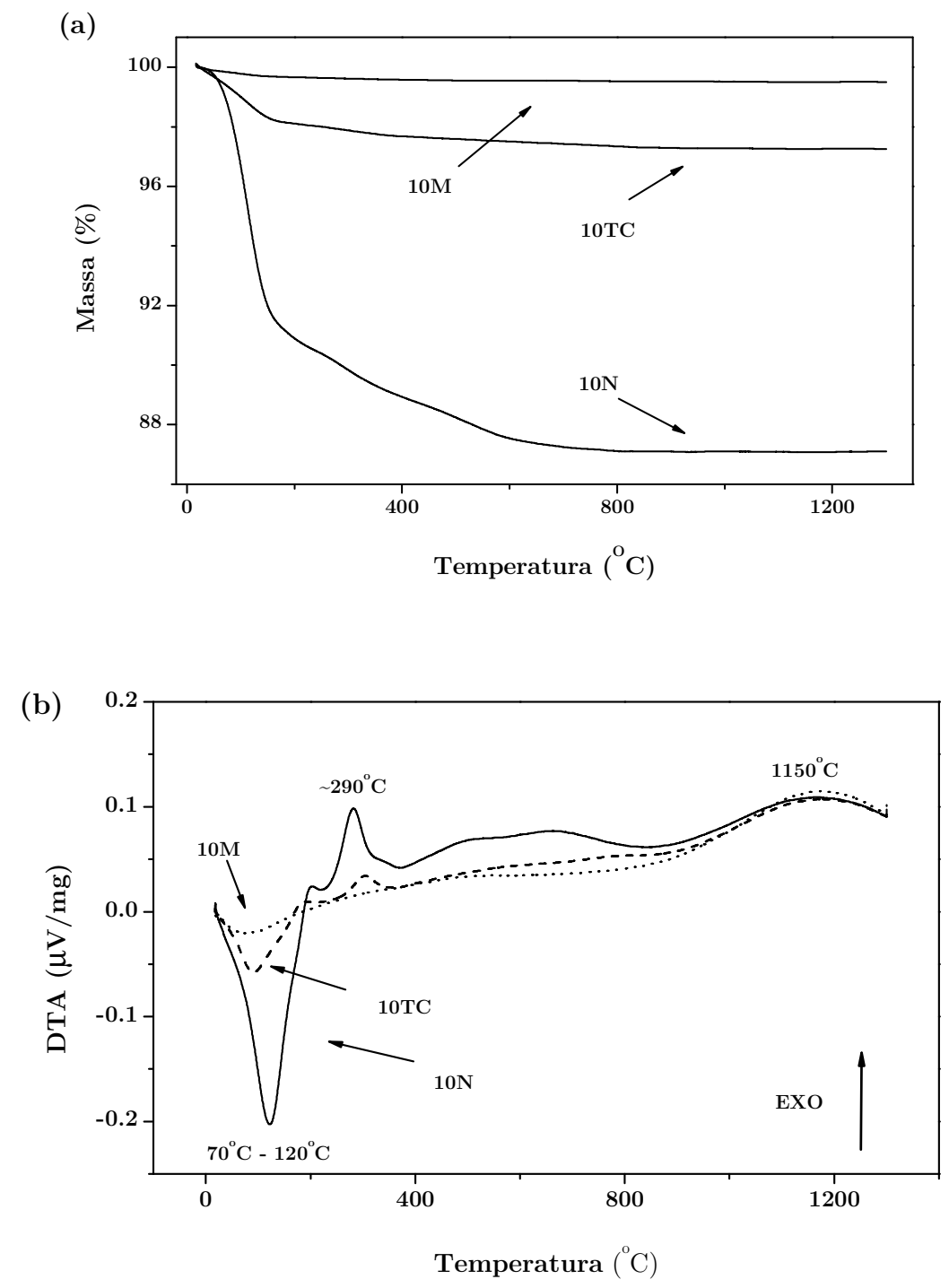

Figura 23: (a) Curvas termogravimétrica e (b) termo diferencial dos materiais de partida. 
A identificação precisa dos demais eventos térmicos presentes nas amostras $10 \mathrm{~N}$ e 10TC só é possível, neste caso, pela comparação dos resultados com informações obtidas por espectrometria de massa. O gráfico da Figura 24 mostra os espectros obtidos para as temperaturas de $100^{\circ} \mathrm{C}, 290^{\circ} \mathrm{C}$ e $400^{\circ} \mathrm{C}$.

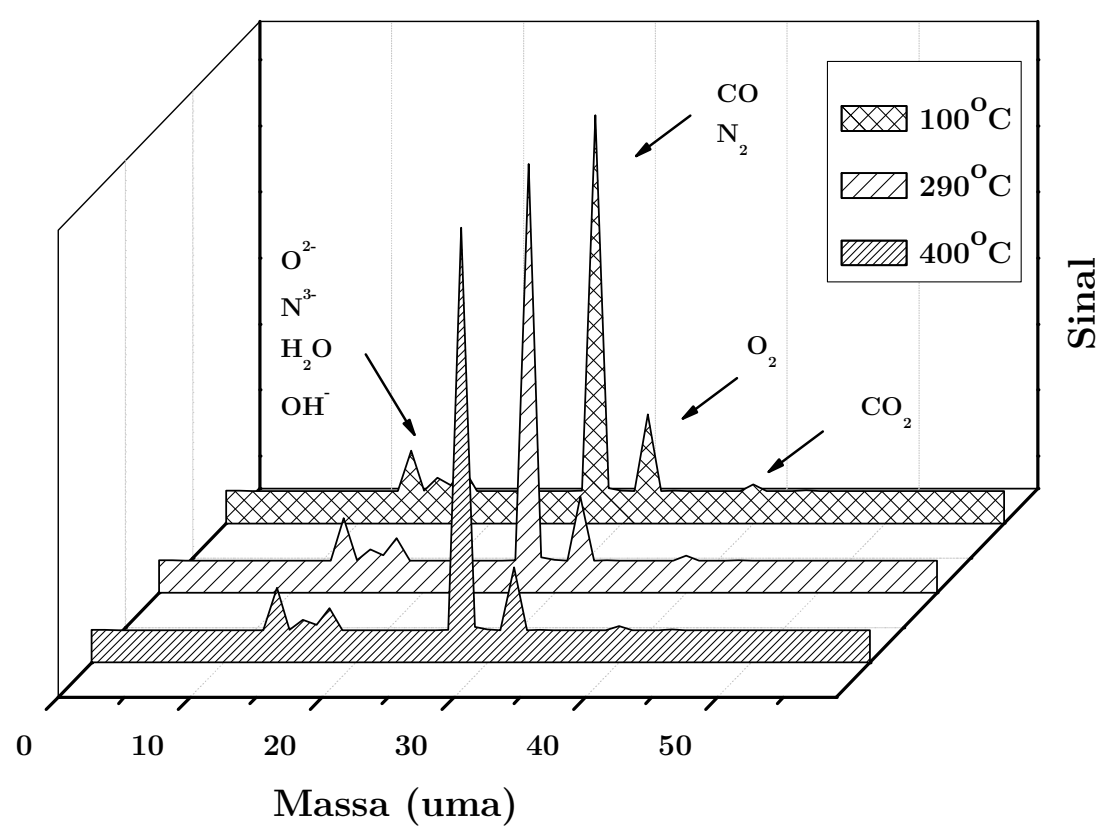

Figura 24: Espectros obtidos a $100^{\circ} \mathrm{C}, 290^{\circ} \mathrm{C}$ e $400^{\circ} \mathrm{C}$ por espectrometria de massa durante análise térmica diferencial da amostra $10 \mathrm{~N}$.

Os resultados indicam a perda de água e possivelmente gases como $\mathrm{CO}$ e $\mathrm{CO}_{2}$ devido à presença de impurezas orgânicas. Tais impurezas podem estar presentes devido ao método de síntese ou serem inseridas nas amostras durante a etapa de beneficiamento do material pelo fabricante. Os resultados de espectroscopia de massa não elucidam conclusivamente todas as reações verificadas pela análise térmica, mas indicam que as mesmas não devem afetar significativamente o comportamento da sinterização do material no estágio intermediário e final da sinterização. Tais impurezas podem, entretanto, ter algum tipo de influência durante a etapa de compactação e estágio inicial de sinterização.

A composição dos pós e os tipos e os teores de impurezas inorgânicas foram determinados por fluorescência de raios $X$. Os resultados indicaram quanti- 
dades de Gd compatível com o informado pelo fabricante. Pequenos teores de cálcio/ silício foram verificados em todos os materiais, sendo da ordem de $0,1 \%$.

\subsubsection{Densidades à verde}

Curvas de compactação foram feitas para estabelecer a melhor rota de elaboração dos compactos. Verificou-se para as mais altas pressões utilizadas que as amostras $10 \mathrm{~N}$ apresentavam trincas superficiais extensas e visíveis a olho nu. Para pressão aplicada de $75 \mathrm{MPa}$ tais trincas não eram mais visualizadas. Assim, optou-se neste trabalho pela aplicação de pressão igual a $70 \mathrm{MPa}$. A Figura 25 mostra a curva de compactação obtida para cada um dos materiais e uma micrografia obtida em microscópio óptico para uma amostra sinterizada 10N.

(a)

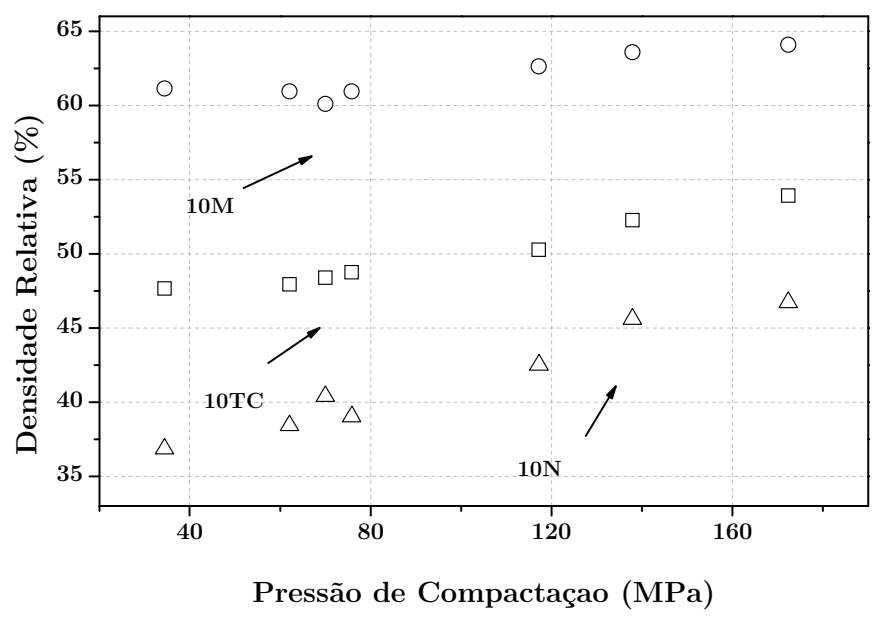

(b)
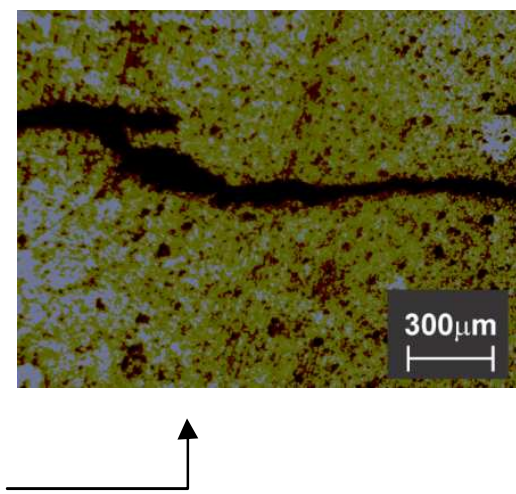

Figura 25: (a) Densidades relativas à verde dos compactos em função da pressão aplicada na compactação isostática. A micrografia em (b) mostra uma típica microtrinca interna verificada na amostra $10 \mathrm{~N}$ após a sinterização.

Verifica-se que apesar da relativamente baixa pressão aplicada durante a compactação, em alguns casos ocorre a formação de trincas.

As densidades à verde das amostras compactadas a $70 \mathrm{MPa}$ foram calculadas para cada um dos materiais pela análise estatística de cerca de 30 amostras. Os resultados são mostrados na Tabela 7. 
Tabela 7: Densidade à verde relativa das amostras elaboradas para cada material.

\begin{tabular}{cl}
\hline Material & $\rho / \rho_{\mathrm{t}}(\%)$ \\
\hline $10 \mathrm{M}$ & $60,1(3)$ \\
$10 \mathrm{TC}$ & $48,4(3)$ \\
$10 \mathrm{~N}$ & $40,4(1)$ \\
\hline
\end{tabular}

A densidade à verde dos materiais é função decrescente da área de superfície específica. Tal comportamento é verificado devido a maior dificuldade de acomodação do pó durante a compactação devido ao atrito entre partículas. Quanto menor o tamanho inicial das partículas, maior quantidade de interfaces e menores as densidades à verde a uma dada pressão aplicada [117,118]. 


\subsection{EFEITO DA ATMOSFERA DE SINTERIZAÇÃO}

Amostras foram sinterizadas utilizando diferentes atmosferas de sinterização, como $\mathrm{N}_{2}$, Ar, mistura de $\mathrm{Ar} / 4 \% \mathrm{H}_{2}$ ou ao ar. Para avaliação do efeito da atmosfera de sinterização na microestrutura e na condutividade elétrica, o patamar foi fixado em $1250^{\circ} \mathrm{C}$ por 2 horas. $\mathrm{O}$ fluxo de gás foi mantido constante em 2 $\mathrm{cm}^{3} / \mathrm{min}$. O perfil de tempo e temperatura adotado na sinterização foi escolhido de modo a obter amostras relativamente densas (densidade relativa $>92 \%$ ) utilizando a menor temperatura possível, sem prolongar excessivamente o tratamento térmico. As densidades desejadas deveriam ser as mais próximas possíveis para evitar a influência da porosidade na análise da condutividade elétrica. Os resultados obtidos para a caracterização das amostras são apresentados a seguir.

\subsubsection{Densificação}

As densidades aparentes das amostras sinterizadas foram calculadas a partir dos valores dos parâmetros geométricos e das massas das amostras. Os valores obtidos são mostrados na Tabela 8.

Tabela 8: Densidades relativas de amostras sinterizadas a $1250^{\circ} \mathrm{C}$ por 2 horas em atmosfera de $\mathrm{N}_{2}$, Argônio, mistura de $\mathrm{Ar} / 4 \% \mathrm{H}_{2}$ e ao ar.

\begin{tabular}{cccc}
\hline \multirow{2}{*}{ Atmosfera } & \multicolumn{3}{c}{ Densidade relativa (\%) } \\
\cline { 2 - 4 } & $\mathbf{1 0 M}$ & $\mathbf{1 0 T C}$ & $\mathbf{1 0 N}$ \\
\hline $\mathrm{Ar}$ & $93,2(12)$ & $95,6(12)$ & $96,8(11)$ \\
$\mathrm{N}_{2}$ & $95,4(10)$ & $96,5(9)$ & $95,1(11)$ \\
$\mathrm{Ar}$ & $95,0(9)$ & $96,9(7)$ & $96,9(13)$ \\
$\mathrm{Ar} / 4 \% \mathrm{H}_{2}$ & $92,1(10)$ & $92,3(10)$ & $93,8(6)$ \\
\hline
\end{tabular}

Os resultados não indicam variações significativas na densidade final das amostras preparadas a partir de pós com diferentes valores de área de superfície 
específica quando utilizadas as diferentes atmosferas de sinterização. Um aumento visível na quantidade de microtrincas, inclusive a olho nu, foi verificado nas amostras sinterizadas em mistura de $\mathrm{Ar} / 4 \% \mathrm{H}_{2}$. Acredita-se que a formação de trincas nesta situação seja devido à expansão química decorrente da redução do $\mathrm{Ce}^{4+}\left(R_{i}=0,97 \mathrm{~nm}\right)$ para o $\mathrm{Ce}^{3+}\left(R_{i}=1,143 \mathrm{~nm}\right)$ [119] e, devido à possível eliminação de gases confinados no material [104]. Os resultados sugerem a importância da utilização de atmosferas oxidantes na sinterização da céria-gadolínia com elevada área de superfície específica para evitar a formação de microtrincas durante a sinterização.

\subsubsection{Redução da céria}

O efeito da utilização de diferentes atmosferas de sinterização na estabilidade química da céria foi estudado sistematicamente. Análises por espectroscopia Raman foram feitas nas amostras com menor tamanho inicial de partícula. Estas são as mais suscetíveis a qualquer efeito produzido pela atmosfera durante o tratamento térmico por apresentar maior área superficial específica. As análises tiveram por objetivo verificar a existência de $\mathrm{Ce}^{3+}$ na superfície das amostras em decorrência de possíveis reações de redução. A Figura 26 mostra espectros selecionados das análises feitas na temperatura ambiente para a amostra $10 \mathrm{~N}$.

A Figura 26a mostra uma banda associada ao modo de vibração $F_{2 g}$ do $\mathrm{CeO}_{2}$ em aproximadamente $460 \mathrm{~cm}^{-1}$ para todas as amostras na região espectral de fônons (inferior a $700 \mathrm{~cm}^{-1}$ ) [120]. Esta banda está associada com o modo vibracional triplamente degenerado da estrutura cúbica tipo fluorita na céria. Entre $\sim 520$ e $\sim 650 \mathrm{~cm}^{-1}$ são detectadas duas bandas de baixa intensidade que estão relacionadas com os defeitos produzidos pela formação de solução sólida. Diversas medidas foram realizadas em várias regiões das amostras e nenhuma banda associada à transição eletrônica ${ }^{2} \mathrm{~F}_{7 / 2} \rightarrow{ }^{2} \mathrm{~F}_{5 / 2}$ do $\mathrm{Ce}_{2} \mathrm{O}_{3}$ em aproximadamente $2165 \mathrm{~cm}^{-1}$ foi detectada [120], como mostrado na Figura 26b. A ausência da banda eletrônica nos espectros Raman pode ser interpretada como consequência da ausência de $\mathrm{Ce}^{3+}$ na superfície das amostras ou pela existência de quantidades inferiores ao limite de detecção pela técnica. Vale ressaltar que mesmo utilizando um feixe de baixa potência, é 
(a)

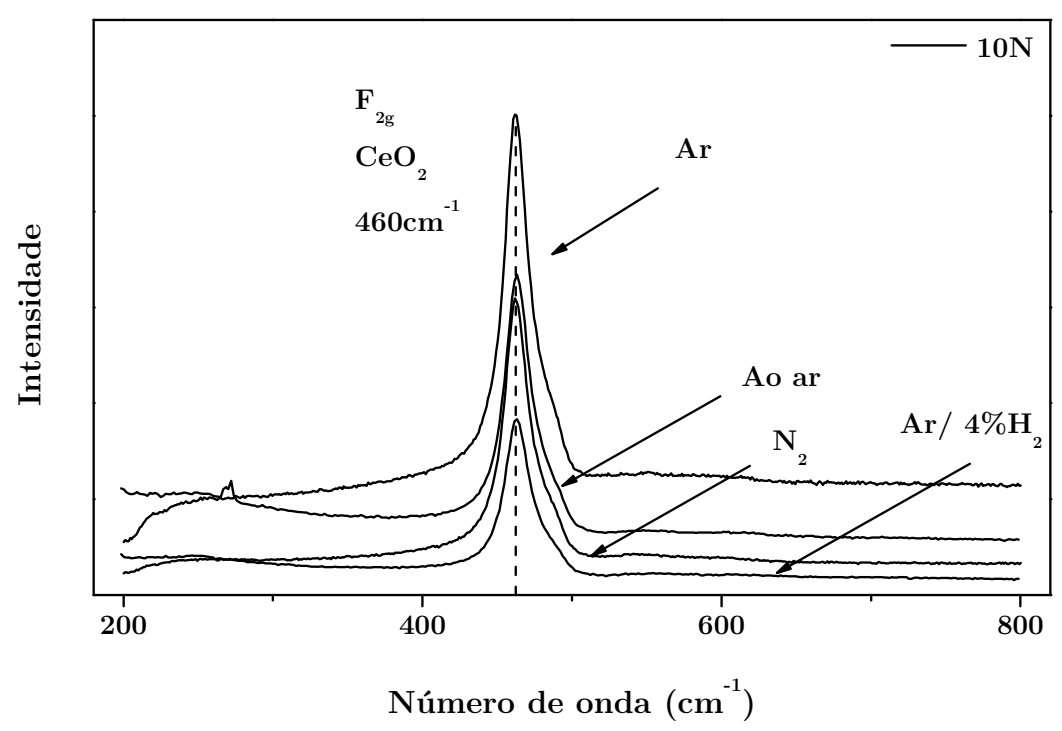

(b)

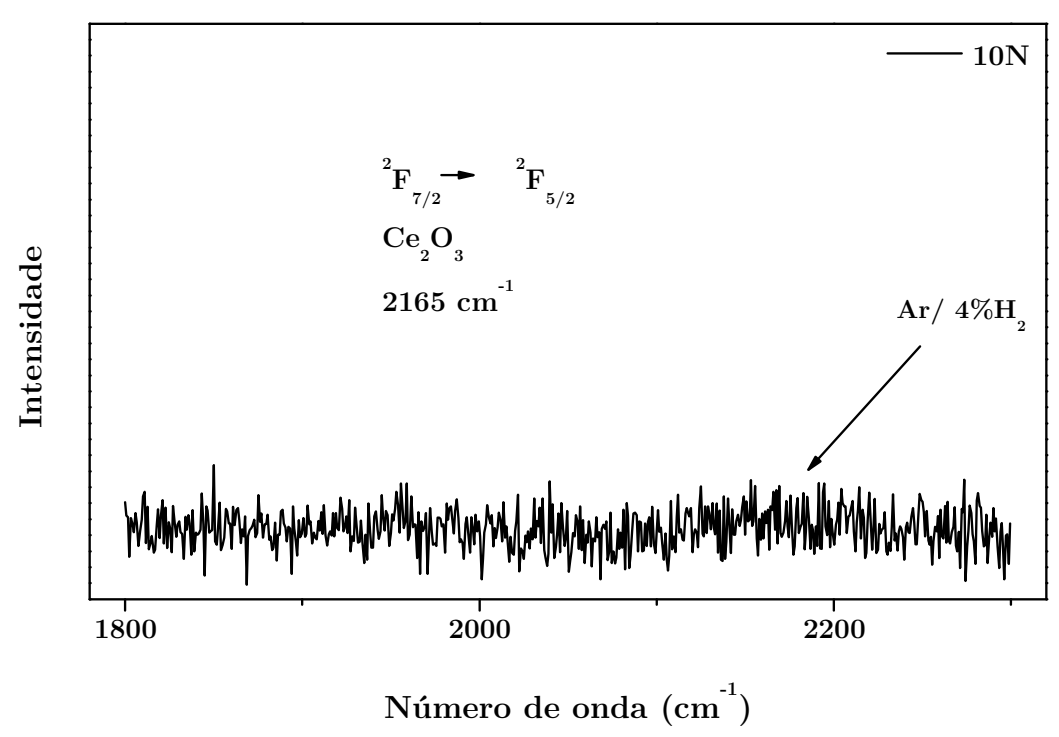

Figura 26: Espectros Raman obtidos para amostras 10N sinterizadas em diferentes atmosferas.(a) região de fônons, (b) região eletrônica.

possível que ocorra algum tipo de interação do feixe do laser com a superfície da amostra promovendo a reoxidação do material.

A fim de determinar se as amostras possuíam concentrações de $\mathrm{Ce}^{3+}$ em seu volume, análises de ressonância paramagnética eletrônica (RPE) foram realizadas na temperatura ambiente. As análises foram feitas inicialmente nos materiais de partida calcinados a $600^{\circ} \mathrm{C}$ por 1 hora, para eliminação das espécies ad- 
sorvidas, como mostrado nos resultados de análises térmicas. A Figura 27 mostra os espectros obtidos incluindo o do porta-amostra.

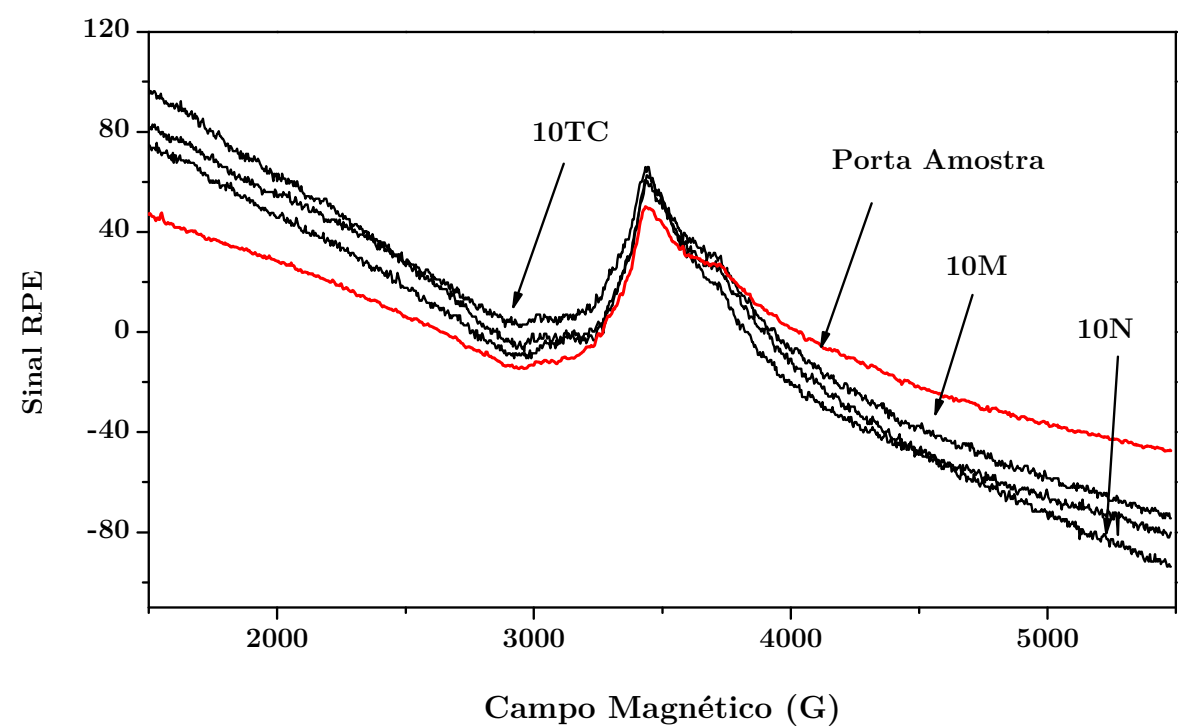

Figura 27: Espectros RPE dos materiais de partida calcinados a $600^{\circ} \mathrm{C}$. Também é mostrado o espectro RPE do porta amostra utilizado.

Sabe-se que o $\mathrm{Ce}^{4+}$ não apresenta sinal na RPE, ao contrário do $\mathrm{Ce}^{3+}$ [121]. Os espectros obtidos para os materiais de partida mostraram sinais desprezíveis, sendo verificado somente aquele devido à interação do campo magnético com o porta amostra. Portanto, quantidades significativas de $\mathrm{Ce}^{3+}$ nos materiais de partida não foram identificadas.

As amostras sinterizadas foram trituradas, sempre um dia antes da realização das medidas. A Figura 28 mostra alguns dos espectros obtidos para a amostra $10 \mathrm{~N}$.

Espectros para o $\mathrm{Ce}_{2} \mathrm{O}_{3}$ já foram reportados na literatura. Em geral bandas estreitas, associadas à existência de $\mathrm{Ce}^{3+}$ no volume do material, são verificadas para $\mathrm{g}=1,967$ e $\mathrm{g}=1,947$ [122-124]. Diferentemente destes resultados uma banda bastante alargada é verificada em todas as amostras sinterizadas e para todo o intervalo medido. O valor do fator $g$ é de aproximadamente 2,0 para todos os espectros. Como pode ser visto na Figura 28 (superior e inferior) o sinal RPE é muito mais intenso para a amostra sinterizada em atmosfera redutora. 

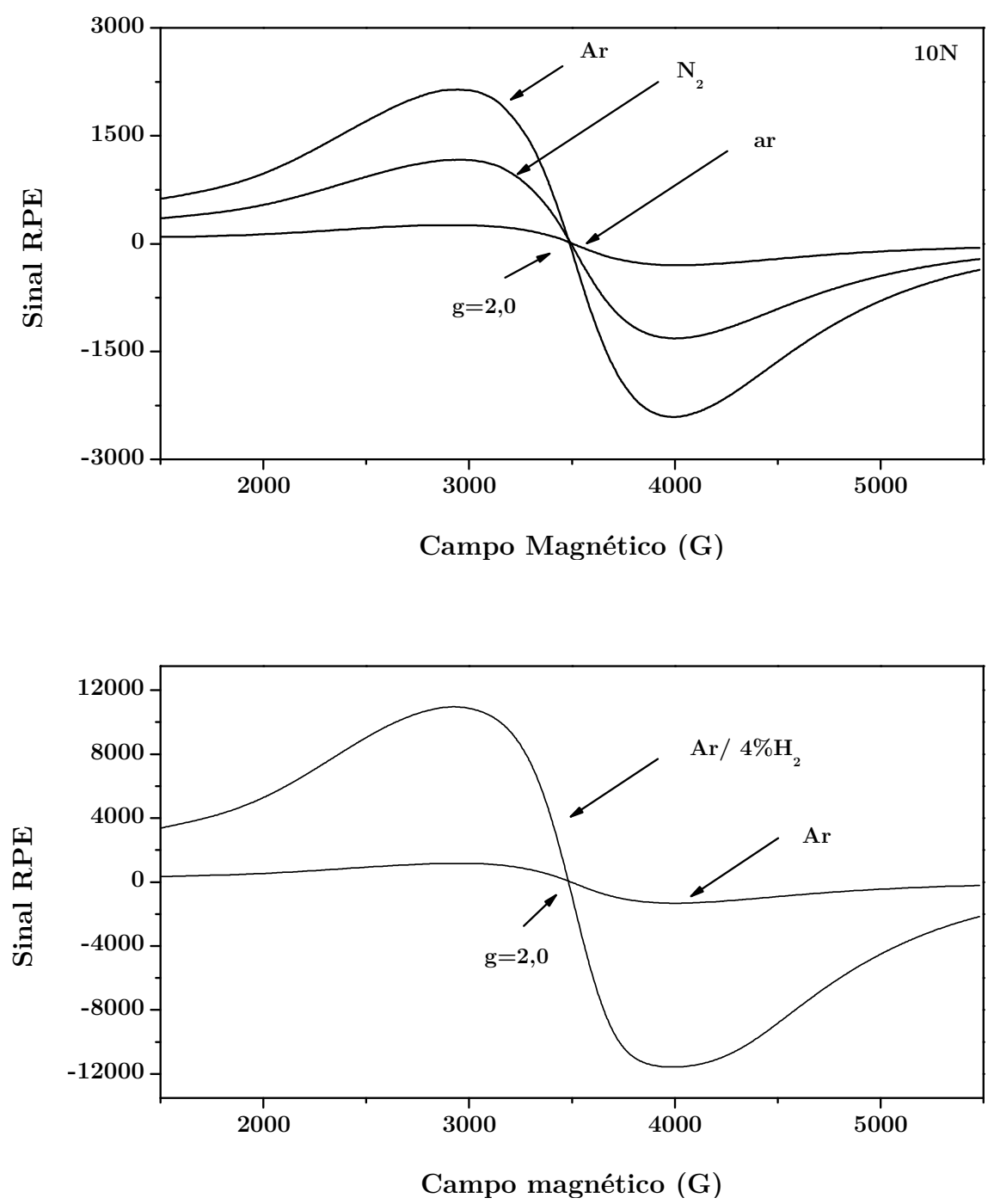

Figura 28: Espectros RPE de amostras sinterizadas a partir do material 10N. Espectros $R P E$ em atmosferas inerte e oxidante (superior) e inerte e redutora (inferior).

O alargamento do sinal RPE já foi reportado na literatura para compostos de céria contendo gadolínia [125-126]. Resultados similares também foram reportados para o vidro $\left\{\left(\mathrm{x} \cdot \mathrm{Gd}_{2} \mathrm{O}_{3}+(1-\mathrm{x}) \cdot\left(\mathrm{La}_{2} \mathrm{O}_{3}-\mathrm{Al}_{2} \mathrm{O}_{3}-\mathrm{B}_{2} \mathrm{O}_{3}-\mathrm{SiO}_{2}-\mathrm{GeO}_{2}\right)\right\}\right.$ e para o supercondutor $\mathrm{GdBa}_{2} \mathrm{Cu}_{3} \mathrm{O}_{y}[127,128]$. Foi mostrado de modo conclusivo que este alargamento do sinal RPE ocorre devido ao acoplamento magnético entre íons $\mathrm{Gd}^{3+}$. Quanto maior a concentração de $\mathrm{Gd}_{2} \mathrm{O}_{3}$, maior o alargamento do sinal RPE. A largura e a intensidade do sinal RPE é fortemente influenciada pelo meio ambiente químico local das espécies $\mathrm{Gd}^{3+}$. Por exemplo, Rakhmatullin e colabo- 
radores analisaram amostras de céria-ítria dopada com gadolínia com diferentes tamanhos de cristalito [126]. Os resultados apresentados não mostraram o alargamento do sinal para diversas amostras contendo gadolínia. Nakamura mostrou dependência da forma do sinal RPE com o tipo de dopante adicionado ao supercondutor $\mathrm{GdBa}_{2} \mathrm{Cu}_{3} \mathrm{O}_{y}$ [127]. Neste trabalho os materiais de partida não apresentaram sinal RPE enquanto os materiais sinterizados sim. Buscando elucidar os resultados as intensidades das bandas foram integradas e normalizadas pela massa das amostras. Os resultados obtidos são mostrados na Tabela 9.

Tabela 9: Intensidades integradas dos sinais RPE medidos. As intensidades foram normalizadas pela massa das amostras.

\begin{tabular}{cccc}
\hline Atmosfera & \multicolumn{3}{c}{ Intensidade .10 $\left.\mathbf{~ ( g}^{-1}\right)$} \\
\cline { 2 - 4 } & $\mathbf{1 0 M}$ & $\mathbf{1 0 T C}$ & $\mathbf{1 0 N}$ \\
\hline Material de partida & 4,03 & 8,15 & 9,62 \\
$\mathrm{Ao} \mathrm{ar}$ & 4,0 & 27,5 & 28,6 \\
$\mathrm{~N}_{2}$ & 6,86 & 42,0 & 103 \\
$\mathrm{Ar}$ & 75,5 & 97,4 & 201 \\
$\mathrm{Ar} / 4 \% \mathrm{H}_{2}$ & 318 & 218 & 241 \\
\hline
\end{tabular}

Verifica-se, de forma geral, que para uma mesma atmosfera de sinterização, um aumento no sinal RPE ocorre com a diminuição do tamanho inicial de partícula $(10 \mathrm{M}<10 T C<10 \mathrm{~N})$. Um aumento no sinal RPE também é verificado para as atmosferas com maior potencial de redução, sendo tal aumento bastante pronunciado quando utilizada a mistura de $4 \%$ de $\mathrm{H}_{2} / \mathrm{Ar}$. Os resultados obtidos sugerem que a intensidade do sinal RPE (Figura 28) é associada a concentrações de $\mathrm{Ce}^{3+}$ no material. O alargamento devido ao acoplamento magnético dos íons $\mathrm{Gd}^{3+}$ parece ocorrer somente quando presente concentrações de $\mathrm{Ce}^{3+}$ visto que os materiais de partida não apresentam sinal RPE significante.

Para verificação desta hipótese as amostras foram armazenadas ao ar e reanalisadas semanas após as medidas iniciais. Como resultado, nenhuma amos- 
tra apresentou sinal RPE. Assim, pode-se concluir que o sinal verificado é certamente relacionado à concentração de $\mathrm{Ce}^{3+}$ no volume das amostras. A intensidade medida depende do tempo de exposição da amostra ao ar (após a sinterização) e do tamanho inicial de partícula, visto que materiais nanométricos podem oxidar ou reduzir rapidamente devido a alta área superficial específica. Assim, neste trabalho foi possível estabelecer uma relação qualitativa do sinal RPE com o tipo de atmosfera as quais as amostras foram expostas. Isto explica também a diferença de valores obtidos em atmosferas inertes $\left(\mathrm{N}_{2}\right.$ e $\left.\mathrm{Ar}\right)$.

Concentrações de $\mathrm{Ce}^{3+}$ são verificadas em todas as amostras, independentemente da atmosfera de sinterização utilizada, com exceção da amostra $10 \mathrm{M}$ sinterizada ao ar. Atmosferas inertes ou redutoras promoveram um aumento significativo na concentração de $\mathrm{Ce}^{3+}$ no volume das amostras. Os resultados mostraram que a estabilidade química da céria durante a sinterização é maior quando utilizado materiais de partida com maior tamanho inicial de partícula.

\subsubsection{Microestrutura}

Os efeitos devido à utilização das diferentes atmosferas de sinterização na microestrutura dos materiais foram verificados por microscopia eletrônica de varredura. As Figuras 29, 30 e 31 mostram micrografias selecionadas das superfícies polidas de amostras 10M, 10TC e 10N, respectivamente.

Um aumento significativo no tamanho médio de grãos é verificado pela utilização da mistura de gases de $4 \%$ de $\mathrm{H}_{2} / \operatorname{Ar}$ (Figura 29, 30, 31) como atmosfera de sinterização. De modo geral, quanto maior o potencial de redução da atmosfera de sinterização, mais pronunciado é o crescimento de grãos. Os resultados para os tamanhos médios de grãos são sumarizados na Tabela 10. 

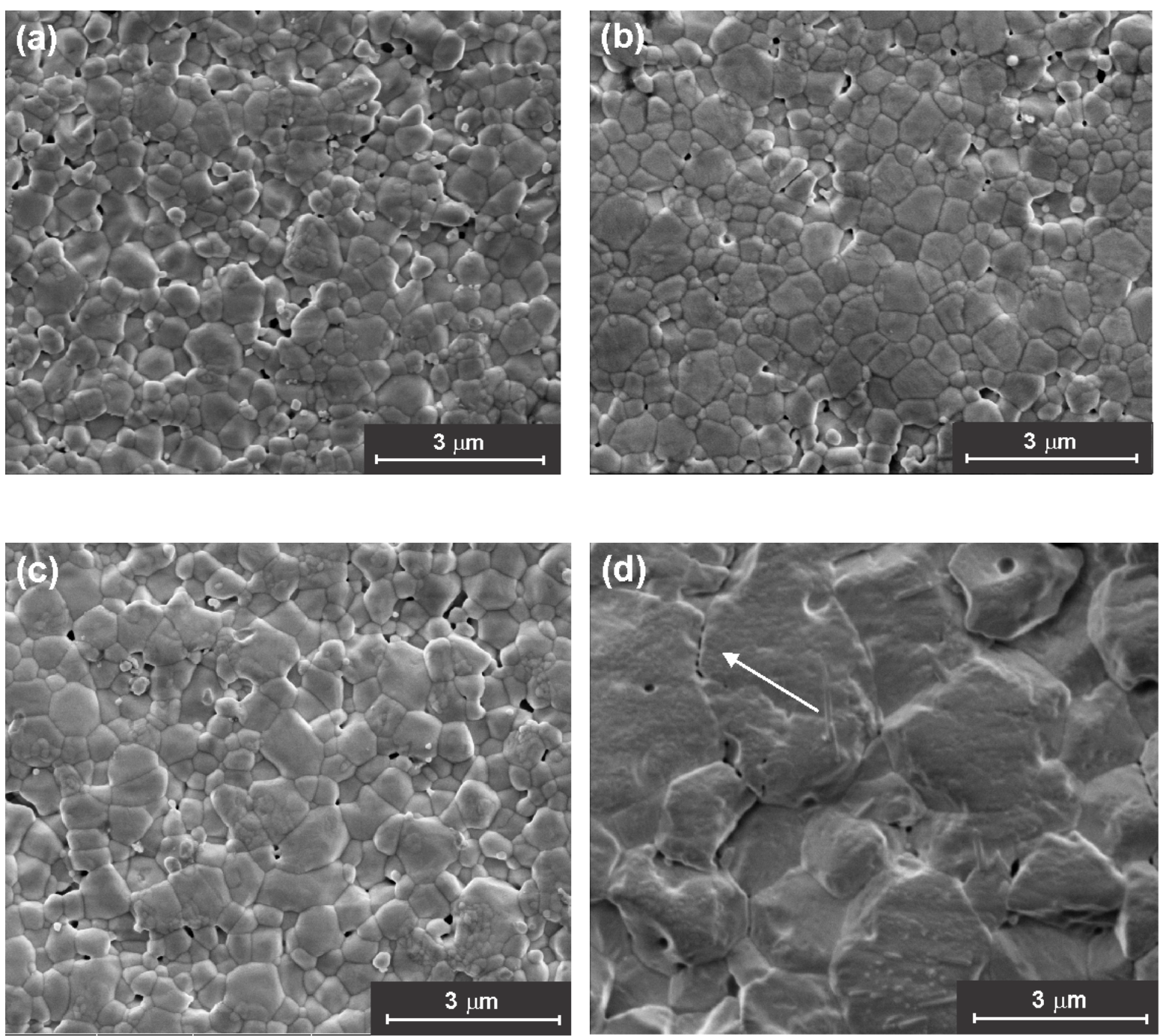

Figura 29: Micrografias selecionadas de amostras elaboradas a partir da 10M e sinterizadas ao (a) ar ou em atmosferas de (b) $\mathrm{Ar}$, (c) $\mathrm{N}_{2}$ e (d) mistura de 4\% de $\mathrm{H}_{2} / \mathrm{Ar}$. 

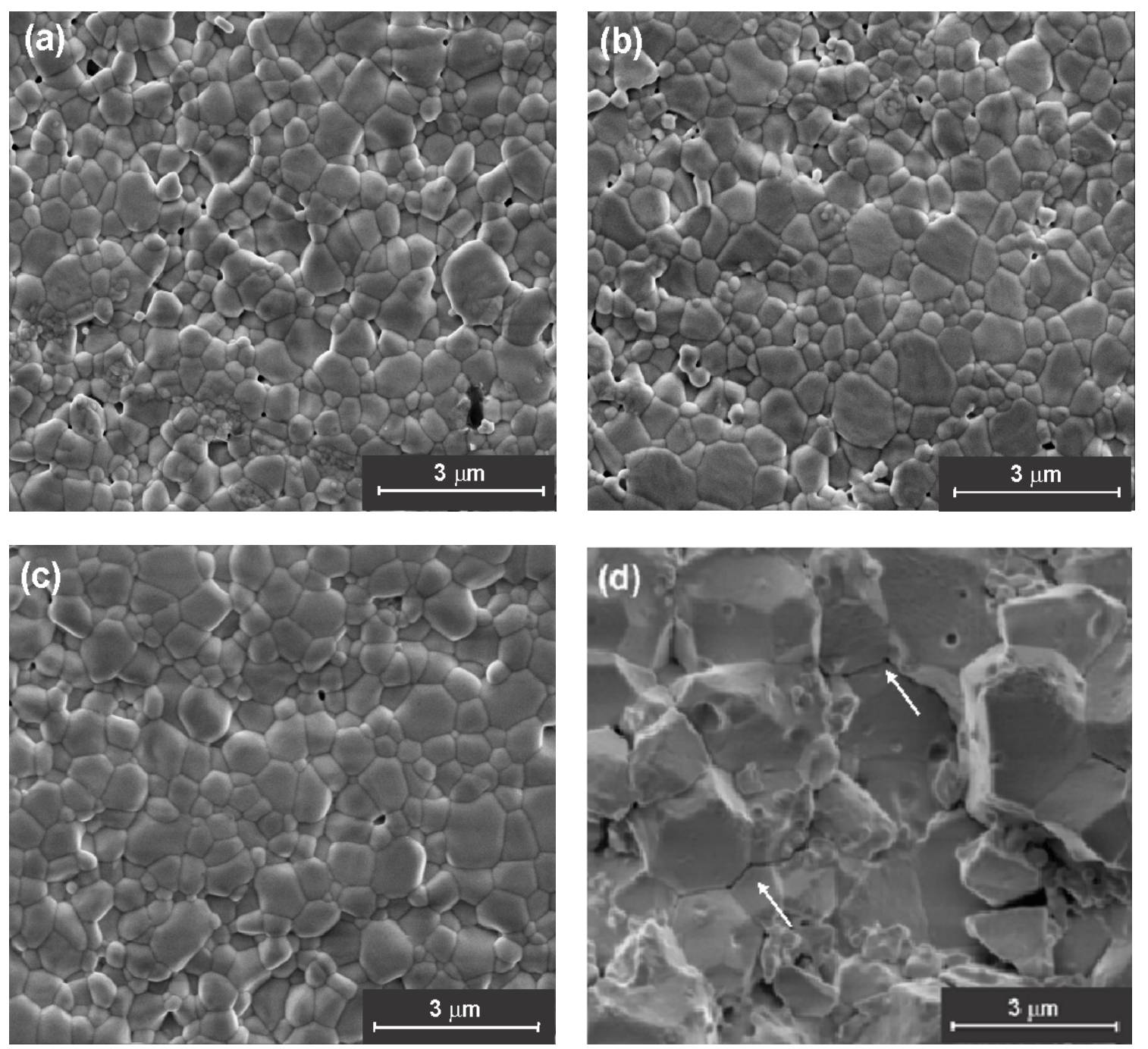

Figura 30: Micrografias selecionadas de amostras elaboradas a partir da 10TC e sinterizadas ao (a) ar ou em atmosferas de (b) $\mathrm{Ar}$, (c) $\mathrm{N}_{2}$ e (d) mistura de 4\% de $\mathrm{H}_{2} / \mathrm{Ar}$. 

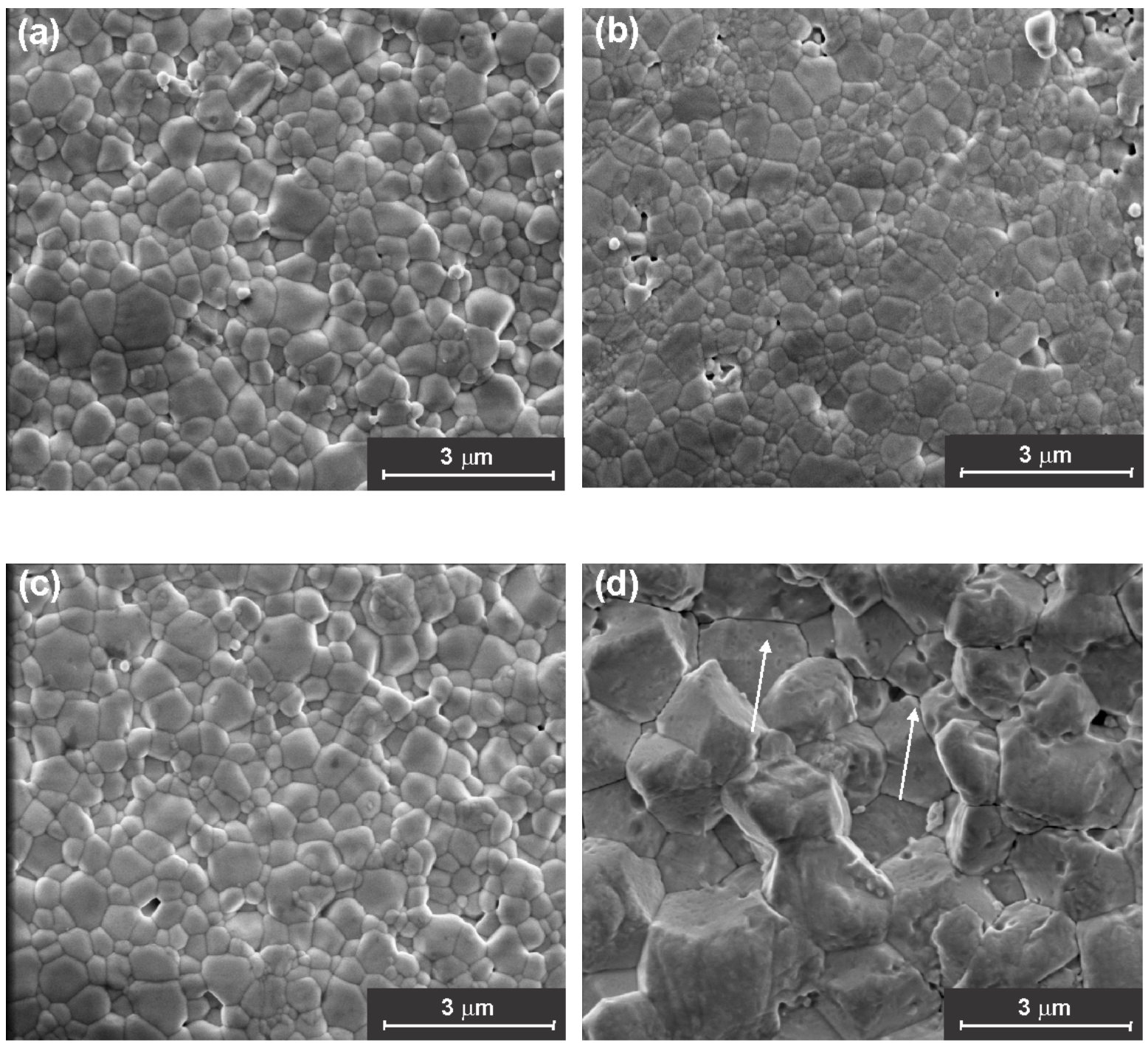

Figura 31: Micrografias selecionadas de amostras elaboradas a partir da $10 \mathrm{~N}$ e sinterizadas ao (a) ar ou em atmosferas de (b) $\mathrm{Ar}$, (c) $\mathrm{N}_{2}$ e (d) mistura de 4\% de $\mathrm{H}_{2} / \mathrm{Ar}$. 
Tabela 10: Tamanho médio de grãos de amostras sinterizadas em diferentes atmosferas.

\begin{tabular}{cccc}
\hline Atmosfera & \multicolumn{3}{c}{ Tamanho médio de grãos (nm) } \\
\cline { 2 - 4 } & 10M & 10TC & 10N \\
\hline Ao ar & $591(6)$ & $614(12)$ & $624(6)$ \\
$\mathrm{N}_{2}$ & $729(13)$ & $710(9)$ & $646(8)$ \\
$\mathrm{Ar}$ & $670(11)$ & $666(8)$ & $629(10)$ \\
$\mathrm{Ar} / 4 \% \mathrm{H}_{2}$ & $2699(29)$ & $2412(39)$ & $2223(21)$ \\
\hline
\end{tabular}

Os resultados ilustram os efeitos das reações de redução do $\mathrm{Ce}^{4+}$ durante a sinterização. A redução do $\mathrm{Ce}^{4+}$ promove o aumento da concentração de vacâncias de oxigênio. Com o aumento da concentração de vacâncias de oxigênio o transporte de massa é aumentado e o crescimento de grãos é acelerado [80].

É nítido também o efeito da expansão química do cério devido às reações de redução quando utilizada a mistura de gases. Microtrincas intergranulares, como aquelas indicadas pelas setas nas Figuras $29 d$, 30d e 31d, são verificadas. As imagens corroboram os resultados de densidade aparente que mostraram uma pequena diminuição na densidade relativa pela utilização desta atmosfera de sinterização.

A utilização de diferentes atmosferas de sinterização produz densidades de contornos de grãos e de superfícies livres diferentes. Assim, é esperado que a condutividade elétrica seja dependente da atmosfera de sinterização.

\subsubsection{Condutividade elétrica}

Outros trabalhos na literatura já haviam mostrado que a utilização de atmosferas pobres em oxigênio proporcionam densificação mais acelerada em compostos à base de céria, entretanto, não são conclusivos na literatura os efeitos da utilização de diferentes atmosferas de sinterização em suas propriedades elétricas [86,91,104,105]. Portanto, medidas da condutividade elétrica foram realizadas utilizando a técnica de espectroscopia de impedância. A Figura 32a mostra um típico diagrama de impedância, sendo este obtido para uma amostra 10TC 
sinterizada ao ar cuja temperatura de medida se encontrava em $245^{\circ} \mathrm{C}$. Diagramas de impedância similares em forma foram verificados para todas as amostras independente da atmosfera de sinterização.

(a)

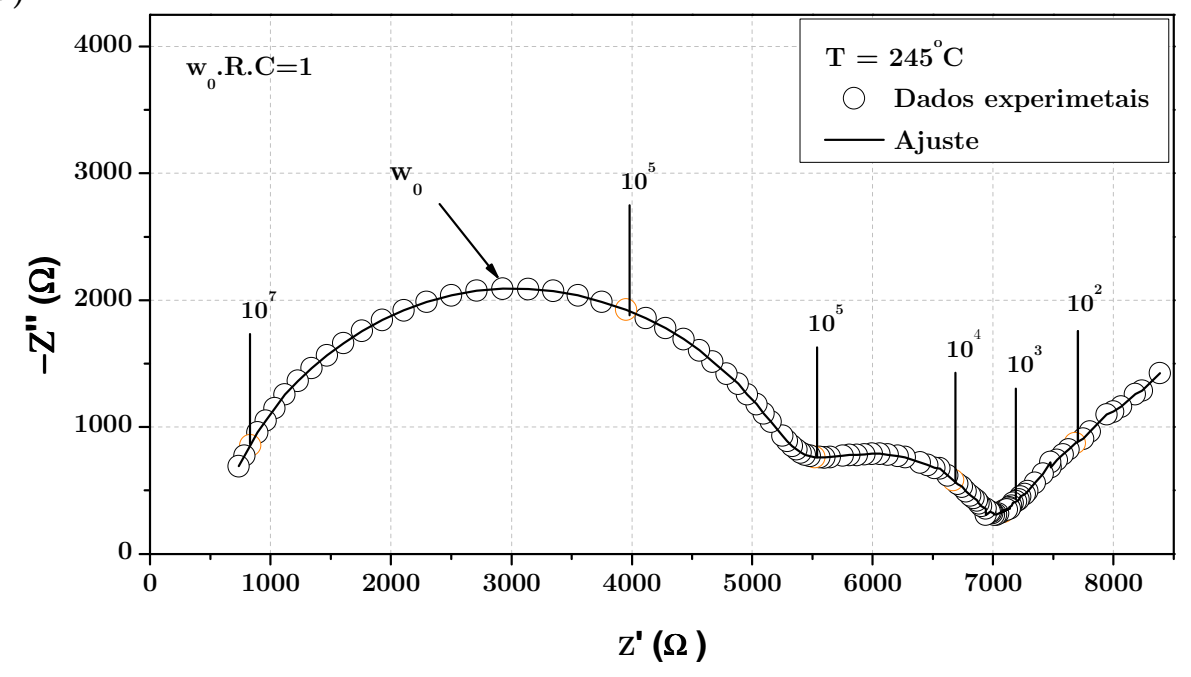

(b)

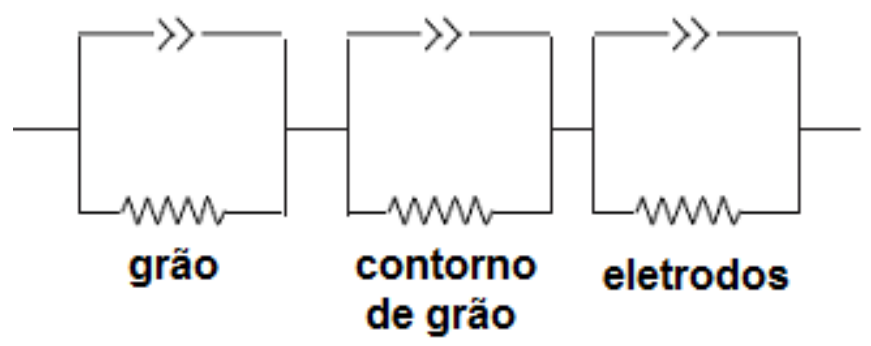

Figura 32: (a) Diagrama de impedância para a amostra da 10TC sinterizada ao ar. Medida realizada a $245^{\circ} \mathrm{C}$. O ajuste não linear foi obtido com o programa LEVM. (b) Circuito equivalente utilizado para efetuar o ajuste aos dados experimentais.

Dois semicírculos podem ser identificados nos diagramas de impedância, sendo aquele de mais alta frequência, entre $10^{7}$ e $10^{5} \mathrm{~Hz}$, associado com a resistência intragranular do material [129]. O semicírculo de menor frequência, entre $10^{5}$ e $10^{3} \mathrm{~Hz}$, é associado ao bloqueio de cargas nas regiões dos contornos de grãos [129]. Em frequências ainda mais baixas nota-se o princípio de um semicírculo, que pode ser atribuído às reações de interface com os eletrodos utilizados nas medidas [129]. As resistências associadas a cada um destes fenômenos foram obtidas através do ajuste dos dados usando o programa LEVM [115]. O cir- 
cuito equivalente utilizado também é mostrado na Figura 32b. A correção devido à indutância do sistema foi feita durante a análise quando necessária. O Apêndice $\mathrm{C}$ discute em maior detalhe os elementos utilizados no circuito equivalente.

O gráfico de Arrhenius da condutividade elétrica intergranular, intragranular e total foram geradas a partir dos resultados dos ajustes. A Figura 33 mostra 0 gráfico de Arrhenius para a condutividade elétrica intragranular após a normalização da condutância pelos parâmetros geométricos das amostras.

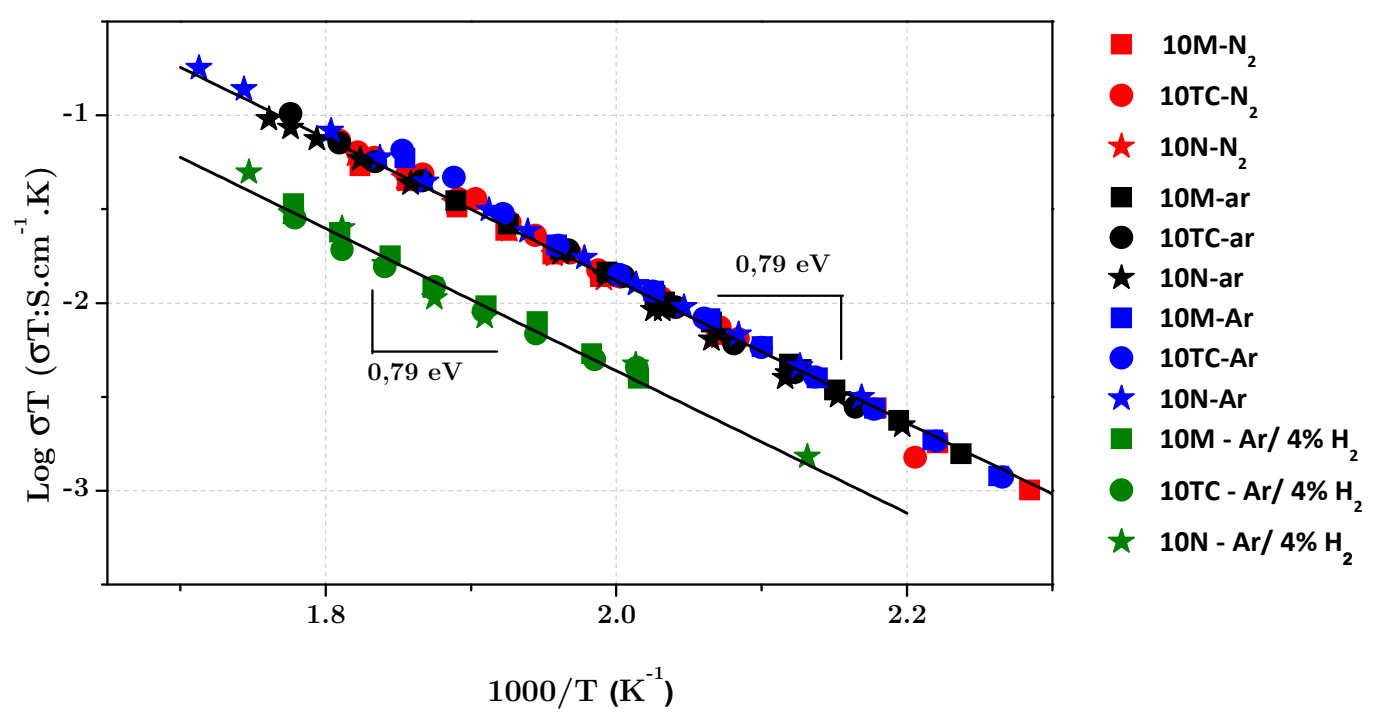

Figura 33: Gráfico de Arrhenius da condutividade elétrica intragranular para amostras sinterizadas em diferentes atmosferas de sinterização.

A análise do gráfico de Arrhenius da condutividade elétrica intragranular mostra que não ocorre uma mudança significativa na condutividade do volume dos materiais pela utilização de atmosferas inertes ou oxidante durante a sinterização. Entretanto, uma sensível diminuição (cerca de meia ordem de grandeza) é verificada para as amostras sinterizadas em atmosfera redutora de $4 \%$ de $\mathrm{H}_{2} / \mathrm{Ar}$. Essa diminuição independe do tamanho inicial das partículas.

As energias de ativação de todas as amostras foram calculadas a partir do ajuste linear aos dados do gráfico de Arrhenius e submetidas à análise de variância. A análise de variância mostrou que dentro das incertezas dos ajustes, todas as energias de ativação são idênticas. A melhor estimativa obtida para energia de 
ativação foi de 0,79 (3) eV, sendo este valor associado a migração de íons $\mathrm{O}^{2-}$ no volume da céria contendo gadolínia [74].

A diminuição da condutividade intragranular para as amostras sinterizadas em mistura de $\mathrm{Ar} / 4 \% \mathrm{H}_{2}$ ocorre devido somente a diminuição do fator pré exponencial. Diversos são os fenômenos que podem produzir esta diminuição. Maior porosidade das amostras sinterizadas em atmosferas redutoras, condutividade elétrica inferior da fase $\mathrm{Ce}_{2} \mathrm{O}_{3}$ em relação à fase $\mathrm{CeO}_{2}$, mudança da solubilidade do $\mathrm{Gd}_{2} \mathrm{O}_{3}$ devido a redução do cério e diminuição da concentração de vacâncias de oxigênio livres para condução. Estas são algumas das possíveis causas para a verificação da diminuição da condutividade elétrica, porém, a correta determinação não é possível somente com as informações obtidas.

A Figura 34 mostra o gráfico de Arrhenius da condutividade elétrica intergranular. Os resultados foram normalizados pelos tamanhos médios de grãos com base na equação 5.1 [130].

$$
\sigma_{c g}=\frac{L}{R_{c g} A} \cdot \frac{\delta_{c g}}{G} \alpha \frac{L}{R_{c g} A} \cdot \frac{1}{G}
$$

onde $\sigma_{\mathrm{cg}}$ é a condutividade elétrica nos contornos de grãos, L o comprimento da amostra na direção transversal da aplicação ao campo, A a área de contato com os eletrodos, $\delta_{\mathrm{cg}}$ a distância transversal média dos contornos de grãos, $\mathrm{G}$ a área de interface média entre dois grãos (tamanho médio de grãos).

O gráfico de Arrhenius da condutividade elétrica intergranular mostra uma pequena diminuição da condutividade elétrica em amostras elaboradas com o material $10 \mathrm{~N}$ e sinterizadas em atmosferas inertes, diferentemente da condutividade intragranular (Figura 33). A diminuição da condutividade em amostras sinterizadas em mistura de gases $\left(\mathrm{Ar} / 4 \% \mathrm{H}_{2}\right)$ é verificada para todas as amostras. $A$ diminuição mais severa em atmosfera redutora pode ser atribuída à redução do cério. Estes resultados concordam perfeitamente com os apresentados anteriormente pela técnica de ressonância paramagnética eletrônica. 


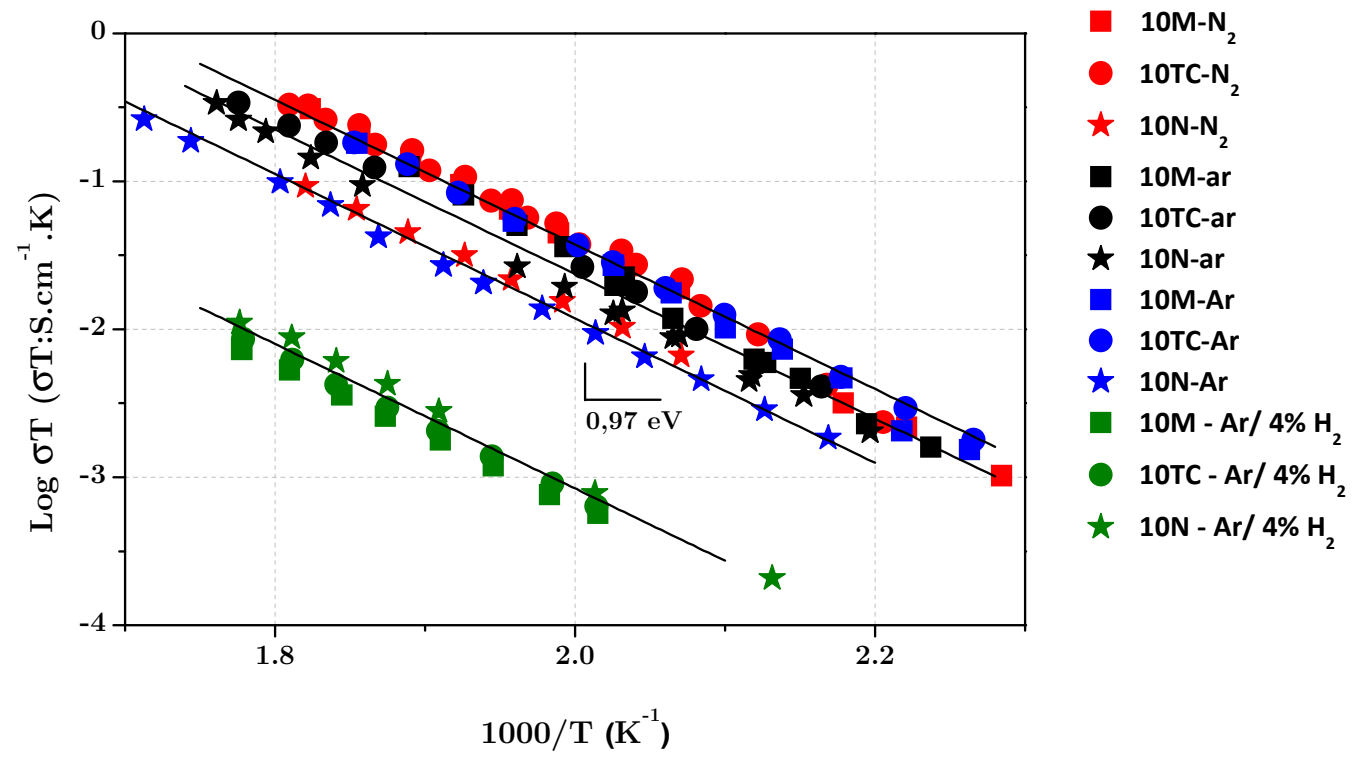

Figura 34: Gráfico de Arrhenius da condutividade elétrica intergranular para amostras sinterizadas utilizadas diferentes atmosferas.

As energias de ativação para condução nos contornos de grãos foram determinadas para todas as amostras. Análise de variância foi feita sobre os dados mostrando que todas as amostras apresentaram a mesma energia de ativação dentro das incertezas. A melhor estimativa obtida foi 0,97 (8) eV. O valor obtido está em pleno acordo com valores verificados por outros pesquisadores $[15,74,131]$.

A condutividade elétrica total é dominada pelo componente intragranular e um pequeno aumento da condutividade elétrica total pode ser obtido pelo aumento do tamanho médio de grãos. A Figura 35 mostra o gráfico de Arrhenius da condutividade elétrica total. As condutâncias foram normalizadas pelos parâmetros geométricos das amostras. 


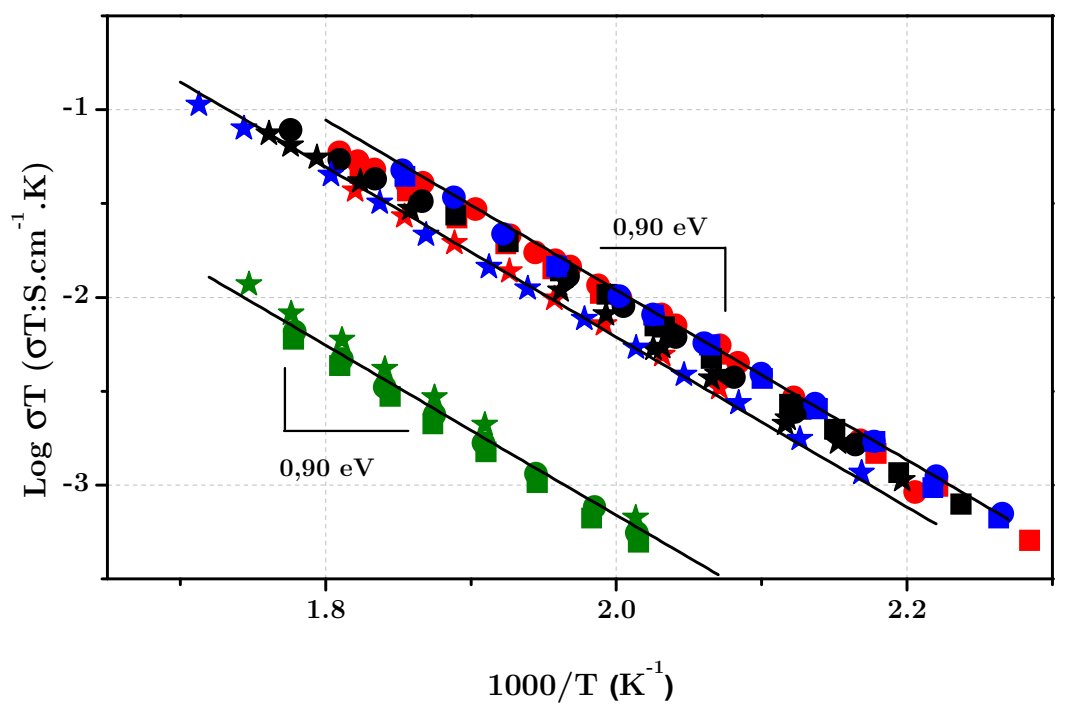

- $10 \mathrm{M}-\mathrm{N}_{2}$

- $10 T C-\mathrm{N}_{2}$

$\downarrow 10 \mathrm{~N}-\mathrm{N}_{2}$

10M-ar

- 10TC-ar

$\star \quad 10 \mathrm{~N}-\mathrm{ar}$

10M-Ar

- 10TC-Ar

^ 10N-Ar

- $10 \mathrm{M}-\mathrm{Ar} / 4 \% \mathrm{H}_{2}$

- $10 \mathrm{TC}-\mathrm{Ar} / 4 \% \mathrm{H}_{2}$

$\star \quad 10 \mathrm{~N}-\mathrm{Ar} / 4 \% \mathrm{H}_{2}$

$1000 / \mathrm{T}\left(\mathrm{K}^{-1}\right)$

Figura 35: Gráfico de Arrhenius da condutividade elétrica total para amostras sinterizadas utilizadas diferentes atmosferas.

Uma pequena diminuição na condutividade elétrica total é verificada para as amostras preparadas com o material $10 \mathrm{~N}$ e sinterizadas em atmosferas pobres em oxigênio. Uma redução bastante significativa é verificada nas amostras sinterizadas utilizando a atmosfera redutora de $4 \%$ de $\mathrm{H}_{2}$ e Ar. A energia de ativação do processo é 0,90 eV. É importante ressaltar a similaridade nos valores de energia de ativação do processo de condução intragranular, intergranular e total. Isto mostra que não há mudança no mecanismo de condução elétrica da cériagadolínia sinterizada em diferentes atmosferas.

Os resultados mostraram conclusivamente os efeitos da utilização de atmosferas pobres em oxigênio durante a sinterização. Quanto maior o potencial de redução da atmosfera utilizada, maior é a concentração de $\mathrm{Ce}^{3+}$ encontrada no volume do material. Como consequência, densificação e crescimento dos grãos acelerados ocorrem durante a sinterização, conforme verificado por outros pesquisadores [91,104]. Se as reações de redução forem suficientemente intensas, gases podem ficar confinados no final do estágio intermediário e no estágio final da sinterização promovendo a formação de microtrincas e descolamento dos grãos. Tal comportamento acarreta uma diminuição significativa da condutividade elétrica intergranular e total do material. Concentrações de $\mathrm{Ce}^{3+}$ foram verificadas independentemente da atmosfera de sinterização utilizada mostrando que altas 
temperaturas favorecem a redução do $\mathrm{Ce}^{4+} \mathrm{em} \mathrm{Ce}^{3+}$. Foi mostrado também que a técnica de ressonância paramagnética eletrônica é uma ferramenta importante para a identificação da redução na céria.

Os resultados para a condutividade elétrica total de amostras sinterizadas em atmosfera redutora são diferentes daqueles obtidos por Esposito e colaboradores [86]. Possíveis razões para estas diferenças estão relacionadas com as amostras (método de síntese, área de superfície específica, impurezas, etc), com o processamento das mesmas (introdução de aditivos, métodos de conformação e sinterização) e com o tipo de atmosfera redutora empregada $\left(\mathrm{N}_{2} / 9 \% \mathrm{H}_{2}\right)$.

A condutividade elétrica dos grãos é substancialmente reduzida em amostras sinterizadas em atmosfera redutora, independentemente do tamanho inicial das partículas. A condutividade intergranular apresenta fraca dependência com a atmosfera de sinterização, exceto quando as reações de redução são mais significativas (conforme os dados de RPE - Tabela 9). Assim, pode-se dizer que a condutividade elétrica total da céria- $10 \%$ mol gadolínia está de acordo com a sequência:

$$
\sigma_{T}^{a r} \simeq \sigma_{T}^{\text {inerte }}>\sigma_{T}^{\text {redutora }}
$$




\subsection{METODOLOGIA PARA CONSTRUÇÃO DA MSC}

Para construção da curva mestre de sinterização (MSC) curvas da densidade em função do tempo e temperatura são necessárias. Estas são usualmente obtidas por meio de ensaios de dilatometria [59-73]. Embora normas existam para a análise da expansão térmica de um material, estas não existem quando os estudos são voltados à sinterização [132]. Como consequência, diferentes laboratórios podem obter valores distintos para uma mesma grandeza física utilizando um mesmo conjunto de dados [133].

$\mathrm{Na}$ literatura diversas metodologias são utilizadas para determinação das curvas de densidade por dilatometria. Kinemuchi e Watari, por exemplo, utilizam a deformação real para determinação das curvas de densidade com diferentes taxas de aquecimento [63]. Os autores aplicam um tratamento térmico inicial ao material de partida que elimina a umidade ou impurezas orgânicas adsorvidas. Blaine, Park e German executam outra metodologia [67]. A retração linear é calculada com a usual correção devido à expansão térmica do tubo do dilatômetro. Em seguida uma nova correção é aplicada aos dados devido ao comportamento irregular das curvas de retração em baixas temperaturas. A contribuição devido à expansão térmica da amostra é subtraída aos resultados de retração linear e as densidades calculadas conforme a equação D.2 do Apêndice D. Por fim, os dados são suavizados e normalizados a 1 para evitar que densidades relativas superiores a densidade teórica do material sejam obtidas. Pouchly e Maca desenvolveram um programa computacional para o cálculo das curvas de densidade a partir dos dados de retração linear [134]. O programa subtrai dos dados a contribuição devido à expansão térmica da amostra, porém, não utiliza qualquer correção devido à perda de massa pelo material. Os autores desenvolvem em seu trabalho uma equação para o cálculo das curvas de densidade em materiais com retração linear anisotrópica. He e colaboradores calculam as curvas de densidade para a céria gadolínia em atmosferas redutoras [91]. Os autores aplicam correções devido à perda de massa e devido a mudança da densidade teórica do material ao longo da sinterização. 
Em outros trabalhos o que se verifica de modo geral é que as curvas de densidades são calculadas a partir dos resultados de retração linear utilizando a equação D.2 do Apêndice D [62, 69]. A retração linear é nestes casos obtida apenas pela aplicando da correção devido a expansão térmica do tubo do dilatômetro.

Uma metodologia para análise dos dados de retração linear é proposta neste trabalho. A nova proposta tem como objetivo eliminar determinadas interferências não aleatórias ao conjunto de dados. A proposta consiste de alguns refinamentos aos dados de retração linear e da utilização de alguns procedimentos já destacados. Novos refinamentos ao método de construção da curva mestre de sinterização ainda são propostos nos próximos itens.

\subsubsection{Retração linear devido à sinterização}

A dilatometria é uma técnica utilizada para medir a alteração dimensional de uma amostra quando sujeita a um tratamento térmico qualquer. A grandeza física medida durante as análises é o deslocamento. Este deslocamento, entretanto, não é aquele produzido somente pela amostra. Tanto o tubo do dilatômetro quanto o terminal que está em contato com a amostra, permanecem na zona de alta temperatura. Qualquer deslocamento produzido pela dilatação térmica destes produz interferências nas medidas realizadas. As interferências podem ser minimizadas quando utilizados tubos e terminais de um mesmo material. Neste caso, devido à configuração do sensor de deslocamento no equipamento, o valor aferido numa medida será dado pela diferença entre o deslocamento da amostra e o deslocamento da porção do tubo paralela à amostra. A Figura 36 esquematiza o princípio de medida e a equação 5.2 quantifica o deslocamento medido.

$$
\Delta L_{\text {Medido }}=\Delta L_{\text {Amostra }}-\Delta L_{\text {Tubo }}
$$




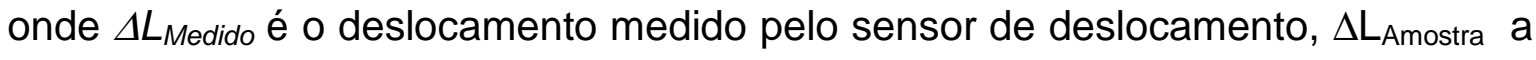
contribuição devido as alterações dimensionais da amostra e $\Delta \mathrm{L}_{\text {Tubo }} \mathrm{o}$ deslocamento devido a porção do tubo paralela a amostra.

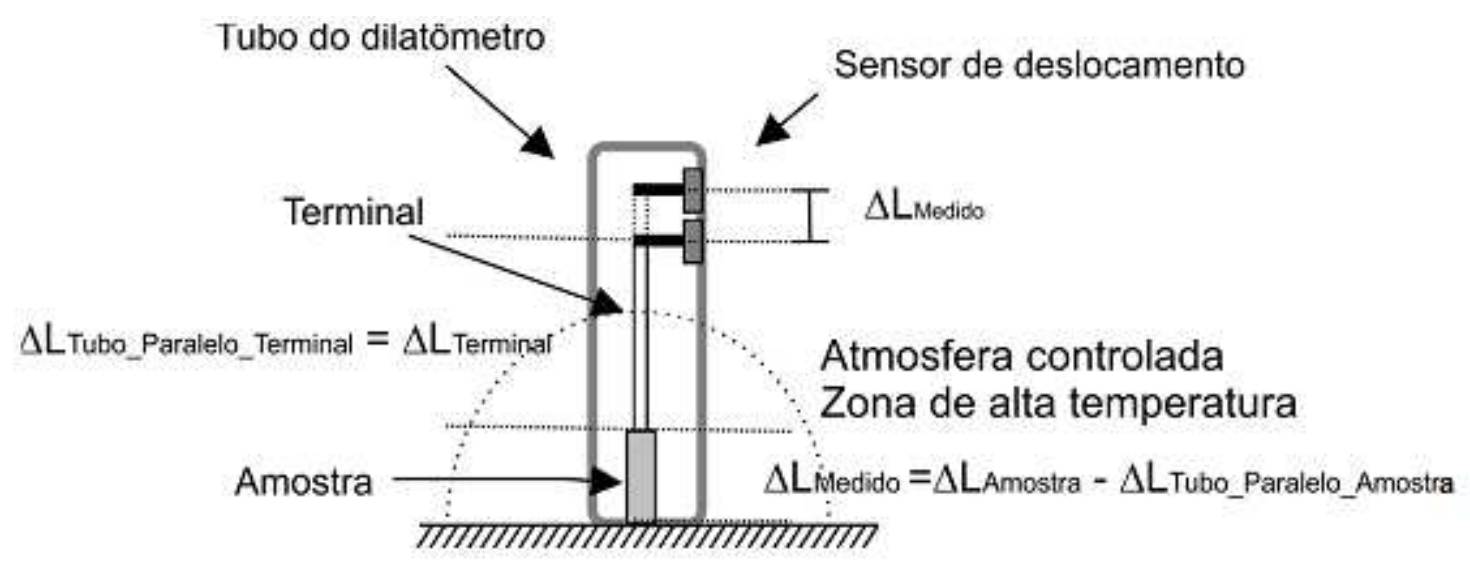

Figura 36: Esquema mostrando os fundamentos envolvidos numa medida de dilatometria. O sensor de deslocamento é preso ao tubo do dilatômetro. Como o terminal que toca a amostra e o tubo são fabricados com o mesmo material, ambos apresentam os mesmos coeficientes de expansão térmica. Assim, a contribuição à medida pela dilatação térmica do terminal é anulada pela contribuição devido a dilatação térmica da porção do tubo paralela ao terminal. O valor aferido pelo sensor de deslocamento é dado então apenas pela diferença entre o deslocamento produzido pelas alterações dimensionais na amostra e pela dilatação térmica da porção do tubo paralela a amostra.

Diversos fenômenos podem promover alterações dimensionais na amostra, como a expansão térmica, a retração linear durante a sinterização, a perda de massa devido à eliminação de gases e transições de fase, entre outros $[135,136]$. Quando as perdas de massa não forem significativas e transições de fase não ocorrerem no material, o deslocamento medido será composto por duas contribuições principais, a expansão térmica e a retração devido à sinterização.

$$
\Delta L_{\text {Amostra }}=\Delta L_{\text {Sinterização }}+\Delta L_{\text {Expterm }}
$$


onde $\Delta \mathrm{L}_{\text {Sinterização }}$ é o deslocamento produzido pela sinterização do material e $\Delta \mathrm{L}_{\text {Expterm }} \mathrm{O}$ deslocamento produzido pela expansão térmica da amostra.

Os modelos teóricos de sinterização não incluem a contribuição devido à expansão térmica, e logo, o objetivo desta proposta é a determinação do termo de deslocamento somente devido à sinterização [31-37]. As considerações abaixo são propostas com esta finalidade.

Inicialmente define-se o comprimento inicial instantâneo da amostra $\mathrm{L}_{0}{ }^{\circ}$ conforme a equação 5.4. Tal grandeza representa o tamanho da amostra caso a análise de dilatometria fosse interrompida e a amostra levada à temperatura inicial de medida. Note que a dilatação térmica da amostra é proporcional ao comprimento inicial instantâneo durante a sinterização.

$$
L_{0}^{\bullet}=L_{0}+\Delta L_{S \text { int erização }}
$$

A partir desta definição podemos equacionar o deslocamento produzido pelo tubo e pela expansão térmica da amostra. $\mathrm{O}$ deslocamento produzido pelo tubo é dado pela equação 5.5 (ver Apêndice E).

$$
\Delta L_{\text {Tubo }}=A_{C} \cdot\left(L_{0}+\Delta L_{S \text { interizaşa }}+\Delta L_{\text {Expterm }}\right)
$$

onde $A_{C}$ é a função correção obtida pela análise da amostra padrão.

O termo cruzado obtido pelo produto do termo relativo à expansão térmica do tubo e à expansão térmica da amostra pode ser desprezado. Assim, obtém-se 5.6 .

$$
\Delta L_{\text {Tubo }}=A_{C} \cdot\left(L_{0}+\Delta L_{S \text { interização }}\right)
$$


Já o deslocamento produzido pela expansão térmica da amostra pode ser equacionado conforme a equação 5.7. Maiores detalhes desta equação são mostrados no Apêndice F.

$$
\begin{gathered}
\Delta L_{\text {Experm }}=L_{0}^{\cdot} \cdot E \\
\Delta L_{\text {Expterm }}=\left(L_{0} \cdot E+\Delta L_{S \text { interziação }} \cdot E\right)
\end{gathered}
$$

onde $\mathrm{E}$ é a função que quantifica a dilatação térmica do material para cada temperatura.

A função $E$ pode ser determinada experimentalmente ao analisar as curvas de retração linear durante o resfriamento da amostra ou pela análise de uma amostra já sinterizada. Neste caso, os procedimentos de análise são aqueles já normatizados pela referência [132]. A substituição das equações 5.7, 5.6 e 5.3 em 5.2 fornece a equação 5.8 .

$$
\Delta L_{\text {Melido }}=\Delta L_{S \text { interização }}+L_{0} \cdot E+\Delta L_{S \text { interizaça }} . E-A_{C} . L_{o}-A_{C} \cdot \Delta L_{S \text { interização }}
$$

A equação 5.8 descreve de modo desacoplado o deslocamento medido em função da expansão térmica da amostra, do tubo e da retração linear da amostra durante a sinterização. Dividindo toda a equação por $L_{0}$ e remanejando a equação, obtemos finalmente o deslocamento devido somente à sinterização do material.

$$
\frac{\Delta L_{S \text { int erizacăo }}}{L_{0}}=\left(\frac{\Delta L_{\text {Medido }}}{L_{0}}+A_{C}-E\right) \cdot\left(\frac{1}{1+E-A_{C}}\right)
$$

A equação 5.9 foi utilizada neste trabalho para o cálculo das densidades das amostras analisadas por dilatometria. $O$ termo $A_{C}$ foi obtido ao analisar uma alumina translúcida Crystalox@ fornecida como padrão para o equipamento. O 
termo $E$ foi obtido pela análise estatística de diversas curvas de resfriamento para cada um dos materiais. A título de exemplo o gráfico da Figura 37 mostra curvas de retração linear em função da temperatura de análise. São mostradas curvas corrigidas (na Figura 37 - corrigidas) conforme a equação 5.9 e curvas corrigidas apenas pela expansão térmica do tubo (na Figura 37 - não corrigidas).

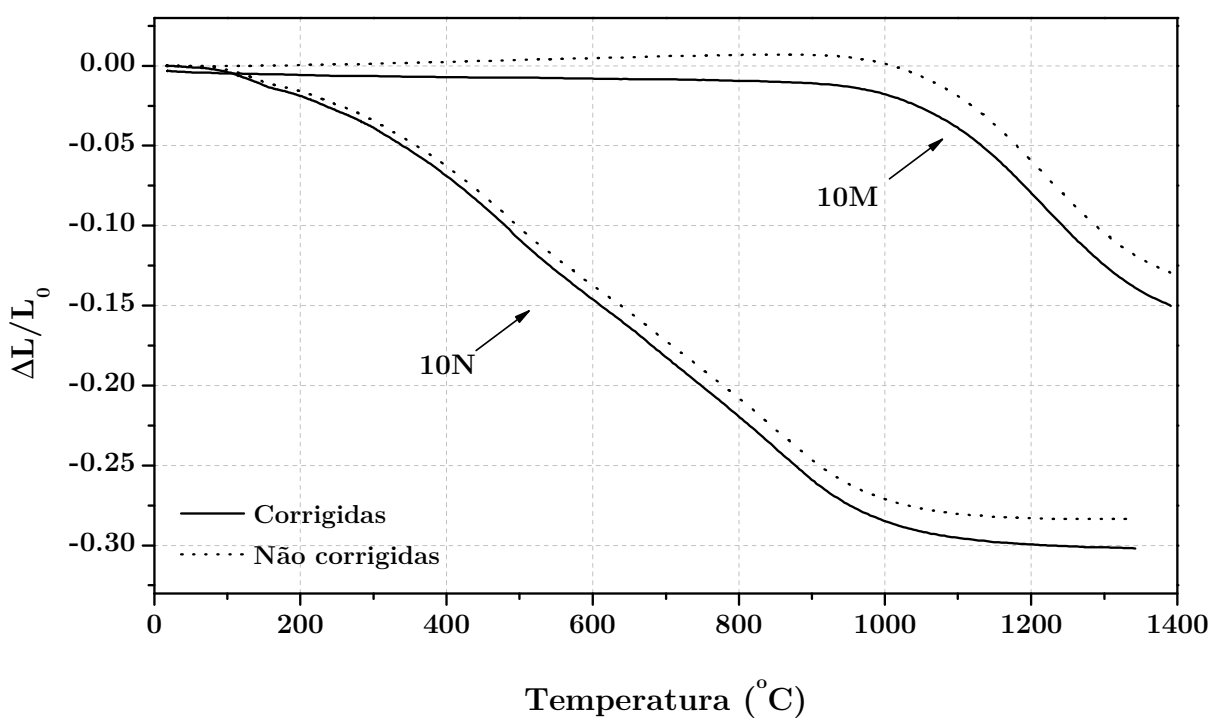

Figura 37: Curvas de retração linear obtidas para amostras elaboradas a partir dos materiais $10 \mathrm{~N}$ e $10 \mathrm{M}$. As curvas sólidas foram obtidas pela utilização da equação 5.9 enquanto as curvas pontilhadas foram obtidas pelo modo usual, sendo feita apenas a correção devido à expansão térmica da porção do tubo paralela à amostra.

Um claro desvio entre as curvas obtidas pela equação 5.9 e pelo método usual é verificado. Quando não corrigida a expansão térmica da amostra, a retração linear é subestimada nas medidas. O desvio entre medidas de retração linear para temperaturas mais elevadas alcança $6 \%$ para a amostra $10 \mathrm{~N}$ e $13 \%$ para a 10M. Dessa forma, um erro sistemático significativo é inserido ao não se efetuar a correção devido à expansão térmica. 


\subsubsection{Outras correções}

Outras correções também foram aplicadas ao conjunto de dados quando necessárias. Estas são brevemente discutidas aqui, embora os cálculos associados sejam apresentados nos Apêndices D, G e H.

Uma das mais importantes correções aplicadas neste trabalho é aquela devido à perda de massa da amostra durante a sinterização. Neste caso, um fator de correção deve ser multiplicado à já conhecida equação para o cálculo da densidade a partir dos dados de retração linear. A equação utilizada é a 5.10 e é demonstrada no Apêndice D.

$$
\rho=\frac{\rho_{0} \cdot f(t, T)}{\left(1+\frac{\Delta L_{S \text { interizaca } \bar{a} o}}{L_{0}}\right)^{3}}
$$

onde $\rho$ é a densidade, $\rho_{0}$ a densidade à verde e $f(t, T)$ a fração da massa inicial do material. A função $f(t, T)$ é uma função do tempo e temperatura e pode ser determinada em experimentos de termogravimetria. Este fator é importante para que os valores de densidade não sejam superestimados, principalmente quando analisados materiais com alta área de superfície específica.

Correções secundárias utilizadas são devido à temperatura inicial de análise, e ao comprimento inicial das amostras. Para a construção da curva mestre de sinterização diversas curvas de retração linear são utilizadas. Ocorre que nem sempre a temperatura inicial de medida é exatamente igual para todas as curvas. Isto pode gerar um pequeno erro não linear no comportamento entre curvas devido à introdução de um erro sistemático no comprimento inicial de cada amostra. Uma correção para este problema é mostrada no Apêndice G. Esta correção frente às demais é muita pequena, podendo ser desprezada.

No início do aquecimento as amostras não apresentam densificação devido à sinterização. Caso o material analisado não apresente perda de massa, esperase que o comportamento seja independente da taxa de aquecimento. Entretanto, irregularidades podem ser verificadas em baixas temperaturas devido uma série 
de fatores. Dois métodos para correção destas irregularidades são propostos e discutidos no Apêndice $\mathrm{H}$.

O gráfico da Figura 38 mostra duas curvas de densidade em função da temperatura para amostras elaboradas a partir da $10 \mathrm{~N}$. Uma delas foi obtida após a aplicação de todas as correções propostas. A outra foi obtida sem a correção devido à perda de massa pelo material. Os dados de retração linear utilizados para o cálculo de ambas as curvas foram aqueles conforme a equação 5.9. Para comparação resultados obtidos para a densidade aparente de amostras sinterizadas em forno convencional são mostrados também.

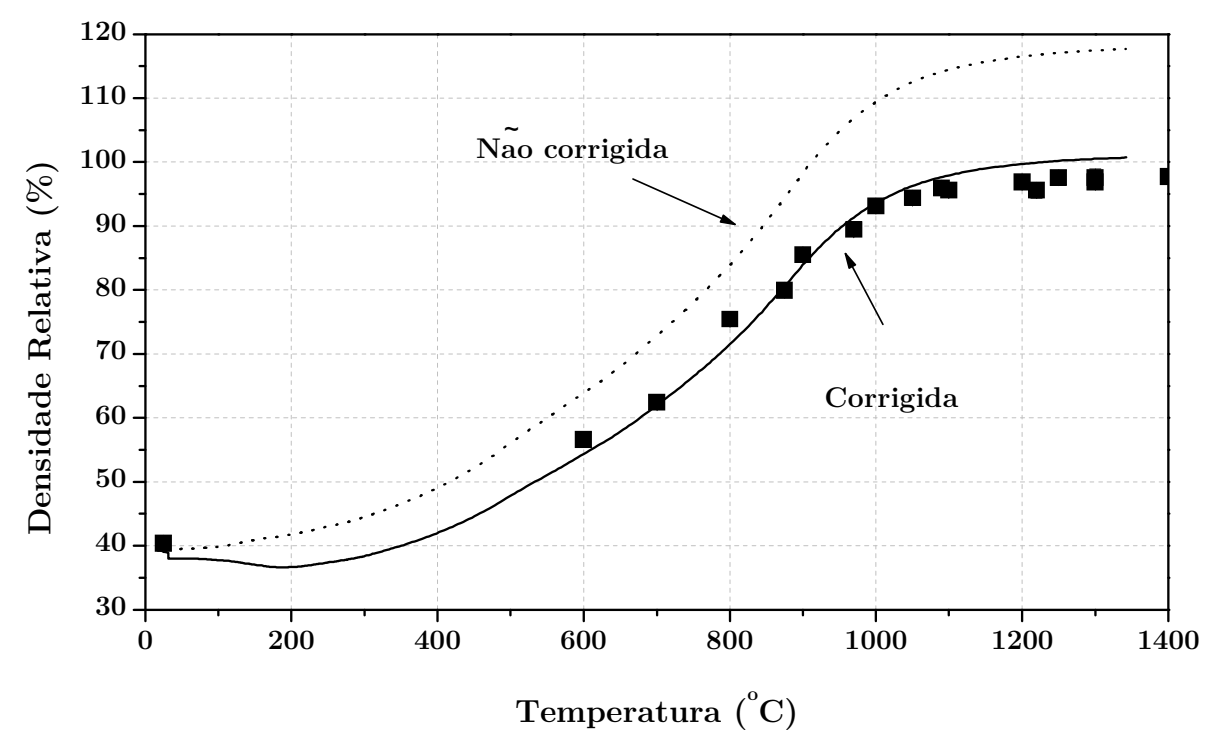

Figura 38: Curvas de densidade em função da temperatura obtidas por dilatometria para amostras elaborada a partir da amostra $10 \mathrm{~N}$ e sinterizadas com taxa de aquecimento constante de $10^{\circ} \mathrm{C} / \mathrm{min}$. A curva sólida foi obtida segundo as correções mostradas neste tópico. A curva em pontilhado foi obtida sem a correção devido à perda de massa pela amostra. Os símbolos representam resultados de densidade aparente obtidos para amostras sinterizadas em forno convencional.

Uma significativa melhora na qualidade dos resultados é verificada pela aplicação da correção de perda de massa. Densidades muito superiores aos $100 \%$ da densidade teórica são obtidas quando não aplicada à correção. As densidades obtidas por dilatometria superam ligeiramente aquelas obtidas pelo método de densidade aparente nas temperaturas de medida mais elevadas. Tais diferenças 
podem ser associadas a erros introduzidos nas medidas de densidade aparente devido à forma irregular das amostras.

\subsubsection{Programa de análise de dados}

A construção da curva mestre de sinterização é uma tarefa que demanda uma quantidade relativamente grande de tempo devido a grande quantidade de ajustes não lineares feitas aos dados. Poucos são os programas de análise de dados disponíveis para esta tarefa. Teng e Chen apresentaram um primeiro programa para esta finalidade [137]. O programa destes é baseado em Visual Basic e é executado numa planilha do Excel. Embora acelere o procedimento de construção da MSC, possui algumas limitações com relação a velocidade e quantidade de dados utilizados. Pouchly e Maca desenvolveram um programa para construção da curva mestre que utiliza uma abordagem relativamente distinta [138]. Ao invés de minimizar o resíduo quadrático médio, o programa minimiza a distância perpendicular média entre as curvas. Apesar da convergência mais rápida ao mínimo global, incertezas não são determinadas pelo método. Park, Chung, Blaine, Suri e German, apresentam um programa computacional desenvolvido para construção e análise da MSC [139]. O programa utiliza a linearização da MSC conforme referência [67]. Dois métodos são utilizados na determinação dos parâmetros, o resíduo quadrático médio e o coeficiente $\mathrm{R}^{2}$ de ajustes lineares. $\mathrm{O}$ algoritmo executa a varredura com energia de ativação fixa de modo a encontrar os parâmetros que minimizam o resíduo quadrático médio ou que maximizam o coeficiente $R^{2}$.

Neste trabalho um programa computacional foi desenvolvido para possibilitar a construção da curva mestre de sinterização e aplicação das correções propostas de modo automatizado. O método utilizado pelo programa para construção da curva mestre é o dos mínimos quadrados não linear. A utilização do método permite a determinação dos limites de confiança para os parâmetros ajustados, permitindo comparações mais seguras entre diferentes conjuntos de dados. Além disso, o tempo necessário para construção da MSC a partir dos dados de retração linear é diminuído consideravelmente, sendo da ordem de poucos minutos. 
A sequência de rotinas executadas pelo programa para construção da MSC é indicada na Figura 39. Inicialmente os dados de retração linear são calculados utilizando as correções desejadas. As curvas de densidade são determinadas a partir dos resultados de retração linear aplicando ou não a correção da perda de massa. Procede-se então conforme a metodologia tradicional de construção da MSC. Ajustes são feitos aos dados de densidade mantendo a energia de ativação fixa. O resíduo quadrático total é calculado para cada ajuste. Os ajustes são executados varrendo os possíveis valores da energia de ativação. A partir desta etapa um refinamento na metodologia tradicional é proposto. Os parâmetros obtidos com o ajuste de menor resíduo quadrático total são passados como valores iniciais para o algoritmo de ajuste não linear utilizando o método dos mínimos quadrados. A utilização destes parâmetros como valores iniciais diminui consideravelmente a convergência a mínimos locais. $O$ ajuste pelo método dos mínimos quadrados é executado e os resultados comparados com os obtidos pela metodologia tradicional (Resultados da varredura) para verificação de consistência dos resultados.

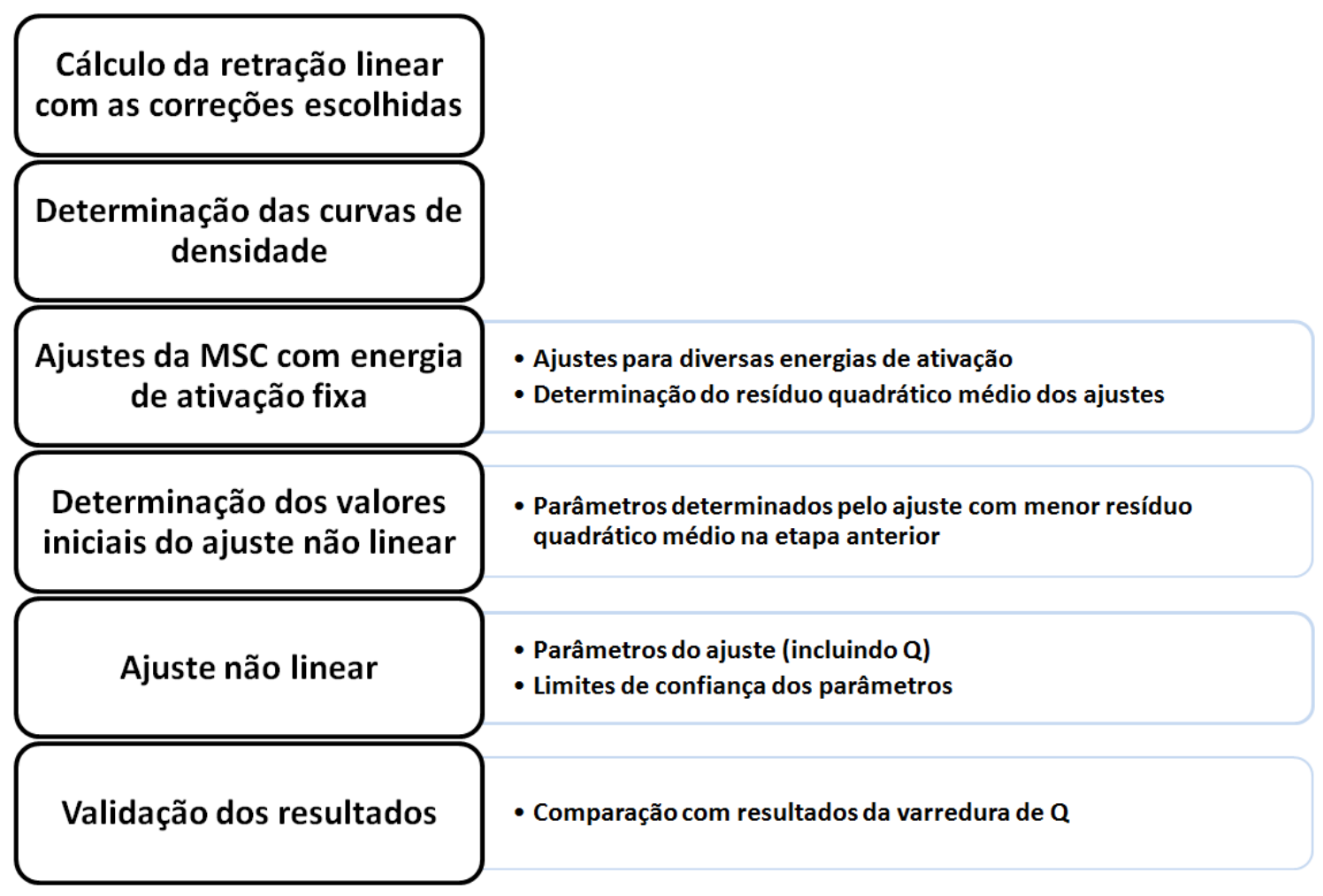

Figura 39: Esquema mostrando o algoritmo desenvolvido e utilizado para construção da curva mestre de sinterização. 
No programa duas funções podem ser utilizadas para os ajustes durante a construção da MSC, a polinomial e a sigmoidal. As equações utilizadas são mostradas em 5.11 e 5.12 .

$$
\begin{gathered}
\rho=a_{0}+\sum_{i=1}^{N_{P}} a_{i} \cdot \Theta^{i}(Q, t, T) \\
\rho=a_{0}+\frac{100-a_{0}}{\left[1+\exp \left(-\ln \Theta(Q, t, T)+a_{1}\right) / a_{2}\right]}
\end{gathered}
$$

onde $N_{P}$ é o grau do polinômio e $a_{i}$ são os parâmetros das funções adotadas. $O$ termo $\Theta(Q, t, T)$ é o trabalho da sinterização dado pela equação 5.13 .

$$
\Theta(Q, t, T)=\int_{0}^{t} \frac{1}{T} \cdot \exp \left(\frac{-Q}{R T}\right) d t
$$

Note que as variáveis independentes utilizadas no ajuste são apenas o tempo e a temperatura. A energia de ativação $Q$ é um parâmetro da função implícita $\Theta(Q, t, T)$ e é obtida no ajuste não linear.

A Figura 40 mostra a título de exemplo a curva mestre obtida para o material $10 \mathrm{~N}$ e uma das telas do programa de análise.

A validação do programa foi feita pela análise de vários conjuntos de dados e os resultados sempre comparados àqueles obtidos pelo método tradicional de varredura. Na próxima seção serão apresentados os resultados obtidos tanto pelo programa quanto pela metodologia tradicional. Os efeitos das correções propostas nos resultados da MSC serão apresentados e discutidos. 


\subsubsection{Discussão}

Nesta seção diversas correções foram propostas para eliminar interferências não aleatórias de resultados obtidos por dilatometria. Desvios expressivos em relação aos valores reais podem ocorrer para a retração linear e para a densidade quando tais correções não são aplicadas corretamente. Foi mostrado, por exemplo, que quando não corrigida a perda de massa, valores acima de $110 \%$ da densidade

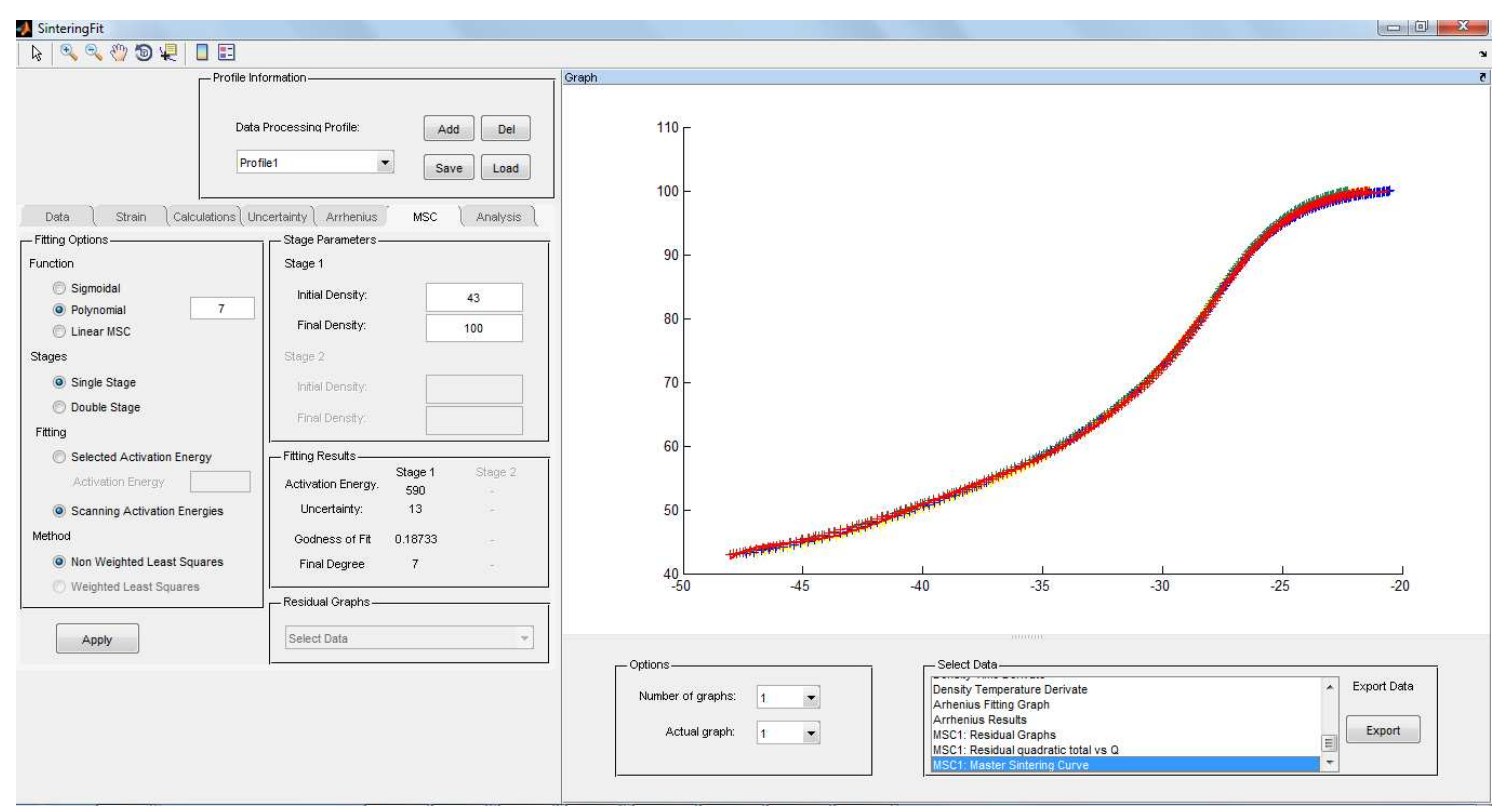

Figura 40: Tela do programa de análise de dados de dilatometria desenvolvido para construção da MSC.

teórica podem ser calculadas para o material 10N. É importante salientar que a não aplicação das correções propostas introduz erros sistemáticos que não podem ser eliminados pela análise estatística de dados.

Algumas das propostas feitas neste trabalho foram apresentadas pela primeira vez na literatura e podem ajudar na construção de uma norma procedimental para análise da sinterização por dilatometria. Todas as correções propostas foram implementadas no programa de análise para acelerar o procedimento de análise de dados. Um novo programa computacional para construção automatizada da MSC foi desenvolvido. A interface elaborada, amigável ao usuário, permite a escolha de diversas condições de análise e simplifica a análise dos resultados. 
Devido à utilização de linguagem de programação orientada a objetos novas funcionalidades poderão ser incluídas no programa futuramente. 


\subsection{DENSIFICAÇÃO}

A densificação da céria-gadolínia foi caracterizada por análises de dilatometria e densidade aparente. Curvas mestres de sinterização foram construídas para cada um dos materiais de partida quando processados conforme a descrição experimental. As diferenças na dinâmica e na cinética de sinterização foram correlacionadas aos diferentes valores de área superficial específica.

Como discutido anteriormente (Fundamentos teóricos- Revisão Bibliográfica), uma grande dispersão de valores é reportado para as energias de ativação aparente para densificação [59-73]. A fim de verificar se tal dispersão pode ser associada à metodologia no processamento de dados de dilatometria, diferentes procedimentos foram utilizados para os mesmos conjuntos de dados. A Tabela 11 sumariza as correções adotadas em cada uma das metodologias. Os efeitos das correções nos resultados são analisados. Todos os gráficos apresentados nesta seção são devidos somente ao método tomado como ideal, o M1.

Tabela 11: Descrição das correções utilizadas em cada uma das metodologias de tratamento de dados de dilatometria.

\begin{tabular}{cc}
\hline Método & Descrição \\
\hline M1 & $\begin{array}{c}\text { Todas as correções propostas (Expansão térmica do tubo e da } \\
\text { amostra, perda de massa e correção de } L_{0} \text { quando necessário) }\end{array}$ \\
M2 & Todas as correções exceto aquela devido a perda de massa \\
M3 & Apenas a correção devido a expansão térmica do tubo \\
M4 & Nenhuma correção \\
\hline
\end{tabular}

\subsubsection{Densidades relativas e retração linear}

O comportamento da densificação e da retração linear dos materiais foi estudado por medidas de densidade aparente e dilatometria. A Figura 41 mostra a retração linear em função da temperatura para compactos produzidos a partir de 
cada um dos materiais de partida. Os resultados foram obtidos por dilatometria com taxa de aquecimento constante de $10^{\circ} \mathrm{C} / \mathrm{min}$.

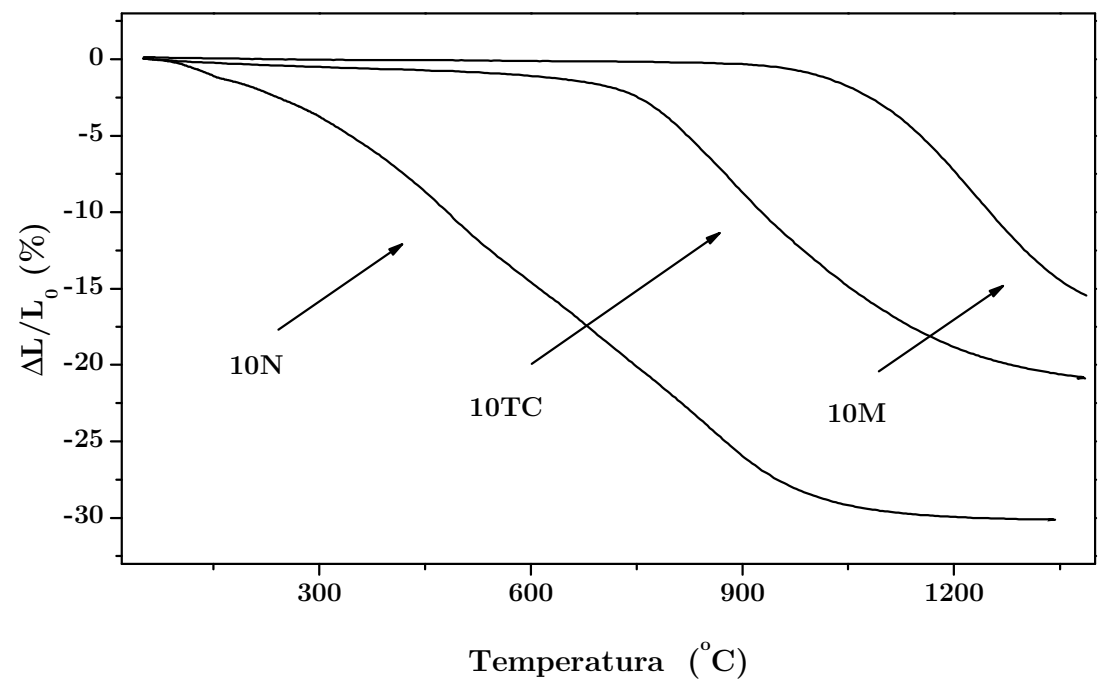

Figura 41: Retração linear em função da temperatura de análise para amostras produzidas a partir de cada um dos materiais analisados. Taxa de aquecimento constante de $10^{\circ} \mathrm{C} / \mathrm{min}$.

Quanto maior a área de superfície específica, menor as temperaturas de início da sinterização e de transição entre seus estágios. Tal comportamento já fora verificado para outros materiais e é atribuído ao aumento da tensão superficial entre as partículas [28,42]. As amostras 10TC e 10M apresentam temperaturas de início da sinterização em torno de 680 e $940^{\circ} \mathrm{C}$ respectivamente. A temperatura de início da sinterização para a amostra $10 \mathrm{~N}$ não pôde ser determinada com precisão por estas análises. Para este material, a retração inicial é dominada pela perda de massa.

Para que as curvas de retração linear possam ser convertidas em curvas de densidade aparente, a retração linear nos materiais deve ocorrer de modo isotrópico. Tal comportamento foi verificado pela aferição da retração linear de amostras sinterizadas em forno convencional. As retrações na direção radial e transversal de amostras cilíndricas foram determinadas para diversas temperaturas de sinterização. O gráfico da Figura 42 mostra os resultados. 


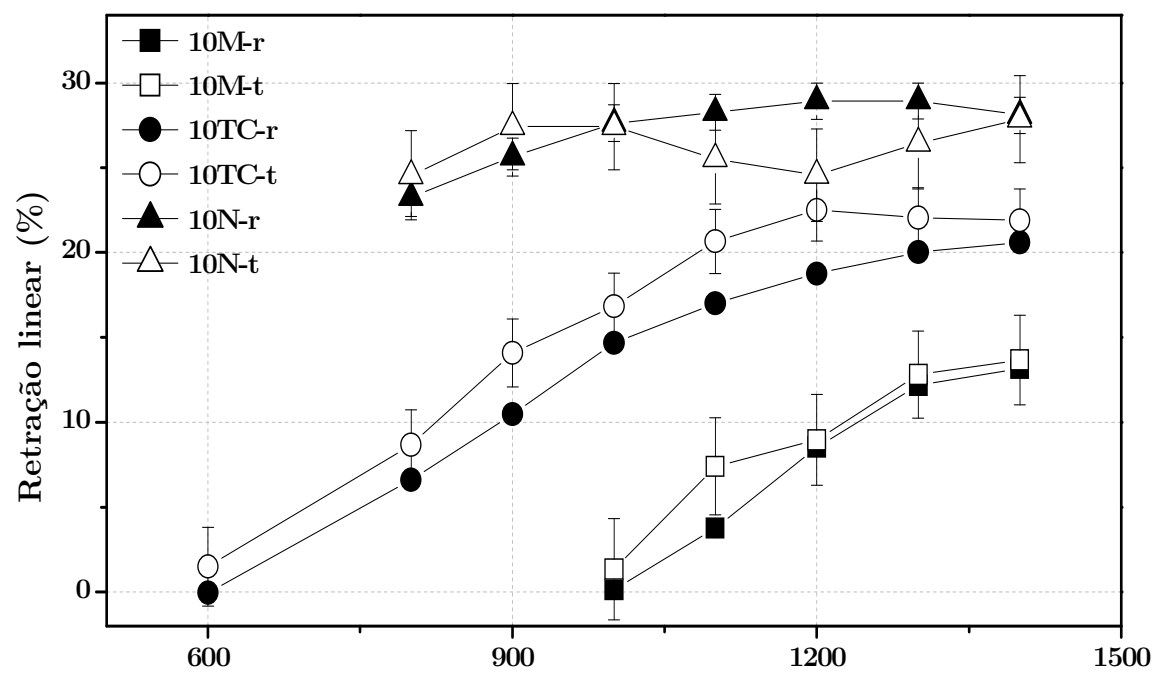

Temperatura de sinterização $\left({ }^{\circ} \mathrm{C}\right)$

Figura 42: Retração linear na direção radial -r e transversal -t de amostras cilíndricas produzidas a partir de compactos das amostras 10N, 10M e 10 TC em função da temperatura de sinterização.

Dentro das incertezas a retração linear é equivalente para a direção radial e transversal, mostrando que é isotrópica em todos os materiais. A hipótese foi verificada utilizando um teste t $\operatorname{com} \alpha=5,0 \%$.

Na Figura 43 são mostrados os dados de densidade aparente em função da temperatura de sinterização. As curvas foram determinadas pela interpolação dos resultados de dilatometria. Os dados discretos foram obtidos pela medição da densidade aparente de amostras sinterizadas em forno convencional pelo método geométrico.

Os resultados obtidos por dilatometria e pelo método geométrico concordam muito bem entre si dentro das incertezas experimentais e da reprodutibilidade dos experimentos. As densidades relativas obtidas pelo método geométrico na temperatura de $1400^{\circ} \mathrm{C}$ são estimadas em aproximadamente $97 \%$ para todos os materiais. Densidades mais elevadas provavelmente podem ser alcançadas para os materiais $10 \mathrm{M}$ e 10TC. Para o material $10 \mathrm{~N}$ esta densidade parece ser limite. 
Este limite foi atribuído à presença de microtrincas, conforme mostrado anteriormente.

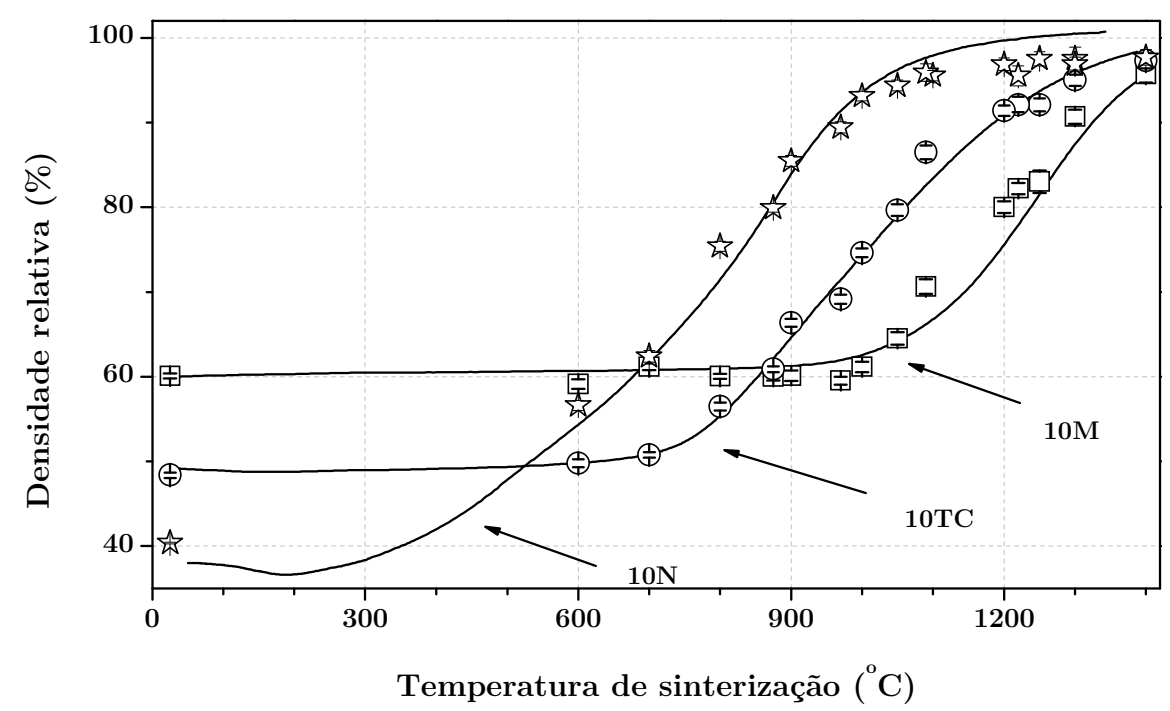

Figura 43: Densidades relativas em função da temperatura de sinterização para amostras elaboradas a partir de cada um dos materiais utilizados neste trabalho. As linhas contínuas mostram os dados interpolados obtidos por dilatometria. Os dados discretos mostram os resultados de densidade aparente determinados pelo método geométrico.

As curvas de densidade foram derivadas em relação à temperatura para a análise da taxa de densificação. Os resultados são mostrados na Figura 44. Pode-se verificar um pico de densificação para a amostra 10M, dois picos superpostos para a amostra 10TC e pelo menos três picos para a amostra 10N. As temperaturas dos picos são inferiores para os materiais com maior área de superfície específica. Para o material $10 \mathrm{M}$ a máxima taxa de retração ocorre em aproximadamente $1250^{\circ} \mathrm{C}$. Para o $10 \mathrm{TC}$ os máximos ocorrem em $920^{\circ} \mathrm{C}$ e $1050^{\circ} \mathrm{C}$. Para a amostra $10 \mathrm{~N}$ os picos ocorrem em 500,700 e $850^{\circ} \mathrm{C}$. Vários processos podem ser associados à existência de picos nas curvas de taxas de densificação, como a atuação de mecanismos de sinterização, perda de massa, presença de aglomerados, mudança de fases, entre outros $[63,134,135]$. 


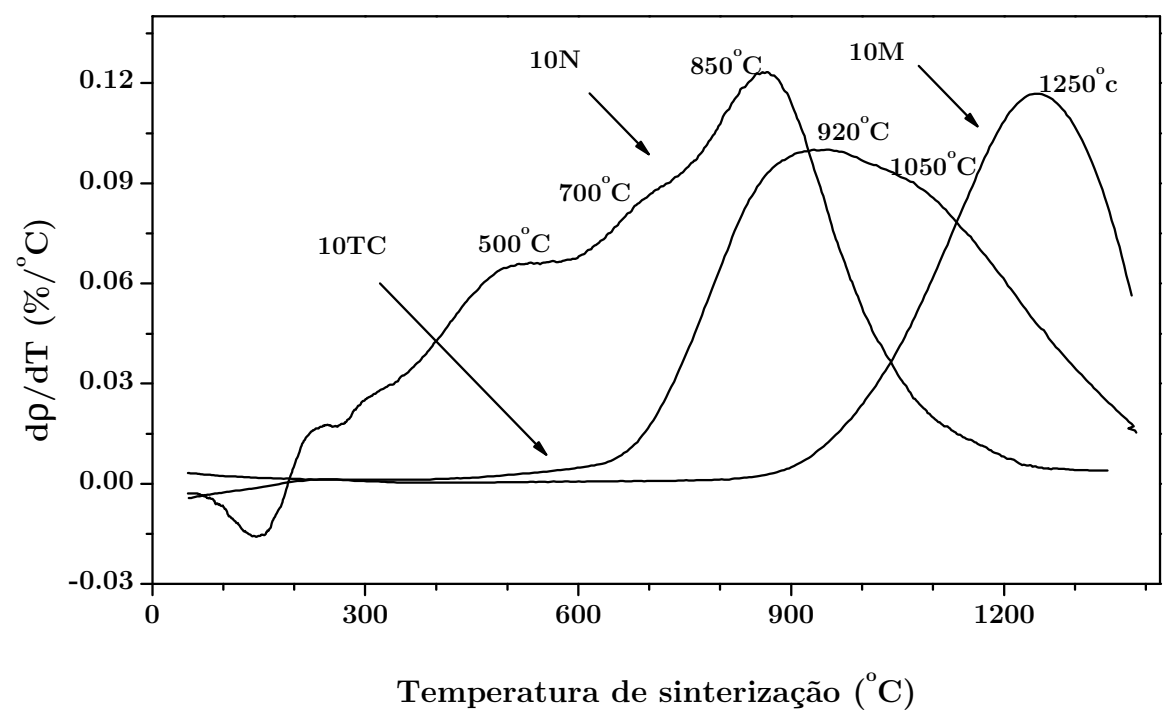

Figura 44: Taxa de variação da densidade com a temperatura em função da temperatura de sinterização para amostras 10N, 10M e 10TC. As curvas foram suavizadas utilizando o algoritmo de interpolação de Savitzky-Golay para preservar os picos das curvas.

\subsubsection{Construção da MSC para o material 10N}

O gráfico da Figura 45 mostra as curvas de densidade relativa obtidas pelo método M1 utilizando diferentes taxas de aquecimento.

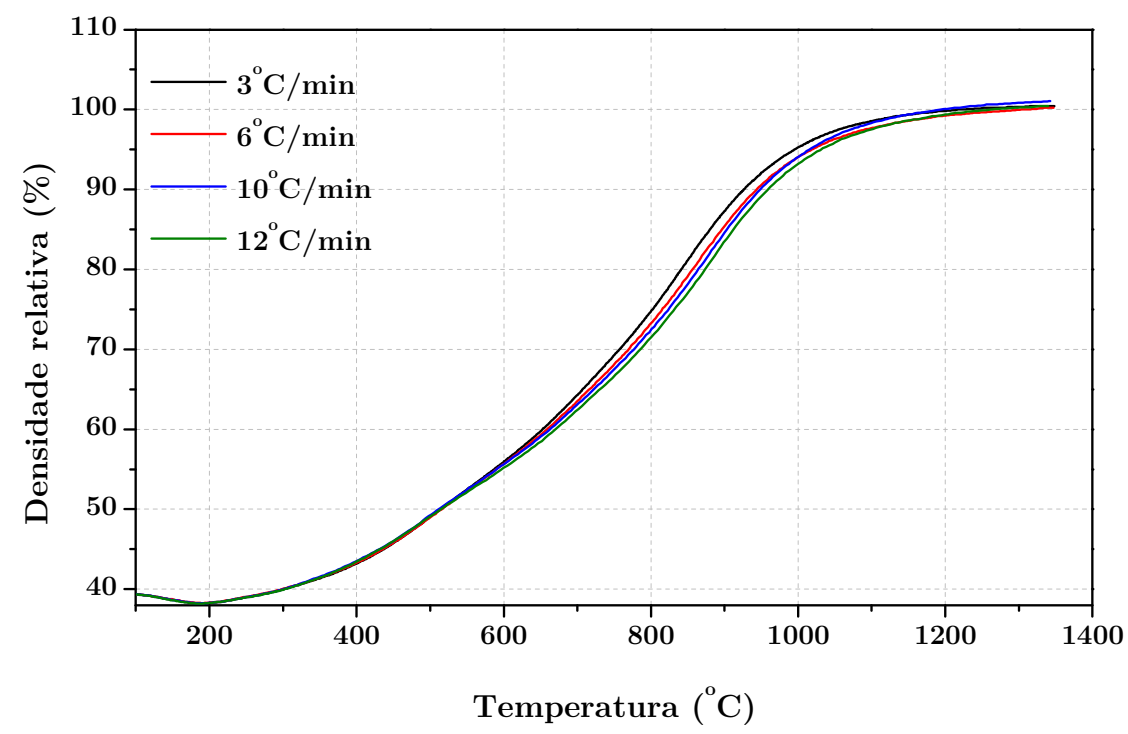

Figura 45: Densidade relativa em função da temperatura de análise. Curvas obtidas com diferentes taxas de aquecimento para amostras elaboradas a partir do material $10 \mathrm{~N}$. 
Para uma mesma temperatura de análise a densidade obtida é maior ou igual para as amostras sinterizadas com menor taxa de aquecimento. Isto ocorre porque uma quantidade maior de energia térmica é transmitida a estas amostras na mesma temperatura. Tal comportamento em relação à taxa de aquecimento tem sido verificado frequentemente na literatura $[12,60,62,63,68,70,140,141]$.

As curvas de densidade e suas derivadas foram utilizadas em análises de Arrhenius (ver Apêndice I) para determinação das energias de ativação aparente. O gráfico da Figura 46 mostra, como um exemplo, os ajustes obtidos no intervalo de densidades relativas entre 44 e $98 \%$.

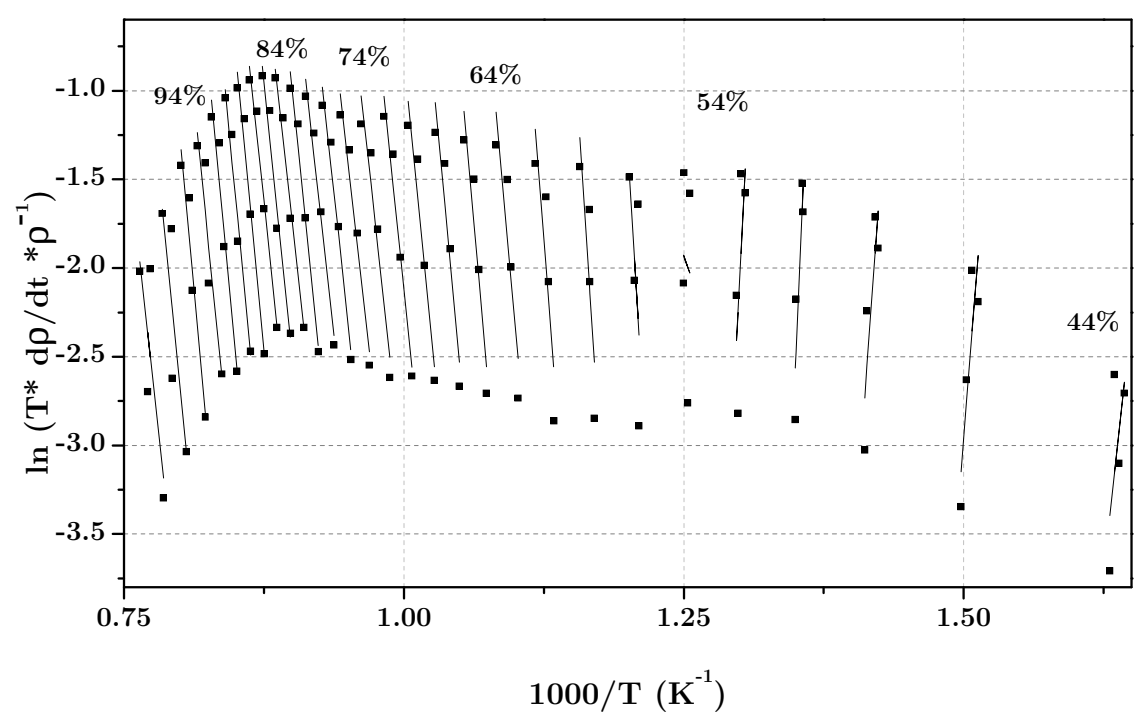

Figura 46: Gráfico de Arrhenius da densidade e ajustes lineares obtidos para o material $10 N$.

Verifica-se uma contínua mudança na inclinação dos ajustes lineares para as temperaturas de medida mais baixas. Para temperaturas mais elevadas, entretanto, as inclinações tendem a um valor médio. Por meio dos coeficientes angulares dos ajustes as energias de ativação aparentes foram determinadas. Os resultados são mostrados na Figura 47. 


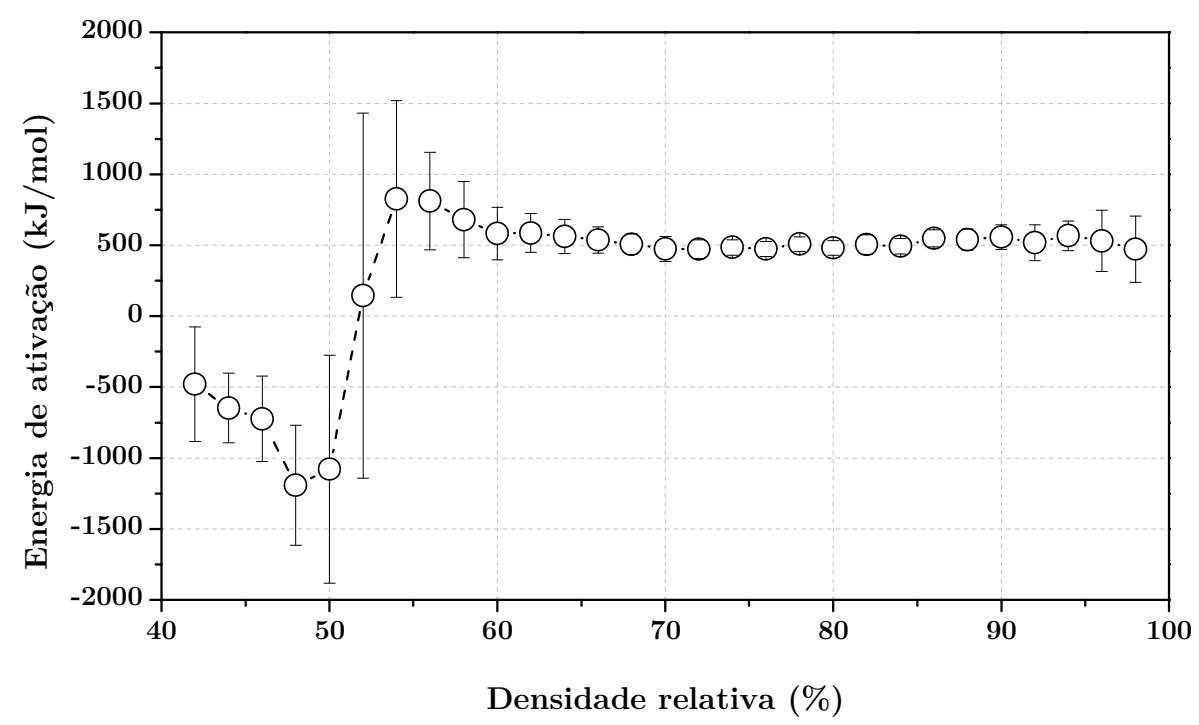

Figura 47: Energias de ativação aparentes em função da densidade relativa utilizada em sua determinação. Energias obtidas para o material 10N.

As estimativas das energias de ativação variam fortemente até aproximadamente $60 \%$ da densidade teórica. Esta variação irregular pode ser associada à perda de massa ou a presença de mais de um mecanismo de sinterização para o material $10 \mathrm{~N}$ no intervalo de temperatura. Após a densidade relativa de $60 \%$ os valores variam entre 470 e $581 \mathrm{~kJ} / \mathrm{mol}$ com média em torno de $520 \mathrm{~kJ} / \mathrm{mol}$. As energias de ativação para o intervalo de densidades estão de acordo com a ordem de grandeza verificada por outros autores para compostos a base de céria. Kinemuchi e Watari, por exemplo, construíram a MSC para céria submicrométrica $\left(65,1 \mathrm{~m}^{2} / \mathrm{g}\right)$ e obtiveram uma energia de ativação aparente de $420 \mathrm{~kJ} / \mathrm{mol}$ [63]. Jud e colaboradores verificaram energias de ativação entre 453 e $602 \mathrm{~kJ} / \mathrm{mol}$ para a densificação da $\mathrm{Ce}_{0,8} \mathrm{Gd}_{0,2} \mathrm{O}_{2-x}\left(26 \mathrm{~m}^{2} / \mathrm{g}\right)$ [82]. A discussão deste e dos demais resultados para as energias de ativação aparente serão feitas ao fim desta seção.

A curva mestre de sinterização foi construída para o material 10N utilizando a função polinomial. Embora a função sigmoidal seja utilizada com maior frequência na literatura [59, 64, 65, 67,69,70], os ajustes não foram satisfatórios com a mesma, resultando em valores do $\chi^{2}$ mais elevados. Para este material não foi verificada dependência das energias de ativação com o intervalo de dados utilizado na construção da MSC. O gráfico da Figura 48 mostra a curva mestre obtida. 


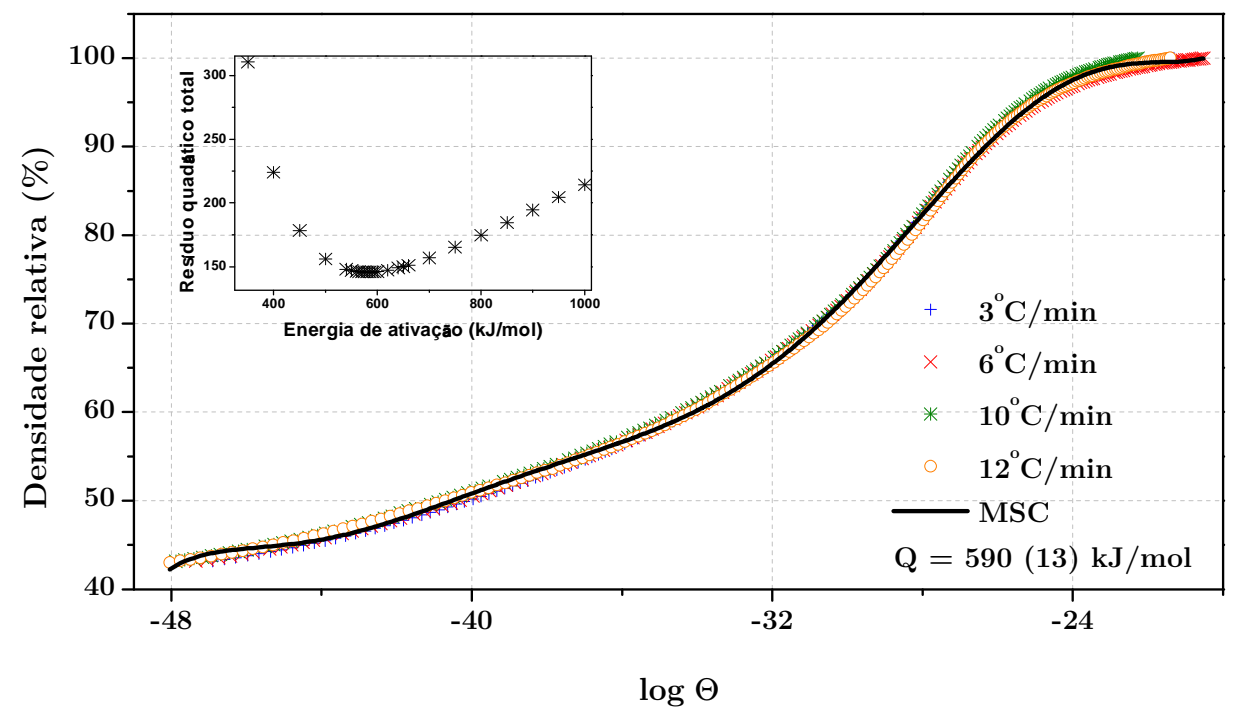

Figura 48: Curva mestre de sinterização para o material 10N. O resíduo quadrático total do ajuste em função da energia de ativação aparente é mostrado na região interna do gráfico.

As energias de ativação obtidas pela construção da MSC utilizando a metodologia tradicional (varredura com energia de ativação fixa) e a metodologia proposta concordam plenamente. A boa concordância entre os resultados mostra a validade do programa desenvolvido. A incerteza para a energia de ativação aparente é de cerca de $2,2 \%$ do valor estimado. O valor resultante é superior à energia de ativação média verificada pelo método de Arrhenius $(520 \mathrm{~kJ} / \mathrm{mol}$, Figura 47). Discrepâncias entre as estimativas obtidas pelo método de Arrhenius e pela MSC podem ser verificadas em outros trabalhos [69, 140]. Pouchly e Maca, por exemplo, analisaram a sinterização da alumina e obtiveram energia de ativação aparente de 825 e $770 \mathrm{~kJ} / \mathrm{mol}$ pelo método Arrhenius e pela MSC, respectivamente [70].

É importante ressaltar as diferenças entre os métodos. Enquanto o método de Arrhenius determina a energia de ativação aparente para um valor fixo de densidade, a curva mestre o faz para um intervalo contínuo de densidades. Ambos os métodos supõem que apenas um mecanismo de sinterização seja dominante e quando mais de um são atuantes, resultados imprevisíveis podem ser obtidos. 
O mesmo procedimento de análise foi repetido ao conjunto de dados obtido pelas metodologias M2, M3 e M4 para o material 10N. As energias de ativação obtidas são mostradas na Tabela 12.

Tabela 12: Energias de ativação obtidas pelo ajuste não linear ao conjunto de dados obtidos pelos métodos M1, M2, M3 e M4 para o material 10N.

\begin{tabular}{cc}
\hline Método & Energia de ativação $(\mathbf{k J} / \mathbf{m o l})$ \\
\hline M1 & $590(13)$ \\
M2 & $631(28)$ \\
M3 & $578(22)$ \\
M4 & $615(26)$ \\
\hline
\end{tabular}

Diferenças pouco significativas foram verificadas para as energias de ativação determinadas pelos diferentes procedimentos de análise. Os resultados sugerem que a dispersão de valores encontrada na literatura [59-73] para materiais similares não possa ser associada à metodologia de tratamento de dados. Vale ressaltar que embora as energias de ativação sejam similares, discrepâncias seriam verificadas para as densidades previstas quando utilizadas as metodologias M2, M3 e M4.

O gráfico da Figura 49 mostra a curva mestre de sinterização obtida e as densidades geométricas de amostras sinterizadas isotermicamente e com taxa de aquecimento constante.

Boa compatibilidade é verificada entre as densidades determinadas pelo método geométrico e previstas pela curva mestre de sinterização. Entretanto, valores ligeiramente superestimados são previstos pela MSC para as sinterizações isotérmicas. Su e Johnson já haviam reportado tal comportamento para as estimativas feitas pela MSC para sinterizações isotérmicas [60]. Os autores atribuíram tais discrepâncias aos efeitos da difusão superficial nestas condições [60]. 


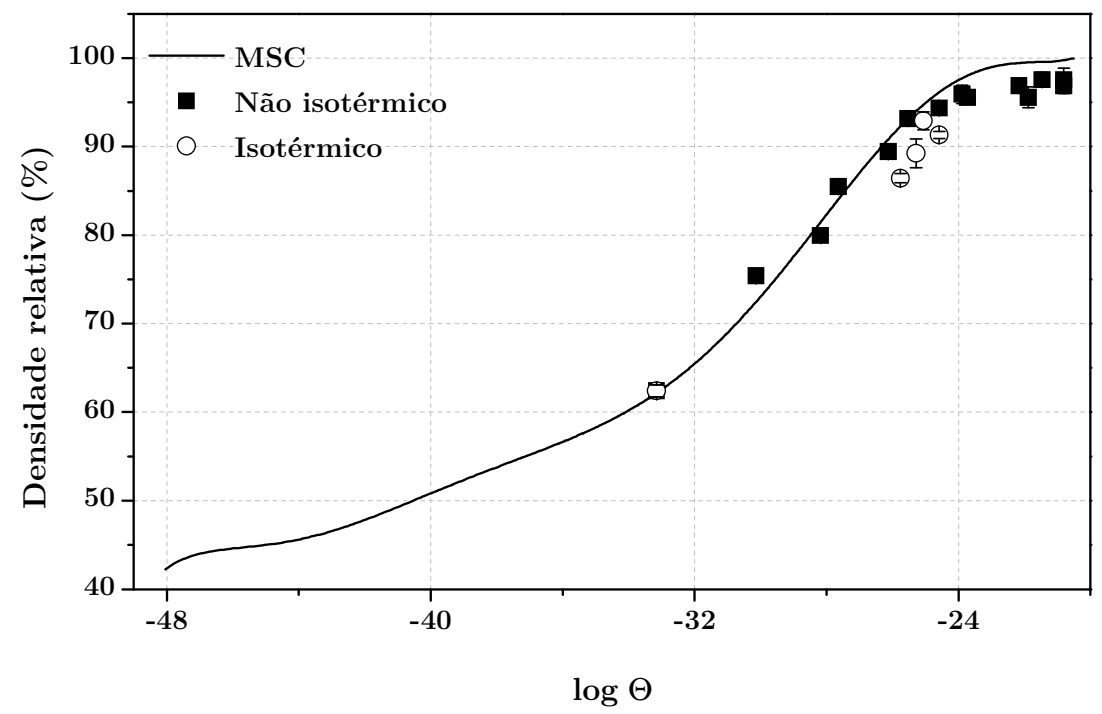

Figura 49: Curva mestre de sinterização para amostras elaboradas a partir do material 10N. Dados discretos representam densidades aparentes de amostras sinterizadadas em forno convencional e determinadas pelo método geométrico.

\subsubsection{Construção da MSC para o material 10TC}

Procedimento similar foi aplicado para construção da curva mestre de sinterização para o material 10TC. O gráfico da Figura 50 mostra as curvas de densidade relativa em função da temperatura de análise para amostras sinterizadas. As curvas foram obtidas por dilatometria com diferentes taxas de aquecimento constante.

As curvas de densidade e suas derivadas foram utilizadas em análises de Arrhenius e na construção da MSC. As energias de ativação determinadas pelo método de Arrhenius são mostradas na Figura 51.

As estimativas para as energias de ativação crescem continuamente com o aumento da densidade do material. Para valores da densidade relativa de até $60 \%$ $\left(\sim 860^{\circ} \mathrm{C}\right)$ os valores se aproximam de $440 \mathrm{~kJ} / \mathrm{mol}$. Para densidades superiores um forte crescimento é verificado até que em aproximadamente $90 \%$ da densidade teórica nova diminuição ocorre. Tal comportamento sugere que mais de um mecanismo de sinterização seja ativo durante a sinterização. As energias de ativação 
variam para o material 10TC entre 360 e $1016 \mathrm{~kJ} / \mathrm{mol}$ com valo $\mathrm{r}$ médio em torno de

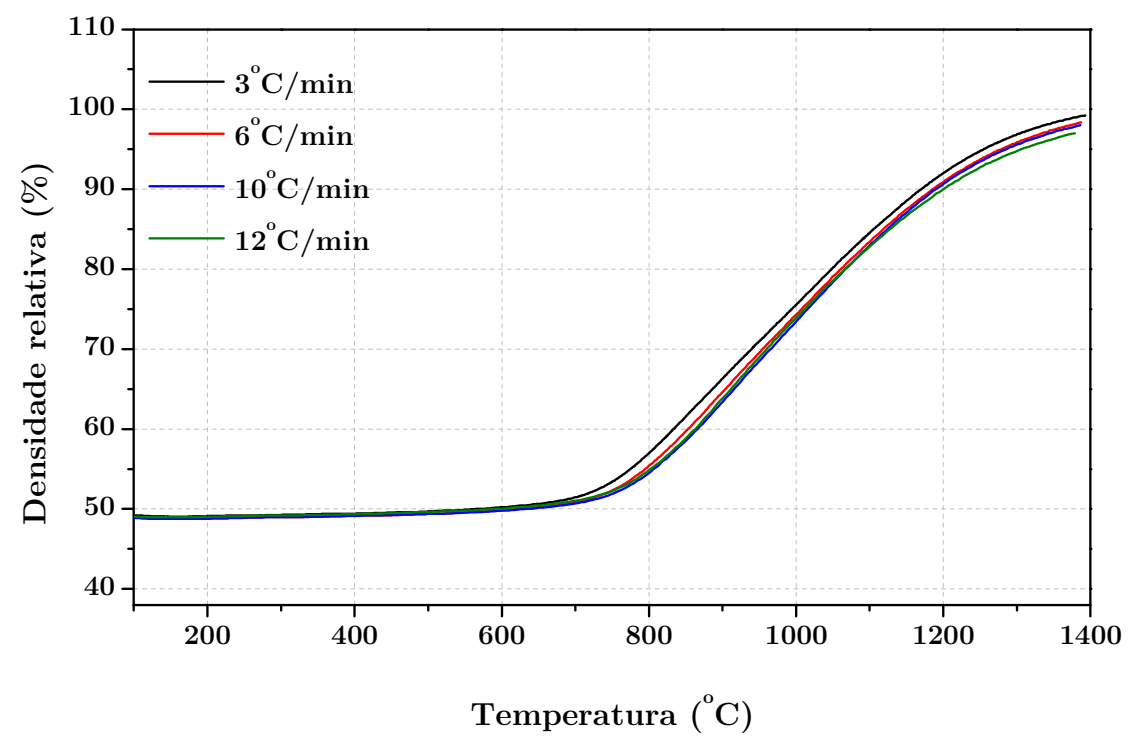

Figura 50: Densidade relativa e em função da temperatura de análise. Os dados foram obtidos pela análise de amostras elaboradas a partir do material 10TC.

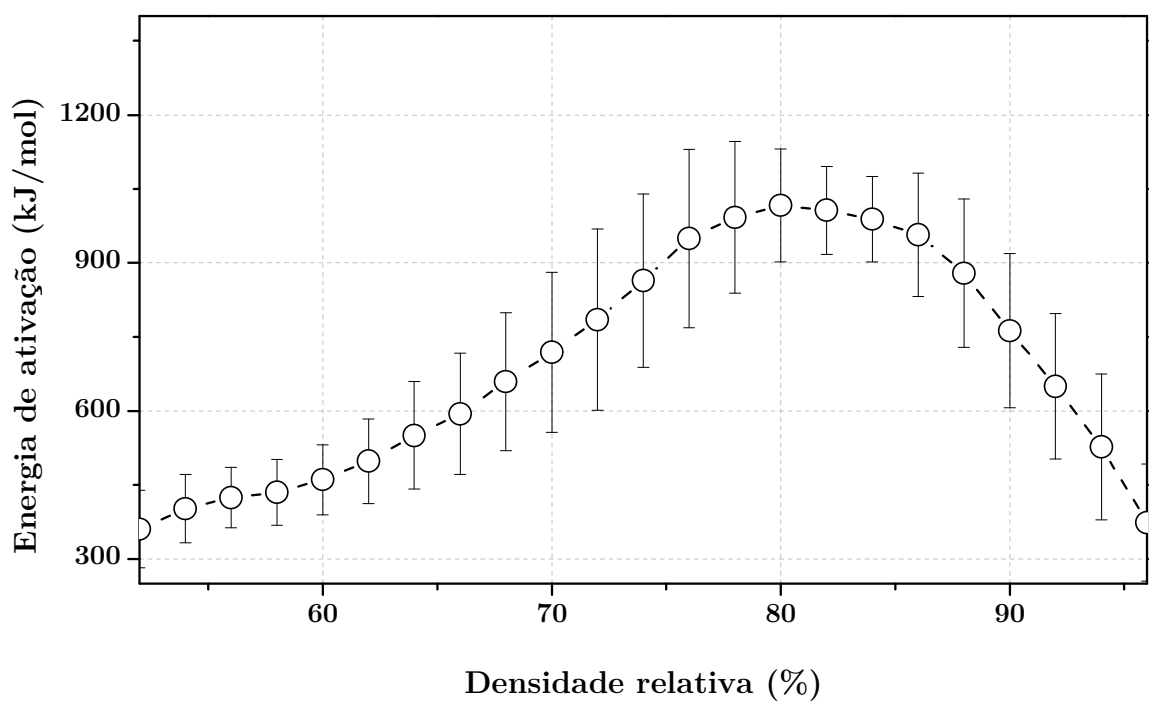

Figura 51: Energias de ativação aparente em função da densidade relativa. As energias de ativação foram obtidas pelo método de Arrhenius para o material 10TC. 
$700 \mathrm{~kJ} / \mathrm{mol}$. Variações para as energias de ativação com o desenvolvimento da sinterização foram reportadas por alguns autores [82, 142, 143]. Shao e colaboradores verificaram energias de ativação entre aproximadamente 350 e $900 \mathrm{~kJ} / \mathrm{mol}$ para a $\square-\mathrm{Al}_{2} \mathrm{O}_{3}$ com a evolução da sinterização [142]. Han, Mantas e Senos estudaram a cinética de sinterização do óxido de zinco dopado com manganês [143]. Energias de ativação entre 280 e $390 \mathrm{~kJ} / \mathrm{mol}$ foram verificadas quando o teor do dopante era de $0,1 \%$ em mol.

Curvas mestres de sinterização foram construídas utilizando os conjuntos de dados obtidos conforme as metodologias M1, M2, M3 e M4. Novamente a função polinomial mostrou-se mais adequada para o ajuste não linear e foi utilizada. $O$ gráfico da Figura 48 mostra o efeito do intervalo de dados na estimativa da energia de ativação. Ajustes foram feitos em diferentes intervalos. A densidade relativa inicial foi mantida fixa em $50 \%$. A densidade relativa final foi variada e as energias de ativação computadas para cada intervalo de análise. O gráfico da Figura 52 mostra os resultados das energias de ativação em função da densidade final do intervalo de dados.

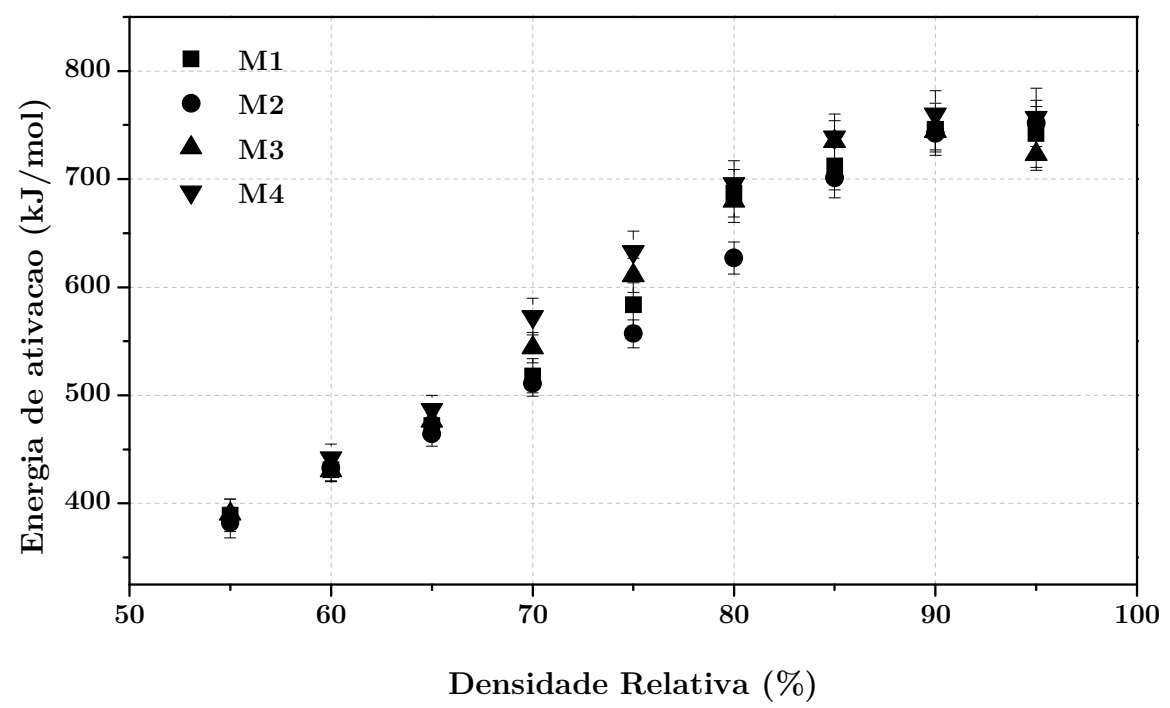

Figura 52: Energias de ativação estimadas em função da densidade relativa final utilizada para composição do intervalo de dados. A densidade inicial foi mantida fixa em $50 \%$ da densidade teórica. Resultados obtidos para o material $10 T C$. 
Comportamento similar àquele verificado pelo método de Arrhenius é verificado para os resultados da curva mestre. As estimativas para as energias de ativação aumentam continuamente com o desenvolvimento da sinterização. A dependência da estimativa para a energia de ativação aparente com o intervalo de densidades já havia sido reportado para outros materiais utilizando o conceito da MSC [63,65]. Song e coautores [65] reportaram estimativas entre 580 e $730 \mathrm{~kJ} / \mathrm{mol}$ para as energias de ativação da alumina. Os valores foram obtidos pela utilização de diferentes intervalos de densidades.

Novamente não foram verificadas diferenças expressivas para as energias de ativação obtidas segundo as metodologias M1, M2, M3 e M4 (Figura 52).

Mesmo supondo a atuação de mais de um mecanismo de sinterização a curva mestre foi construída utilizando todo o intervalo de dados. Os resultados são mostrados na Figura 53.

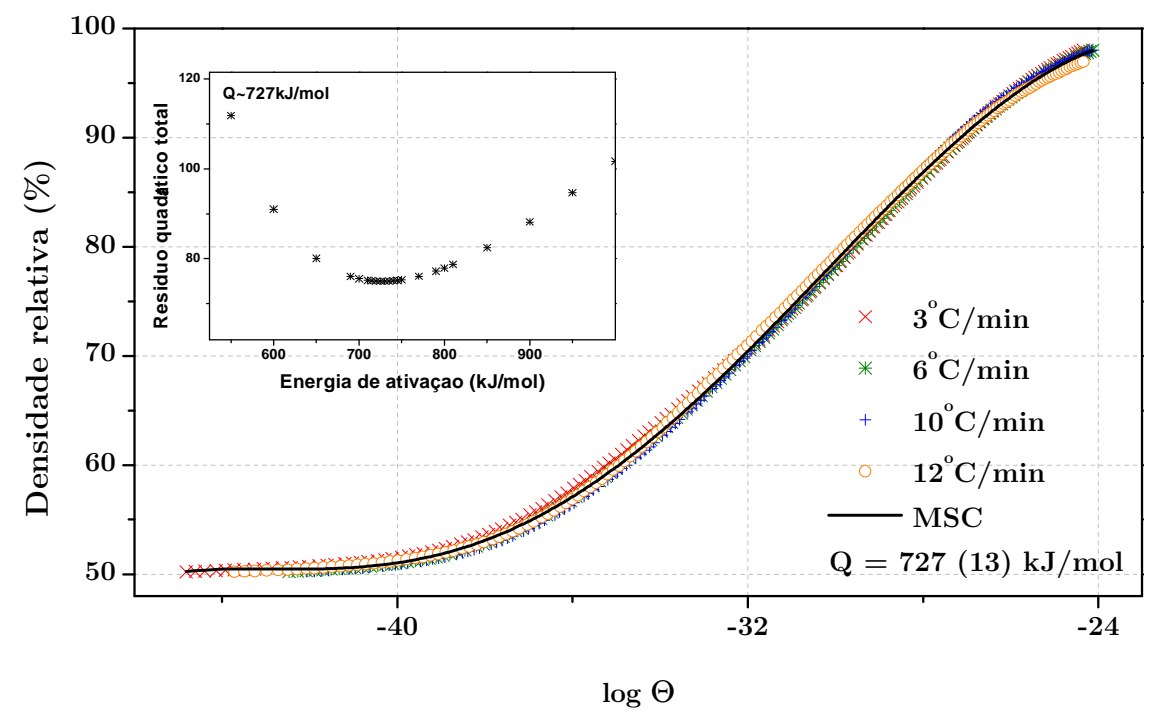

Figura 53: Curva mestre de sinterização para o material 10TC. O resíduo quadrático total do ajuste em função da energia de ativação aparente é mostrado na região interna do gráfico.

Novamente se verifica clara concordância entre a energia de ativação obtida com o programa de análise desenvolvido e através da metodologia de varredura da energia de ativação. A energia de ativação aparente determinada pela construção da MSC para o material 10TC é de $727 \pm 13 \mathrm{~kJ} / \mathrm{mol}$. Este valor é compatível 
com o resultado médio obtido pelo método de Arrhenius $(\sim 700 \mathrm{~kJ} / \mathrm{mol})$ e com aquele obtido por Zhang e colaboradores para a céria [93], $731 \pm 61 \mathrm{~kJ} / \mathrm{mol}$.

Com base na curva mestre, densidades podem ser previstas para qualquer perfil de tempo e temperatura. A Figura 54 mostra as densidades previstas pela curva mestre e as densidades determinadas pelo método geométrico para amostras sinterizadas isotérmica e não isotermicamente.

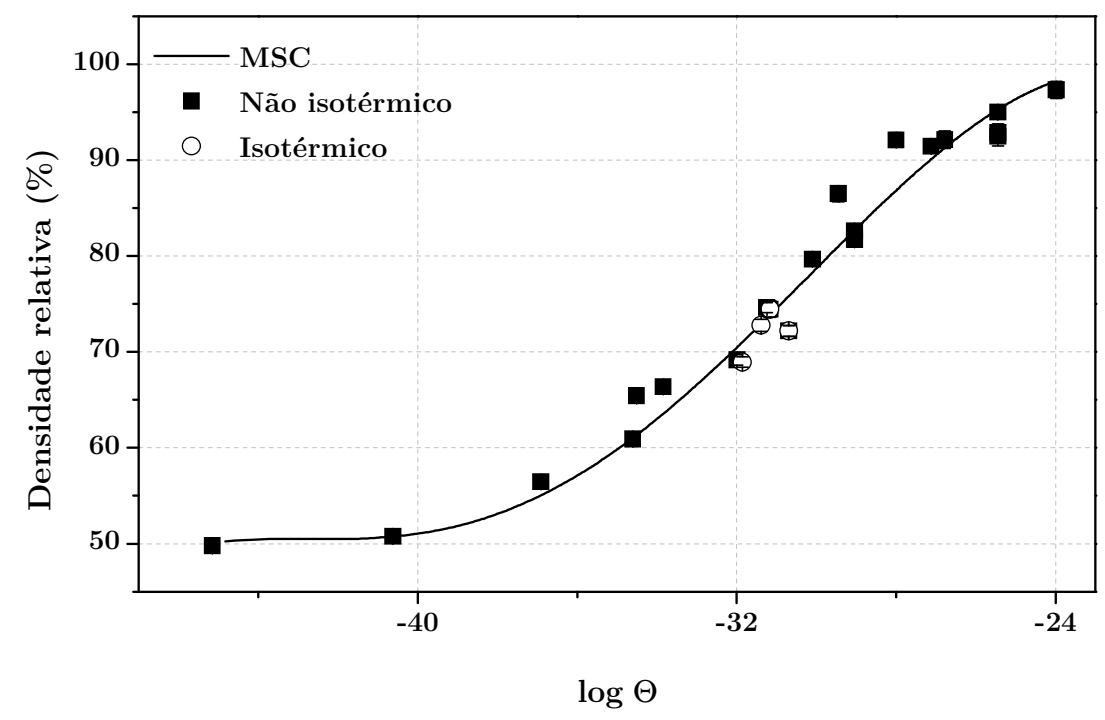

Figura 54: Curva mestre de sinterização para amostras elaboradas a partir do material 10TC. Dados discretos representam densidades aparentes de amostras sinterizadadas em forno convencional e determinadas pelo método geométrico.

Novamente muito boa compatibilidade é verificada entre os valores previstos pela curva mestre e entre os resultados de densidade aparente. Apesar da variação da energia de ativação ao longo da interização, a curva mestre ainda continua sendo uma útil ferramenta para previsão das densidades obtidas para o material 10TC.

\subsubsection{Construção da curva mestre para a 10M}

O mesmo procedimento já mostrado anteriormente foi adotado para construção da curva mestre do material $10 \mathrm{M}$. Inicialmente curvas de densidade relativa em função da temperatura foram obtidas utilizando diferentes taxas de aqueci- 
mento. Neste caso as análises foram repetidas para cada taxa de aquecimento a fim de garantir a qualidade dos dados. A Figura 55 mostra as curvas de densidade em função do tempo de análise. Excelente repetibilidade dos dados pode ser verificada.

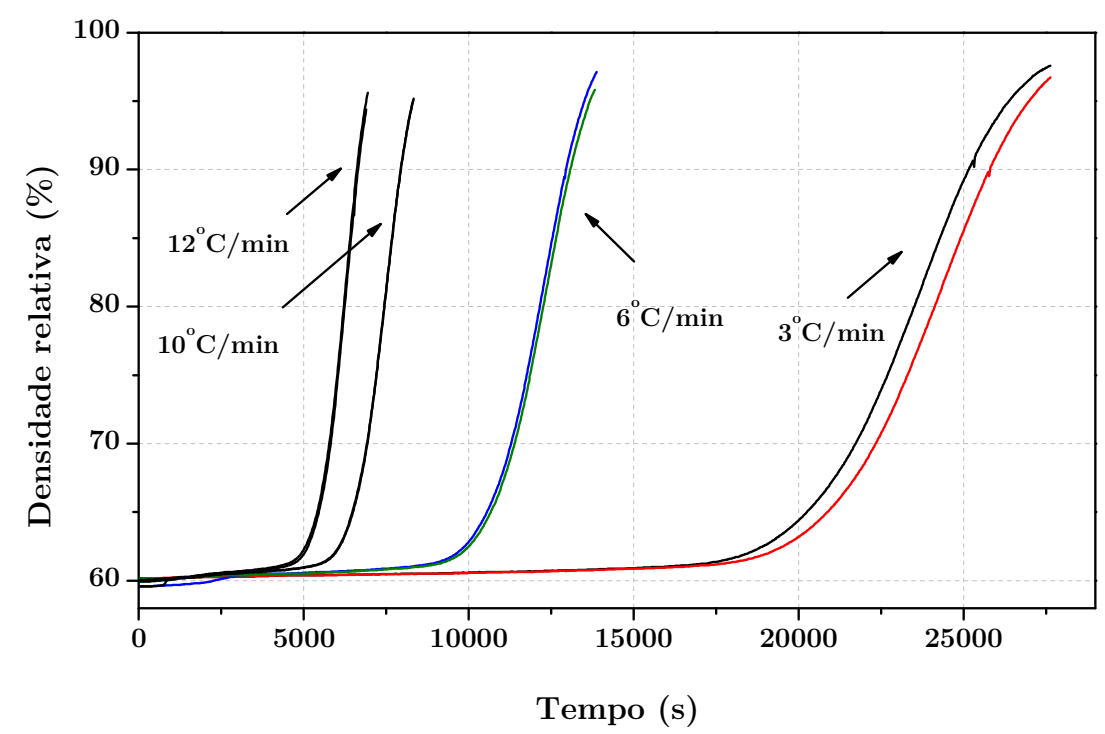

Figura 55: Densidade relativa em função do tempo de análise para amostras sinterizadas com diferentes taxas de aquecimento. A temperatura inicial de todas as análises é de aproximadamente $25^{\circ} \mathrm{C}$.

Os resultados foram utilizados inicialmente em análises de Arrhenius para verificação do comportamento das energias de ativação aparente em função da densidade. Os resultados são mostrados na Figura 56.

A energia de ativação aparente cresce continuamente com o aumento da densidade do material $10 \mathrm{M}$, embora o crescimento seja menos pronunciado que no caso do material 10TC. O valor médio para energia de ativação aparente no intervalo de 64 a $88 \%$ da densidade teórica é de $890 \mathrm{~kJ} / \mathrm{mol}$. O resultado é maior do que aqueles determinados para os materiais $10 \mathrm{~N}$ e 10TC, porém, as energias de ativação estão dentro do intervalo de valores verificado para outros materiais cerâmcos. Pouchly, Maca e Shen, por exemplo, determinaram uma energia de ativação aparente de $1270 \mathrm{~kJ} / \mathrm{mol}$ para zircônia contendo $3 \% \mathrm{em} \mathrm{mol}$ de ítria [70]. De Florio e colaboradores, por outro lado, obtiveram uma energia de ativação de $265 \mathrm{~kJ} / \mathrm{mol}$ para a céria contendo $10 \%$ em de gadolínia $\left(\mathrm{GdO}_{1,5}\right)$ [64]. 


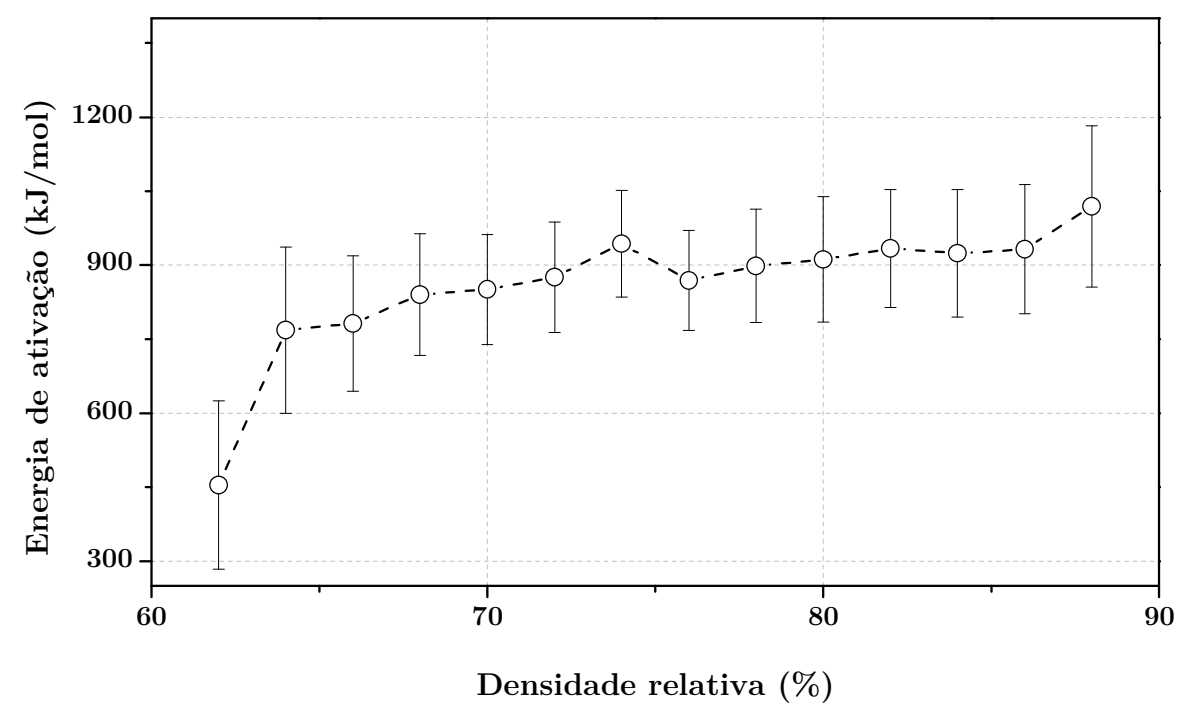

Figura 56: Energias de ativação aparente estimadas pelo método de Arrhenius. Resultados obtidos para amostras elaboradas a partir do material 10M.

Curvas mestres de sinterização foram construídas para os conjuntos de dados calculados obtidos pelas metodologias M1, M2, M3 e M4. Ajustes um pouco melhores foram verificados pela utilização de funções polinomiais em relação à utilização de funções sigmoidais. A Figura 57 mostra o resíduo quadrático médio dos ajustes com energia de ativação fixa e a curva mestre de sinterização construída pelo ajuste não linear para o material 10M.

A incerteza determinada para a energia de ativação é da ordem de $1 \%$ do valor da estimativa. Não foi verificada dependência significativa para a energia de ativação aparente com o intervalo de dados para o material 10M. Claramente é notada a compatibilidade entre os resultados obtidos pelo ajuste não linear e pelo metodologia tradicional de construção da MSC. A energia de ativação obtida pela MSC para o material $10 \mathrm{M}(1002 \mathrm{~kJ} / \mathrm{mol})$ é, assim como para o material $10 \mathrm{~N}$, maior do que a energia de ativação aparente média obtida pelo método de Arrhenius $(890 \mathrm{~kJ} / \mathrm{mol}$, Figura 56$)$. 


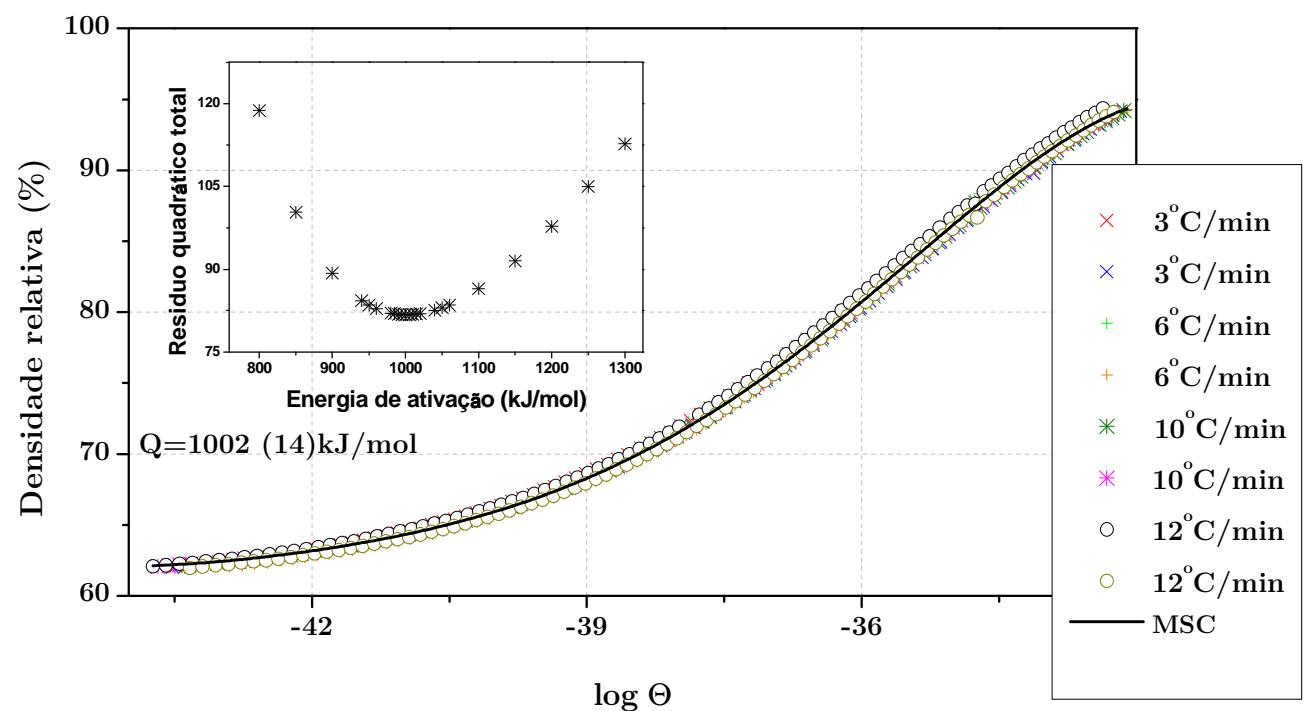

Figura 57: Curva mestre de sinterização para o material 10M. O resíduo quadrático total do ajuste em função da energia de ativação aparente é mostrado na região interna do gráfico.

A curva mestre de sinterização foi comparada aos resultados de densidade aparente de amostras sinterizadas em forno convencional. Os resultados são mostrados na Figura 58.

Os resultados confirmam a possibilidade da utilização da curva mestre para previsão da densificação durante a sinterização de amostras elaboradas a partir do material $10 \mathrm{M}$. 


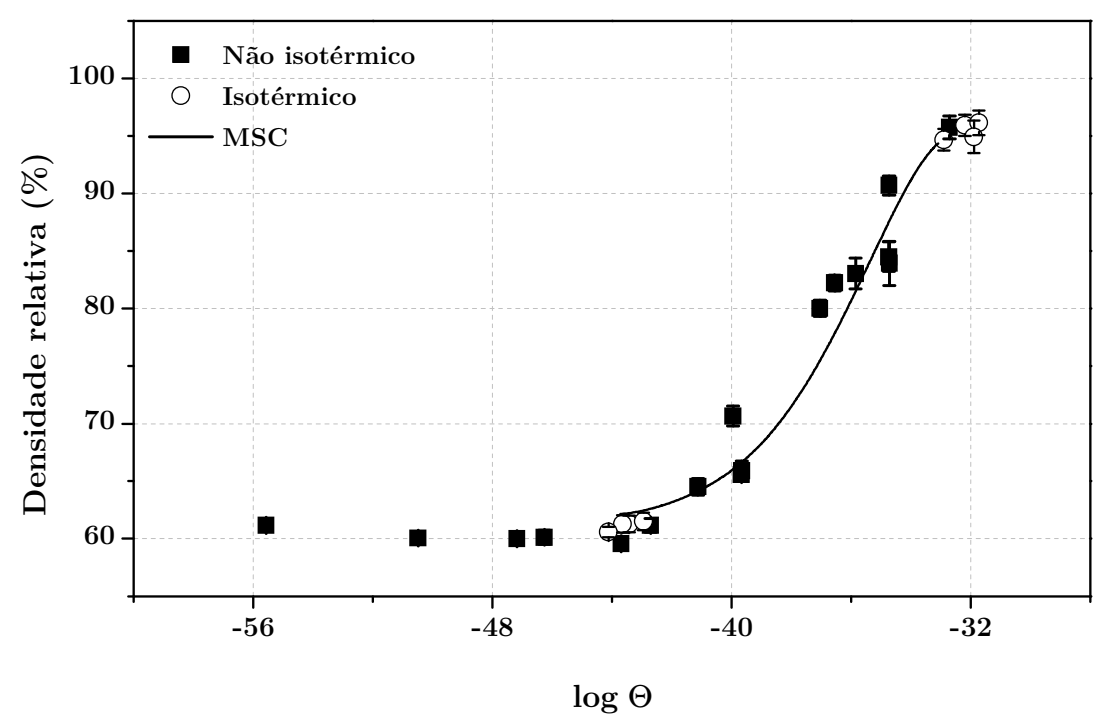

Figura 58: Curva mestre de sinterização para amostras elaboradas a partir do material 10M. Dados discretos representam densidades aparentes de amostras sinterizadadas em forno convencional e determinadas pelo método geométrico.

\subsubsection{Discussão}

Energias de ativação significativamente diferentes foram determinadas para cada um dos materiais analisados neste trabalho utilizando o conceito da MSC. As energias de ativação determinadas foram $590 \pm 13 \mathrm{~kJ} / \mathrm{mol}, 727 \pm 13 \mathrm{~kJ} / \mathrm{mol}$ e $1002 \pm 14 \mathrm{~kJ} / \mathrm{mol}$ para os materiais $10 \mathrm{~N}, 10 \mathrm{TC}$ e $10 \mathrm{M}$, respectivamente. Tais discrepâncias não podem ser associadas à composição dos materiais ou teores de impurezas. Os resultados de fluorescência mostraram que dentro das incertezas, proporções essencialmente idênticas entre céria e gadolínia são encontradas. Além disso, os teores e tipos de impurezas são similares. De forma geral também foi verificado que a estimativa para a energia de ativação utilizando o conceito da MSC não é afetada de forma relevante por correções como a expansão térmica da amostra ou perda de massa. Os resultados indicam, portanto, que mais de um mecanismo de sinterização atue durante a sinterização da céria gadolínia. A associação destes resultados com a energia de ativação para um único mecanismo de sinterização é indevida.

Mais do que isso, como foi discutido ao longo da apresentação de resultados desta seção, uma grande dispersão de valores é encontrada na literatura. 
Diversos pesquisadores têm se dedicado a tarefa de identificar os mecanismos de sinterização dominantes utilizando o conceito da MSC ou os métodos de Arrhenius e derivados. Entretanto, o que os resultados mostram é que, com exceção de casos específicos, tais informações não podem ser obtidas por estas análises. Até que o motivo para a verificação de tal dispersão de valores seja conhecido, interpretações físicas devem ser tomadas com maior cautela. Algumas das possíveis causas para esta dispersão incluem: efeitos de heterogeneidades nas amostras à verde, acoplamento de mecanismos de sinterização, ou desvios da condição de que os tamanhos de grãos são apenas funções da densidade.

Embora para este trabalho as energias de ativação não possam ser associadas a um mecanismo de sinterização específico, os resultados mostraram a validade da MSC para previsão do comportamento de densificação dos materiais. As energias de ativação aparente mostraram-se maiores para os materiais com maior tamanho inicial de partícula, sendo tal comportamento compatível com as curvas de densidade. Quanto maior os tamanhos iniciais de partícula, maior a temperatura inicial de sinterização do material.

Os resultados obtidos para a MSC mostraram-se dependentes com a função utilizada para sua construção. No caso da céria-gadolínia a função que meIhor se aderiu aos dados foi a polinomial. Embora a função sigmoidal seja utilizada com frequência na literatura, esta não se mostrou adequada neste trabalho. Novas funções têm sido propostas na literatura [66,67], mas estudos adicionais devem ser realizados para garantir sua aplicabilidade. A determinação de uma função adequada e o significado físico dos seus parâmetros pode vir a ser outro possível campo de investigação no tema.

Juntamente com a curva mestre de sinterização, as análises de Arrhenius se mostraram úteis na interpretação dos resultados das energias de ativação aparente. Como foi mostrado, os resultados de ambos os métodos são relativamente convergentes, reforçando a validade de alguns dos conceitos aplicados. 


\subsection{EVOLUÇÃO MICROESTRUTURAL}

Nesta seção serão apresentados os resultados relativos à evolução microestrutural de amostras elaboradas para cada um dos materiais de partida.

\subsubsection{Crescimento do tamanho médio de cristalito}

A técnica de difração de raios $X$ foi utilizada para estudar a evolução dos tamanhos de cristalito durante a sinterização. Os métodos de análise utilizados foram o refinamento Rietveld e o WPPM. O gráfico da Figura 59 mostra os tamanhos médios de cristalitos obtidos pelo refinamento Rietveld.

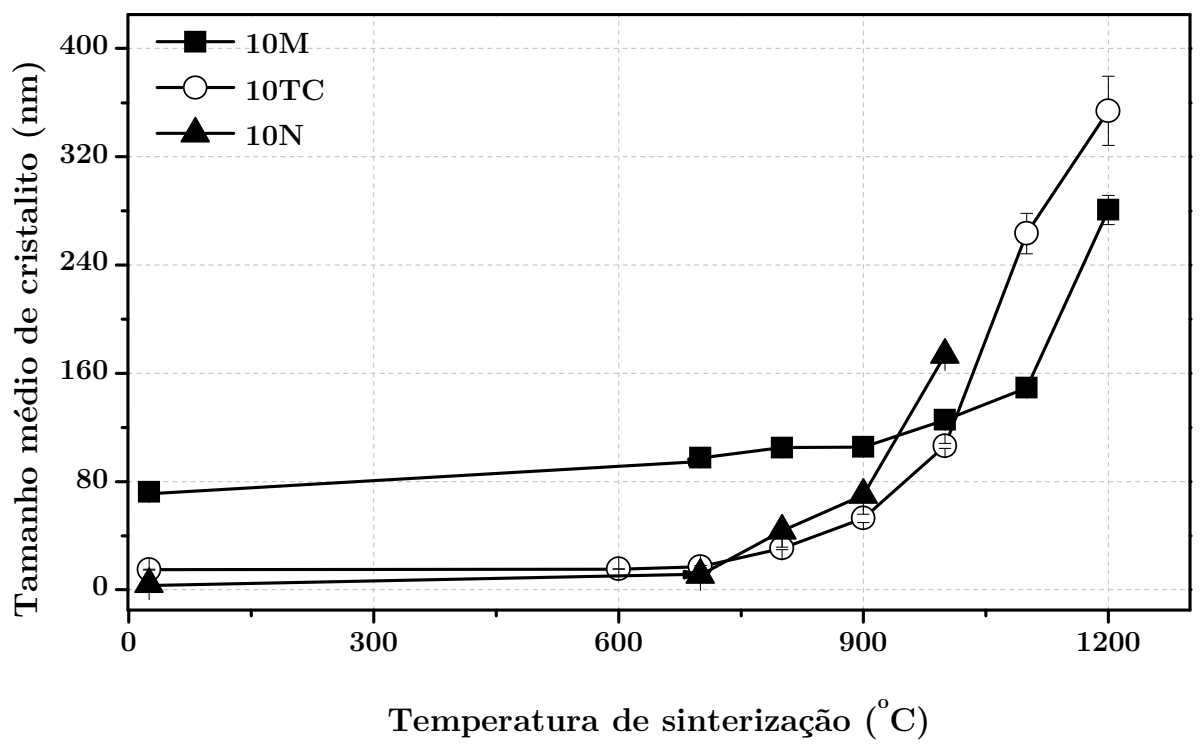

Figura 59: Tamanho de cristalito em função da temperatura de sinterização para as amostras sinterizadas por tempo nulo na temperatura de patamar.

Os resultados confirmam que a temperatura de início de sinterização é menor para os materiais com menor tamanho inicial de partículas. Para as amostras $10 \mathrm{~N}$ e $10 \mathrm{TC}$ a sinterização se inicia em aproximadamente $700^{\circ} \mathrm{C}$. Para a amostra $10 \mathrm{M}$ a sinterização se inicia de modo significativo em aproximadamente $900^{\circ} \mathrm{C}$. 
Tais resultados são compatíveis com as curvas das taxas de retração obtidas por dilatometria (Figura 43).

O crescimento de cristalito para todos os materiais pode ser dividido em dois estágios no intervalo de temperaturas analisado. O primeiro estágio apresenta um crescimento pouco significativo e ocorre em menores temperaturas. O segundo estágio apresenta um rápido crescimento e ocorre em temperaturas mais altas. $\mathrm{O}$ crescimento acelerado para os materiais com menor tamanho inicial de cristalito é notável. Uma inversão nos tamanhos de cristalito é verificada para temperaturas de aproximadamente $1000^{\circ} \mathrm{C}$. Tal comportamento foi associado à diminuição da temperatura de transição entre estes os estágios citados. Os resultados verificados estão de acordo com outros reportados na literatura, tanto para metais como para cerâmicos [51, 58, 144-146].

\subsubsection{Evolução das distribuições de tamanho de cristalito}

A evolução da forma da distribuição de tamanho de cristalito foi investigada para os materiais $10 \mathrm{~N}$ e 10TC. Tais resultados não foram obtidos para o material $10 \mathrm{M}$ devido ao tamanho inicial de cristalito do material. Ajustes com boa exatidão não foram obtidos para tamanhos médios de cristalito acima de $70 \mathrm{~nm}$ quando utilizado o método WPPM. O gráfico da Figura 60 mostra os resultados obtidos. Uma distribuição log normal de cristalitos esféricos foi considerada em todas as análises. Embora tal hipótese não seja verdadeira durante toda sinterização, informações relevantes ainda podem ser obtidas pelo método.

Um contínuo alargamento das distribuições de tamanhos de cristalito é verificado com o aumento da temperatura de sinterização. O alargamento da distribuição é acompanhado pelo crescimento do tamanho médio e pela eliminação dos menores cristalitos. O resultado é compatível com o esperado para o crescimento normal de grãos, onde os maiores grãos crescem em detrimento dos menores $[7,42]$.

É importante notar que embora as distribuições apresentem contínuo aumento da dispersão absoluta, a dispersão relativa $(\sigma D /<D>)$ diminui com 0 aumento da temperatura de sinterização. O comportamento da dispersão relativa para as distribuições de tamanhos de grãos/cristaitos parece não ter sido reporta- 
do na literatura para sinterizações não isotérmicas. Alguns trabalhos similares utilizando o método WPPM analisaram o comportamento de materiais particulados sujeitos a

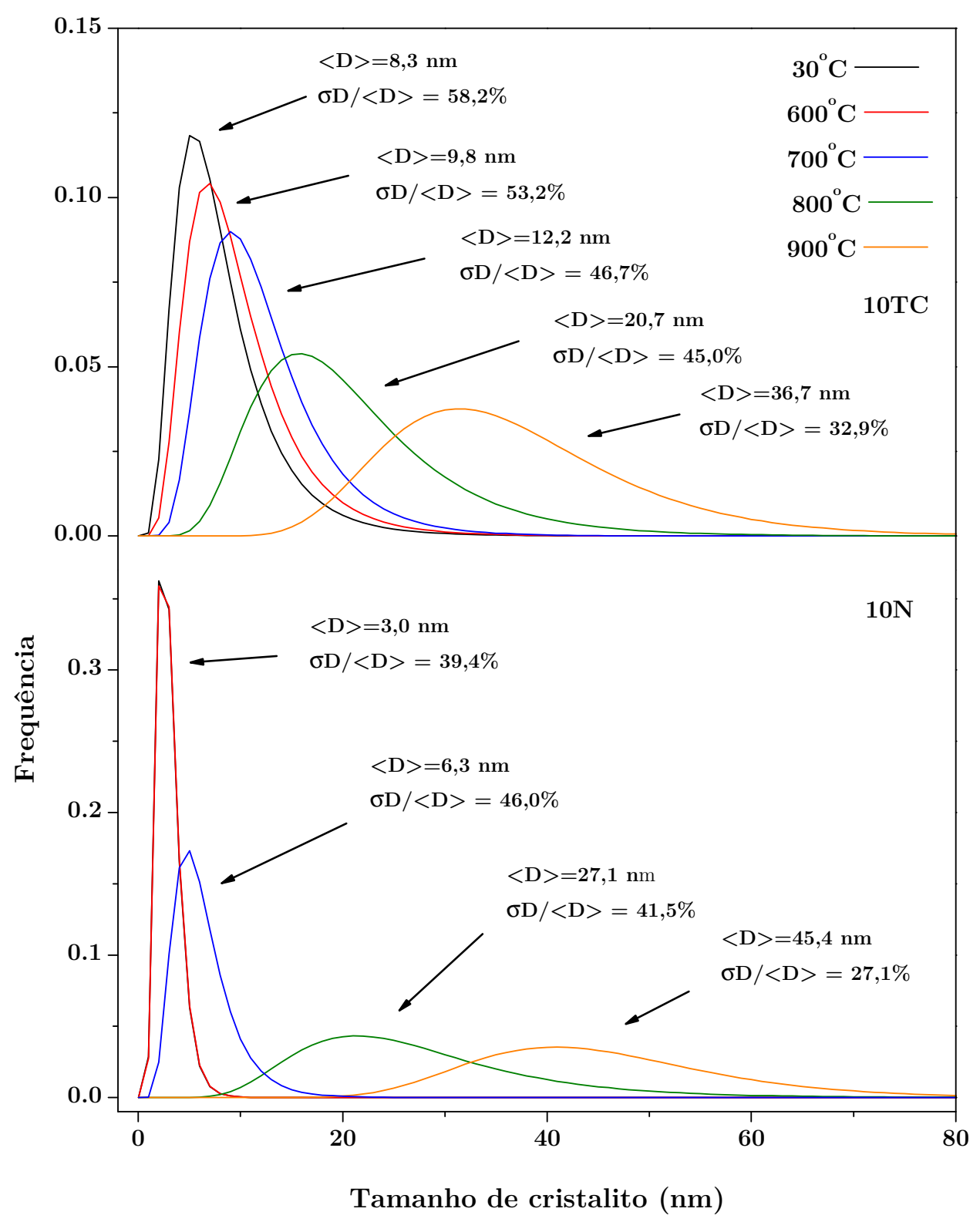

Figura 60: Evolução das distribuições de tamanhos de cristalito com o aumento da temperatura de sinterização para os materiais $10 \mathrm{~N}$ e 10TC. Resultados obtidos supondo uma distribuição lognormal de cristalitos esféricos. 
calcinações, envelhecimento térmico ou moagem, mas não para sinterizações não isotérmicas [112,147, 148]. Alguns trabalhos mostram, por meio de simulações numéricas, que as dispersões relativas aumentam durante sinterizações isotérmicas. Os autores associam o aumento da dispersão relativa à diminuição da taxa de densificação com a evolução da sinterização. Neste trabalho, no entanto, foi mostrado que as taxas de densificação crescem continuamente até a temperatura de $850^{\circ} \mathrm{C}$ (Figura 44). Outros estudos são necessários para interpretação deste comportamento, mas os resultados sugerem que novas informações relevantes possam ser obtidas a partir destes resultados indicando diferenças entre a cinética de sinterizações iso e não isotérmicas.

\subsubsection{Curvas de trajetória para crescimento de cristalito}

As curvas de trajetória para crescimento de cristalito foram construídas para cada um dos materiais utilizando os resultados obtidos pelo refinamento Rietveld. As curvas são mostradas na Figura 61.

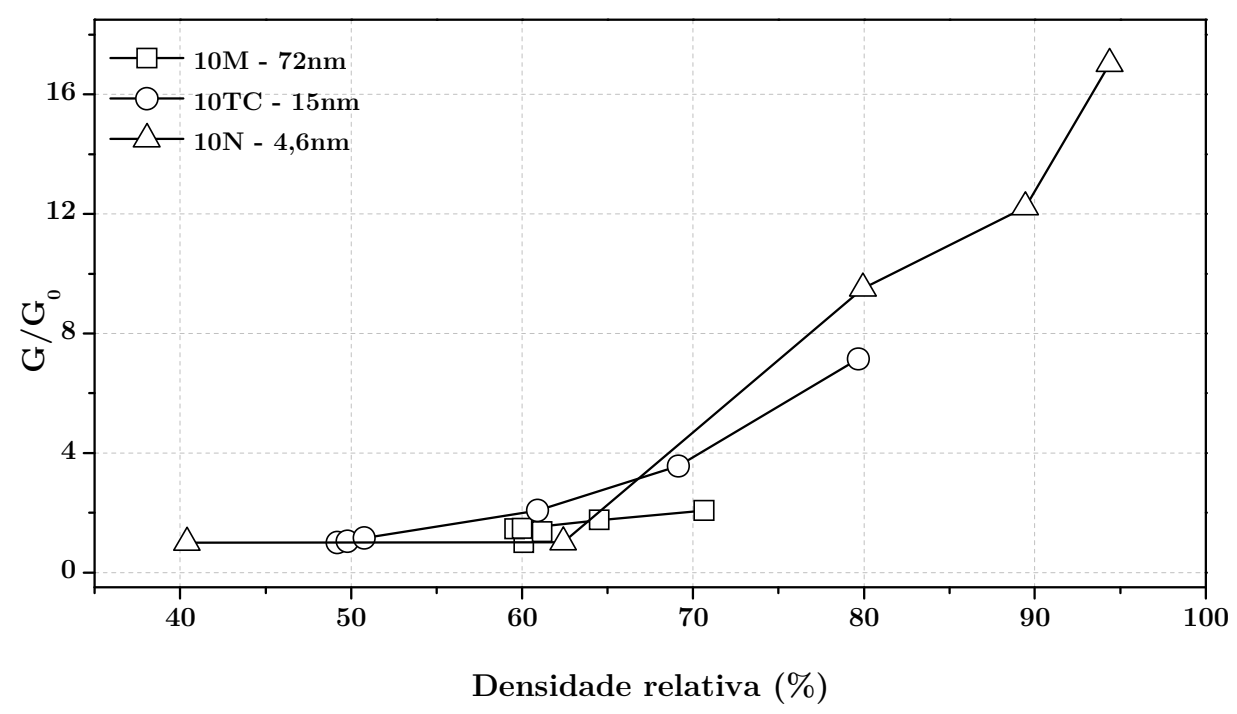

Figura 61: Curvas de trajetória para o crescimento de cristalito da céria gadolínia com diversos tamanhos iniciais de cristalito. Os tamanhos médios de cristalito são normalizados pelo tamanho inicial. 
O efeito do tamanho inicial de partícula é notável nas curvas de trajetória para o crescimento de cristalito. Para o material de maior tamanho de partícula (10M), mecanismos superficiais dominam o início da sinterização. O tamanho médio de cristalito dobra sem que mudanças significativas sejam observadas na densidade do material. Para os outros materiais, de menor tamanho inicial de partícula, o crescimento é acompanhado pela densificação ao longo de toda a sinterização.

O crescimento de cristalito é mais acelerado no início da sinterização para as amostras do material 10TC, e não para o material 10N. Apesar de parecer contraditório, tal fato pode ser explicado ao se analisar as distribuições de tamanhos de cristalito. A dispersão relativa para a distribuição do material 10TC é significativamente maior que a do material $10 \mathrm{~N}$. Isto implica em maiores gradientes do potencial químico na microestrutura à verde, que forçam o transporte de massa prematuramente. $O$ efeito devido à largura da distribuição de tamanhos de partícula foi verificado experimentalmente em alguns trabalhos na literatura [151-153]. Tal comportamento também é previsto por simulações numéricas [150].

De modo geral pode-se verificar uma inversão na curva de trajetória para densidades mais elevadas. Quanto menor o tamanho inicial de partícula, maior o tamanho médio de cristalito para as densidades mais elevadas. Estes resultados, juntamente com aqueles obtidos por Kanters e colaboradores em simulações numéricas [154], indicam que o mecanismo predominante para o crescimento de grãos na céria-gadolínia durante o início da sinterização, é o de arrastamento de poros ("pore drag"). Quando controlado pelos poros os mecanismos de sinterização dominantes são, ou a difusão superficial, ou a evaporação condensação, ou a difusão via volume nos grãos [155]. 


\section{CONCLUSÕES}

A cinética de sinterização da céria gadolínia é fortemente afetada pela área superficial específica dos materiais de partida. Quanto maior a área superficial específica, menores as temperaturas para o início da sinterização e para transição entre seus estágios. O aumento do tamanho médio de cristalito ocorre em temperaturas menores para os materiais com menor tamanho inicial de partícula.

Com o aumento da temperatura de sinterização as distribuições de tamanhos de cristalitos/grãos tornam-se mais alargadas. A dispersão relativa, entretanto, diminuiu no intervalo de temperaturas analisado. Os resultados indicaram a migração de poros ("pore drag") como mecanismo dominante para o crescimento de cristalito durante o início da sinterização.

Uma nova equação foi proposta para o cálculo da retração linear em análises de dilatometria permitindo a determinação do componente de deslocamento devido somente à sinterização do material.

Um programa de análise de dados foi desenvolvido e validado para análise de dados obtidos por dilatometria. O programa permite a determinação de curvas de retração linear e de densidades aparentes aplicando uma série de correções. Funcionalidades extras foram implementadas para permitir a análise da densificação segundo os métodos de Arrhenius e utilizando o conceito da curva mestre de sinterização.

Valores das energias de ativação aparente para densificação foram obtidas utilizando materiais com diferentes valores de área superficial específica. Foi verificado um aumento na energia de ativação aparente com a diminuição da área superficial específica. A dispersão de resultados indicou que mais de um mecanismo de sinterização atua durante a sinterização dos materiais.

Curvas mestres de sinterização foram construídas para céria gadolínia com diferentes tamanhos iniciais de partícula. As curvas foram validadas mostrando-se úteis ferramentas para previsão das densidades aparentes após a sinterização.

Os efeitos da utilização de atmosferas redutoras, inertes e oxidantes na sinterização da céria gadolínia foram investigados. Foi verificado por medidas de 
ressonância eletrônica paramagnética que concentrações de $\mathrm{Ce}^{3+}$ estão presentes nos materiais, independente da atmosfera utilizada. As concentrações verificadas são maiores quando utilizadas atmosferas com maior potencial de redução. Como consequência, o crescimento de grãos é acelerado no material.

A utilização de atmosfera redutora de $4 \%$ de $\mathrm{H}_{2} / \mathrm{Ar}$ resultou numa diminuição da condutividade elétrica total, intragranular e intergranular na céria gadolínia. 


\section{APÊNDICE A - Notação de Kroeger e Vink}

A notação de Kroeger e Vink [78,79] é útil para a descrição de reações de defeitos em sólidos cristalinos. A Tabela 13 mostra a notação utilizada nas reações mostradas neste trabalho.

Tabela 13: Notação de Kroeger e Vink para os termos utilizados nas reações de defeitos.

\begin{tabular}{ll}
\hline Símbolo & Descrição \\
\hline $\mathrm{Ce}_{\mathrm{Ce}}{ }^{\prime}$ & $\begin{array}{l}\text { Cério } \mathrm{Ce}^{3+} \text { na posição normal da rede } \\
\text { com carga efetiva negativa }\end{array}$ \\
$\mathrm{V}_{\mathrm{Ce}}{ }^{\prime \prime}$ & $\begin{array}{l}\text { Vacância de cério triplamente ionizada } \\
\text { com carga efetiva negativa }\end{array}$ \\
$\mathrm{V}_{\mathrm{O}}{ }^{\prime \prime}$ & Vacância de oxigênio duplamente ioni- \\
$\mathrm{M}_{\mathrm{Ce}}{ }^{\prime \prime}$ & zada com carga efetiva positiva \\
$\mathrm{M}_{\mathrm{Ce}}{ }^{\prime}$ & Dopante com dupla carga efetiva nega- \\
$\mathrm{O}_{0}{ }^{\mathrm{X}}$ & tiva \\
\hline
\end{tabular}




\section{APÊNDICE B - Refinamentos Rietveld}

É bem aceito que a função que melhor descreve o perfil de difração produzido pelos raios $X$ na estrutura cristalina é aquela do tipo Voigt. Porém, funções do tipo pseudo-Voigt e Pearson VII têm sido utilizadas recorrentemente como aproximações satisfatórias nos refinamentos Rietveld devido a sua maior velocidade nos cálculos [156]. A função de perfil utilizada em todos os refinamentos Rietveld deste trabalho foi a número \#2 do programa GSAS que trabalha com a regra de integração de Simpson para múltiplos termos da Pseudo-Voigt proposta por Thompson, Cox, Hastings. A escolha da utilização desta função reside no fato de que a mesma tem sido utilizada com sucesso por outros pesquisadores e que a aquisição de dados não é feita para baixos ângulos [157]. A aquisição de dados a baixos ângulos possibilitaria a utilização do termo de assimetria de Finger- CoxJephcoat, que é mais adequado, e logo da função de perfil \#4, porém, tal aquisição de dados demandaria um tempo de aquisição demasiado longo.

Segundo a função \#2 do programa GSAS, a largura à meia altura dos picos de difração é composta por um componente gaussiano e um componente lorentziano, onde estes são dados respectivamente pelas equações B.1 e B.2.

$$
\begin{gathered}
\Gamma_{G}^{2}=U \cdot \tan ^{2} \theta+V \cdot \tan \theta+W+P / \cos ^{2} \theta \\
\Gamma_{L}=X / \cos \theta+Y \cdot \tan \theta+Z
\end{gathered}
$$

onde $\Gamma$ é a largura à meia altura do perfil de difração, U, V, W, X, Y, Z, P são parâmetros refináveis e, $L$ e G, denotam os componentes Lorentziano e Gaussiano respectivamente. A equação $A .1$ é baseada na formulação de Cagliotti para difração de nêutrons e o último termo adicionado por Young e Desai devido ao alargamento produzido pelo tamanho dos cristalitos [157].

O alargamento produzido pelo tamanho dos cristalitos e pela microdeformação da rede cristalina mostram dependências angulares distintas, podendo ser 
identificados e separados no padrão de difração. O comportamento produzido pelo alargamento devido ao tamanho dos cristalitos e a microdeformação são dados respectivamente pelas equações B.3 e B.4. Os termos refináveis $X$ e $P$ são associados ao alargamento produzido pelo tamanho dos cristalitos e, os termos $\mathrm{V}$ e $Y$, são associados ao alargamento produzido pela microdeformação da rede cristalina. Vale ressaltar que muitas vezes a correta determinação dos parâmetros é difícil devido a forte correlação entre os mesmos.

$$
\begin{gathered}
\beta_{S}=\lambda / D_{v} \cdot \cos \theta \\
e=\beta_{D} / 4 \cdot \tan \theta
\end{gathered}
$$

onde $\lambda$ é o comprimento de onda da radiação do difratômetro, $\theta 0$ ângulo, $e$ a microdeformação, $D_{v} \circ$ tamanho de cristalito ponderado pelo volume, $\beta$ a largura integral e $D$ e $S$ os subíndices associados a microdeformação e ao tamanho dos cristalitos respectivamente.

Em todos os refinamentos feitos os parâmetros $X, P, V$ e $Y$ do perfil de difração foram refinados. A função escolhida para o ajuste da radiação de fundo foi a "Shifted Chebyschev", que faz uso de uma combinação linear dos polinômios de Chebyschev. A função de rugosidade de Suortti foi utilizada quando necessária para impedir que os coeficientes térmicos adquirissem valores negativos. A função de orientação preferencial que faz uso dos harmônicos esféricos foi utilizada, embora esta não tenha modificado sensivelmente os refinamentos. O perfil instrumental foi determinado pelo refinamento de uma céria padrão, cujo tamanho de cristalito era superior a $10 \mu \mathrm{m}[108,109]$. Somente os parâmetros $\mathrm{W}$ e $Y$ do perfil foram refinados no perfil instrumental conforme procedimento proposto por Balzar [157]. Os parâmetros iniciais dos refinamentos foram obtidos pelo refinamento Le Bail dos dados [158]. Tal procedimento foi adotado para evitar a convergência a mínimos locais durante o refinamento.

O gráfico da Figura 62 mostra como exemplo o ajuste feito aos dados para o material de partida $10 \mathrm{~N}$. 


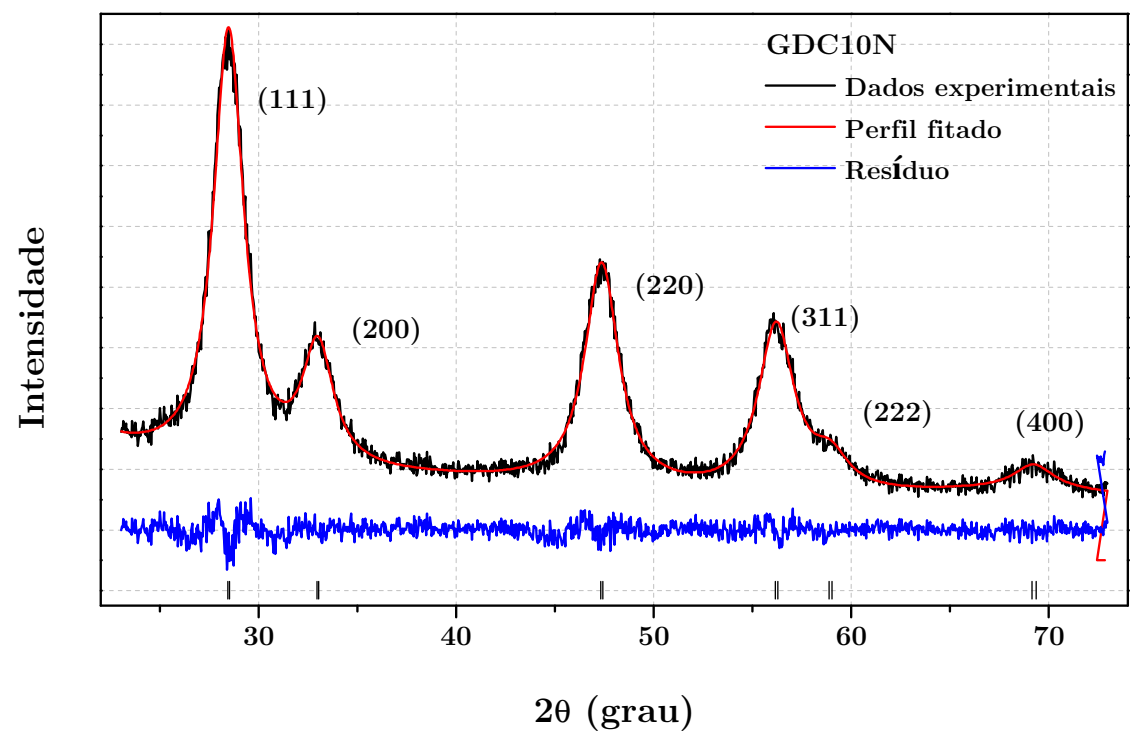

Figura 62: Difratograma de raios $X$ do material GDC10N, perfil refinado e resíduo entre os dois obtidos pelo refinamento Rietveld. O valor do chi quadrado reduzido para o refinamento foi de 1,05. Os números entre parênteses são os respectivos índices de Müller associados a cada pico.

Análises de difração de raios $X$ foram realizadas em amostras elaboradas a partir de cada um dos materiais utilizados neste trabalho e sinterizadas sob diversas temperaturas. Os valores dos $\chi^{2}$ dos ajustes são mostrados em função da temperatura de sinterização utilizada (Figura 63).

Nota-se que para algumas amostras o valor obtido do $\chi^{2}$ do ajuste é da ordem de 3 ou até superior, entretanto, quando analisados os ajustes mostram-se de acordo com os dados experimentais. Tais valores, relativamente altos, devemse principalmente a dificuldade do ajuste da função de assimetria utilizada e a alta intensidade dos dados. O gráfico da Figura 64 mostra o refinamento obtido para a amostra sinterizada a $700^{\circ} \mathrm{C}$ e elaborada a partir da GDC $10 \mathrm{M}$. O valor do $\chi^{2}$ do ajuste é de 3,63, porém nota-se a clara concordância entre o perfil ajustado e 0 perfil experimental. Na região ampliada do gráfico é mostrado o ajuste ao pico de maior intensidade. 


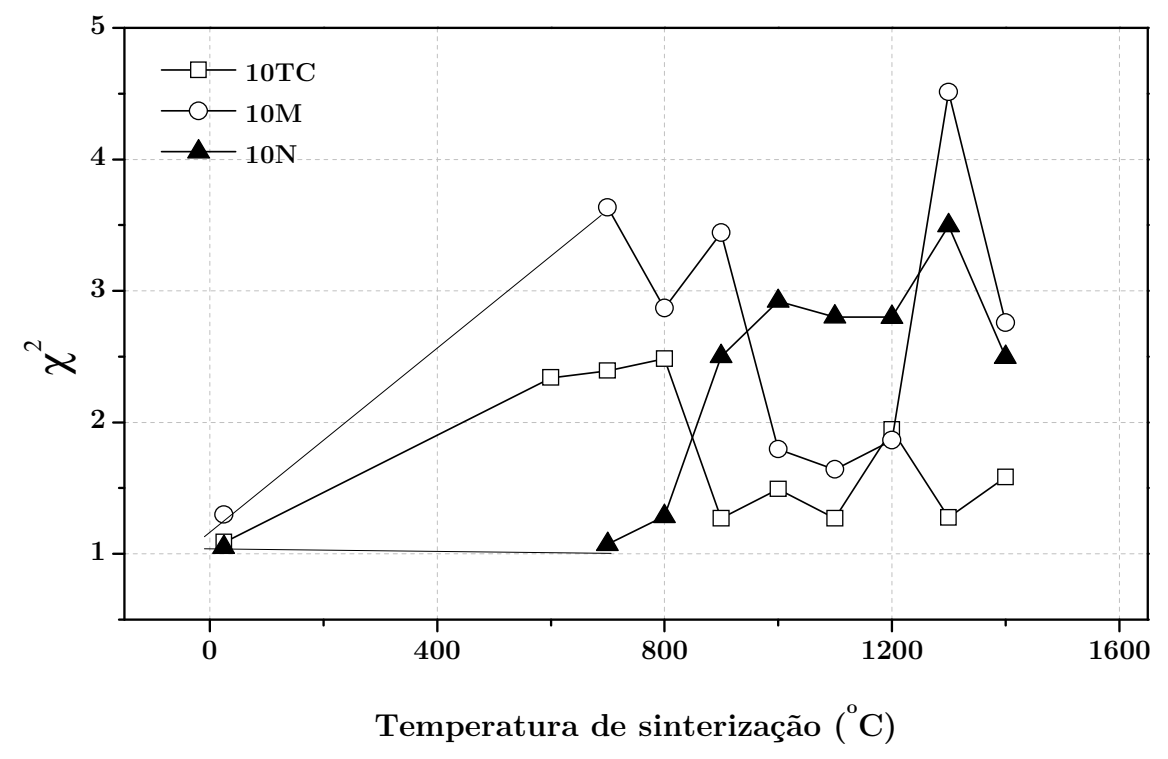

Figura 63: Valores do $\chi^{2}$ dos ajustes das análises realizadas em amostras elaboradas a partir de cada um dos materiais de partida. Os resultados são mostrados em função da temperatura de sinterização. A temperatura de $25^{\circ} \mathrm{C}$ é associada aos materiais como recebidos.

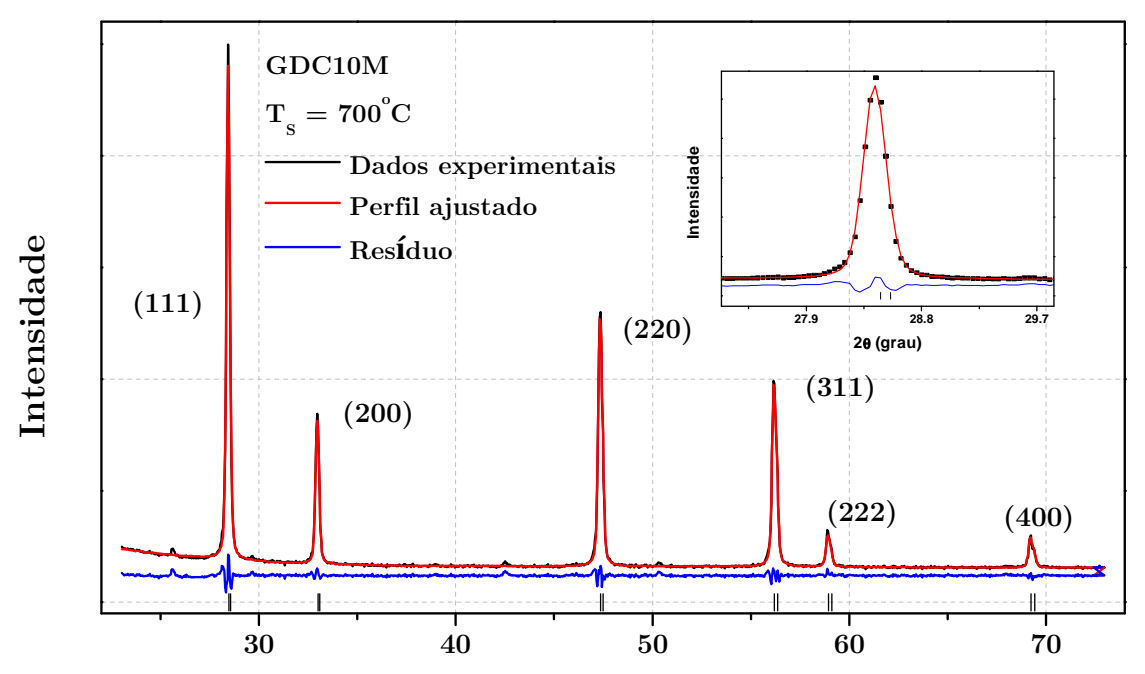

$2 \theta$ (grau)

Figura 64: Gráfico do refinamento Rietveld da amostra $10 \mathrm{M}$ sinterizada à $700^{\circ} \mathrm{C} . O \chi^{2}$ do ajuste é de 3,63. Na região ampliada do gráfico é mostrado a aderência da curva ajustada aos dados experimentais na região do pico de maior intensidade. 
A correção dos parâmetros do ajuste associados ao alargamento pelo (equações B.1 e B.2) perfil instrumental é feita diretamente através da equação B.5 [159].

$$
\begin{gathered}
\Gamma_{\text {corrigido }}=\Gamma_{\text {amostra }}-\Gamma_{\text {padrão }} \\
\beta_{L} / \Gamma_{L}=\frac{\pi}{2} \\
\beta_{G} / \Gamma_{G}=(2 \pi)^{\frac{1}{2}}
\end{gathered}
$$

Os parâmetros corrigidos são utilizados para determinação da largura integral conforme as equações B.6 e B.7. A microdeformação e o tamanho médio dos cristalitos ponderado pelo seu volume são por fim determinados pela utilização dos valores das larguras integrais nas equações B.3 e B.4. 


\section{APÊNDICE C - ZARC}

Um ZARC é um elemento que pode ser interpretado como um resistor em paralelo com um elemento de fase constante (CPE). A Figura 65 mostra o circuito equivalente do ZARC [160].

\section{Elemento de fase constante (CPE)}

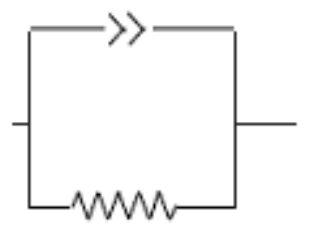

Resistor

Figura 65: Circuito equivalente ao ZARC.

O ZARC produz uma curva no plano complexo de impedância representado por um semi círculo descentralizado. A impedância do circuito é dada pela equação C.1 [160].

$$
Z=\frac{R}{1+(i . \tau \cdot w)^{\pi}}
$$

onde $R$ é a resistência, $\tau$ o tempo de relaxação para o processo de polarização, $w$ a frequência de polarização e $\pi$ uma constante. Quanto menor o valor de $\pi$, maior é o ângulo de descentralização do semicírculo. Quando $\pi$ é igual a 10 semicírculo não é descentralizado e o circuito comporta-se como uma resistência em paralelo com um capacitor.

Durante a análise dos diagramas de impedância os ajustes foram feitos supondo dois ou três ZARCs em série. Para cada ZARC três parâmetros eram obtidos com os ajustes, sendo a resistência $R$, o tempo de relaxação $\tau$ e a constante $\pi$. 


\section{APÊNDICE D - Cálculo de densidade aparente por dilatometria}

Curvas de densidade em função do tempo ou temperatura são usualmente obtidas a partir dos resultados de retração linear obtidos por dilatometria [59-73]. Uma condição necessária para que as curvas possam ser determinadas é que o material analisado apresente retração linear isotrópica. Caso tal hipótese seja válida, a equação D.1 será verdadeira.

$$
-\frac{1}{L} \frac{d L}{d t}=\frac{1}{3} \frac{d \rho}{d t}
$$

onde $L$ é o comprimento de uma amostra, $\rho$ a densidade e $t$ o tempo.

A resolução da equação diferencial em D.1 fornece como solução a equação D.2, que permite o cálculo da densidade a partir dos dados de retração linear.

$$
\begin{gathered}
3 . \ln \left(\frac{L_{0}}{L_{F}}\right)=\ln \left(\frac{\rho}{\rho_{0}}\right) \\
3 . \ln \left(\frac{L_{0}}{L_{F}-L_{0}+L_{0}}\right)=\ln \frac{\rho}{\rho_{0}} \\
\ln \left(\frac{L_{0}}{\Delta L+L_{0}}\right)^{3}=\ln \frac{\rho}{\rho_{0}} \\
\frac{1}{\left(1+\Delta L / L_{0}\right)^{3}}=\frac{\rho}{\rho_{0}} \\
\rho=\frac{\rho_{0}}{\left(1+\Delta L / L_{0}\right)^{3}}
\end{gathered}
$$

onde $\rho_{0}$ e $L_{0}$ são a densidade e o comprimento à verde da amostra. 
A equação D.2 é uma expressão já conhecida e utilizada na literatura. Porém, o desenvolvimento acima não considera uma possível perda de massa do material durante o aquecimento. A perda de massa no início da sinterização ocorre com relativa frequência no início da sinterização. A correção devido a tal perda de massa é feita ao multiplicar uma função correção $f(t, T)$ a equação D.2. A função correção é dada pela fração de massa do material nas condições de análise. A equação D.2 pode ser reescrita conforme D.3 com tal finalidade.

$$
\rho=\frac{\rho_{0} \cdot f(t, T)}{\left(1+\Delta L / L_{0}\right)^{3}}
$$

onde $f(t, T)$ é a fração da massa inicial do material.

A fração da massa inicial pode ser determinada experimentalmente em análises de termogravimetria e, como visto anteriormente (Resultados), pode introduzir erros da ordem de $20 \%$ ou maior nas densidades relativas caso não considerada. 


\section{APÊNDICE E - Correção interna em medidas de dilatometria}

Medidas exatas de dilatometria requerem a determinação prévia de uma função correção devido à expansão térmica do tubo do dilatômetro. Esta função pode ser determinada experimentalmente pela análise de uma amostra padrão com dilatação térmica bem conhecida. Neste caso, a função correção será dada por E.1.

$$
A_{C}=\frac{\Delta L_{\text {Tubo }}}{L_{0}}=\frac{\Delta L_{\text {Amostra }}}{L_{0}}-\frac{\Delta L_{\text {Medido }}}{L_{0}}
$$

onde $A_{C}$ é a função correção interna, $\mathrm{L}_{0} 0$ comprimento inicial da amostra padrão analisada e $\Delta \mathrm{L}_{\text {Tubo }} \mathrm{O}$ deslocamento da porção do tubo paralela a amostra. $\mathrm{O}$ primeiro termo do lado direito da equação é conhecido e o segundo medido durante a análise. Assim, a função correção é determinada experimentalmente.

A equação E.1 pode induzir o leitor a imaginar que a função correção seja aplicável apenas para amostras com tamanho inicial similar ao da amostra padrão. Entretanto, isto não é verdade. Como é mostrado no Apêndice $C$, o deslocamento produzido pelo tubo pode ser matematicamente definido pela equação E.2.

$$
\Delta L_{\text {Tubo }}=L_{0} \cdot\left(e^{\int_{T 0}^{T F} \cdot d T}-1\right)
$$

onde $\alpha$ é o coeficiente de expansão térmica do tubo, T0 e TF a temperatura inicial e final de medida $e, L_{0}$, o comprimento inicial da porção do tubo paralela à amostra. Ao calcular a razão entre os deslocamentos do tubo em medidas com amostras de tamanhos distintos teremos: 


$$
\frac{\Delta L_{T u b o-A}}{\Delta L_{T u b o-B}}=\frac{L_{0-A} \cdot\left(e^{\int_{T 0}^{T F} \cdot d T}-1\right)}{L_{0-B} \cdot\left(e^{\int_{T 0}^{T F} \cdot d T}-1\right)}
$$

Os subíndices A e B designam uma medida A e B onde as amostras possuem tamanhos distintos. Tanto o comprimento inicial $\mathrm{L}_{0}$ como os valores $\Delta \mathrm{L}_{\text {Tubo }}$ são diferentes para cada medida. A equação E.3 pode ser simplificada de modo a obter

$$
\frac{\Delta L_{T u b o-A}}{L_{0-A}}=\frac{\Delta L_{T u b o-B}}{L_{0-B}}=A_{C}
$$

que mostra que a função correção $A_{C}$ é independente do tamanho da amostra analisada.

Por fim o deslocamento do tubo pode ser descrito conforme a equação E.5. Uma versão modificada desta equação é utilizada no item que aborda a acuidade em medidas de dilatometria durante a apresentação dos resultados deste trabaIho.

$$
\Delta L_{\text {Tubo }}=A_{C} \cdot L_{0}
$$




\section{APÊNDICE F - Expansão térmica}

O coeficiente de expansão térmica instantâneo $\alpha$ de um material é definido conforme a equação F.1 [129].

$$
\alpha=\frac{1}{L} \cdot \frac{d L}{d T}
$$

Após a separação de variáveis podemos integrar a equação diferencial obtendo:

$$
\begin{gathered}
\ln \left(\frac{L_{F}}{L_{0}}\right)=\int_{T 0}^{T F} \alpha \cdot d T \\
L_{F}=L_{0} \cdot e^{\int_{T 0}^{T F} \alpha . d T}
\end{gathered}
$$

Lembrando que o comprimento final $L_{F}$ é dado por

$$
L_{F}=L_{0}+\Delta L
$$

podemos reescrever a equação F.2 conforme F.4.

$$
\Delta L=L_{0} \cdot\left(e^{T F} \alpha d x\right.
$$

A equação F.4 é utilizada em diversas deduções nesta tese. 


\section{APÊNDICE G - Correção da temperatura inicial de medida}

A temperatura inicial das análises de dilatometria das amostras utilizadas na construção da curva mestre de sinterização deve ser a mesma ou um erro não linear será introduzido ao conjunto de dados. O comprimento inicial das amostras deve ser aferido para uma mesma temperatura tomada como inicial. Matematicamente isto é equivalente a expressão G.1.

$$
\lim _{T \rightarrow T_{0}} \Delta L=0
$$

onde $T_{0}$ é a temperatura tomada como inicial para todas as medidas.

Em geral pequenos desvios da temperatura inicial de medida são verificados entre diferentes análises. Um procedimento possível para correção deste efeito é adotar uma nova temperatura como inicial para todas as amostras. Esta temperatura necessariamente deve ser pertencer ao intervalo medido para todas as curvas. Visto que o comprimento inicial das amostras deve ser medido na nova temperatura inicial, alteramos o comprimento inicial da amostra conforme a expressão G.2.

$$
L_{0 \text {-corrigido }}=L_{0-\text { Medido }}+\Delta L_{T \rightarrow T_{0}}
$$

onde $\mathrm{L}_{0 \text {-corrigido }}$ é o comprimento inicial corrigido, $\mathrm{L}_{0 \text {-medido }} \mathrm{o}$ comprimento inicial na temperatura inicial de medida e $\Delta \mathrm{L}_{\mathrm{T} \rightarrow \mathrm{TO}} \mathrm{O}$ deslocamento aferido na nova temperatura adotada como inicial para a medida.

Os deslocamentos são medidos sempre em relação ao comprimento inicial da amostra, portanto, todos os deslocamentos devem ser corrigidos conforme a equação G.3.

$$
\Delta L_{\text {Corrigido }}=\Delta L_{\text {Medido }}-\Delta L_{T \rightarrow T_{0}}
$$




\section{APÊNDICE H - Correção do comportamento inicial das curvas de retração}

Irregularidades no comportamento inicial nas curvas de retração são relativamente frequentes. Isto pode ocorrer pela eliminação da umidade, eliminação de aditivos, falta de exatidão do termopar ou pela acomodação térmica do equipamento durante os primeiros minutos de medida. Dois métodos foram propostos para corrigir tais irregularidades. Os métodos devem ser usados com cautela pois são do que métodos empíricos.

Para exemplificar os métodos considere o seguinte conjunto de dados mostrado na Figura 66.

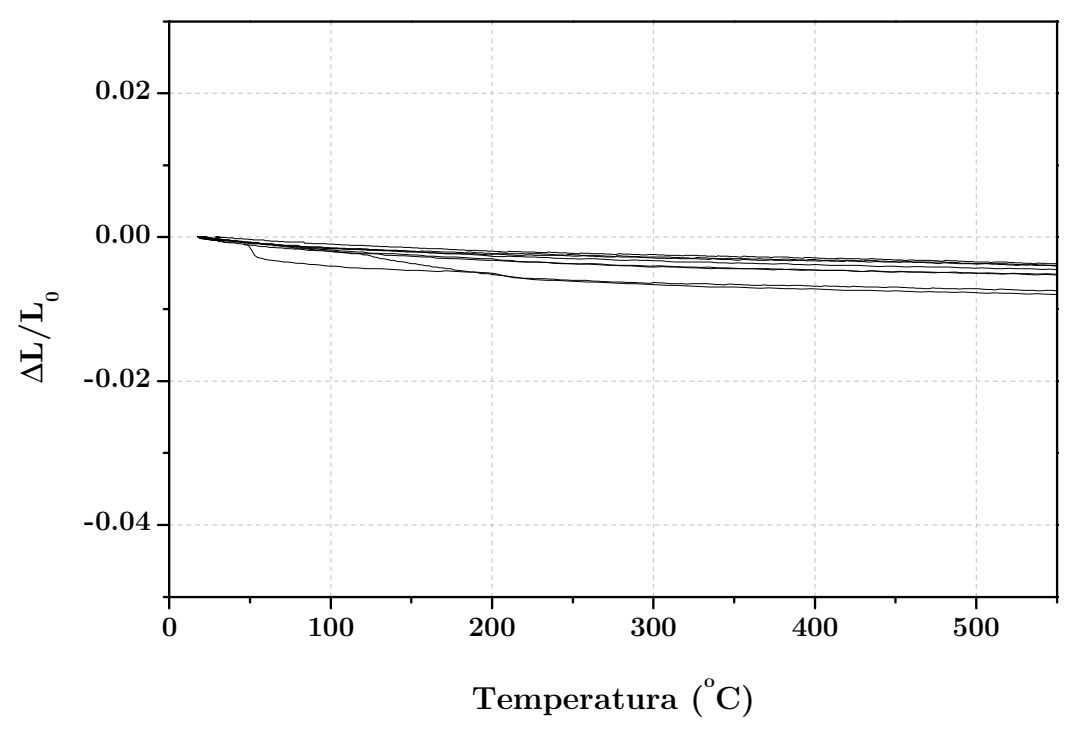

Figura 66: Curvas de retração linear obtidas para amostras elaboradas a partir da 10TC. Nenhuma correção foi aplicada ao comportamento inicial das amostras.

Uma pequena diferença entre os comportamentos iniciais das amostras podem ser verificados. Seria plausível que o comportamento das mesmas fosse igual visto que a sinterização ainda não ocorre e que todas as amostras possuem os mesmos coeficientes de expansão térmica.

O primeiro método consiste em fixar uma das curvas e transladar todas as outras de modo que as curvas colidam em um dado intervalo de temperaturas 
escolhido. A Figura 67 mostra as mesmas curvas após a correção pelo método discutido.

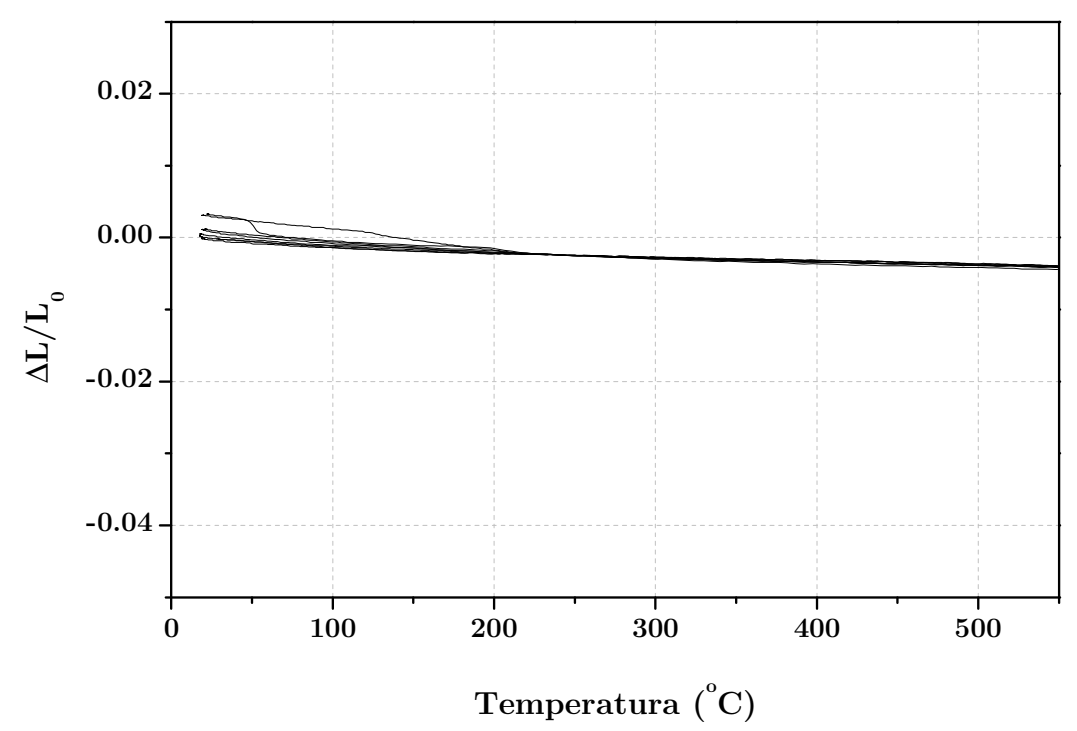

Figura 67: Curvas de retração linear obtidas para amostras elaboradas a partir da 10TC e corrigidas pelo método de translação descrito no texto.

Para fazê-lo o deslocamento médio de cada curva é calculado no intervalo escolhido. A diferença entre o valor médio de cada curva e o valor médio da curva de referência é somada aos dados da curva a ser transladada.

O segundo método consiste em fazer um ajuste linear no intervalo escolhido. O coeficiente linear é computado e somado aos dados de modo que todas as curvas se iniciem do valor nulo. A Figura 68 mostra os resultados após a correção proposta. 


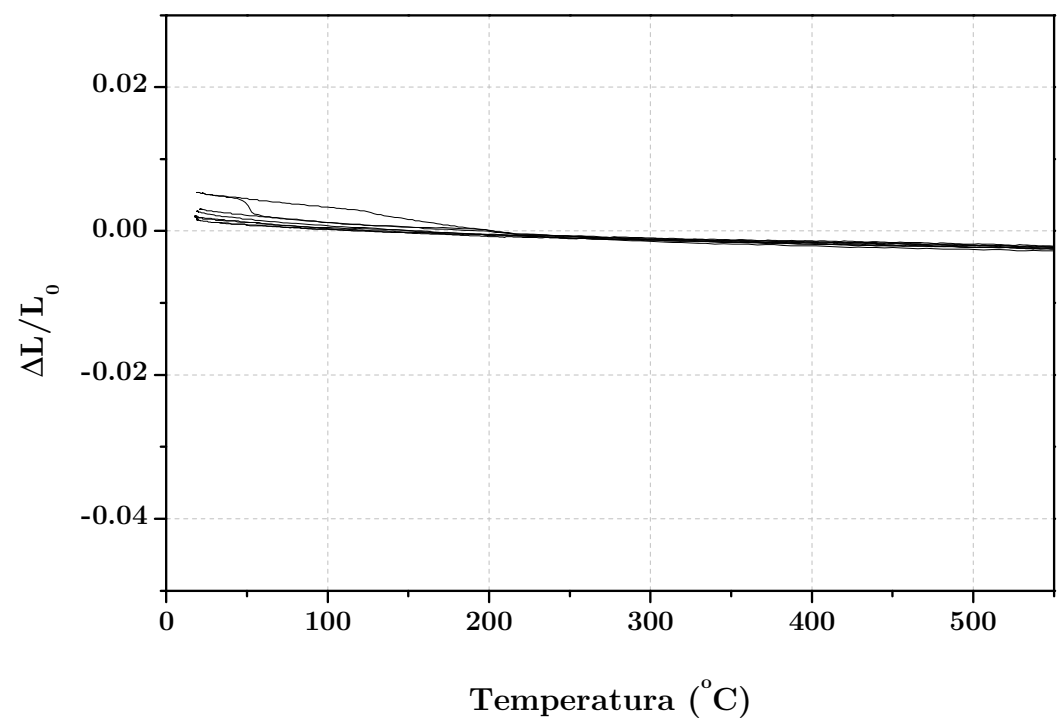

Figura 68: Curvas de retração linear obtidas para amostras elaboradas a partir da 10TC e corrigidas pelo método de extrapolação já descrito no texto. 


\section{APÊNDICE I - Método de Arrhenius para densificação}

O modelo combinado de sinterização foi utilizado neste trabalho. A taxa de densificação de um material isotrópico durante a sinterização é descrita matematicamente conforme a equação I.1.

$$
\frac{d \rho}{3 \rho d t}=\frac{\gamma \Omega}{k T}\left(\frac{\delta D_{g b} \Gamma_{G g b}}{G^{4}}+\frac{D_{v} \Gamma_{G_{v}}}{G^{3}}\right)
$$

onde $\rho$ é a densidade do material, $t o$ tempo, $T$ a temperatura, $G$ o tamanho médio de grão, $k$ a constante de Boltzmann, $\gamma$ a energia livre superficial específica, $\Omega 0$ volume atômico, $\delta$ a espessura dos contornos de grãos e $D$ e $\Gamma_{G}$ os coeficientes de difusão e fatores geométricos. Os subíndices $g b$ e $v$ são associados aos mecanismos de difusão via contornos de grão e via volume respectivamente. Os fatores geométricos $\Gamma_{G}$ são variáveis dependentes de diversas características da microestrutura, como a curvatura dos grãos ou a área dos contornos de grãos. Os coeficientes de difusão por sua vez são definidos pela equação I.2.

$$
D_{i}=D_{0 i} \cdot \exp \left(\frac{-Q_{i}}{k T}\right) \quad i=g b \text { ou } v
$$

O fator pré exponencial $D_{0 i}$ e a energia de ativação $Q_{i}$ são parâmetros dependentes do mecanismo de difusão indicado pelo subíndice $i$.

Supondo que apenas um dos mecanismos de densificação seja dominante para um dado intervalo de temperaturas, pode-se então aplicar o logaritmo dos dois lados da equação a fim de obter a equação I.3.

$$
\ln \left(\frac{T}{\rho} \frac{d \rho}{d t}\right)=\ln \left(\frac{3 \gamma \Omega}{k T} \frac{D_{0 v} \Gamma_{v}}{G^{3}}\right)-\frac{Q}{k T}
$$

Para aplicação do método de Arrhenius algumas hipóteses devem ser impostas. Assim como no método da MSC deve-se impor a condição de que o tamanho médio de grãos é apenas função apenas da densidade. Quando tomada 
como verdadeira tal hipótese o primeiro termo do lado direito da equação será apenas função da densidade.

A metodologia de análise consiste em determinar curvas de densidade por meio de análises de dilatometria com diferentes taxas de aquecimento constante. A partir dos resultados o termo do lado esquerdo da equação é calculado para cada uma das curvas obtidas para um mesmo valor de densidade. Quando plotados os valores calculados contra o inverso da temperatura um comportamento linear deve ser verificado. A energia de ativação aparente para densificação é obtida pelo coeficiente angular do ajuste linear aos dados. O procedimento pode ser realizado para diversos valores de densidade a fim de analisar o comportamento da energia de ativação aparente durante diversas etapas da sinterização. Variações do método são encontradas na literatura, sendo a mais amplamente aplicada proposta por Wang e Raj [161]. 


\section{REFERÊNCIAS BIBLIOGRÁFICAS}

[1] German, R. M.; Introduction to sintering. In: Sintering Theory and Practice. New York: Wiley, 1996. Cap. 1, p. 1-22.

[2] German, R. M.; Powder metallurgy of iron and steel. New York: John Wiley and Sons, 1998.

[3] German, R. M.; History of sintering: empirical phase. Powder Metall., v. 56, p. 117, 2013.

[4] Shewmon, P.; Diffusion in a concentration gradient. In: Diffusion in solids. $2^{\text {a }}$ Edição. Pittsburgh: The Minerals, Metals \& Materials Society, 1989. Cap. 4, p. 131-150.

[5] Mehrer, H.; Dependence of diffusion on temperature and pressure In: Diffusion in solids: Fundamentals, methods, materials, diffusion-controlled processes. Berlin: Springer- Verlag, 2007. Cap. 8, p. 127-150.

[6] Rahaman, M. N.; Sintering of Ceramics: Fundamentals. In: Sintering of Ceramics. Boca Raton: CRC Press, 2008. Cap. 1, p. 1-43.

[7] Rahaman, M. N.; Grain growth and microstructure control. In: Ceramic processing and sintering. $2^{a}$ edição. New York: Marcel Dekker, 1995. Cap. 9, p. 540619.

[8] Kingery, W. D.; Bowen, H. K. e Uhlmann, D. R.; Introduction to Ceramics. 2a edição. New York: Wiley, 1968.

[9] Callister, W. D.; Fundamentals of Materials Science and Engineering. 5a edição. New York : John Wiley and Sons, 2001.

[10] Frenkel, J.; Viscous flow of crystalline bodies under the action of surface tension. J. Phys., v. 9, p. 385, 1945.

[11] Rahaman, M. N.; Theory of solid-state and viscous sintering. In: Ceramic processing and sintering. 2ª̣edição. New York: Marcel Dekker, 1995. Cap. 8, p. 470539.

[12] DiAntonio, C. B. e Ewsuk, K. G.; Master sintering curve and its application in sintering of electronic ceramics. In: Fang, Z. Z.; Sintering of advanced materials. Cambridge: Woodhead, 2010. Cap. 6, p. 130-161.

[13] Rahaman, M. N.; Kinetics and mechanisms of densification. In: Fang, Z. Z.; Sintering of advanced materials. Cambridge: Woodhead, 2010. Cap. 2, p. 33-64.

[14] Niu, W. e Pan, J.; Computer modeling of sintering: theory and examples. In: Fang, Z. Z.; Sintering of advanced materials. Cambridge: Woodhead, 2010. Cap. 10, p. 249-288.

[15] Inaba, H. e Tagawa, H.; Ceria-based electrolytes. Solid State Ionics, v. 83, p. 1, 1996.

[16] Fergus, J. W.; Electrolytes for solid oxide fuel cells. J. Power Sources, v. 162, p. 30, 2006. 
[17] German, R. M.; Fundamentals of sintering. In: Fang, Z. Z.; Sintering of advanced materials. Cambridge: Woodhead, 2010. Cap. 1, p. 1-32.

[18] Kang, S. L.; Thermodynamics of the interface. In: Densification, grain growth, and microstructure. Oxford: Elsevier, 2005, Cap. 2, p. 9-18.

[19] Kang, S. L.; Sintering Process. In: Densification, grain growth, and microstructure. Oxford: Elsevier, 2005, Cap. 1, p. 3-8.

[20] Kang, S. L.; Liquid phase sintering. In: Fang, Z. Z.; Sintering of advanced materials. Cambridge: Woodhead, 2010. Cap. 5, p. 110-129.

[21] Liu, J. e German, R. M.; Densification and shape retention in supersolidus liquid phase sintering. Acta Mater., v. 47, p. 4615, 1999.

[22] de Oliveira, M. J.; Princípio de Clausius-Gibbs. In: Termodinâmica. São Paulo: Livraria da Física, 2005. Cap. 3, p. 33-50.

[23] Mehrer, H.; Point Defects in Crystals. In: Diffusion in solids: Fundamentals, methods, materials, diffusion-controlled processes. Berlin: Springer-Verlag, 2007. Cap. 5, p. 69-93.

[24] Porter, D. A.; Easterling, K. E. e Sherif, M. Y.; Thermodynamics and Phase Diagrams. In: Phase Transformations in Metal and Alloys. 3a Edição. Boca Raton: CRC Press, 2009. Cap. 1, p. 1-61.

[25] Bordia, R. K. e Camacho-Montes, H.; Sintering: Fundamentals and Practice. In: Bansal, N. P. e Boccaccini, A. R.; Ceramic and Composites Processing Methods. New York: John Wiley and Sons, 2012. Cap. 1, p. 3-42.

[26] Mehrer, H.; Diffusion and external driving forces. In: Diffusion in solids: Fundamentals, methods, materials, diffusion-controlled processes. Berlin: SpringerVerlag, 2007. Cap. 11, p. 179-190.

[27] de Oliveira, M. J.; Potenciais Termodinâmicos. In: Termodinâmica. São Paulo: Livraria da Física, 2005. Cap. 4, p. 51-74.

[28] Herring, C.; Effect of change scale on sintering phenomena. J. Appl. Phys., v. 21, p. 301, 1950.

[29] Kang, S. L.; Initial stage sintering. In: Densification, grain growth, and microstructure. Oxford: Elsevier, 2005, Cap.4, p. 39-55.

[30] Ashby, M. F.; A first report on sintering diagrams. Acta Metall., v. 22, p. 275, 1974.

[31] Kingery, W. D. e Berg, M.; Study of the initial stages of sintering solids by viscous flow, evaporation- condensation, and self- diffusion. J. Appl. Phys., v. 26, p. 1205, 1955.

[32] Coble, R. L.; Initial sintering of alumina and hematite. J. Am. Ceram. Soc., v. 41, p. 55, 1958.

[33] Rockland, J. G. R.; The determination of the mechanism of sintering. Acta Metall., v. 15, p. 277, 1967.

[34] Schwed P.; Surface diffusion in sintering of spheres on planes. Trans. AIME, v. 191, p. 245, 1951.

[35] Cabrera, N.; Sintering of metallic particles. Trans. AIME, v. 188, p. 667, 1950. 
[36] Kuczynski, G.; Self-diffusion in sintering of metallic particles. Trans. AIME, v. 185 , p. $169,1949$.

[37] Beeré, W.; The intermediate stage of sintering. Metal Sci. J., v. 10, p. 294, 1976.

[38] Coble, R. L.; Sintering crystalline solids. I. Intermediate and final state diffusion models. J. Appl. Phys., v. 32, p. 787, 1961.

[39] Hansen, J. D.; Rusin, R. P.; Teng, M. e Johnson, D. L.; Combined-stage sintering model. J. Am. Ceram. Soc., v. 75, p. 1129, 1992.

[40] DeHoff; Path and kinetics of microstructural change in simple sintering . In: Fang, Z. Z. Sintering of advanced materials. Cambridge: Woodhead, 2010. Cap. 3, p. 65-85.

[41] German, R. M. Solid-state sintering fundamentals. In: Sintering Theory and Practice. New York: Wiley, 1996. Cap.3, p. 67-141.

[42] Fang, Z. Z. e Wang, H.; Sintering of ultrafine and nanosized particles. Cambridge: Woodhead, 2010. Cap. 17, p. 434-473.

[43] Lange,F. F.; Sinterability of agglomerated powders, J. Am. Ceram. Soc., v. 67, p. 83, 1984.

[44] Kingery, W. D. e Francois, B.; Sintering of crystalline oxide, I. Interactions between grain boundaries and pores. In: Kuczynski, G. C.; Sintering and related phenomena. New York: Gordon and Breach, 1984, p. 83-89.

[45] Rhodes, W. D.; Agglomerate and particle size effects on sintering yttria- stabilized zirconia. J. Am. Ceram. Soc., v. 64, p.19, 1981.

[46] Kimura, T.; Matsuda, Y.; Oda, M. e Yamaguchi, T.; Effects of agglomerates on the sintering of alpha- $\mathrm{Al}_{2} \mathrm{O}_{3}$. Ceram. Int., v. 13, p. 27, 1987.

[47] Lange, F. F.; Powder processing science and technology for increased reliability. J. Am. Ceram. Soc., v. 72, p. 3, 1989.

[48] Blais, C; Atmosphere Sintering. In: Fang, Z. Z.; Sintering of advanced materials. Cambridge: Woodhead, 2010. Cap. 7, p. 165-188.

[49] Zhou, Y. e Rahaman, M. N.; Effect of redox reaction on the sintering behavior of cerium oxide. Acta Mater., v. 45, p. 3635, 1997.

[50] Lange,F.F. e Kellet,B.J.; Thermodynamics of densification. 2.Grain growth in porous compacts and relation to densification. J. Am. Ceram. Soc., v. 72, p. 735, 1989.

[51] Fang, Z.; Maheshwari, X.; Wang, X.; Sohn, H. Y.; Griffo, A. e Riley, R.; An experimental study of the sintering of nanocrystalline WC-Co powders. Int. J. Refract Met. H., v. 23, p. 249-257, 2005.

[52] Zeng, P.; Zajac, S.; Clapp, P. C. e Rifkin, J. A.; Nanoparticle sintering simulations. Mater. Sci. Eng. A, v. 252, p. 301, 1998.

[53] Bordia, R. e Olevsky, E.; Advances in sintering science and technology. J.

Am. Ceram. Soc., v. 92, p. 1383, 2009. 
[54] Munir, Z. A.; Anselmo- Tamburini, U.; Ohyianagi, M. The effect of electric field and pressure on the synthesis and consolidation of materials: A review of the spark plasma sintering method. J. Mater. Sci., v. 41, p. 763, 2006.

[55] Muccillo, R. M.; Kleitz, M.; Muccillo, E. N. S. Flash grain welding in yttria stabilized zirconia. J. Eur. Ceram. Soc., v. 31, p. 1517, 2011.

[56] Quach, D. V.; Groza, J. R.; Anselmi-Tamburini, U.; Fundamentals and applications of field/current assisted sintering. In: Fang, Z. Z. Sintering of advanced materials. Cambridge: Woodhead, 2010. Cap. 10, p. 249-288.

[57] Agrawal, D..; Microwave sintering of ceramics, composites, and metal powders. In: Fang, Z. Z. Sintering of advanced materials. Cambridge: Woodhead, 2010. Cap. 9, p. 222-248.

[58] Wei-Chen, I.; Wang, X. H. Sintering dense nanocrystalline ceramics without final-stage grain growth. Nature, v. 404, p. 168, 2000.

[59] Park, S. J.; Johnson, J. L.; Wu, Y.; Kwon, Y.; Lee, S.; German, R. M.; Analysis of the effect of solubility on the densification behavior of tungsten heavy alloys using master sintering curve approach. Int. J. Refract. Met. H., v.37, p. 52, 2013.

[60] Su, H.; Johnson, D. L.; Master sintering curve: A practical approach to sintering. J. Am. Ceram. Soc., v. 79, p. 3211, 1996.

[61] Blaine, D.C.; Gurosik, J.D.; Park, S.J.; Heaney, D.F. e German, R.; Master sintering curve concepts as applied to the sintering of molybdenum. Metallurg. Mater. Trans. A, v. 37A, p. 715, 2006.

[62] Shao, W. Q.; Chen, S. O.; Li, D.; Cao, H. S.; Zhang, Y. C.; Ge, X. H. Prediction of densification during low heating rate sintering of microcrystalline alumina ceramics based on master sintering curve theory. Mater. Tech., v. 23, p. 19, 2008.

[63] Kinemuchi, Y.; Watari, K. Dilatometer analysis of sintering behavior of nano$\mathrm{CeO}_{2}$ particles. J. Eur. Ceram. Soc., v. 28, p. 2019, 2008.

[64] de Florio, D. Z.; Esposito, V.; Traversa, E.; Muccillo, R.; Fonseca, F. C. Master sintering curve for $\mathrm{Gd}$-doped $\mathrm{CeO}_{2}$ solid electrolytes. J. Therm. Anal Calorim., v. 97, p. $143,2009$.

[65] Song, X.; Lu, J.; Zhang, T.; Ma, J. Two-stage master sintering curve approach to sintering kinetics of undoped and $\mathrm{Al}_{2} \mathrm{O}_{3}$-doped 8 mol\% yttria- stabilized cubic zirconia. J. Am. Ceram. Soc., v. 94, p. 1053, 2011.

[66] Kiani, S.; Pan, J. e Yeomans, J.A.; A new scheme of finding the master sintering curve. J. Am. Ceram. Soc., v. 89, p. 3393, 2006.

[67] Blaine, D. C.; Park, S. e German, R. M.; Linearization of master sintering curve. J. Am. Ceram. Soc., v. 92, p. 1403, 2009.

[68] Aminzare, M.; Mazaheri, M.; Golestani- Fard, F.; Rezaie, H. R.; Ajeian, R. Sintering behavior of nano alumina powder shaped by pressure filtration. Ceram. Int., v. 37, p. 9, 2011.

[69] Banerjee, J.; Ray, A.; Kumar, A. e Banerjee, S.; Studies on sintering kinetics of $\mathrm{ThO}_{2}-\mathrm{UO}_{2}$ pellets using master sintering curve approach. J. Nucl. Mater., v. 443, p. 467, 2013. 
[70] Pouchly, V.; Maca, K. e Shen, Z.; Two-stage master sintering curve applied to two-step sintering of oxide ceramics. J. Eur. Ceram. Soc., v. 33, p. 2275, 2013.

[71] Brandt, B.; Naghib-Zadeh, H. e Rabe, T.; Improved co-firing of ferrite and dielectric tape based on master sintering curve predictions and shrinkage mismatch calculations. J. Am. Ceram. Soc., v. 96, p. 726, 2013.

[72] Mitra, S.; Kulkarni, A. R. e Prakash, O.; Densification behavior and two stage master sintering curve in lithium sodium niobate ceramics. Ceram. Int., v. 39, p. S65, 2013.

[73] Mazaheri, M.; Simchi, A.; Dourandish, M. e Golestani-Fard; Master sintering curves of a nanoscale 3Y-TZP powder compacts. Ceram. Int., v. 35, p. 547, 2009.

[74] Mogensen, M.; Sammes, N. M.; Tompsett, G. A.; Physical, chemical, and electrochemical properties of pure and doped ceria. Solid State Ionics, v. 129, p. 63, 2000.

[75] Stelzer, N.; Nölting, J. e Riess, I.; Phase diagram of nonstoichiometric 10\% mol $\mathrm{Gd}_{2} \mathrm{O}_{3}$-doped cerium oxide determined from specific heat measurements. J. Solid State Chem., v. 117, p. 392, 1995.

[76] Körner, R.; Ricken, M.; Nölting, J. e Riess, I.; Phase transformations in reduced ceria: Determination by thermal expansion measurements. J. Solid State Chem., v. 78, p. 136, 1989.

[77] Linardi, M.; In: Introdução à Ciência e tecnologia de células a combustível. São Paulo: Artliber, 2010.

[78] Kröger, F. A. Detailed description of crystalline solids, imperfections. In: The chemistry of imperfect crystals. Amsterdam: North- Holland, 1964. Cap. 7, p. 194214.

[79] Per Kofstad; Nonstoichiometry diffusion, and electrical conductivity in binary metal oxides. New York: Wiley Interscience, 1972.

[80] Kang, S. L.; Densification and grain growth in ionic compounds. In: Densification, grain growth, and microstructure. Oxford: Elsevier, 2005, Cap.13, p. 181-192.

[81] Goodenough, J. B.; Oxide-ion electrolytes. Annu. Rev. Mater. Res., v. 33, p. 91, 2003.

[82] Jud, E.; Huwiler, C. B. e Gauckler, L. J.; Sintering analysis of undoped and cobalt oxide doped ceria solid solutions. J. Am. Ceram. Soc., v. 88, p. 3013, 2005.

[83] Liang, J.; Zhu, Q.; Xie, Z.; Huang, W.; Hu, C.; Low-temperature sintering behaviors of nanosized $\mathrm{Ce}_{0.8} \mathrm{Gd}_{0.2} \mathrm{O}_{1.9}$ powder synthesized by co-precipitation combined with supercritical drying. J. Power Sources, v. 194, p. 640, 2009.

[84] Gil, V.; Moure, C.; Durán, P. e Tartaj, J.; Low-temperature densification and grain growth of $\mathrm{Bi}_{2} \mathrm{O}_{3}$-doped-ceria gadolinia ceramics. Solid State Ionics, v. 178, p. 359, 2007.

[85] Tianshu, Z.; Hing, P.; Huang, H.; Kilner, J. A.; Early-stage sintering mechanisms of $\mathrm{Fe}$ - doped $\mathrm{CeO}_{2}$. J. Mater. Sci., v. 37, p. 997, 2002. 
[86] Esposito, V.; Ni, D. W.; He, Z.; Zhang, W.; Prasad, A. S.; Glasscock, J. A.; Chatzichristodoulou, C.; Ramousse, S. e Kaiser, A.; Enhanced mass diffusion phenomena in highly defective doped ceria. Acta Mater., v. 61, p. 6290, 2013.

[87] Rockenhäuser, C.; Butz, B.; Schichtel, N.; Janek, J.; Oberacker, R.; Hoffmann, M. J. e Gerthsen, D.; Microstructure evolution and cation interdiffusion in thin $\mathrm{Gd}_{2} \mathrm{O}_{3}$ films on $\mathrm{CeO}_{2}$ substrates. J. Eur. Ceram. Soc., v. 34, p. 1235, 2014.

[88] De Biasi, R. S.; Grillo, M. L. N.; Electron magnetic resonance investigation of gadolinium diffusion in ceria powders. J. Am. Ceram. Soc., v. 92, p. 1139, 2009.

[89] Yan, R.; Chu, F.; Ma, Q.; Liu, X. e Meng, G.; Sintering kinetics of samarium doped ceria with addition of cobalt oxide. Mater. Lett., v. 60, p. 3605, 2006.

[90] Reis, S. L.; Souza, E. C. C.; Muccillo, E. N. S.; Solid Solution formation, densification and ionic conductivity of $\mathrm{Gd}$ - and Sm-doped ceria. Solid State Ionics, v. 192, p. 172, 2011.

[91] He, Z.; Yuan, H.; Glasscock, J. A.; Chatzichristodoulou, C.; Phair, J. W.; Kaiser, A.; Ramousse, S.; Densification and grain growth during early-stage sintering of $\mathrm{Ce}_{0,9} \mathrm{Gd}_{0,1} \mathrm{O}_{1,95-d}$ in a reducing atmosphere. Acta Mater., v. 58, p. 3860, 2010.

[92] Chen, P.; Chen, I.; Sintering of fine oxide powders: II, Sintering mechanisms. J. Am. Ceram. Soc., v. 80, p. 637, 1997.

[93] Zhang, T.; Hing, P.; Huang, H. e Kilner, J.; Sintering study on commercial $\mathrm{CeO}_{2}$ powder with small amount of $\mathrm{MnO}_{2}$ doping. Mater. Lett., v. 57, p. 507, 2002.

[94] Kilo, M.; Borchardt, G.; Lesage, B.; Kaïtasov, O.; Weber, S. e Scherrer, S.; Cation transport in yttria stabilized cubic zirconia: ${ }^{96} \mathrm{Zr}$ tracer diffusion in $\left(Z r_{x} Y_{1-}\right.$ x) $\mathrm{O}_{2-x / 2}$ single crystals with $0.15 \leq x \leq 0.48$. J. Eur. Ceram. Soc., v. 20, p. 2069, 2000.

[95] Fonseca, F. C. Propriedades elétricas de compósitos cerâmicos à base de zircônia. 2001. 167f. Tese (Doutorado em Ciências) - Instituto de Pesquisas Energéticas e Nucleares, Universidade de São Paulo, São Paulo, 2001.

[96] Lakki, A.; Herzog, R.; Weller, M.; Schubert, H.; Reetz, C.; Görke, O.; Kilo, M. e Borchardt, G.; Mechanical loss, creep, diffusion, and ionic conductivity of $\mathrm{ZrO}_{2}-$ 8 mol\% polycrystals. J. Eur. Ceram. Soc., v. 20, p. 285, 2000.

[97] Hayashi, H.; Kanoh, M.; Quan, C. J.; Inaba, H.; Wang, S.; Dokiya, M.; Tagawa, H.; Thermal expansion of Gd-doped ceria and reduced ceria. Solid State Ionics, v. 132, p. 227, 2000.

[98] Hayashi, H.; Saitou, T.; Maruyama, N.; Inaba, H.; Kawamura, K.; Mori, M.; Thermal expansion coefficient of yttria stabilized zirconia for various yttria contents. Solid State Ionics, v. 176, p. 613, 2005.

[99] Research, chemicals, metals, and materials. Lancashire. Alfa Aesar - A Johnson Matthey Company. 2011- 2013.

[100] Hansen, J. D.; Rusin, R. P.; Teng, M.; Johnson, D. L.; Combined-stage sintering model. J. Am. Ceram. Soc., v. 75, p. 1129, 1992.

[101] Gupta, T. K.; Possible correlation between density and grain size during sintering. J. Am. Ceram. Soc., v. 55, p. 276, 1972. 
[102] Willians, J.; Barnes, E.; Scott, R. e Hall, A.; Sintering of uranium oxides of composition $\mathrm{UO}_{2}$ to $\mathrm{U}_{3} \mathrm{O}_{8}$ in various atmospheres. J. Nucl. Mater., v. 1, p. 28, 1959.

[103] Yan, M. F.; Effects of physical, chemical, and kinetic factors on ceramic sintering. In: Messing, G. L.; Mazdiyasni, K. S.; McCauley, J. W.; Haber, R. A.; Advances in ceramics: Ceramic powder science, v.21, p.635. 1987.

[104] Zhou, Y. e Rahaman, M. N.; Effect of redox reaction on the sintering behavior of cerium oxide. Acta Mater., v. 45, p. 3635, 1997.

[105] Anantharaman, S. B., Bauri, R.; Effect of sintering atmosphere on densification, redox chemistry, and conduction behavior of nanocrystalline $\mathrm{Gd}$-doped $\mathrm{CeO}_{2}$ electrolytes. Ceram. Int., v. 39, p. 9421, 2013.

[106] American Society for Testing Materials - ASTM C1274-12 - Standart Test method for advanced ceramic specific surface area by physical adsorption. Geneva: ASTM, 1994.

[107] Luo, L. H.; Tok, A. I. Y.; Boey, F. Y. C.; Aqueous tape casting of $10 \% \mathrm{~mol}$ $\mathrm{Gd}_{2} \mathrm{O}_{3}$ - doped $\mathrm{CeO}_{2}$ nanoparticles. Mater. Sci. Eng. A., v. 429, p. 266, 2006.

[108] Galvão, A. S. A.; Desenvolvimento de amostras padrão de referência para difratometria. Dissertação de mestredo. Instituto de Pesquisas Energéticas e Nucleares. São Paulo, 2010.

[109] Martinez, L. G.; Galvão, A. S. A.; Rossi, J. L.; Orlando, M. T. D.; Corrêa, H. P. S. e Turrillas, X.; Development of standard reference materials for powder diffraction. In: LNLS Activity Report, 2010.

[110] Larson, A. C.; Von Deele, R. B.; General Structure analysis system (GSAS). Los Alamos National Laboratory Report LAUR 86-748 (1994).

[111] Scardi, P; Ortolani, M; Leoni, M; WPPM: microstructural analysis beyond Rietveld method. Mater. Sci. Forum, v. 651, p. 155, 2010.

[112] Scardi, P. e Leoni, M; Whole Powder Pattern Modelling. Acta Cryst., v. A58, p. 190, 2002.

[113] Russ, J. C.; DeHoff, R. T.; Introduction. In: Practical stereology. New York: Kluwer Academic, 2000. Cap. 1, p. 1-18.

[114] Mendelson, M. I.; Average grain size in polycrystalline ceramics. J. Am. Ceram. Soc., v. 52, p. 443, 1969.

[115] MacDonald, J. R.; Potter, L. D. Jr.; A flexible procedure for analyzing impedance spectroscopy results: description and illustrations. Solid State lonics, v. 23, p. 61, 1987.

[116] Kharton, V. V.; Figueiredo, F. M.; Navarro, L.; Naumovich, E. N.; Kovalevsky, A. V.; Yaremchenko, A. A.; Viskup, A. P.; Carneiro, A.; Marques, F. M. B. e Frade, J. R.; Ceria-based materials for solid oxide fuel cells. J. Mater. Sci., v. 36, p. 1105, 2001.

[117] German, R. M. Microstructure and processing relations in solid- state sintering. In: Sintering Theory and Practice. New York: Wiley, 1996. Cap.4, p. 142-177.

[118] Rahaman, M. N.; Powder consolidation and forming ceramics. $2^{\mathrm{a}}$ edição. New York: Marcel Dekker, 1995. Cap. 6, p. 328- 423. 
[119] Shannon, R. D.; Revised effective ionic radii and systematic studies of interatomic distances in halides and chalcogenides. Acta Cryst., v. A32, p. 751, 1976.

[120] Otake, T; Yugami, H.; Naito, H.; et al.; $\mathrm{Ce}^{3+}$ concentration in $\mathrm{ZrO}_{2}-\mathrm{CeO}_{2}-\mathrm{Y}_{2} \mathrm{O}_{3}$ studied by electronic Raman spectroscopy. Solid State Ionics, v. 135, p. 663, 2000.

[121] Figaj, M. e Becker, K. D.; An electron paramagnetic resonance study of impurities in ceria, $\mathrm{CeO}_{2}$. Solid State Ionics, v. 141, p. 507, 2001.

[122] Abi-aad, E.; Bechara, R.; Grimblot, J. e Aboukaïs, A.; Preparation and characterization of $\mathrm{CeO}_{2}$ under an oxidizing atmosphere. Thermal analysis, XPS, and EPR study. Chem. Mater., v. 5, p. 793, 1993.

[123] Fierro, J. L. G.; Soria, J.; Sanz, J. e Rojo, J. M.; Induced changes in ceria by thermal treatments under vacuum or hydrogen. J. Solid State Chem., v.66, p.154, 1987.

[124] Li, G.; Mao, Y.; Li, L.; Feng, S.; Wang, M. e Yao, X.; Solid solubility and transport properties of nanocrystalline $\left(\mathrm{CeO}_{2}\right)_{1-x}\left(\mathrm{BiO}_{1.5}\right)_{x}$ by hydrothermal conditions. Chem. Mater., v. 11, p. 1259, 1999.

[125] Sin, A.; Dubitsky, Yu.; Zaopo, A.; Àrico, A. S.; Gullo, L.; La Rosa, D.; Siracusano, S.; Antonucci, V.; Oliva, C. e Ballabio, O.; Preparation and sintering of $\mathrm{Ce}_{1-x} \mathrm{Gd}_{x} \mathrm{O}_{2-x / 2}$ nanopowders and their electrochemical and EPR characterization. Solid State Ionics, v. 175, p. 361, 2004.

[126] Rakhmatullin, R. M.; Aminov, L. K.; Kurkin, I. N.; Böttcher, R.; Pöppl, A.; Avila-Paredes, H.; Kim, S. e Sen, S.; Electron paramagnetic resonance linewidth narrowing of $\mathrm{Gd}^{3+}$ ions in $\mathrm{Y}$-doped ceria nanocrystals with decreasing crystallite size. J. Chem. Phys., v.131, p. 124515, 2009.

[127] Nakamura, F.; Senoh, K.; Tamura, T.; Ochiai, Y. e Narahara, Y.; Magnetic interactions in $\mathrm{GdBa}_{2} \mathrm{Cu}_{3} \mathrm{O}_{y}$. Physica C, v.162-164, p. 1287, 1989.

[128] Kliava, J.; Malakhovskii, A.; Edelman, I.; Potseluyko, A.; Petrakovskaja, E.; Melnikova, S.; Zarubina, T.; Petrovskii, G.; Bruckental, Y. e Yeshurun, Y.; Unusual magnetic transitions and nature of magnetic resonance spectra in oxide glasses containing gadolinium. Phys. Rev. B, v.71, 104406, 2005.

[129] Bauerle, J. E.; Study of solid electrolyte polarization by a complex admittance method. J. Phys. Chem. Solids, v. 30, p. 2657, 1969.

[130] Guo, X. e Waser, R.; Electrical properties of the grain boundaries of oxygen ion conductors: Acceptor-doped zirconia and ceria. Prog. Mater. Sci., v. 51, p. 151, 2006.

[131] Jasper, A.; Kilner, J.A. e McComb; TEM and impedance spectroscopy of doped ceria electrolytes. Solid State Ionics, v.179, p.904, 2008.

[132] American Society for Testing Materials - ASTM E228-11 - Standart Test method for linear thermal expansion of solid materials with a push-rod dilatometer. West Conshohocken: ASTM, 2011.

[133] Vanin, V. R.; Gouffon, P.; Helene, O.; Análise estatística de medidas em ciências exatas. Versão de Agosto de 2011 (a ser publicada), cap. 9, p. 265 - 286. 
[134] Maca, K.; Pouchly, V. e Boccaccini, A. R.; Sintering densification curve - a practical approach for its construction from dilatometric shrinkage data. Sci Sinter., v.40, p. 117, 2008.

[135] Ravat, B.; Oudot, B.; Perron, A.; Lalire, F. e Delaunay, F.; Phase transformations in PuGa 1 at.\% alloy: Study of whole reversion process following martensitic transformation. J. Alloy Compd., v. 580, p. 298, 2013.

[136] Hillman, S. H. e German, R. M.; Constant heating rate analysis of simultaneous sintering mechanisms in alumina. J. Mater. Sci., v. 27, p. 2641, 1992.

[137] Teng, M.; Lai, Y. e Chen, Y.; A computer program of master sintering curve model to accurately predict sintering results. Western Pacific Earth Sci., v.2, p.171, 2002.

[138] Pouchly, V. e Maca, K.; Master sintering curve - A practical approach to its construction. Sci. Sinter., v.42, p. 25, 2010.

[139] Park, S. J.; Chung, S. H.; Blaine, D.; Suri, P. e German, R. M.; Master sintering curve software and its applications. In: Advances in powder mettalurgy \& particulate materials, 2004, Chicago. Proceeding of the 2004 International Conference on Powder Mettalury \& Particulate Materials, Chicago: Metal Powder Industries Federation, 2004. V.1, p. 13.

[140] Rajeswari, K.; Padhi, S.; Reddy, A. R. S.; Johnson, R. e Das, D.; Studies on sintering kinetics and correlation with sinterability of $8 Y$ zirconia ceramics based on the dilatometric shrinkage curves. Ceram. Int., v.39, p. 4985, 2013.

[141] Chu, M.; Rahaman, M. N.; De Jonghe, L. C.; Effect on heating rate on sintering and coarsening. J. Am. Ceram. Soc., v.74, p. 1217, 1991.

[142] Shao, W. Q.; Chen, S. O.; Li, D.; Cao, H. S.; Zhang, Y. C. e Zhang, S. S.; Apparent activation energy for densification of a- $\mathrm{Al}_{2} \mathrm{O}_{3}$ powder at constant heatingrate sintering. Bull. Mater. Sci., v.31, p. 903, 2008.

[143] Han, J.; Mantas, P. Q. e Senos, A. M. R.; Sintering kinetics of undoped and Mn-doped zinc oxide in intermediate stage. J. Am. Ceram. Soc., v.88, p. 1773, 2005.

[144] Shen, Z.; Peng, H.; Liu, J. e Nygren, M.; Conversion from nano- to microsized structures: experimental observations. J. Eur. Ceram. Soc., v.24, p. 3447, 2004.

[145] Song, X.; Zhang, J.; Li, L.; Yang, K. e Liu, G.; Correlation of thermodynamics and grain growth kinetics in nanocrystalline metals. Acta Mater., v.54, p. 5541, 2006.

[146] Lu, K.; Sintering of nanoceramics. Int. Mater. Rev., v.53, p. 21, 2008.

[147] Rane, G. K.; Welzel, U. e Mittemeijer, E. J.; Grain growth studies on nanocrystalline Ni powder. Acta Mater., v.60, p. 7011, 2012.

[148] Leoni, M.; Di Maggio, R.; Polizzi, S. e Scardi, P.; X-ray diffraction methodology for the microstructural analysis of nanocrystalline powders: Application to cerium oxide. J. Am. Ceram. Soc., v.87, p. 1133, 2004. 
[149] Wonisch, A.; Kraft, T.; Moseler, A. e Riedel, H.; Effect of different particle size distributions on solid-state sintering: A microscopic simulation approach. $\mathbf{J}$. Am. Ceram. Soc., v.92, p. 1428, 2009.

[150] Bjork, R.; Tikare, V.; Frandsen, H. L. e Pryds, N.; Effect of particle size distributions on the microstructural evolution during sintering. J. Am. Ceram. Soc., v.96, p. 103, 2013.

[151] Ma, J. e Lim, L. C.; Effect of particle size distribution on sintering of agglomerate-free submicron alumina powder compacts. J. Eur. Ceram. Soc., v.22, p. 2197, 2002.

[152] Shiau, F.; Fang, T. e Leu, T.; Effect of particle-size distribution on the microstructural evolution in intermediate stage of sintering. J. Am. Ceram. Soc., v.80, p. 286, 1997.

[153] Yeh, T. e Sacks, M. D.; Effect of particle size distribution on the sintering of alumina. J. Am. Ceram. Soc., v.71, p. C484, 1988.

[154] Kanters, J.; Eisele, U. e Rödel, J.; Effect of initial grain size on sintering trajectories. Acta Mater., v.48, p. 1239, 2000.

[155] Bernard-Granger, G. e Guizard, C.; New relationships between relative density and grain size during solid-state sintering of ceramic powders. Acta Mater., v.56, p. 6273, 2008.

[156] Balzar, D. e Popa, N. C.; Crystallite size and residual strain/stress modeling in Rietveld refinement In: Mittemeijer, E. J. e Scardi, P.; Diffraction analysis of the microstructure of materials. Berlin: Springer, 2004, p.125

[157] Balzar, D.; Audebrand, N.; Daymond, M. R.; Fitch, A.; Hewat, A.; Langford, J. I.; Le Bail, A.; Louër, D.; Masson, O.; McCowan, C.N.; Popa, N. C.; Stephens, P. W.; Toby, B. H.; Size-strain line-broadening analysis of the ceria round-robin sample. J. Appl. Cryst., v. 37, p. 911, 2004.

[158] McCusker, L. B.; Von Dreele, R. B.; Cox, D. E.; Louër, D.; Scardi, P.; Rietveld guidelines. J. Appl. Cryst., v. 32, p.36, 1999.

[159] H.P. Klug e L.F. Alexander; Crystallite size and lattice strains from line broadening. In: X-Ray Diffraction Procedures for Polycrystalline and Amorphous Materials; New York: Wiley, 1974, 2ª edição, p. 618.

[160] MacDonald, J. R. e Johnson, W. B.; Fundamentals of impedance spectroscopy. In: Barsoukov, E. e MacDonald, J. R.; Impedance spectroscopy: Theory, experiment, and applications. New Jersey: Wiley Interscience, cap.1, p.1-26, 2005.

[161] Wang, J e Raj, R.; Estimate of activation energies for boundary diffusion from rate-controlled sintering of pure alumina, and alumina doped with zirconia or titania. J. Am. Ceram. Soc., v. 73, p. 1172, 1990. 